\title{
ENVIRONMENTAL POLICY INTEGRATION AND ENERGY \\ CONCEPTUAL CLARIFICATION AND COMPARATIVE ANALYSIS OF \\ STANDARDS AND MECHANISMS
}

\author{
PROEFSCHRIFT
}

ter verkrijging van

de graad van doctor aan de Universiteit Twente, op gezag van de rector magnificus, prof.dr. H. Brinksma,

volgens besluit van het College voor Promoties in het openbaar te verdedigen

op woensdag 2 december 2009 om 13.15 uur

door 
Dit proefschrift is goedgekeurd door de promotoren:

Prof.dr. J.Th.A. Bressers

Prof.dr. W.M. Lafferty 
In de reeks Schone Technologie en Milieubeleid worden

milieuvraagstukken belicht vanuit wetenschappelijke visies

op overheidsbeleid, technologie en management.

Deel 1 De effectiviteit van gemeentelijke milieubeleidsplanning F.H.J.M. Coenen

Deel 2 Bevordering van milieumanagement in organisaties T.J.N.M. de Bruijn en K.R.D. Lulofs

Deel 3 The feasibility of Dutch environmental policy instruments Josee J. Ligteringen

Deel 425 jaar milieubeleid in Nederland: instrumenten, incidenten en effecten R.A. van de Peppel, P-J. Klok en D. Hoek

Deel 5 The endurance of Mexican Amate Paper R. Citlalli Lopez Binnquist

Deel 6 Sustained Diffusion of Renewable Energy Valentina Dinica

Deel 7 Water Governance and Institutional Change Stefan M.M. Kuks

Deel 8 Innovation and Institutional Change Peter S. Hofman

Deel 9 Transparancy in the Food Chain Agni Kalfagianni

Deel 10 Land Markets and Public Policy Wilbert Grevers

Deel 11 Corporate social Responsibility and Public Policy-Making Arno Mathis

Deel 12 Private Equity; Public Principle David Regeczi

Deel 13 Understanding how actors influence policy implementation Katharine A. Owens

Deel 14 Geruisloos Beleid Derek Jan Fikkers

Deel 15 The Power to Produce Annemarije Kooijman-Van Dijk

Deel 16 Join the Club! Johannes Boshuizen

Deel 17 Environmental Policy Integration and Energy Jørgen K. Knudsen 
Colofon

Editing manuscript: Ada Krooshoop, Universiteit Twente / CSTM

Vormgeving omslag: deel 4 ontwerpers, Jo Molenaar

Druk en uitgave: Universiteit Twente / CSTM

(c) Jørgen K. Knudsen, Universiteit Twente / CSTM / 2009

Niets uit deze uitgave mag worden vermenigvuldigd door middel van druk, fotocopie of welke andere wijze ook zonder schriftelijke toestemming van de auteur.

ISBN 9789036529464 


\section{Content}

\section{Preface and acknowledgements}

$1 \quad$ Analytical framework and outline of the dissertation 1

1.1 Introduction 3

Background 3

Brief overview of the research questions and individual studies 6

1.2 The analytical framework 9

1.2.1 Governance and policy analysis for sustainable development 9 Towards an analytical model for EPI 13

1.2.2 The issue of EPI standards: How will we know it when we see it? 16 $\begin{array}{ll}\text { Decoupling, re-coupling, and path creation } & 17\end{array}$ $\begin{array}{lr}\text { Substantive vs. procedural standards of EPI } & 18\end{array}$

$\begin{array}{ll}\text { 1.2.3 EPI and Multi-Level Governance } & 20\end{array}$

$\begin{array}{lll}\text { 1.2.4 EPI mechanisms and the policy cycle } & 23\end{array}$

$\begin{array}{lll}1.2 .5 & \text { Contextual factors } & 26\end{array}$

$\begin{array}{lll}1.2 .6 & \text { Summary } & 28\end{array}$

$\begin{array}{lll}1.3 & \text { Methodological considerations } & 28\end{array}$

$1.4 \quad$ Outline and main insights from the studies composing the thesis 33

1.4.1 Chapter 2:'The issue of "balance” and trade-offs in environmental
policy integration: How will we know EPI when we see it?'

1.4.2 Chapter 3: 'Pursuing sustainable development in Norway: The challenge of living up to Brundtland at home’ 34

1.4.3 Chapter 4: 'Norway: Trying to maintain maximum RES-E in a petroleum driven economy’ 34

1.4.4 Chapter 5: 'De- and re-coupling energy: Environmental Policy Integration (EPI) and the case of renewable electricity in Scandinavia' 35

1.4.5 Chapter 6: 'Integration of environmental concerns in a trans-Atlantic perspective: The case of renewable electricity'

1.4.6 Chapter 7: 'Monitoring towards more sustainable energy policies? A comparative assessment of procedures and political impacts in Norway and Sweden'

1.5 Conclusion 37

$2 \quad$ Environmental Policy Integration and multi-level Governance $\quad 41$

2.1 Introduction 43

2.2 Existing EPI orientations: Key ideas and selected models 44

2.2.1 The three 'pillars' and 'decoupling' 44

2.2.2 The EEA-OECD 'evaluation framework' 45

2.2.3 EPI as policy analysis and learning: The PINTS project 47

2.2.4 EPI as a governing principle in the European Union 49

$2.3 \quad$ Resolving sectoral policy trade-offs 52 
2.3.1 EPI as a 'first-order principle' 52

2.3.2 Clarifying the nature of 'principled priority' 54

2.3.3 Governing mechanisms for enhancing EPI as policy output 57

2.4 Conclusion 64

$3 \quad$ Pursuing sustainable development in Norway: The challenge of $\quad 67$ living up to Brundtland at home

3.1 Introduction 69

3.2 Strategic initiatives for sustainable development in Norway 70

$\begin{array}{lll}3.2 .1 & \text { Key SD documents } & 70\end{array}$

3.2.2 Integrating SD horizontally at the national level 72

$\begin{array}{lll}\text { 3.2.3 SD strategies and vertical integration } & 75\end{array}$

3.2.4 Implementing SD-related initiatives at the national level 75

3.2.5 Participation in the SD strategy process 76

$\begin{array}{lll}\text { 3.2.6 Monitoring and evaluation } & 77\end{array}$

$\begin{array}{lll}\text { 3.2.7 Summary of the SD strategy process } & 78\end{array}$

$\begin{array}{lll}3.3 & \text { Analysing the Norwegian SD profile } & 79\end{array}$

3.4 Conclusions 81

$4 \quad$ Norway: Trying to maintain maximal RES-E in a petroleum $\quad 83$

$\begin{array}{llr}4.1 & \text { Introduction } & 85\end{array}$

4.1.1 The EU RES-E Directive and Norway 86

4.2 General profile of the Dominant Energy System for electricity in Norway 87

$\begin{array}{lll}4.2 .1 & \text { Hydropower } & 88\end{array}$

4.2.2 New renewable energy sources for electricity 89

4.2.3 The related challenges of renewable heating and natural gas 90

4.3 Major actors affecting production and consumption of RES-E 91

4.3.1 Partisan politics and positions towards RES-E 91

4.3.2 The role of relevant state entities 93

$\begin{array}{lll}\text { 4.3.3 Branch organizations } & 95\end{array}$

4.3.4 The major RES-E-related companies 96

4.3.5 NGOs and growing local resistance to RES-E production 97

4.4 The policy framework for RES-E in Norway 98

4.4.1 The basic legal-regulatory structure for hydropower 98

4.4.2 The Energy Act and the case of wind power 99

$\begin{array}{ll}\text { 4.4.3 Nord Pool ASA } & 100\end{array}$

$\begin{array}{ll}\text { 4.4.4 Guarantees of origin and the RECS } & 100\end{array}$

$\begin{array}{ll}\text { 4.4.5 The evolving policies for RES-E } & 101\end{array}$

$\begin{array}{ll}\text { 4.4.6 RES-E promotional measures } & 102\end{array}$

4.5 Efforts for RES-E innovation 103

4.6 Phasing in RES-E at the regional level 104

4.7 Summary assessment 106

$\begin{array}{lll}4.8 & \text { Conclusion } & 108\end{array}$ 
5 De- and re-coupling energy: Environmental Policy Integration (EPI) and the case of renewable electricity in Scandinavia

5.1 Introduction

$\begin{array}{lll}5.2 & \text { Analytical framework } & 114\end{array}$

5.3 RES-E and EPI standards in Scandinavia 118

$\begin{array}{lll}\text { 5.3.1 Denmark } & 118\end{array}$

$\begin{array}{ll}5.3 .2 & \text { Norway } \\ 5.3 .3 & 120\end{array}$

$\begin{array}{lll}\text { 5.3.3 Sweden } & 122\end{array}$

5.4 Summary assessment of RES-E initiatives and EPI standards 124

$\begin{array}{ll}5.5 & \text { The importance of contextual factors } \\ 5.65\end{array}$

$\begin{array}{lll}5.6 & \text { Conclusion } & 127\end{array}$

$6 \quad$ Integration of environmental concerns in a trans-Atlantic $\quad 129$ perspective: The case of renewable electricity

6.1 Introduction 131

6.2 Analytical dimensions: EPI and multi-level governance 132

6.3 EPI and RES-E in an EU-Nordic context 135

6.3.1 The EU level 135

6.3.2 The linkage between RES-E promotion and EPI in the
Nordic countries

6.4 RES-E promotion and GHG mitigation efforts in the

6.4.1 RES-E and climate-change in the U.S. context

6.4.2 RES-E promotion and climate-change mitigation in the New England States 139

6.5 Comparative assessment of the EU and U.S. approaches 142

$\begin{array}{lll}6.6 & \text { Conclusion } & 146\end{array}$

$7 \quad$ Monitoring towards more sustainable energy policies? 147 A comparative assessment of procedures and political impacts in Norway and Sweden

$\begin{array}{lll}7.1 & 149\end{array}$

$\begin{array}{lll}7.2 & \text { Analytical framework } & 150\end{array}$

7.3 Comparing SD-relevant monitoring and evaluation procedures 155

$\begin{array}{lll}7.3 .1 & 155\end{array}$

$\begin{array}{lll}7.3 .2 & \text { Sweden } & 157\end{array}$

$\begin{array}{lll}\text { 7.3.3 Comparative summary } & 159\end{array}$

$\begin{array}{lll}7.4 & \text { Possible political consequences and adjustments } & 159\end{array}$

$\begin{array}{lll}7.4 .1 & \text { Norway } & 159\end{array}$

$\begin{array}{lll}7.4 .2 & \text { Sweden } & 161\end{array}$

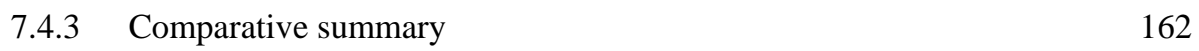

7.5 Explaining differing procedures and evaluation potentials 162

$\begin{array}{lll}7.6 & \text { Conclusion } & 165\end{array}$ 
References

Summary

About the author

191 


\section{Preface and acknowledgements}

The research of the present dissertation has mainly been conducted at the Program for Research and Documentation for a Sustainable Society (ProSus), at the University of Oslo. In late 2005 I had the privilege of being offered a position as researcher at ProSus, by the Program's Director, professor William M. Lafferty. Coming from a position as a bureaucrat in the Norwegian Ministry of the Environment, it was highly stimulating and inspiring to work within such a vital and policy-related research unit as ProSus. The ProSus programme depends on a high degree of interactive cross-disciplinary research, and I am most grateful for the constant exchange of perspectives and research findings, as well as the high degree of personal support and ongoing collegiality.

I am particularly grateful also for the research guidance and council provided by the programme's Director, Professor William M. Lafferty. As a political scientist, it has been particularly fruitful for me to work in a research environment that combines the best standards of the discipline with a mandate for promoting more effective governance for sustainable development. As my primary supervisor for the dissertation, I am most grateful for Professor Lafferty's ongoing guidance and support.

An important additional bonus of working at ProSus has been the access to an extensive international research network. Within this network, the Center for Clean Technology and Environmental Policy (CSTM) at the University of Twente has been a core institution. In 2007, I was generously offered the opportunity by the CSTM of being affiliated with the Centre as an external PhD student. During visits to CSTM I have had highly constructive meetings with the staff, both professionally and socially. I have very much enjoyed the open and inclusive atmosphere at the CSTM, and I always feel warmly welcomed when visiting the Centre.

In this regard, I would like to particularly thank the 'founding spirit' of CSTM and 'first promoter' of the dissertation, Professor Hans B. Bressers for both his academic contributions and direct feedback on earlier drafts of the disstertation. I would also like to thank the current Director, Dr. Frans Coenen, and the Office Manager, Ada Krooshoop, for their ongoing assistance and support.

I am also grateful to Dr. Maarten Arentsen at CSTM who has provided me with very valuable feed-backs and comments. Maarten also convened a seminar at the CSTM where I could present the dissertation research, in February 2008. At this occasion, I received numerous fruitful comments and helpful advice on the further work with the dissertation. I want to thank all the participants at the seminar for their constructive feed-back and support.

Writing a doctoral dissertation is for most people a challenging, and rarely a straight-forward process. I got to know these challenges as well. At the same time, I feel it has been a valuable and very instructive period of my life. I have been lucky 
to be part of a daily working environment with supportive and highly interested colleagues. In this regard, I want particularly to thank Dr. Audun Ruud for his most valuable in-put (on many fronts) during the whole process. Audun has been an enthusiastic and constructive motivator both for my dissertation, and for research activities related to it. We worked closely together on the SUSTEN project, and he is one of the co-authors of the case study on Norwegian policies for renewable electricity included in the present dissertation (Chapter 4).

I am also grateful to Olav Mosvold Larsen, a former colleague working at ProSus. He is the second co-author of the Norwegian case for the SUSTEN project (paper 3). In addition, I worked with Olav on assessments of Norwegian efforts for sustainable development (SD), and he is also a co-author of the paper on the Norwegian SD strategy that is included in the dissertation (Chapter 3), together with William M. Lafferty. I also want to thank Olav for many engaging and inspiring discussions.

Rolf Marstrander, senior advisor at ProSus, with a very impressive background from Norwegian industry and public life, has provided me with many valuable perspectives and insights, not least from the point of view of business and engineering. Rolf has also been instrumental for the 'transition' of ProSus-related research activities to SINTEF Energy Research, a very interesting and important opportunity to continue the research in closer cooperation with industry and innovation - for which I am very grateful. The last semester of the dissertation I have been employed by SINTEF Energy Research, and I want to thank my present employer for their support during the last phase of the process.

I also want to thank Gerd B.Jacobsen, a colleague from both ProSus and SINTEF. Gerd has provided valuable feed-backs and comments, as well as very helpful, and always very efficient, practical assistance.

It also feels appropriate to thank the many researchers of the international network I have been presented for, particularly during the 'ProSus years'. Professor Miranda A. Schrerurs and the Department of Government and Politics at the University of Maryland generously introduced me to Washington DC, and offered valuable advice and insights as to the US policy context. I have also learnt a great deal from the many conferences and seminars within the framework of the EU-sponsored project Environmental Policy Integration and Multi-Level Governance (EPIGOV).

I must, however, convey my highest and most deeply felt thanks to William M. Lafferty who has provided me with valuable moral and academic support as daily promoter and supervisor of the dissertation. I am heavily indebted to his present and former scientific work on governance for sustainable development, as well as his many insights and advanced knowledge of nearly all relevant aspects of political science. Without his engaged and patient guidance, this dissertation might have been completed in another academic context - but that is a hypothesis I'm glad to leave unexplored. 
Finally, I will thank my family and friends for always being supportive and having encouraged me throughout - not least reminding me about the value of the ordinary, but unbeatable pleasures of everyday life.

Jørgen K. Knudsen

Oslo,

August 2009 
Analytical framework and outline of the dissertation 

The principal theme of the present doctoral dissertation is to provide new insights into ‘environmental policy integration' (EPI) as a normative and practical steering instrument in the promotion of sustainable development. The empirical focus of the research is on energy policy as a means for affecting climate-change.

The present chapter provides an introduction and background for the six research papers that compose the dissertation, and outlines the theoretical framework and methodology employed, as well as conveying the main data and results provided by the individual papers.

In the present section, I will first outline a historical and political background for the overall problematic. Secondly, I will present and substantiate the main research question and related questions that have guided the research.

\section{Background}

Since Our Common Future (1987) there has been both an academic and a political focus on the issue of governance for sustainable development (SD). The issue was given a highly substantial and profiled treatment in the processes following the publication of the Brundtland report in 1987. The same report also pointed to the need of amending the political-administrative systems within which sectoral policies - such as energy - are formulated and implemented (WCED 1987: 313). A core assumption here is that the integration of environmental concerns into decisionmaking at the outset would provide policy decisions with a higher probability for contributing to such a transition. A particular focus on the environmental dimension has been associated with the concept of 'environmental policy integration' (EPI).

In order to better realise EPI - still a major challenge more than 20 years after the publication for the Brundtland report - various processes and more-or-less formalised governance mechanisms have been introduced at international, national and sub-national levels. EPI has been perceived as a particular challenge to public governance, and has constituted a core focus in several related studies. In addition to more academically based research, there have over the last one and a half decades also been a number of EPI-relevant studies from a more practical, politicaladministrative approach, most particularly those conducted by the European Environment Agency (EEA) and the OECD. These studies have focused mainly on strategies and governance mechanisms in industrialized societies (Lafferty \& Meadowcroft 2000a; OECD 2001a, 2001b, 2002a, 2002b; Jacob \& Volkery 2004; Lafferty 2004b; EEA 2005a, 2005b; Jordan and Lenschow 2008b).

Simultaneous with these developments, there has also been an accelerated focus on climate-change mitigation and adaptation on the global policy agenda, and this in turn has led to an increased interest in the development of 'alternative' ('sustainable') energy solutions. These developments are most clearly represented by the progression of climate and energy policy in the European Union, culminating 
in the most recent climate and energy plan (2008) which establishes a triple 20 percent target for Green-House Gas (GHG) emission reductions, increased use of energy from renewable sources (RES), and increased energy efficiency by 2020 (CEC 2008).

This overall agenda implies a need for more integrated governance and policy approaches. Although the increased emphasis on climate-change implies a more limited focus than the broader SD agenda, nearly 20 years of experience from initiating, implementing and developing governance mechanisms for sustainable development have provided international organisations, national and sub-national authorities with important experiences from EPI, all with direct relevance for climate-change policies as well.

In general, EPI stands out, as a particularly well elaborated, and empirically tested, instrumental approach to the implementation of SD (Lafferty 2002b; Lenschow 2002a; EEA 2005a; Jordan \& Lenschow 2008b). EPI-relevant analyses encompass, moreover, studies of substantive priorities and standards, and specific instruments within both national and supra-national (EU) settings. In particular, the EU has provided good examples and represents an 'early mover' in the EPI field. This is not least related to Article 6 of the EC Treaty which requires that:

'Environmental protection requirements must be integrated into the definition and implementation of the Community policies and activities [. . . ] in particular with a view to promoting sustainable development' (EC 2006).

Despite the Article's role as relatively 'soft law', this constitutional principle implies a substantial responsibility for governing procedures of the different policy sectors. There remains, however, considerable disagreement as to how EPI in general, and Article 6 in particular, are to be interpreted (Pallemaerts 2006; Williams 2007; Jordan et al. 2008: 159-160).

A major portion of the EPI studies are, however, generally less concerned with identifying the normative core of EPI in a conceptual sense, and more focused on describing and explaining the ways in which different actors interact to develop and implement 'positive interpretations' of EPI in 'every-day policy-making situations' (Jordan \& Lenschow 2008c: 11). According to this view, EPI is a process through which 'non-environmental sectors' consider the overall environmental consequences of their policies, and take active and early steps to incorporate an environmental understanding of them into policy-making at all relevant levels of governance (ibid.). In the present dissertation, however, this prevailing view is challenged, with a main objective being a further conceptual clarification of 'EPI'; a clarification that provides a clearer linkage between the normative core and specific governance mechanisms in a sectoral setting.

Few academic contributions have, moreover, treated EPI in relation to specific policy sectors (such as energy), and there are nearly no cross-national comparisons of how EPI is being pursued at the sectoral level of governance. In this context, the 
following problematic has been formulated as the main research question of the present dissertation:

\section{$\Rightarrow$ How can we clarify the conceptual nature of EPI so as to strengthen its analytic potential as a framework for comparative evaluation of sectoral policy implementation?}

The energy sector stands out as a vital sector in relation to EPI. Promoting sustainable development vis-à-vis the way energy is produced, distributed and used implies structural changes of traditional energy systems and their negative sideeffects, such as resource depletion and ecological degradation (in the form of greenhouse gas (GHG) emissions). A more sustainable energy system should be based on renewable sources, and provide less energy-intensive production and consumption patterns. It is important, therefore, to identify and assess sectoral governing mechanisms; what works where, when and how? What are the crucial normative criteria for realising EPI in practice, and how are such criteria manifested (or not) in different sectoral contexts?

In an attempt to answer these questions more specifically, the dissertation research focuses on renewable electricity (RES-E); here considered to represent a more delimited case of the promotion of sustainable development. An increased focus on RES-E in both an EU and US context over the last 10-15 years is intimately linked to the objectives of halting GHG emissions. Although this is a less prevalent motivation in the USA than in Europe, it constitutes nonetheless an important underlying motivation for the more ambitious strategies and policies at US state level. There is thus a wider rationale behind a focus on RES-E as a focused instance of EPI in an SD perspective. RES-E can, moreover, be seen as a critical test case of the robustness of EPI, as it represents an economically important sector affecting widely different interests in its actual implementation (cf. physical localization), and constitutes a challenge vis-à-vis technological development and adaptation, infrastructure and the contextual nature of regional and local settings.

A related issue in a European context is the targets for energy production and usage that are set by the EU (that is, EU Directives on renewable electricity and renewable energy; CEC 2001, 2009), often supplemented and supported by national targets (Lafferty \& Ruud 2008c). These can be considered as criteria by which we can comparatively test and evaluate national policies and governance mechanisms. In order to follow up such targets appropriately at national and sub-national levels, however, it is necessary to adapt these according to the relevant context (Lafferty \& Ruud 2008b). An EPI approach can, in this regard, also provide a more coherent and context-sensitive understanding of the implementation of SD-related energy policies, across levels of governance. 


\section{Brief overview of the research questions and individual studies}

As will be further elaborated in section 1.2, the dissertation identifies three prevalent analytical dimensions in the current EPI research: (1) analyses of the normativepragmatic importance of EPI as an instrument for implementing sustainable development; (2) studies of how EPI can be implemented and followed up within a multi-level governance framework - in the present context by comparing the EU with the USA; and (3) studies of the nature and specific consequences of EPI mechanisms. In the present context, the last dimension is most specifically investigated in relation to mechanisms for monitoring and policy evaluation and the related potential for policy development and learning. As a fourth, supplemental dimension, several of the studies also provide analyses of the importance of contextual factors as to the status and implementation of EPI standards and mechanisms.

The individual studies composing the dissertation are based on the premise that EPI is an important instrument for realising sustainable development. As will be elaborated under sections 1.2 and 1.3 , this is further related to strategic, applied research activities, with further implications for the employment of analytical perspectives and theoretical approaches. Building on such an understanding, political science can provide a contribution to a more applied understanding of challenges to governance and implementation of sustainable development. A more specific challenge is also related to developing a more systematic set of evaluation standards and mechanisms for EPI, and to expand the empirical foundation with additional case studies, which in turn can contribute to a further refinement of the understanding of EPI in practice.

Furthermore, the dissertation aims to provide new, empirically informed insights that can contribute to the further development of a consensual research model for EPI. Building on the seminal insights of earlier EPI research, a revised analytic model will be presented in section 1.2.

The six research papers of the dissertation thus illustrate, in different degrees and different ways, key conceptual and empirical aspects of the ongoing research on environmental policy integration. A special effort has also been made to relate the studies to the important work carried out in the EU-sponsored 'Concerted Action' on Environmental Policy Integration and Multi-Level Governance (EPIGOV) - a consortium of 19 research institutions from 10 European countries (EPIGOV, 2008). ${ }^{1}$

\footnotetext{
${ }^{1}$ The project duration was 2006-09. See the project's web site at: http://ecologic.eu/projekte/epigov/ for more information. The site also provides complete access to all the research papers produced as part of the project. The present author participated in EPIGOVas researcher at the Program for Research and Documentation for a Sustainable Society (ProSus) at the University of Oslo, a regular partner to the project. Paper 1 of the present dissertation was written as part of the EPIGOV project.
} 
The next few paragraphs briefly indicate the main issues taken up by the individual studies, while section 1.4 will elaborates more explicitly on how each of the issues relates to the main research question posed above.

Chapter 2: Lafferty, William M. and Jørgen Knudsen (2007): "The issue of 'balance' and trade-offs in environmental policy integration: How will we know EPI when we see it?”. EPIGOV Paper No. 11, Berlin: Ecologic (Lafferty \& Knudsen 2007). To be published in von Homeyer et al. (eds) The Promise and Practice of Environmental Policy Integration. A Multi-Level Governance Perspective. Cheltenham UK: Edw. Elgar Publ.

Regarding the first analytical dimension referred to above, there has yet to emerge a clear conceptual consensus as to what EPI implies (or should imply) for governing strategies for sustainable development (SD). The first research paper (chapter 2) thus focuses on the concept of EPI, based on an analysis of the conceptual discussion in the current research. The chapter develops a normative baseline for the concept, closely related to sustainable development. This conceptual understanding of EPI then constitutes the key theoretical reference for the other five research papers.

Chapter 3: Lafferty, William M., Jørgen Knudsen and Olav Mosvold Larsen (2007): "Pursuing sustainable development in Norway: The challenge of living up to Brundtland at home", in European Environment, Voluem 17, pp. 177 - 188 (Lafferty et al. 2007).

Building on insights reflected in chapter 2, the second paper (chapter 3) provides a case study of Norway's Strategy for sustainable development, as well as the country's efforts for SD and EPI. Such a strategy is considered to depend on an interaction between the horizontal (intra-governmental) and vertical (sector-specific) dimensions of EPI. The article employs these dimensions in a systematic evaluation of Norwegian governmental initiatives to implement SD goals and policies.

Chapter 4: Knudsen, Jørgen, Olav Mosvold Larsen and Audun Ruud (2008): "Norway: Trying to maintain maximum RES-E in a petroleum driven economy", in W.M. Lafferty and A. Ruud (eds) Promoting Sustainable Electricity in Europe: Challenging the Path Dependency of Dominant Energy Systems. Cheltenham UK: Edward Elgar (Knudsen et al. 2008). ${ }^{2}$

\footnotetext{
${ }^{2}$ Chapter 4 was written as part of a recently finalised research project ('Promoting Sustainable Electricity in Europe'; SUSTEN), coordinated by ProSus at the University of Oslo. The project has produced a comparative assessment of the implementation of the EU RES-E Directive (Dir 2001/77/EC) in eight European countries (Austria, Denmark, Finland, Ireland, Netherlands, Norway, Spain and Sweden) (Lafferty \& Ruud 2008c).
} 
As a basis for an understanding of EPI within the energy sector, chapter 4 provides an analysis of the conditions for a transition of the energy system towards sustainable development. The empirical background is the promotion of renewable electricity (RES-E) through the EU RES-E Directive from 2001 ${ }^{3}$, assessing Norway's follow-up and the contextual factors that condition the promotion of RES$\mathrm{E}$ in the country.

Chapter 5: Knudsen, Jørgen K. (2009): “De- and re-coupling energy: Environmental Policy Integration (EPI) and the case of renewable electricity in Scandinavia”, SINTEF Technical Report TR A6844, Trondheim: SINTEF Energy Research (Knudsen 2009a). Submitted to Environment and Planning C: Government and Policy.

Chapter 5 raises the more specific issue as to the connection between EPI and the promotion of RES-E, focusing how RES-E initiatives can reflect the level and type of EPI standards at the national level in the three Scandinavian countries (Denmark, Norway and Sweden). In addition, chapter 5 provides an analysis of contextual factors conditioning such a connection.

Chapter 6: Knudsen, Jørgen K. (2009): “Integration of environmental concerns in a trans-Atlantic perspective: The case of renewable electricity”, SINTEF Technical Report TR A6843, Trondheim: SINTEF Energy Research AS (Knudsen 2009b). Revised and re-submitted to Review of Policy Research.

This research paper focuses explicitly on the second analytical dimension referred to above, the multi-level governance challenge of EPI. The paper provides a comparative assessment of the EU and USA in order to determine the importance of different structures and processes between the supranational/federal level and the national/state level. The empirical focus is on the integration of environmental concerns in the case of renewable electricity (RES-E).

Chapter 7: Knudsen, Jørgen (2008): “Monitoring towards more sustainable energy policies? A comparative assessment of procedures and political impacts in Norway and Sweden”, paper presented at the Easy-Eco Vienna 2008 Evaluation of Sustainability Conference, the Research Institute for Managing Sustainability, Vienna University of Economics and Business Administration, 11 - 14 March 2008 (Knudsen 2008). Selected for publishing in a forthcoming special issue of Environmental Policy \& Governance.

\footnotetext{
${ }^{3}$ The EU's 'climate-energy package' of 2008 , also referred to earlier, included a proposal for a Directive on the promotion of energy produced from renewable sources (RES). The RES Directive was finally adopted in 2009 (CEC 2009), and replaces the former RES-E directive (CEC 2001). The new RES Directive sets national targets for the total share of RES by 2020 including both electricity and heating/cooling (CEC 2009). In addition, the RES Directive obligates the EU Member States to fulfil a 10 percent share of renewable fuels in the transport sector by 2020 (ibid.).
} 
Chapter 7 focuses the third analytical dimension referred to above by assessing the monitoring mechanisms for SD-relevant policy evaluation of stationary energy in Norway and Sweden. The main question here raised is to what extent these mechanisms provide feed-back to decision-makers and, thereby, a basis for a more sustainable energy sector. A preliminary analysis of contextual factors is also included in the paper.

Finally, the present framework chapter proceeds with an elaboration of the theoretical foundation and analytical framework of the dissertation, in section 1.2. Section 1.3 provides an outline of the methodological approach employed, whereas section 1.4 presents the main insights and conclusions provided by the various papers. Section 1.5 then provides a conclusion in which the different insights related to the research questions are drawn together, and implications for the further study of EPI are outlined.

\section{The analytical framework}

The present section outlines the general analytical framework employed in the papers composing the present dissertation. As indicated above, the framework is primarily related to three dimensions of environmental policy integration (EPI). In addition, the vital role of contextual factors is also discussed. To begin with, however, I will outline some main features of the broader theoretical discourse relevant for the study of EPI, namely governance and policy analysis.

\section{Governance and policy analysis for sustainable development}

Though there are different definitions of 'sustainable development' (Lafferty \& Langhelle 1999), it is possible to identify two major types of discourse, one academic and one political (Lafferty \& Meadowcroft 2000b; 9-14). The academic debate has never been - and probably never will be - settled (Lafferty 2002b: 6), and is not subject to analysis in the present context. The dissertation is based on the understanding of sustainable development emanating from the WCED and UNCED processes which have provided both moral legitimacy (through democratic process and international commitment) and instrumental-operational knowledge and insight (ibid.).

'Governance' as a concept and focus in political science emerged in the 1990's, increasingly employed in lieu of 'government' in order to capture the changed role of the state and new processes of governing (Rhodes 1997: 15). Governance studies highlighted the increasingly important role of interactions among formal procedures and institutional patterns on the one hand, and more informal 'advocacy coalitions', 'path dependencies' and other more 'bottom-up' mechanisms on the other.

Although widely used, the concept of governance is, however, far from precise and has taken a number of alternative, and even contradictory, meanings in the literature 
(Pierre 2000; Pierre \& Peters 2005). A more delimited employment of the notion was proposed at an early stage, mainly referring to self-organising, interorganisational networks characterised by interdependence, leading to the notion of 'governance without government' (Rhodes 1997: 15).

Addressing this development, Pierre \& Peters (2005) observe that the dominant divergence in governance analyses separates studies with a network-oriented perspective from approaches with a stronger state focus. The latter perspectives do, however, also recognise the limitations of the state vis-à-vis other societal actors, albeit emphasising the state's dominating force by controlling critical resources (ibid.). This approach maintains that given the formidable requirements for governing, governments must retain a central position in that activity (Pierre \& Peters 2005: 5). It has also been emphasised that the governance research field has undergone several shifts as to conceptual and analytical scope, which also implies a need for a much stronger multidisciplinary orientation (Kooiman 2003; van Kersbergen \& van Waarden 2004). This is not least the case when speaking of environmental concerns ('environmental governance'; Durant et al. 2004b).

Several contributions have pointed to the challenge of combining the concepts of 'governance' and 'sustainable development' which are considered as equally difficult to decompose in an unequivocal manner (Jordan 2008). Referring to the numerous ways that the notions of 'governance' and 'sustainable development have been combined, Jordan calls for a clearer linkage between SD studies and the mainstream governance studies (ibid: 17).

Kemp et al. (2005: 13) contend that both 'governance' and 'sustainable development' are 'children of similar history and parentage', sharing characteristics and representing overlapping research potentials. They argue further, however, that the linkage between the two concepts remains understudied (ibid.). In this regard, they suggest that 'transition management' can constitute a relevant framework for the exploration of pathways to a more sustainable future (ibid: 26). They here employ 'the Dutch model' for transition management, which is considered to be a form of process management, based on societal goals and visions of sustainability (ibid. 24). They also draw attention to the need for a multi-dimensional perspective on institutions through which governance is exercised (ibid: 26).

In an earlier contribution, however, Meadowcroft (1999) emphasises that the governance challenge posed by sustainable development resembles long-discussed issues in political science. In particular the strategic nature of SD governance mechanisms is of relevance to established debates about social and economic planning practices, and particularly for the potential for governments to consciously reorient the path of societal development (ibid: 234). Governance for SD also implies stronger mechanisms for multipartite consultation and participation, which again relates to recurrent questions concerning the interaction between the state and established interests. Questions of pluralism, corporatism and interest mediation are here of central importance (ibid.). These are highly relevant questions for treating 
the nature of EPI in both its 'horizontal' (cross-sectoral) and 'vertical' (intrasectoral) dimensions.

In his in-depth discussion of governance for SD, Lafferty (2004d) introduces the relationship between 'form and function', as 'an ongoing theme of the ancient discourse of political steering'. Any given 'form' of government is understood to reflect the dominant 'function' of the system and actors that are to be governed (ibid: 1). Following from this, governance for sustainable development represents a challenge of adapting existing forms to a changing function. The challenge of sustainable development implies a political-administrative focus on ecological and social systems under stress, which represents a new function that requires new governmental responses. Governance for SD can thus be addressed as a discourse devoted to the adaptation of current democratic values, procedures and institutions to the functional prerequisites of SD (Lafferty \& Meadowcroft 1996; Lafferty 2004d: 2).

Lafferty (2004a) also elaborates further on the interdependence between the horizontal and vertical dimensions of political steering for SD. The cross-sectoral, horizontal dimension is related to a need for trade-offs among sectoral concerns within a specific level of governance (supra-national, national or sub-national); and the vertical dimension is related to the implementation of SD within specific sectoral domains (Lafferty and Hovden 2003; Lafferty 2004a: 205-208). These dimensions have been explicitly related to EPI, with an emphasis on the role of EPI in achieving 'decoupling' as a crucial mechanism in the promotion of sustainable development (Lafferty 2004a; Lafferty \& Knudsen 2007).

In this perspective, EPI mechanisms are related to the 'strategic' frameworks developed by the UN, OECD and EEA, as well as the more 'academic', politicalscience based approaches. Here the connection with sustainable development is specifically crucial, and strategies for SD are focused as a sector-encompassing framework for EPI efforts within sectors (Lafferty 2004a).

The differentiated emphasis of formal vs. informal aspects of governance is also reflected in the growing number of EPI studies. In this regard, the emergence of new policy networks, and the growing challenge for governments to coordinate both within governmental procedures and across levels of governance, has been emphasised as a major challenge for EPI, not least in an EU context (Jordan \& Schout 2008). Building on this challenge of complexity, EPI studies have also focused on the importance of 'policy learning' and gradual, institutional capacitybuilding as an important way of inducing a stronger bottom-up integration of environmental concerns (see section 1.2.4 below).

A governance perspective on EPI has also been extensively followed up by the recently completed EU-funded project EPIGOV, also referred to above. The project has co-ordinated and synthesised ongoing and existing research on EPI and multilevel governance in order to generate new impulses for further research (European Research Area 2009). The EPIGOV research team has aimed at broadening the 
scope of EPI research, in particular focusing how different modes of governance interact with EPI. The 'concerted action' has distinguished between two ways of analysing modes of governance which support EPI (European Research Area 2009): (1) An analysis of 'basis modes' which mainly focuses on possible EPI consequences of modes of governance which exist independently of specific efforts to improve EPI (such as hierarchical governance, co-ordinated market economy, corporatism and network governance); and (2) more specific 'EPI modes of governance' which are directly linked to EPI initiatives and how these can affect governance arrangements in general.

The EPIGOV project has, however, devoted less attention to the way EPI is reflected more substantially in policy performance, either across sectors or within specific sectors. Hence there is still a need for further clarifications of the role of EPI priorities and EPI as a substantive governing standard vis-à-vis sectoral policies. Furthermore, this lack highlights a need to supplement studies of how EPI fits into different governance settings with a perspective on EPI as a process, and thereby to distinguish between different phases of the policy-making process (Jordan \& Lenschow 2008c: 11-17).

In this regard, the research field of policy implementation, by posing the essential questions of 'what works, where, when and how' provides a basis for an improved understanding of how EPI standards and mechanisms can be followed up within different governance settings (Lafferty 2004d: 7). This research field represents, moreover, an academic discourse that has progressed far enough - theoretically and empirically - to enable a discussion of competing approaches and schools of understanding (ibid.).

The research related to policy analysis and implementation has traditionally been substantially engaged in discussions on the importance of an explicitly expressed intention and objective behind the policy, without which there would have been virtually nothing to implement (c.f. Pressman \& Wildavsky 1984: 22). In this vein, Mazmanian \& Sabatier (1983) developed and refined models for the understanding of implementation, based on environmental policy. Sabatier (1999) has more recently anchored this thinking within main currents of the academic discourse, by designating his own 'advocacy coalition framework' and Elinor Ostrom's 'Institutional Analysis and Development' framework as the most fruitful approaches.

This 'decision-oriented' approach has for a long time been contrasted with more 'process-oriented' approaches (c.f. Elmore 1980; Kjellberg \& Reitan 1995). A particular issue of dispute has been the question of the need for more adequate theory as a prerequisite for actual changes in policy outcomes. An early critique pointed to the futility of searching for objective theories linking policy measures and behavioural change, given the ideological and political nature of such questions (Barret \& Fudge 1981). As far as sustainable development is concerned, however, it is hard to imagine how one could entirely circumvent a theoretical discussion and 
understanding of the concept, and the related issues of policy objectives, measures and societal change.

On the other hand, a further development of, and a more systematic employment of implementation research in relation to sustainable development is required. Assessments of implementation research more generally have, however, for some time had the tendency to understate and/or oversee the amount of relevant research (O’Toole 2000). Reflecting further on this situation, Bressers (2004: 286-287) criticises the paradoxical down-playing of and lack of interest for implementation by both academics and practitioners, whereas empirical studies broadly document that the implementation phase constitutes the real bottleneck for achieving change - not least related to sustainable development.

As pointed out by O'Toole (2004), the SD programme in itself poses new challenges to the research on implementation, since one has to deal here with a cross-sectoral, long term and normative policy project (ibid.). O’Toole emphasises that implementation analysis lacks a core theory that can be employed in its entirety towards such a multi-faceted challenge (ibid: 33). He further maintains that a combination of the traditional top-down and bottom-up approaches to implementation should be applied to meet the particular challenges of sustainable development (ibid: 40).

O'Toole also suggests, however, that policy learning and interactive institutionbuilding should constitute crucial elements of a more well-thought and 'SDadapted' approach to implementation. In this direction, a more process- and institution-oriented approach, specifically linked to the implementation of EPI, has been undertaken by Swedish EPI researchers in the so-called PINTS ${ }^{4}$ project (Nilsson \& Eckerberg 2007). The emphasis here has been on the importance of learning processes to formulate and develop EPI in the agriculture and energy policy sectors in Sweden (ibid.). This approach has also been employed in earlier contributions, more explicitly focusing Sweden's energy policy sector (Nilsson 2005a, 2005b).

\section{Towards an analytical model for EPI}

The PINTS project also conducted a thorough review of the EPI literature within a policy-analysis perspective, and provided a summary baseline of explanatory variables and conditions that clearly underlie the more descriptive 'checklists' of assessment criteria provided by the OECD and EEA (Persson 2007). This was also related to an earlier contribution, where researchers involved in the PINTS research team propose an analytic framework (or 'model') for understanding the nature of 'policy outcomes' from EPI (Nilsson \& Persson 2003) (reproduced here as Figure 1). As indicated, the framework depicts a relatively standard social-science

\footnotetext{
${ }^{4}$ Policy Integration for Sustainability (PINTS).
} 
approach, distinguishing between 'background', 'independent' and 'dependent variables'. In this regard, the 'Nilsson-Persson model' provides a conceptual 'bridge' to the broader field of policy analysis.

Figure 1.1

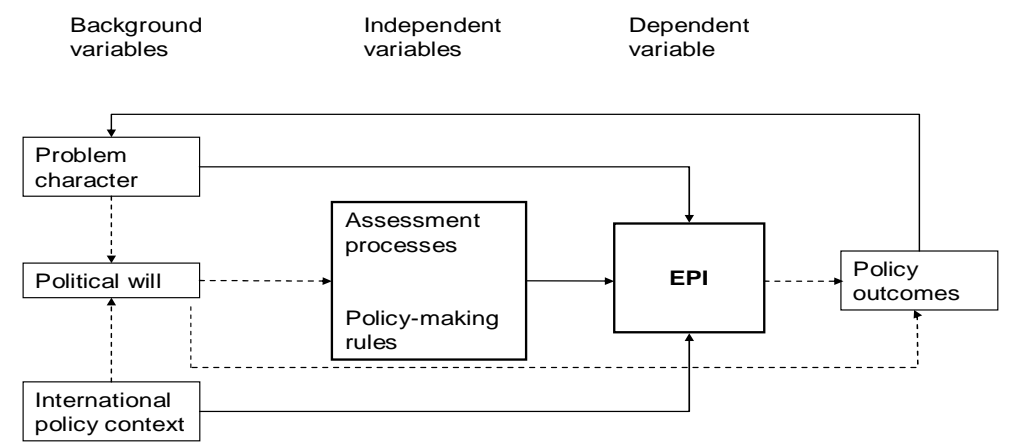

(Source: Nilsson \& Persson 2003: 354).

Three important aspects of this framework will here be discussed, reflecting perspectives on the model developed in the individual studies composing the present dissertation.

First, Figure 1.1 outlines a residual 'black box' for EPI which, implicitly, contains parameters treated elsewhere in Nilsson's and Persson's analysis, but which are not brought directly into the framework. The EPI box in the model warrants further discussion, however, as to what is actually prescribed/expected as an indication of 'EPI in practice'. This is here related to the conceptual discussion of EPI, referred to above, and which is the principal focus of chapter2. In this regard, the dissertation distinguishes between EPI standards and mechanisms as further elaborated in section 1.2.2 below.

Second, a recurrent issue in the PINTS project is whether EPI should be seen as mainly a political-administrative framework for decision-making with a focus on rules and procedures, or more in terms of substantial results 'on the ground' (Persson 2007). We are dealing, in other words, with the distinction between policy outputs and policy outcomes, as succinctly pointed out by Vedung (2004). While the former can generally be considered results of the decision-making process and the formal products of policy formulation; the latter can be understood as the actual effects and impacts of the policy within the field of action being governed (ibid: 5). In the present dissertation, the main empirical references are 'policy outputs'; that is the priorities set and the designated instruments designed to achieve policy goals. 
As understood here, the model provides variables for the 'contextualization' of EPI with respect to: (1) the nature of the 'the problem', that is, the nature of the sectoral activity in question; and (2) the 'international policy context', that is, for Europe, supranational policy as channelled and sanctioned through the European Union. Whereas the latter aspect is directly relevant for the focus on multi-level governance in the present context, the model does not specify sector-specific socio-economic structures and institutions that can be assumed to impact substantially on 'political will'. This latter issue is most explicitly addressed in chapters 3,5 and 7 of the dissertation.

The latter dimension also invoke the important challenge of determining the degree to which the factors identified are general enough to warrant broad recommendation in action plans for EPI; or whether the contextual effect is, in fact, so strong as to warrant a much more ‘ideographic’ approach (Lafferty \& Knudsen 2007).

Given the extensive and specifically analytical character of the Nilsson-Persson model, I have built on the insights provided and aimed to contribute to a further specification of the variables employed by relating the findings of the dissertation to the model. Summing up here, I will first address the EPI variable by providing a perspective on substantive and procedural standards with relevance for a given policy sector. Secondly, I will focus the connection between EPI and policy outputs, which can be considered to represent the analytical level preceding policy outcomes - as stipulated by the original model.

Thirdly, as far as the model's usage of contextual factors is concerned, it is important to have in mind the plethora of relevant factors that have been suggested by various policy-analysis and implementation theories, frequently highlighting different aspects of the decision-making system as well as of the wider socioeconomic structure (see, for example Sabatier 1999; van Meter \& van Horn 1975). Many of these approaches may invoke quite comprehensive empirical mappings and assessments, and can be considered as adequately designed for the study of specific policy decisions. Given the limited space of the individual studies of the present dissertation, an approach emphasising the factors that have played the most direct and relevant roles in an EPI perspective (either explicitly or identifiable as such) have been investigated.

Building on the original Nilsson-Persson model, and in order to specify the focused variables as stipulated above, the remainder of the present section will be related to the three major analytical dimensions of EPI, briefly presented in section 1.1: (1) The concept of 'EPI' understood as specific standards for changing policy outcomes; (2) EPI in a multi-level governance perspective (the international policy context of the model); and (3) EPI as understood within a policy cycle, focusing institutional and procedural mechanisms for policy formation, monitoring and evaluation (focusing the relationship between EPI and policy outputs). In addition, the importance of contextual factors will be discussed more explicitly (section 1.2.5). 
The first analytical dimension to be presented and discussed is related to identifying the core meaning of the concept of EPI, in order to derive standards that can function as criteria for an evaluation of policy performance. The conceptual assessment is further elaborated in chapter 2 . In the present section I will outline the background for this discussion, and point to some major analytical implications that have guided the other five research papers as well.

As indicated in the previous section, a major aspect of the conceptual discussion on EPI is its relationship to sustainable development. In brief, the present understanding of EPI has generally been related to two core ideas: (1) The widely recognised SD goal of 'balancing the interests/concerns/priorities of the so-called 'three pillars': the economic, social and environmental dimensions of societal developments; and (2) the crucial OECD notion of 'decoupling' the drivers of 'business as usual' from negative environmental impacts.

On the first of these ideas, Lafferty and Hovden (2003: 9) have defined EPI as implying:

'... the incorporation of environmental objectives into all stages of policymaking in nongovernmental policy sectors, with a specific recognition of this goal as a guiding principle for the planning and execution of policy'.

The application of this 'guiding principle' should furthermore be accompanied by: 'an attempt to aggregate presumed environmental consequences into an overall evaluation of policy, and a commitment to minimise contradictions between environmental and sectoral policies by giving principled priority to the former over the latter.'

This crucial interpretation of EPI is considered to clearly reflect basic values expressed in the Brundtland report (WCED 1987: 313). This definition does not always imply, however, outcomes in favour of the environmental dimension of SD. What it does indicate according to the authors is, however, that the environmental aspect should be accorded 'principled priority' and the status of 'trump' in tradeoffs between the different concerns. That is, the idea of 'trump' should provide basic guidelines for judicious decision-making, not administrative fiats for predetermined policy outcomes (Lafferty \& Knudsen 2007).

The essential requirement of EPI as 'first-order principle' is, therefore, to guarantee that every effort is made to assess the impacts of the policies - short, medium and long term - on the life-sustaining capacities of the affected ecosystems; and to clearly limit or otherwise qualify in advance those impacts that represent unacceptable risks of degradation.

To be 'judicious' in this context thus means to apply crucial EPI mechanisms in a reflective, prudent and transparent manner. The 'balance' among the environmental/ecosystem concerns and other policy objectives will have to be decided on a case-by-case basis. The outcome of trade-offs between different sets of 
concerns depends on the normative balance of the process applied, most specifically how social and economic concerns are taken into consideration. This will in turn depend on whether the decision-makers employ a medium- or long-term perspective, and, further, whether they perceive relevant changes within a local, national or global context (c.f. Lafferty \& Langhelle 1999).

This perspective on EPI also resonates with juridical interpretations of Article 6 in the EC Treaty (Williams 2007). Whereas the Article's wording is in imperative terms it cannot be regarded as laying down a standard according to which environmental concerns are always taken to be the prevalent interest (ibid.). According to this interpretation, however, the Article requires that environmental concerns always must be taken into account (ibid.).

\section{Decoupling, re-coupling, and path creation}

The second core idea stipulated by the Lafferty/Hovden definition is related to 'decoupling'. This concept, as first and most prominently put forth by the OECD, proclaims that the dominant economic practices of existing Western societies can be shown to be negative for the environment, and efforts must be made, therefore, to 'decouple' such practices from their negative environmental impacts (OECD 2001a: 13). Maintaining functioning ecosystems that can support economic and social development is recognised as crucial for development to last, especially when no substitutes are available (ibid.).

Building further on the notion of decoupling, 're-coupling' has been viewed as the process of defining and implementing new, more sustainable means of production and consumption; that is, an enhancement of 'green innovation' (Lafferty \& Ruud 2006). Re-coupling also resonates with another crucial premise of the Brundtland report; the idea that continued economic growth is necessary, provided that the quality of growth changes (WCED 1987: 52). In this perspective, energy policy can be viewed within a context of innovation policy initiatives, where the goal is a more SD-effective consideration of environmental concerns.

This line of thought can also be related to the notions of 'path dependence' and 'path creation', here constituting crucial concepts in the case study of RES-E implementation in Norway (chapter 4). These concepts are here employed to capture the effects of those contextual variables at the national and regional-local levels which condition and channel the currently dominant techno-market instruments used to promote the implementation of RES-E policies (Lafferty \& Ruud 2008b:17-23).

The assumption is that, at the point of substantive inception of RES technologies into the energy system, there exists a 'dominant energy system' (DES), the nature of which is strongly influenced by the exigencies of its particular historical development (Garud \& Karnøe 2001, 2003; Lafferty \& Ruud 2008b: 19). The realisation of renewable energy illustrates the challenges of inducing structural changes within societal segments with well-established infrastructures, institutions and arrangements favouring specific technological solutions. National energy 
systems are strongly embedded in specific institutions and practices (thereby the notion of 'dominant energy systems') which represent specific barriers at both national and regional-local levels (Lafferty \& Ruud 2008b:17-18). The promotion of RES-E must, therefore, be differentiated and adapted according to specific contextual settings if policy outcomes are to be successful. This dimension is thus also related to the importance of contextual factors, which is further discussed in section 1.2 .5 below.

In sum, 'path dependence' must be taken into consideration as a basis for conceptualising the integration of RES-E into the DES as a process of 'path creation' (Lafferty \& Ruud 2008a). As such, a focus on processes of path dependence and path creation provides a more sector- and technology-specific basis for studying de- and re-coupling in practice.

The problematic of de- and re-coupling can also be related to the research on transition management (Driessen \& Glasbergen 2002; Elzen et al. 2003; Kemp et al. 2005). Whereas this perspective is not explicitly treated by any of the research papers presented here, it clearly provides important and highly relevant insights for the study of governance for sustainable development (c.f. Meadowcroft 2005).

\section{Substantive vs. procedural standards of EPI}

With respect to the development of standards, EPI has been associated with norms related to communicative, organisational and procedural processes and tools (Persson 2007; Jordan \& Lenschow 2008b). However, as demonstrated by studies of European countries, concrete EPI mechanisms are generally not sufficient in themselves to induce shifts in sectoral policy outputs and outcomes (EEA 2005a; Jordan \& Lenschow 2008a). This implies that a more stringent and clarified conceptual understanding of EPI is required. As mentioned above, however, there is no agreement as to the normative intent of the concept. A prevailing view has been that EPI should produce policy outputs that are somehow balanced with respect to the three pillars of sustainable development. In contrast, the perspective put forward here is emphasising the intent of EPI as to produce policy outputs and outcomes that, in one way or another, reflect the semantic essence of the concept: the integration of environmental concerns (Lafferty \& Knudsen 2007). That is, stating EPI as a first-order principle, as is also stipulated by the EC Treaty's Article 6.

The research and debate on EPI demonstrates, therefore, that integrating new policy demands into existing policy areas requires some sort of substantive norm or principle for realising integration in practice. Accepting that the political system essentially 'involves an authoritative allocation of values and resources' (Easton 1953), some means must be at hand to determine what is going to be 'authoritative' (ibid.). In a democracy such means can only be provided by transparent norms for decision-making and the resolution of policy trade-offs among competing interests. Indeed, SD raises substantial challenges as to the allocation and reallocation of resources, in local, national and global contexts. Some sort of standard as to how conflicting interests and concerns can be reconciled and translated into effective 
policy outcomes, stands out as an important measure for applying EPI as a key instrument for SD.

I will here argue, therefore, that the critical question is not the number and design of specific EPI mechanisms, but the quality, and to what extent and how the mechanisms reflect an overall thinking and priority, with the potential of substantially affecting actual policy decisions ('outputs'). Hence, it is fruitful to distinguish between procedural and substantive standards for assessing EPI performance. Procedural standards will also be associated with specific EPI mechanisms - as will be further elaborated in section 1.2 .3 below. In this perspective, it is important that such a 'tool-oriented' approach to EPI is supplemented by clarified criteria as to what these mechanisms are designed to realise or contribute to.

According to the approach elaborated in chapter 2, the way EPI is understood in the present dissertation is that environmental concerns should be integrated as central premises within an SD perspective, as well as being adequately addressed and reflected in the relevant sector's policy decisions. Building on this perspective, a key question is to what extent normative premises can be translated into actual policy-making premises, and further to policy decisions that can affect actual behaviour (Persson 2007: 31). A crucial problematic is thus to identify mechanisms providing such 'translations', as well as 'when, where and how'.

Chapter 2 points in this regard to three main categories of mechanisms considered to be of particular importance in order to convey more solidly the normative core to actual practice in decision-making processes: (1) improved integration of scientific knowledge concerning the capacity of ecosystems; (2) improved environmental assessments and strengthened position of strategic assessments concerning policies and programmes; (3) a legal-administrative institutionalisation of the precautionary principle; and (4) a stronger and more active political mandate, providing a more continuous engagement and responsibility from the top.

In the present dissertation, chapters 5 and 6 address EPI mostly as substantive standards related to climate-change, whereas chapter 7 also addresses the procedural aspect of EPI empirically, focusing specific mechanisms for monitoring and policy evaluation. In addition, as indicated above, EPI essentially involves trade-offs between different SD concerns. Actual mechanisms for making such trade-offs are, therefore, also crucial elements in the case studies provided by particularly chapters 3, 5 and 7, whereas Chapter 2 provides an overall discussion of relevant mechanisms. Given the lack of an explicit recognition of SD and EPI in the U.S. context, the comparative importance of EPI in decision-making, as expressed for example in Article 6 of the EC Treaty, is an important dimension of chapter 6. 
As indicated earlier, SD and EPI are concepts stemming from the international level, but are to be implemented nationally and at regional-local levels. Furthermore, SD and EPI are frequently claimed value references for ambitious EU targets. In the U.S. context the emerging interest for climate-change mitigation points to a potential for an EPI focus. Hence, studying how EPI is implemented and transferred across different levels of governance stands out as a crucially important research task.

The focus on multi-level governance (MLG) is most explicit in chapter 6, but is also touched upon in the other papers; most particularly in relation to the assessment of the RES-E directive in Norway (chapter 4), but also as a key contextual variable in the assessment of EPI and RES-E in the Scandinavian countries (chapter 5). So as to highlight the framework employed, I will here outline some key points of relevance from the literature on MLG.

In general terms, multi-level governance is an extensively employed, but relatively contended concept, with numerous contributions as to different patterns of interaction and causal mechanisms (Hooghe \& Marks 2003; Pierre \& Peters, 2005: 80-100). It has been generally recognized that MLG is also a major challenge for EPI, but beyond such recognition there are few overviews of empirical studies (EEA 2005a: 46; Homeyer \& Knoblauch 2008). Some recent works have, however, attempted to explore EPI within specific federal-state contexts (see Jordan et al. 2008; Hornbeek 2008; Wurzel 2008). Other contributions have emphasized the need for increasing the overall institutional and administrative capacity for coordination, both vertically across levels, and horizontally within national and EU-level administrations, in order to fully accommodate EU ambitions for 'coherence' within different sectoral policy areas (Schout and Jordan 2005; Schout and Jordan 2007; Jordan \& Schout 2008).

The lack of 'MLG-EPI' studies is, however, surprising since there is a very explicit EU focus in the EPI research field. EPI-relevant assessments of the EU are, however, mainly focused on general EPI mechanisms, rather than addressing the importance of different sectoral contexts, across levels of governance - as is the present problematic. An important exception is provided by the PINTS project mentioned above, which also addresses how EU policies have impacted upon Sweden's mechanisms and processes for EPI (Nilsson \& Eckerberg 2007). In addition, there are studies of EPI within specific policy fields at the EU level (see for example Hertin \& Berkhout 2003).

What is generally lacking, therefore, is a clearer analysis of how a trans-sectoral orientation to EPI interacts with a more 'vertical', sector-specific orientation given different constitutional and structural conditions for multi-level governance interaction. This is particularly relevant and interesting in the EU context, since the EU has demonstrated a clear willingness to address and implement EPI along both the horizontal and vertical dimensions. This is in direct contrast to the USA where a 
general lack of federal priorities (under the Bush administration) spurred important initiatives at the state and local level, implying stronger bottom-up processes than those manifest in the EU (Schreurs 2007; Rabe 2008).

Given the EU's presumed role as an EPI front-runner (with specific reference to Article 6 of the consolidated EC Treaty), one would expect the EU to be relatively good at integrating environmental thinking into the work of all of its policy sectors (Jordan et al. 2008: 159). Bomberg (2004: 61) has, however, argued that EU's advocacy of EPI, both within and outside its borders, is a clear example of the EU outstripping its capacity to translate political promises into practice. Lundqvist (2004: 330), on the other hand, maintains that a more 'coherent' approach to SD governance by the EU is possible, providing that one considers the positive resources provided by the Union's multi-level pluralistic structure. Lundqvist (2004) also stresses, however, that several institutional features of the EU work against a stronger priority for SD, most notably the lack of a strong and consistent political leadership. Analyses like these clearly document the challenges and tensions underlying the EU's EPI ambitions.

The research on multi-level governance in the broader sense has generally also been particularly focused on the EU, specifically focusing the transition to a less statecentred, more complex regional polity (Bache \& Flinders 2004: 195-200). Pierre and Peters (2005) criticize this 'EU-centricity' and highlight U.S.-based research on federal-state relations which places greater emphasis on legal and political aspects. Such divergences between 'EU- and US-approaches' to multi-level governance does not solely reflect, therefore, diverging theoretical stances, but can also be seen in light of the diverging constitutional and political frameworks of the two polities. Three categories of general factors warrant a closer scrutiny in this context.

First, an important basic distinction is the different roles of the federal level vs. the state level in the two polities. Whereas the distribution of powers between these levels is relatively settled by the US Constitution, this is much less so in the EU, where the more open notion of subsidiarity is an important (but still diffuse and very 'elastic') governing concept. This notion involves a more functional (less legalistic) principle for determining how goals transcending the nation state in Europe should best be pursued, by whom and at what level of governance (Bomberg 2004: 81). A major aim of the principle is to balance the goals of achieving effectiveness and maintaining closeness to the citizens. The underlying tension of the principle is clearly visible in matters pertaining to EPI, and can be clearly illustrated by the energy-policy sector (Collier 2002). U.S. federalism, on the other hand, implies a firmer horizontal (between the branches of government) and vertical (federal-state) separation of powers. Hence, the federal centre and its powers are clearly more carefully defined and circumscribed in the US than in the EU (Martinelli 2007a: 96).

Secondly, the role of the public sector in the economy has been seen as one of the main distinctions between the two polities, particularly in terms of levels of taxation and public-sector involvement (Chiesi, 2007: 44). In addition, there are also important differences as to how economic interests are mediated and represented 
within the polity, not least with respect to environmental protagonists. The US system is often characterized as more 'pluralistic', while European countries are seen as more 'corporatist' (Martinelli 2007a: 129-134). There are, however, variations in this regard within the EU itself. Whereas relatively strong ties between labour organisations, industrial federations and political authorities characterize the traditional mode of governance in the Nordic countries (Pallesen 2006), the EUlevel and its institutions are more often featured as a pluralistic polity, resembling that of the USA, with a large number of interests competing in order to get access in a complex decision-making system (Martinelli 2007a: 130).

Thirdly, American policy development is generally considered to be more driven by judicial mechanisms than in Europe. During the last two decades, however, a common legal framework has been an increasingly important instrument for fulfilling the EU's reinforced ambitions of common policies, including EPI (see chapter 6). US governance is, however, still remarkably more characterized by litigious approaches to policy development (c.f. Lieberman, 1983) than the EU. This can also explain the recalcitrance of U.S. legislators to formulate legally binding objectives with economic consequences for commercial interests, as succinctly illustrated by the federal political in-action vis-à-vis climate-change mitigation (Schreurs 2004).

Taken together these background variables imply different potentials for EPIrelevant policy intervention from the supranational/federal levels in Europe and the United States. In general, the EU employs a broader portfolio of approaches and instruments, reflecting the European tradition of a more active public steering of the economy, and less settled legalistic principles for top-down governance.

Despite this clear indication of the importance of governmental structures in a federal-state level interaction, a major share of the MLG research seems to downplay the role of governments and institutions, and in stead highlights the roles of networks and negotiations (Pierre \& Peters 2005). Pierre \& Peters (2005) emphasise by contrast the continuous institutional 'grip' on political processes within the EU Member States, and between the national and supranational actors within the EU which, although increasingly relaxed, remains strong and even further strengthened by the state if and when considered necessary (ibid: 80-81).

It is, therefore, crucial to recognise that MLG constitutes a potentially diverse framework; a framework from which it is necessary to deduce driving-forces and barriers of specific relevance for EPI in an EU-US comparison. In this way, the present dissertation takes a pragmatic stance on the debate referred to above, although it clearly supports Pierre \& Peters' emphasis of the importance of 'traditional political steering' (effective governance presupposes good governing!).

In line with this, the empirical and analytical focus in chapter 6 is most explicit about the roles of the state/national authorities as compared to the federal/supranational political institutions. As such, there is ample room for additional analyses that more substantially focus the role of non-public actors within 
the processes analysed in chapter 6 . Such analyses would constitute a significant value-added and complementary contribution to the research problem.

Furthermore, different perspectives on the distribution of power, as well as the goals and modes for conducting interaction and exchange between levels of governance, can be discerned in the MLG literature. In a directly relevant contribution Knill and Lenschow (2005a, 2005b) identify, for example, three ideal-type modes of governance that affect EU-national policies: the prescriptive mode which is based on the compliance of national implementers with legally binding EU rules; the communicative mode associated with information exchange between national and EU-level regulatory agents in a legal or institutional framework; and the competitive mode, understood as competition between national administrative systems to achieve EU requirements. Building on these modes, chapter 6 provides a comparative assessment of the interaction between the federal and state/national level in the EU and the USA.

The third main analytical dimension of EPI employed in the present dissertation concerns the employment of more specific EPI mechanisms and how they impact upon policy formulation and implementation. As previously emphasised, SD is a concept largely stemming from the international/global level, and has to be followed up and implemented at national and sub-national levels. It is, therefore, an important task for strategic research to focus on how to provide for a more effective implementation, including more context-sensitive EPI mechanisms. This requires an improved understanding of what in fact functions where, when and how; not least related to the different phases of policy formulation and implementation within the 'policy cycle'. ${ }^{5}$

As emphasised above (section 1.2.1), the broader research fields of policy analysis and policy implementation provide a comprehensive and fruitful discourse within which one can anchor EPI research, most particularly studies of specific EPI mechanisms.

The issue of EPI as an implementation problematic is also increasingly addressed in recent EPI research. Jordan \& Lenschow (2008a: 330-335), for example, point to policy analysis - distinguishing between the different phases of policy-making processes (from agenda-setting to evaluation and revision) - as a key perspective for future EPI studies. They maintain that different types of EPI instruments (symbolic, organizational and procedural governing mechanisms) should be related to and

\footnotetext{
${ }^{5}$ In the present context the term 'policy cycle' is primarily employed as a heuristic to capture different stages or phases in policy formulation and implementation. The dissertation does not, therefore, aim to relate to the important debate about the fruitfulness and eventual revisions of this concept (see for example Jann \& Wegrich 2006).
} 
studied according to their function within a policy cycle perspective. This can then be further analysed from institutional, political and/or cognitive perspectives (ibid.).

A crucial issue that emerges here is where in the policy cycle one should place EPI mechanisms and tools in order to fulfil the substantive standards stipulated under section 1.2.2. This problematic also resonates with the wider issue of policy instrumentation, and the sequencing and 'packaging' of instruments (BemelmansVidec \& Vedung 1998; Vedung 1998).

The approach employed in the present dissertation is explicitly based on a multidimensional perspective of relevant EPI mechanisms, where a horizontal, sectorencompassing dimension interacts with a sector-specific, vertical dimension. This implies, moreover, that EPI mechanisms should be considered as parts of an interactive whole (serving the promotion of SD) rather than as isolated instruments. It also presupposes a coherent perspective on policy formulation and implementation; which, again, presupposes a clear distinction between policy outputs and policy outcomes (see section 1.3).

This approach builds further on, and concretely applies, the 'benchmark approach' developed by Lafferty (2002a, 2004a), on the basis of specific mechanisms for SD governance documented by the OECD (2002a) (see Text boxes 1.1 and 1.2).

It is crucial to stress here that the coordination and overall integration of horizontal and vertical mechanisms, as manifested by the EPI benchmarks, is of vital importance. The lack of an over-arching, sector-encompassing priority of SD, based on a clear political-institutional mandate, often leads to a withering of responsibility (see also chapter 3). Sectoral initiatives can particularly reflect and support EPI by the existence and character of sector-specific programmes and the eventual linkage between such plans and a national strategic framework for SD.

There are, however, different perspectives as to how strategies for promoting sustainable development (SDS) can (and should) be related to EPI. Steurer (2008) distinguishes between EPI instruments and SDS, and contends that unlike many other EPI instruments an SD strategy does not have a clearly defined position in the policy cycle. Whereas individual EPI instruments mostly focus on specific phases such as policy formulation, implementation or feed-backs - an SDS is considered to represent a holistic approach which combines aspects of formal planning and incremental learning (ibid: 95). Empirical studies have indicated, however, that national SD strategies are extremely important for EPI, since their adoption provides a political commitment to the crucial role that the UNCED process has assigned EPI in the national policymaking context (Lafferty \& Meadowcroft 2000a; Lenschow 2002a; EEA 2005a). 
Text box 1.1: Benchmarks for the vertical dimension of EPI (VEPI):

1. Scoping reports of sectoral activity identifying major environmental impacts associated with key actors and processes

2. Sectoral forums for dialogue and consultation with relevant stakeholders and affected citizens

3. Sectoral strategies for change, with basic principles, goals, targets and timetables

4. Sectoral action plans with specified initiatives for achieving goals with target-group related policy instruments

5. Green budgets for highlighting, prioritizing and carrying through action plans

6. Monitoring programs for evaluating implementation and revising strategies and action plans

Source: Lafferty (2004a): 205-206.

\section{Text box 1.2: Benchmarks for the horizontal dimension of EPI (HEPI):}

1. A "constitutive" mandate providing principles and procedures for reconciling conflicts and trade-offs related to decoupling and environmental policy integration

2. An over-arching strategy for SD goals and operational principles, and a political mandate for implementation with direct backing from the chief executive authority.

3. A national action plan with both over-arching and sectoral targets, indicators and time-tables.

4. A responsible executive body with designated responsibility (and powers) for the overall coordination, implementation and supervision of the integration process.

5. A communications plan stipulating sectoral responsibility for achieving overarching goals, and outlining how cross-sectoral communications are to be structured and made transparent.

6. An independent auditor with responsibility for monitoring and assessing implementation at both governmental and sectoral levels, and for proposing revisions in subsequent generations of strategies and action plans.

7. A board of petition and redress for resolving conflicts of interest between environmental and other societal objectives, interests and actors.

Source: Lafferty (2004a): 207-208.

In line with this overall perspective, chapter 7 discusses the issue of specific EPI mechanisms, by particularly focusing effective means of monitoring and evaluating policy performance as tools for amending policy decisions in a more sustainable direction. This builds also on the benchmark approach, within which monitoring activities are included as one of the crucial (vertical) benchmarks, as well as a 
(sector-encompassing) independent auditor with the mandate of assessing implementation and proposing strategic revisions (Lafferty 2004a: 204-208).

Since policy evaluations are understood to contribute to an updated understanding of the connection between policy outputs and policy outcomes, the focus on policy evaluation in chapter 7 can also be related to a stronger emphasis on policy learning as a way of studying EPI. As referred to above, the PINTS research project has conducted a comparative assessment of EPI in the agricultural and energy sectors in Sweden (Nilsson \& Eckerberg 2007). The focus of the project on policy learning is employed on the basis of an observation that environmental concerns in sectoral policymaking have been systematically undervalued, despite democratically established policy goals (Nilsson et al. 2007b: 4). A more rational approach, in view of the authors is, therefore, to enhance the attention to environmental knowledge in economic sectors, and the potential of policy-learning processes to drive a normative reorientation within the sector (ibid.). As such, the project mainly employs a bottom-up approach to policy implementation. Along these same lines, Jordan \& Lenschow (2008c: 13) contend that 'decentralised societies' may lead to stronger EPI, as these are more capable of developing a feeling of ownership at the grassroots level and hence provide bottom-up support for EPI.

O’Toole (2004: 40) employs a somewhat broader perspective by emphasising the fruitfulness of combining top-down and bottom-up approaches to implementation as a more suitable approach to sustainable development.

Building on these insights, the present dissertation provides a preliminary analysis of the basis for defining a more coherent linkage between substantive standards of EPI and actual policy outputs. That is, it assesses specific energy-policy initiatives in relation to EPI and SD standards and principles. It is primarily chapters 5 and 7 that provide insights in this regard. The next step is then to integrate such insights into a more stringent assessment of the 'EP-effect' in terms of specific policy outcomes. As emphasised above, however, and as will be elaborated further in section 1.3 below, this involves a methodology that has little to build on in existing EPI research.

\section{Contextual factors}

Finally, as highlighted by the research field on policy analysis and policy implementation, different sets of contextual factors are important in order to understand how policy projects and programmes, including specific policy instruments, are followed up and realised. As indicated in section 1.2.1, this is also a central feature of the EPI research model developed by Nilsson \& Persson (2003). In the present dissertation the empirical studies will provide insights in a comparative perspective as to how contextual factors directly structure and channel EPI steering instruments, and, furthermore, on the related implications for the connection between EPI and sectoral policy outputs. The analysis of contextual factors in the present context is also substantially guided by and building on previous studies on the critical relationship between the function and context of 
specific policy instruments, including the importance of national policy styles (Arentsen 1998; Bemelmans-Videc \& Vedung 1998: 271-272).

The importance of identifying and assessing contextual factors is most explicitly addressed in chapter 4 (Norway-RES-E), which was written as part of a broader project where this was a major problematic and research question (Lafferty \& Ruud 2008c). Building on an overview of existing analyses of EU RES-E policies, the SUSTEN project found that these studies almost exclusively employ a 'technomarket' approach; an analytic framework focusing the combination of technology development with market penetration and learning (Lafferty \& Ruud 2008b: 15-16). Some of the projects openly recognised the limitations of such an approach, and acknowledged the need for 'grounding' (contextualising) the crucial techno-market parameters (ibid.). There were, however, at that time virtually no studies available that explicitly employed a contextual approach (ibid.). On this background, the SUSTEN project identified two sets of contextual variables: (1) Structural variables conditioning energy-system resistance (inertia) to RES-E - identified as 'path dependence'; and (2) contextual variables conditioning the actual introduction and integration. Such variables are in the present context further identified and assessed in the Norwegian case (in chapter 4).

Contextual variables and contextual differentiation are, however, also crucial parameters for an effective implementation of SD and EPI in the wider sense. Of socio-political factors the recognition of political will and an enduring political commitment have been widely identified as key variables for sustained efforts to promote SD and EPI, most succinctly in the model of Nilsson-Persson (Figure 1 above), but also more extensively in Lafferty \& Meadowcroft (2000a), Lafferty (2004b), EEA (2005a, 2005b), and Jordan \& Lenschow (2008b). Fewer studies document, however, the factors that condition and eventually stimulate political will to prioritise a higher degree of EPI. Schout \& Jordan (2007) argue that political commitment interacts with the administrative framework, and that functioning, wellcoordinated administrative mechanisms should thus be viewed as resources that both can increase and partly replace political commitment. The research of the present dissertation has not found any evidence to support this last assumption, however; although the institutional framework of the energy sector is generally found to be important for the status of EPI, albeit in interaction with the political priority and commitment of sustainable development (see chapters 3, 5 and 7).

The importance of context is even more evident when studying a specific policy sector. With respect to EPI, this aspect has thus far been most broadly and thoroughly treated by the Swedish PINTS project, referred to several times above (Nilsson \& Eckerberg 2007). The PINTS project clearly documents how specific procedures, time-bound processes and industrial actors affect the nature of EPI policy outputs. 
The present dissertation employs three analytical dimensions, in addition to contextual factors, in a normative-empirical analysis of EPI within the energy sector. These dimensions are addressed to different degrees by the six research papers, and can be considered as supplemental perspectives on EPI.

The discussion presented in section 1.2.2 entails a fundamental understanding of EPI which underlies all the individual studies. The bottom-line of this understanding is to emphasise the concept's normative function as a 'first-order-principle' for resolving trade-offs between sectoral policy goals and environmental concerns by which one can achieve an actual decoupling (Lafferty \& Ruud 2006; Lafferty \& Knudsen 2007). Based on this understanding, a major question to be addressed in the present dissertation is, therefore, the nature of evaluative standards inherent in the EPI concept. This involves basic values as well as benchmarks for actual procedures and institutional mechanisms, as highlighted by the discussion in section 1.2.4. This is, furthermore, related to a multi-level governance context - as well as to an investigation of crucial contextual factors affecting EPI, and the connection between EPI standards and mechanisms on the one side, and sectoral policy outputs on the other.

The three dimensions addressed will also provide insights that can further develop and specify an analytical research model for EPI, as outlined by Nilsson and Persson (2003) (Figure 1.1).

A more fundamental question is, however, the extent to which it is possible to capture and explain the complexity of the policy activity of a modern society, by any single theory or model (c.f. Parsons 1995). What is of essential importance in the present context, however, is that the relevance of academic theory for an effective implementation of EPI is strongly dependent on its ability to take on and enlighten the particular nature of the concept (c.f. Lafferty 2004c: 335-336). This statement implies a conscious, explicit and systematic interactive research between conceptual clarifications, academic-theoretical discourses and a more applied policy-practice discourse. This interaction will, at least ideally, lead to a more fruitful and eclectic use of theoretical approaches, and, thereby also (hopefully) contribute to a less polemic and more consolidated research field. The following section will further elaborate on this research approach.

\section{3}

\section{Methodological considerations}

The major research question guiding the sub-tasks of the dissertation is related to the normative, analytical and empirical aspects of environmental policy integration (EPI) and energy. As pointed out, EPI research encompasses a wide range of studies and approaches, with differing foci and differing analytical scopes. There is thus no general analytic design available that prescribes how EPI case studies should be conducted. On the other hand, there are several studies that map and assess more 
concrete EPI mechanisms and instruments. For some of these instruments - strategic environmental assessments (SEA), for example - there are more specialised methodologies available (Sadler 2005).

An important basis for methodological considerations in the present context is the issue of applying EPI standards and mechanisms to specific policy initiatives ('outputs') and their actual consequences ('outcomes'). As stated in section 1.2.1, building on Vedung's (2004) methodological approach, the official prescriptive aspects of policy initiatives (with respect to goals, policy instruments, etc) are here viewed as policy outputs; while the actual effects of the policies - impacts on target groups and the field of activity to be changed, as well as what occurs beyond the addressees in the chain of influence - are termed policy outcomes. Vedung also uses the term 'impacts' for the latter, distinguishing here between 'immediate', 'intermediate' and 'ultimate outcomes' (2004: 5).

In this regard, it is fruitful to build on Vedung's model, in order to place EPI within the stipulated chain from policy initiation to implementation, as presented in Figure 1.2. This 'model' clearly illustrates the basic stages crucial for the implementation of EPI, as well as policy evaluations concerning the specific outcomes and impacts related to EPI (c.f. Vedung 2004) (See chapter 7 for a more explicit discussion of policy evaluation and EPI).

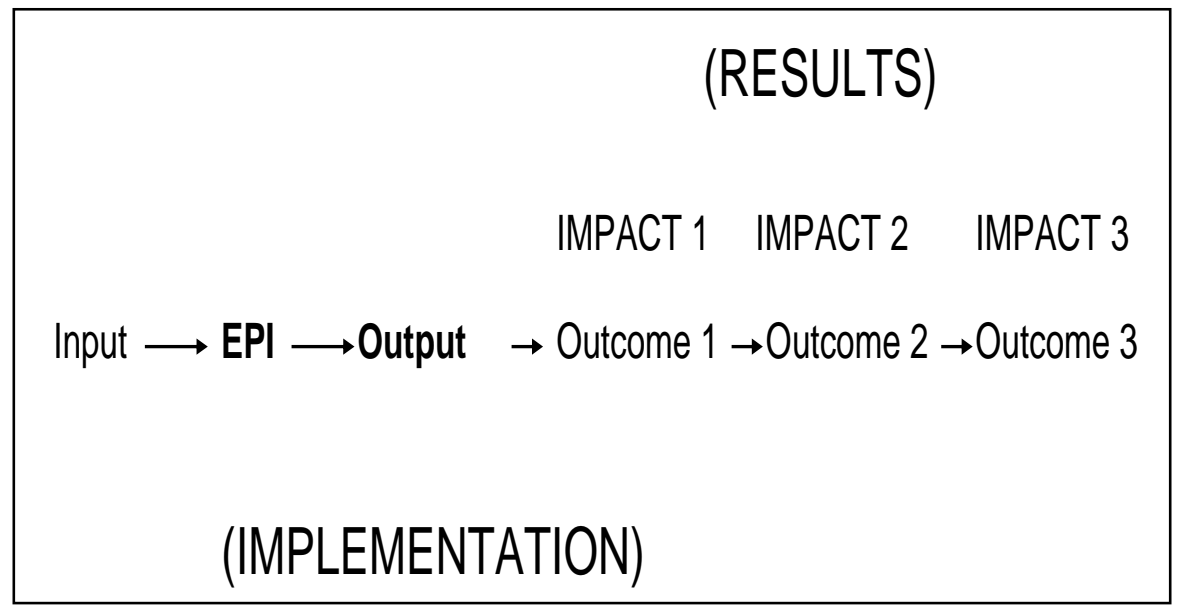

Figure 1.2 Building on Figure 1.2 in Vedung 2004: 5

Clearly, it is highly challenging to identify an actual and precise impact of a governance tool in the form of a policy outcome, since outcomes often depend on a range of other factors, at several scales and operating within differing contexts. The PINTS project did, however, conduct a relatively technical analysis of sectoral policy outcomes in relation to general EPI standards (Nilsson \& Eckerberg 2007). The project did not, however, aim at establishing direct causal links between EPI and policy outcomes; that is, the 'ex-post' state of the environment (Nilsson et al. 
2007a). On the other hand, the edited volume of Jordan and Lenschow (2008b), as well as the individual studies that compose it, carefully avoids linking EPI to concrete policy outcomes at all.

Given the complexity of such a task, and as stressed in section 1.2, the main empirical focus has here been policy outputs; the formal plans and procedures for achieving change (c.f. Vedung 2004: 5). The present dissertation is, therefore, specifically focusing on the connection between the 'EPI' box and outputs in a sectoral context, as reflected in the Nilsson-Persson model (Figure 1.1), presented in section 1.2.1.

Given the focus on this connection, it has been considered as important to strive for a highest possible degree of conceptual stringency across the individual studies in the different papers. This is sought by employing the conceptual understanding developed in chapter 2 as a common ground for all the other papers, and the EPIrelated analysis therein. Secondly, and as clearly pointed out in section 1.2, the dissertation seeks to document and analyse linkages between the substantive and procedural aspects of EPI. As emphasised in section 1.2.2, this specific linkage is not much studied thus far in EPI research, and there are, therefore, few other contributions that have tested this approach vis-à-vis a sectoral context.

The present dissertation aims, therefore, to constitute a contribution of both academic and applied-science value, anchored within a 'normative-empirical' research discourse, related to the specific strategic goals of democratic decisionmaking for - in the present case - sustainable development. In this regard, the dissertation builds on a strategic research orientation developed first at the Department of political science, at the University of Oslo, and subsequently applied as the core methodology of the strategic programme ProSus sponsored by the Research Council of Norway. ${ }^{6}$ The basic steps of the normative-empirical approach have been outlined by Lafferty (2002c), as reproduced in Text box 1.3.

\footnotetext{
${ }^{6}$ A main activity of the programme was to document and evaluate Norway's follow-up of the Rio accords and the guidelines of the United Nations Commission for Sustainable Development (CSD) through on-going evaluations of Norway's progress with respect to the declared goals and values. In addition, the programme provided goal-oriented strategic research on the barriers hampering a more rational and effective realisation of sustainable development. This activity was conducted in cooperation with other national and international research institutions, with comparative methodology and assessments as a major output (see for ex. Lafferty \& Eckerberg 1998; Lafferty \& Meadowcroft 2000a; Lafferty 2001; Lafferty \& Narodoslawsky 2003; Lafferty 2004b; Lafferty \& Ruud 2008c). Thirdly, the programme provided information and dissemination of alternative strategies of governance, steering instruments and normative future perspectives for more sustainable societies locally, nationally and globally.
} 
Text box 1.3: Basic steps of normative-empirical research

1. Identification of a specific practical discourse where questions of democratic norms are at issue; e.g. sustainable development. The discourse can be related to any aspect of political performance, and at any level of governance (international, supranational/federal, national, regional-local).

2. Connection of the specific issue in question to one or more academic discourses related to the problematic.

3. 'Translation' of the practical-discourse problem into a normative-theoretical discourse problem: clarifying the implications of the problem within a normativetheoretical context.

4. Formulation of empirical criteria, drawn from the field of the practical discourse, by which the normative problem could be addressed and clarified.

5. Determination of the relevant empirical methodology necessary to an objective analysis of the normative problematic.

6. Execution of the empirical analysis, with conclusions for both the practical discourse and the normative-theoretical discourse.

Source: Lafferty 2002c: 8.

A crucial dimension of this research orientation is thus to evaluate policy objectives set in democratic processes, in order to assess the legitimacy and the effectiveness of the follow-up initiatives (Lafferty 2002c: 7). This approach is further specified by the basic steps displayed in Text Box 1.3 above.

Based on this approach, the overall analytical question in the present context is related to the democratically set norm of sustainable development, within which EPI is an instrumental approach for implementation. Building on the first step outlined in Box 3 above, this norm is here further considered as a practical challenge in terms of implementation within a sectoral context (energy policy), studied at several levels of governance. This is further related to the controversy, outlined above, on the EPI concept, and alternative understandings of the interdependency between the normative aspect of the 'political' discourse and the practical, applied aspect of the 'academic' approach. As elaborated in section 1.2, I argue in the present context for a stronger and more stringent normative anchoring of the concept, which is also in line with the political discourse developed since the publication of Our Common Future.

According to the second step of the approach, EPI is here further studied as an issue within the broader scientific discourses of governance and policy analysis, focusing on EPI as a crucial applied instrument. In this way, the concept of 'EPI' is addressed and clarified within a normative-theoretical discourse. In order to set criteria for the evaluation of policy performance according to EPI, the dissertation opens with a conceptual clarification. This is in line with what is stipulated by step 3 in the text box.

Furthermore, the discussion of EPI standards in section 1.2 is the basis for the identification of empirical instances. In line with the fourth step stipulated by Box 1.1, empirical criteria have then been drawn from the practical discourse - as 
demonstrated by the benchmarks outlined in section 1.2.4 that are building on an assessment of existing EPI mechanisms.

Building on what is stipulated by steps 3 and 4, I finally arrive at defining a concept of 'EPI' which includes bottom-line, normative-empirical criteria for the evaluation of the status of EPI within a sectoral context. As the final steps (according to five and six in Box 1.3), the selection of cases, empirical methodology and the more specific employment of particular theoretical perspectives of the dissertation, are based on the interactive employment of the various discourses outlined by the first four steps.

The steps outlined above thus constitute a strategic research framework within which four crucial dimensions can be discerned in order to assess policy performance empirically; that is, the fulfilment of the democratically set objectives: (1) Mapping and evaluation of the related policy programmes and activities; (2) identification of barriers as to the implementation of relevant policies; (3) comparative analysis of how barriers are sought overcome; and (4) infer implications for further policy initiatives. These dimensions have constituted operational guidelines for the dissertation research.

The empirical aspect of the methodological approach is mainly anchored in the comparative analysis of qualitative case studies. Here, the standard requirements for case studies as put forth by Yin (1994) have been applied. The dissertation contains two separate descriptive-analytic case studies (chapters 3 and 4), and three comparative case studies (chapters 5-7).

Building on the general distinction between Most Similar Systems Design (MSSD; comparison of different outcomes across similar countries), and Most Different Systems Design (MDSD; comparison of similar outcomes across different countries) (Landman 2008: 28), these three papers employ combinations of both. In relation to chapters 5 and 7, an MSSD design has been employed through the comparison of Scandinavian countries which are mostly similar in governance structures (except for the affiliation with the EU) and political culture. Chapter 6, on the other hand, employs an MDSD design by comparing two different multi-level governance contexts (the EU and USA), but where both cases demonstrate combinations of EPI and RES-E (similar outcomes). The MDSD design thus induces a framework for interpreting how comparable processes of change with direct relevance for EPI are played out in different ways within each context (c.f. Collier 1993: 108).

Furthermore, the research conducted through the individual research papers is mostly based on documentary analysis, supplemented by interviews with selected informants. Quantitative data have also been assessed, mostly in the form of figures related to energy production and usage.

A highest possible degree of validity has been sought by studying of a high diversity of primary and secondary sources. As for primary sources, official documents from 
the EU, US federal, and national and state authorities have been the main sources. Secondary sources have been studied, both as commentaries and assessments of official documents, and as linkages to the wider theoretical and scientific discourse -most particularly related to governance for sustainable development. In developing the individual papers, I have, therefore, aimed at theoretical and empirical triangulation (Yin 1994: 90-94), by checking out the broadest possible array of relevant and available documents, scientific reports, book chapters and journal articles.

In sum, the individual studies provided by the present papers are primarily related to a policy and program level. Hence, and in line with the above argument on the challenge of an EPI methodology, the insights and conclusions provided here mainly depict interaction, and avoid statements on possible causalities. The present studies should therefore eventually be supplemented by more case-specific studies related to even more delimited instances, that is, in the form of a specific policy decision.

\section{Outline and main insights from the studies composing the dissertation}

The present section will present an overview summary of the main insights provided by the six papers composing the present dissertation. The outline will refer to the research questions presented in section 1.1 , as well as to the analytical framework elaborated under section 1.2.

\section{Chapter 2:'The issue of "balance" and trade-offs in environmental policy integration: How will we know EPI when we see it?'}

Chapter 1 (Lafferty \& Knudsen 2007) provides a clarification of the conceptual nature of EPI so as to strengthen its analytic potential as a framework for comparative evaluation of sectoral policy implementation. The paper maintains that EPI must be understood and further developed with reference to the overall concept of sustainable development. The paper provides this clarification after having discussed key elements of alternative approaches to EPI.

Building on previous conceptual and empirical work conducted at ProSus at the University of Oslo, the paper elaborates how EPI can be seen as a normativeprocedural governing mechanism for sustainable development. Emphasis is placed on EPI as an instrument of 'principled priority' for resolving trade-offs between economic, social and environmental concerns. The argument is made that this conceptual clarification addresses key challenges identified by other important, recent and existing, research efforts. More crucially, the approach is considered to be in line with the normative position of the Brundtland Report.

As an operational implication, chapter 2 also discusses and identifies effective mechanisms for a stronger connection with SD as an overall, sector-encompassing 
dimension and concern, and by developing three procedural steps for strengthening EPI as a governing mechanism to achieve decoupling: (1) developing a 'canon for practical judgement' for resolving EPI-related trade-offs; (2) strenghtening the canon through a more focused integration of science, strategic assessments, and the precautionary principle; and (3) anchoring the mandate for EPI in a more 'robust' institutionalization of 'political will' for sustainable development. living up to Brundtland at home'

The second paper (Lafferty et al. 2007) focuses a broader concept than EPI as such by assessing the status of Norway's Strategy for sustainable development (SDS), and the historical and political context of the Norwegian efforts for SD and EPI. Building on insights reflected in chapter 2, chapter 3 assesses the Norwegian efforts in light of the interaction between the horizontal (intra-governmental) and vertical (sector-specific) dimensions of EPI.

Furthermore, chapter 3 points to the crucial importance of political will interacting with administrative culture as factors conditioning the country's SD efforts. These factors are in the Norwegian case further conditioned by the national socioeconomic interests and structures. With the Norwegian Prime Minister, Gro Harlem Brundtland, as chair of the World Commission on Environment and Development, Norway became an early mover in politics for Sustainable Development (SD). The pursuit of SD goals was subsequently expressed in several national policy documents, though it was not until 2002 that Norway adopted an explicit 'National Strategy for Sustainable Development'. The analysis shows, however, that neither of these initiatives has been actively implemented, despite recent evaluation and revision by the 'red-green' coalition government of 2005-09.

The chapter presents and assesses strategic SD initiatives from 1989 until 2007, arriving at the significant conclusion that the Norwegian SD profile is 'long on promise' but 'short on delivery'; and that a prevalent reason for this profile is the influence of a booming petroleum economy on distributional politics. An exceptional growth in public revenues due to oil and gas fosters intense political competition over the dispensation of economic and welfare benefits - both between political parties and within governing coalitions - and undermines the 'political will' to pursue the SD agenda. Given the ability to also use the surplus for development assistance, Norway stands forth as an SD 'frontrunner' in international aid, and an SD 'laggard' in sustainable production and consumption at home.

\section{Chapter 4: 'Norway: Trying to maintain maximum RES-E in a petroleum driven economy'}

Chapter 4 (Knudsen et al. 2008) provides a sector-specific, empirical basis for understanding the conditions for EPI by assessing how a highly hydro-dominant electricity system like Norway is faced with very particular challenges in relation to RES-E. In this connection, the paper can also be related to a broader discussion of 
the potential for de- and re-coupling of the energy sector; processes here analysed in terms of the crucial dynamics between 'path dependency' and 'path creation' within the national context.

Having adopted political limits in principle hindering further development of largescale hydropower, Norway's ability to meet RES-E targets is shown to be dependent on either a stabilisation of consumption at current levels, or the development of additional 'new' RES-E. The attempts to promote significant new RES have thus far, however, been only moderately successful. Despite an early deregulation of electricity production and distribution in Norway, the paper documents that national political decisions (or the lack of some) still constitute crucial framework conditions. First, despite recent increases in public financial allocations and industrial interest, Norway lacks a strategic framework and adequate mechanisms for more effective implementation and phase-in of non-hydro RES-E. Secondly, there is no coherent framework for making overall trade-off's related to an eventual decoupling of the energy sector.

The case of Norway's RES-E promotion thus illustrates a specific example of how substantial de- and re-coupling is hampered by certain barriers within a crucial sectoral context. (EPI) and the case of renewable electricity in Scandinavia'

Chapter 5 of the dissertation (Knudsen 2009a) discusses more explicitly how the promotion of RES-E in the Scandinavian countries is of direct relevance for the EPI research discourse. In this context, chapter 5 provides a comparative assessment of the promotion of RES-E in Denmark, Norway and Sweden.

The chapter documents that Danish and Swedish RES-E initiatives to a larger extent than in Norway can be related to de- and re-coupling, and therefore more strongly reflect EPI standards. This is primarily due to the anchoring of RES-E initiatives within more consistent policy frameworks addressing energy production and usage, with decoupling as a core perspective. Furthermore, Danish RES-E initiatives also imply a stronger and more innovative re-coupling potential than the other two countries.

Denmark and Sweden also illustrate how different approaches to RES-E promotion reflect different modes of EPI. This is demonstrated by the more consistent procedural and institutional linkages between the strategic level and related followup mechanisms in the two countries (as compared to Norway), although in different ways. The Danish approach is more sector-specific and includes a stronger interaction with stakeholders in bottom-up processes; whereas the Swedish approach is characterised by a more sector-encompassing strategy, within a relatively centralized bureaucratic framework. The two cases thus illustrate the strengths and weaknesses of the vertical and horizontal approaches to EPI. 
In sum, contextual differences among the Scandinavian states have provided different bases for the promotion and integration of RES-E into existing energy systems. The different energy 'paths', and the outcomes they have conditioned, confirm the need to contextualise de- and re-coupling efforts. On a more general level, however, the paper concludes that although positive EPI results are strongly dependent on enduring political commitments, but that, even in two cases as 'progressive' on RES-E as Denmark and Sweden, there is still a need for greater integration of the horizontal and vertical dimensions.

\section{Chapter 6: 'Integration of environmental concerns in a trans-Atlantic perspective: The case of renewable electricity'}

The sixth chapter (Knudsen 2009b) addresses the second of the three main analytical dimensions of EPI, outlined in section 1.2: the importance of EPI in a multi-level governance context, as illustrated by a comparison of RES-E initiatives in the EU and USA. Although EPI and SD, in contrast to the EU, are not explicitly recognized as goals in the USA, efforts to establish policy strategies and instruments for climate-change mitigation and the promotion of renewable electricity at both US state and regional levels are clearly of interest for exploring the constitutional and contextual nature of EPI standards and mechanisms. By assessing the promotion of RES-E in the six 'New England' states of the USA (Connecticut, Maine, Massachusetts, New Hampshire, Rhode Island and Vermont), compared to the Nordic countries in Europe (Denmark, Finland, Norway and Sweden), the paper attempts to highlight the importance of different multi-level governing structures in this regard.

The chapter thus documents that in the New England states, the promotion of RES$\mathrm{E}$ has thus far not been substantially integrated with climate-change concerns, whereas the EU has employed a more top-down approach to RES-E where climatechange is much more prevalent. Policies stemming from the EU level thus represent an increasingly important driver for the Nordic countries, whereas in the USA such impulses have been clearly lacking from the federal government.

Compared to the EU, there are few indications in the U.S. context of either strengthened rule-based or communication-based modes of interaction between the federal and state levels in relation to RES-E and climate-change. This situation points towards a continued reliance on competition between different interests within and between the states, thereby affecting the formulation of eventual future federal regulations.

The New England states' participation in the Regional Greenhouse Gas Initiative (RGGI) does represent, however, a genuine novelty in U.S. policy development. In light of the Nordic cooperation in this area, this indicates the importance of the regional level - and most crucially the interdependence between different federalregional levels of governance - as an instrument for promoting RES-E both in Europe and in the United States. 
Chapter 7 (Knudsen 2008) provides a comparative assessment of Norwegian and Swedish SD-related monitoring and evaluation arrangements vis-à-vis stationary energy production and usage. The paper thereby documents an instance of specific EPI mechanisms, and - more particularly, how concrete EPI mechanisms can impact on policy outputs, as well as how EPI standards can be reflected by the EPI mechanisms and the related practice. More particularly, monitoring and evaluation in an SD perspective can provide important feed-backs for future policy amendments with, in particular, a stronger integration of environmental concerns.

The chapter documents that Sweden is characterised by relatively more robust arrangements than Norway, based on a more independent mandate and focused decoupling. The Swedish system also stands out with a dynamic and cyclical character. A major finding is, however, that monitoring and evaluation arrangements do not trigger political interest and engagement, nor do they in general appear to substantially influence the political debate, or give rise to political amendments by themselves. The quality of the Swedish arrangements is, nevertheless, viewed to provide a basis for improved policy decisions, and thereby more transparent and legitimate SD-policies. The Swedish system thus appears to constitute a more robust platform for policy-learning processes in general, and for a more sustainable transition of the dominant energy system in particular.

Finally, chapter 7 discusses the difference between Norway and Sweden in light of contextual factors. A stronger political priority of SD-related objectives, together with a more coherent structure of the energy sector, stand out as important variables explaining Sweden's more robust arrangements; while in Norway the dominant hydropower regime is seen to hamper a more coherent treatment of the policy sector. Chapter 7 thereby clearly illustrates the importance of the particular interplay of political and institutional factors, which in turn depends on the national context. This difference also constitutes an important background for understanding the change dynamics between dominant and alternative energy systems, thereby also echoing main insights in chapter 4.

\section{Conclusion}

The overall research objective of the present dissertation has been to clarify the conceptual nature of EPI so as to strengthen its analytic potential as a framework for comparative evaluation of sectoral policy implementation. Although the energy policy field has been characterised by an increasing level of internationalised deregulation, the sector is still heavily engraved with specific national features. The energy sector thus constitutes a crucial area of study for EPI, decoupling and sustainable development. This applies to issues of intra-governmental coherence and policy trade-offs, as well as multi-level governance. 
In line with recent and current research on EPI, the dissertation has documented that there is still room for further development of both the conceptual framework for EPI, as well as the understanding of the nature and specific consequences of EPI mechanisms. A crucial dimension here is the linkage between a normative-empirical understanding of 'EPI' - firmly rooted in the concept of 'sustainable development' - and the strategic challenge of implementing the related, democratically set objectives for SD and EPI. There are clearly substantial, and increasing, challenges for strategic governance, particularly in a national context - not least due to intertwined processes of internationalisation and deregulation, with clear consequences for public steering pertaining to environmental concerns (c.f. Durant et al. 2004a). As long as there are democratically set objectives for SD, there is a need for a clear rationale for a coherent, overall and strategic framework for pursuing sustainable development through EPI, with (ideally) a sectorencompassing political-administrative mandate. In order to relate the dissertation to this overall challenge for governance for sustainable development, two major issues warrant a concluding comment.

Even in the cases where individual sectors only relate to an overall SD strategy and EPI in an incremental and, seemingly, counter-productive way, a sectorencompassing strategic approach provides a framework that can induce processes of policy learning, including a better sector-specific understanding of EPI, as indicated in section 1.2.4. In this regard, one can observe a growing interest for a reflexive governance approach to SD strategies (Meadowcroft 2007a: 159-161). Such an approach was already suggested as a follow-up of the Agenda 21, and implies a coordinated, participatory and iterative process of thoughts and actions, where continuous learning is crucial (UNCSD 2002: 8). At the same time, however, and in line with what is documented by research on SD strategies (Lafferty \& Meadowcroft 2000c), a focus on policy learning must be complemented by some form of 'commitment' to policy programmes that include specific goals and timeframes, if these strategies are to be effective.

Secondly - and again related to the importance of the involvement of policy sectors, in terms of both stakeholders and related institutions - it is important to stress the need for improved mechanisms that both induce governing constraints on the policy sectors, and also capture and aggregate more effectively the perspectives, knowledge and interests of the concerned actors (c.f. Meadowcroft 2004, 2007b). As the experiences from the RES-E field demonstrate, and as documented in chapters 4, 5 and 6, it is also necessary to differentiate relevant EPI mechanisms in order to be effective in a sectoral context. As further indicated by the Danish and Swedish cases in chapter 5, however, one can differentiate among (and learn from) alternative approaches to sectoral institutions and stakeholders. In this regard, the Danish approach represents a specifically interesting case, where relevant EPI standards and mechanisms build on sector-based, bottom-up processes which specifically attribute an important role to designated strategic actors in the policy output itself. 
In order to provide a basis for a more robust approach to EPI within sectors, as highlighted by the debates referred to above, the present dissertation reveals the importance of providing a conceptual baseline with clear evaluation standards, albeit building on a clear understanding of the sectoral context in question. Drawn together, the individual studies of the dissertation - to different degrees and in different ways - illustrate three dimensions of crucial importance for the evaluation and improvement of EPI governing mechanisms.

The first dimension is represented by the discussion presented in section 1.2.2, and further developed in chapter 2, which entails a fundamental understanding of EPI underlying all the individual studies. The bottom-line of this understanding is to emphasise the concept's normative function as a 'first-order-principle' for resolving trade-offs between sectoral policy goals and environmental concerns by which one can achieve an actual decoupling (Lafferty \& Ruud 2006; Lafferty \& Knudsen 2007). Based on this understanding, a major question addressed in the dissertation has been the nature of evaluative standards inherent in the EPI concept. This involves basic values as well as benchmarks for actual procedures and institutional mechanisms. This has, furthermore, in line with expanded EPI agenda of the EPIGOV project, been related to the issue of multi-level governance; as well as to the investigation of crucial contextual factors affecting EPI, and the connection between EPI standards and mechanisms on the one hand, and sectoral policy outputs on the other.

The dissertation has thus demonstrated that EPI can be employed as both a substantive, normative standard in the study of the energy sector, as well as designating an area for the empirical analysis of procedural and institutional mechanisms.

Furthermore, the conceptual clarification of chapter 2, and the empirical insights provided by the other papers, can be considered as contributions to the further development of an analytical research model for EPI, as presented in section 1.2. The present dissertation has thereby aimed at providing a conceptual specification of 'EPI' as employed by this model, as well as specifying the connection between a refined EPI concept and specific, sectoral policy outputs. Thirdly, the dissertation has aimed to provide new insights as to the importance of contextual factors for these connections, not least the importance of different multi-level governance structures and processes.

Building on this analytical approach, the individual papers of the dissertation have sought to demonstrate the importance of combining a perspective on the overall, SD-related anchoring of EPI - conceived as a horizontal, sector-encompassing dimension - with a more sector-specific- and differentiated approach. In conclusion, it has been found both analytically and empirically fruitful to consider EPI in a sectoral context within such an interactive, two-dimensional framework.

Finally, the dissertation has employed a normative-empirical research approach, within the framework of strategic, applied research. It is believed that such an 
approach is necessary in order to provide insights of both academic and applied value, and thereby contribute to an emerging 'strategic research' paradigm for governance for sustainable development. As emphasised by the many recent evaluations of EPI within an EU context, there is still considerable disagreement as to both the normative implications of EPI (the meaning of Article 6 of the EC Treaty), as well as the best governing mechanisms to achieve EPI-based change. Hopefully, the present study can constitute a valuable contribution to an improved understanding in the field along both dimensions. 
Environmental Policy Integration and multi-level Governance

published before as:

Lafferty, William M. and Jørgen Knudsen (2007): 'The issue of 'balance' and tradeoffs in environmental policy integration: How will we know EPI when we see it?', EPIGOV Paper No. 11, Ecologic - Institute for International and European Environmental Policy: Berlin. 

As previously outlined (Lafferty 2004d), the concept of 'Environmental Policy Integration' (EPI) can be viewed as an integral aspect of two major discourses on sustainable development (SD): the political discourse and the academic discourse. The political discourse takes its point of departure from the report of the World Commission on Environment and Development (WCED 1987), the so-called 'Brundtland Report' (Our Common Future). This line of analysis focuses on the promotion of sustainable development as a principal goal of the United Nations and its member states. In this context, EPI has been identified as a key instrument for promoting SD in all the major documents, strategies and action plans adopted by the UN. This perspective has in turn been taken up by other international and regional organizations such as the European Union, the Nordic Council, the OECD, and (most specifically for EPI) the European Environment Agency. This discourse has established SD as an overarching normative goal in Europe, with EPI as a highly consensual instrument for achieving the goal.

Within the academic discourse EPI is treated as an aspect of (mainly) politicalscience studies of policy implementation. Here the focus is on increasing the scientific understanding of EPI as both a part of the general policy-making process, and as a steering mechanism for environmental and SD governance. What does EPI entail as a concept, and how does it actually work to achieve the implied goals? Major issues here are clarity and consistency of definition; exploration of relevant theoretical approaches from policy analysis; definitions of testable criteria for measurement (how will we know it when we see it?); and the generalization of empirical findings for policy theory and practical implementation.

While the crucial role of EPI with respect to SD goals and programs is relatively non-controversial, questions as to what EPI actually involves as an instrument of governance, and the development of criteria for assessing its success or failure, definitely are controversial. Furthermore, a great deal of the controversy seems to revolve around alternative understandings of the interdependency between the normative aspect of the 'political' discourse and the practical, applied aspect of the 'academic' approach. Viewing EPI as a question of 'What works, where, when and how?' tends to convert into debates as to: (1) what EPI 'really' entails as a normative goal; (2) how it should be operationalized to achieve the goal; and (3) how it can be assessed for determining success and revision. A clarification of one's normative interpretation of EPI is thus a decisive point of departure (and ongoing reference point) for both defining the concept as a pragmatic instrument of governance, and for assessing the effects of the instrument in practice.

We have earlier presented our own understanding of the history of EPI within the SD discourse (Lafferty 2001a; Lafferty and Hovden 2002, 2003), and we have further elaborated on what we see as crucial issues of normative clarification and empirical assessment (Lafferty 2004a). Researchers at SUM/ ProSus at the University of Oslo have also carried out empirical assessments of EPI in Norway (Knudsen 2001; Hovden and Torjussen 2002; Larsen 2005; Lafferty, Ruud and 
Larsen 2005; Lafferty and Ruud 2006; Lafferty, Larsen and Ruud 2008). The purpose of the present paper is to further develop this 'Oslo approach' by focusing solely on the challenge of resolving trade-offs among economic, social and environmental concerns. The emphasis is on EPI as a governing mechanism for sustainable development within a political-administrative context.

The task as we see it (at the outset of the EPIGOV project) is to clearly communicate, clarify and expand on the approach we have developed. Towards this end - in the service of promoting synthesis and a broader consensus on the issues we profile the approach in relation to three major bodies of ongoing EPI analysis:

- work directed at the political-strategic aspects of EPI by the OECD and EEA/IEEP (OECD 2001a, 2001b, 2002a, 2002b; EEA 2005a, 2005b, 2005c)

- work directed at the more academic, policy-analytic aspects of EPI conducted by the PINTS program at the Stockholm Environment Institute (SEI) (Persson 2004; Nilsson and Persson 2003; Nilsson 2005a; Nilsson and Eckeberg 2007)

- the seminal work of Andrea Lenschow on EPI in an EU context (Lenschow 2002a, 2002c).

These works are by no means exhaustive of current research on EPI, but they represent leading-edge contributions with respect to the two 'critical issues' selected. The principal purpose of the exercise is to profile the issues in a manner conducive to greater consensus on the nature and purpose of alternative EPI approaches. We begin with a brief outline of major points for further reference from each of the three approaches selected.

\subsection{Existing EPI orientations: Key ideas and selected models}

\section{The three 'pillars' and 'decoupling'}

The task of relating EPI to sustainable development boils down to a choice of which SD principles and idea are most relevant for the EPI idea. In our earlier work we have come to the conclusion that the most relevant ideas for associating EPI with strategies for SD are: (1) the widely recognized central SD goal of 'balancing' the 'interests'/'concerns'/ 'priorities' of the so-called 'three pillars': the economic, social and environmental dimensions of societal development; and (2) the crucial OECD notion of 'decoupling' the drivers of 'business as usual' from negative environmental impacts.

With respect to the first point, we feel that the conventional 'three-pillar' language is either too vague (balancing 'interests', 'pillars', 'dimensions'), or too narrow (focusing on sectoral 'priorities'). We have, therefore, suggested the use of either 'objectives' or 'concerns' in this context (Lafferty and Hovden 2003; Lafferty 2004e). The notion of economic, social or environmental 'objectives' captures the goal-oriented nature of what is to be 'balanced'; and the notion of 'concerns' indicates that the policies or initiatives in question are inherently normative. This 
latter is particularly important since claims on behalf of the 'environment' are usually put forth by organisations that express 'interests' that are quite different from the concept of 'interests' normally employed by mainstream economists and social scientists. Whereas the latter are related to either specific market actors or identifiable 'interest groups' within the means of production, the former are most often put forth by 'idealistic organisations' that speak on behalf of the environment.

As for the concept of 'decoupling', we simply endorse the key role that both the OECD and EEA attribute to this idea (OECD 2001a, 2001b, EEA 2005a). In a very fundamental and direct way, the idea proclaims that the dominant economic practices of existing western societies (or at least pre-Brundtland western societies) can be shown to be negative for the environment; and that efforts should be made to 'decouple' these practices from their negative environmental impacts. The idea has been developed in direct conjunction with the OECD's work on the so-called DPSIR model, where the logic is that the existing drivers create pressures on environmental states, resulting in demonstrable impacts, which must then be addressed by appropriate decoupling responses (policies, initiatives). The model and its inherent logic have been widely applied in OECD countries, and provide thereby a vital common reference point for analysing and applying EPI principles and instruments.

\section{The EEA-OECD 'evaluation framework'}

In 2005 the EEA coordinated, in cooperation with the Institute for European Environmental Policy (IEEP), a comprehensive review of EPI-concepts and approaches. The two major reports resulting from this effort (EEA 2005a and 2005b) provide the best single overview of the political-strategic approach to EPI to date. Given that the reports also incorporate significant aspects of the more academic discourse on EPI, there is no doubt that this body of work represents a 'definitive' reference point for further specification of EPI approaches.

The executive summary of the first report concludes by outlining 'Key challenges and opportunities' and 'Next steps' for promoting and improving EPI as a vital governing mechanism for sustainable development. We will return to these aspects of the report below, and concentrate here only on a third feature of the summary: 'A proposed framework for evaluating EPI'. The framework builds on the DPSIR orientation of the OECD, and serves to express in a very succinct form many of the most crucial aspects of the EPI discourse (Figure 1.1). The EEA refers to the figure as a 'checklist' designed to promote comparative assessments of EPI in practice, and we fully endorse this aim. ${ }^{1}$ Here, however, we would simply like to point out that: the checklist expressed by the framework is specifically directed towards 'sectoral and cross-sectoral' criteria; that these criteria are viewed in the context of sectoral

\footnotetext{
${ }^{1}$ In both form and substance, the EEA framework reflects the somewhat broader 'checklist' of the OECD (2002b) with criteria for 'Improving policy coherence and integration for sustainable development'.
} 
'drivers, pressures, states and impacts'; and that the framework identifies 'ecoefficiency' through 'decoupling' as a principal goal of EPI.

With respect to 'Key challenges and opportunities', the executive summary makes the following concise statement:

Clear internal mission statements, new structures and better coordination mechanisms within organisations, greater resources and capacity, and improved information, decision-support and public participation mechanisms can help to overcome existing 'compartmentalisation'. An overarching independent authority to push forward integration can also be valuable. The need for integration to be reflected across multiple levels of governance is also increasingly important. (EEA 2005a: 9)

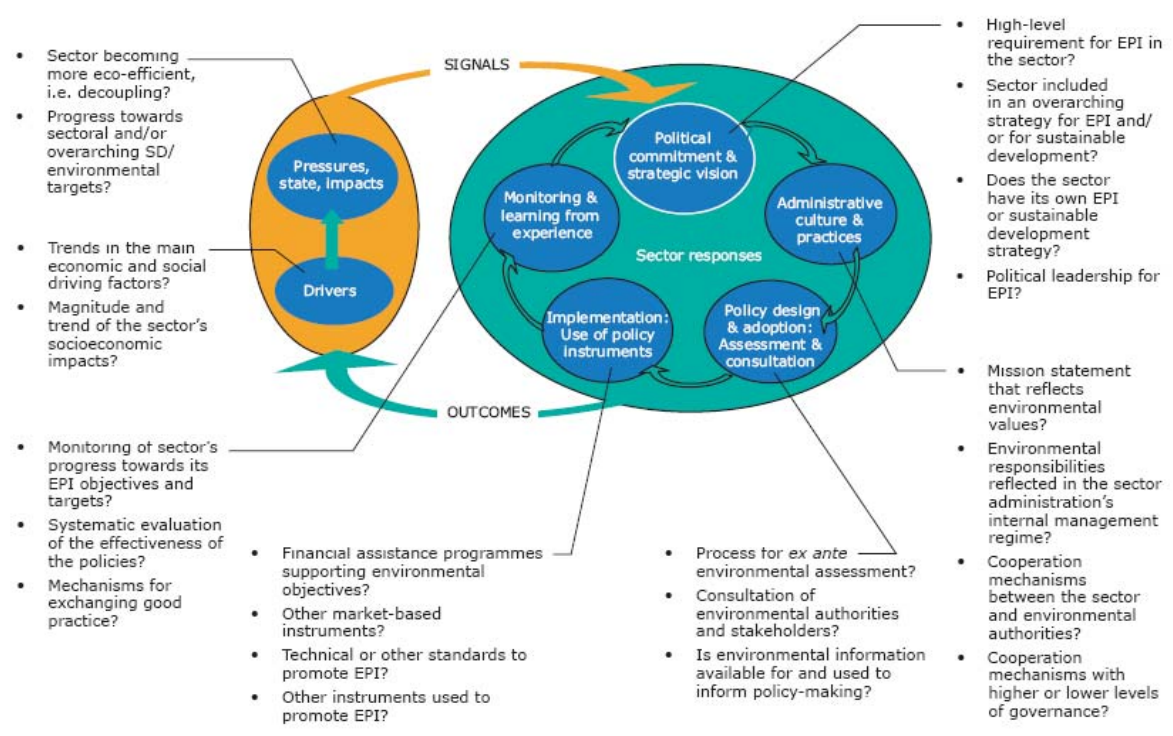

Figure 2.1 EEA Framework for evaluating EPI as sectoral policy

Source: EEA (2005a):10

This position clearly reflects (and complements) the OECD 'checklist' over measures for 'Improving policy coherence and integration for sustainable development' (OECD 2002b), and can be viewed as a 'short list' of crucial governing mechanisms for promoting EPI.

Finally, we can simply note that in terms of 'next steps', the EEA states that, despite positive developments along certain dimensions, 'progress is not sufficiently visible across the board'. The executive summary then concludes by pointing out that:

... additional analysis appears to be warranted, in order to deepen our understanding of whether and under what circumstances certain EPI mechanisms can be effective. Work should help with the identification of concrete examples of good practice covering both 
general and sector-specific activities, as well as supporting refinements of the EPI evaluation framework. (EEA 2005a: 9)

In our view the mechanisms outlined in relation to the two crucial issues discussed below directly address these needs.

\subsubsection{EPI as policy analysis and learning: The PINTS project}

Turning to the more 'academic' discourse on EPI, we wish to highlight two key aspects of the work being done within the Swedish PINTS programme at the Stockholm Environmental Institute (SEI). ${ }^{2}$ As we see it, the strength of the Swedish approach lies in, first, its focus on the question of explanation - how is EPI achieved in practice?; and, second, in the empirical richness of the project - an in-depth analysis of two crucial sectors in Sweden, energy and agriculture. The final report of the project is not yet published, so we concentrate here only on the theoretical approach. Two features are of particular interest: the differentiation by Persson (2004: 26-36) of the 'analytical variables and underlying factors' that have been used to explain EPI; and the 'analytic framework' developed by Nilsson and Persson (2003), and applied by Nilsson in his doctoral dissertation under the PINTS project (Nilsson 2005a).

Persson conducts a thorough review of the EPI literature within a policy-analysis perspective, and summarizes her results in terms of three categories of 'explanatory factors': normative factors, organisational factors and procedural factors (Table 1.1). Underlying this categorization are two more general distinctions that she finds relevant to the studies considered. First, she feels that the approaches in general can be divided into: the toolbox approach, 'which involves identifying concrete measures that can be implemented in the short to medium-term'; and the longerterm policy reform approach, 'which involves trying to change fundamental structures in policy-making'. Second, she points out that: the relative effectiveness of measures to achieve EPI 'is likely to be dependent on context; and further that most authors suggest 'a comprehensive approach comprising a mix of measures' (Persson 2004: 36).

\footnotetext{
${ }^{2}$ The PINTS Project - 'Policy Integration for Sustainability' - has been funded by the Swedish Research Council for Environment, Agricultural Sciences and Spatial Planning (FORMAS), and carried out principally at the Stockholm Environment Institute (SEI). The project was formally concluded in December 2006, and the final report of the project is scheduled for publication by Earthscan Publications in early 2007 (Nilsson and Eckeberg 2007).
} 
Table 2.1 Categories of explanatory factors in EPI research

Normative factors

- High-level political commitment

- Societal backing

- Definition of a policy framework for EPI or sustainable development

- Fundamental change in policy paradigm and tradition

- Time perspective

- Use of knowledge and science

Organisational factors

- Changes in governmental architecture to overcome sector compartmentalisation, e.g. integrated departments, new institutions, new mandates

- Accountability mechanisms

- Coordination and communication mechanisms, e.g. environmental correspondents, networks among bureaucrats

- Restructuring of the government budgetary process

- Training and awareness programmes

- Interaction with external actors

Procedural factors

- Implementation of an EPI system: sector report, consultation forum, sector strategy, action plan, monitoring

- Change of routine procedures: impact assessment of policy proposals, consultation and participation, rules of decision-making

Source: Persson (2004: 36)

These perspectives provide us with a summary baseline of explanatory variables and conditions that clearly underlie the more descriptive 'checklists' of assessment criteria provided by the OECD and EEA. They provide a conceptual 'bridge' to the field of policy analysis within political science which aims to develop more comprehensive and 'robust' theories of how change is achieved through policymaking and implementation (see, for example, Parsons (1995), Sabatier (1999), and the critical discussion in the concluding chapter of Lafferty 2004b). In many ways, the challenge here is to determine the degree to which the factors identified are general enough to warrant broad recommendation in action plans; or whether the contextual effect is, in fact, so strong as to warrant a much more 'ideographic' approach.

Nilsson and Persson (2003) build further on these perspectives by formulating the selected 'factors' into an analytic framework (or 'model') for understanding the nature of 'policy outcomes' from EPI (reproduced here as Figure 1.2). As indicated, the framework depicts a relatively standard social-science approach, distinguishing between 'background', 'independent' and 'dependent variables'. Two features of the framework worth emphasizing in the present context are: (1) the 'contextualization' of EPI with respect to (a) the nature of the 'the problem' (that is, type of sectoral activity) in question, and (b) the 'international policy context' (that is, for Europe, international policy as channeled and sanctioned through the European Union); (2) an emphasis on three key conditioning variables in specific national contexts - 'political will', 'assessment processes', and 'policy-making 
rules'3; and (3) a residual 'black box' for EPI, which, presumably, contains parameters for the 'organisational' and 'procedural' factors listed in Table 1.1, but which are not brought directly into the framework. In relation to the latter, we also note that - given the designation of the 'ultimate' dependent variable as 'policy outcomes' - the EPI box warrants further discussion as to what is actually prescribed/expected as an indication of 'EPI in practice'.

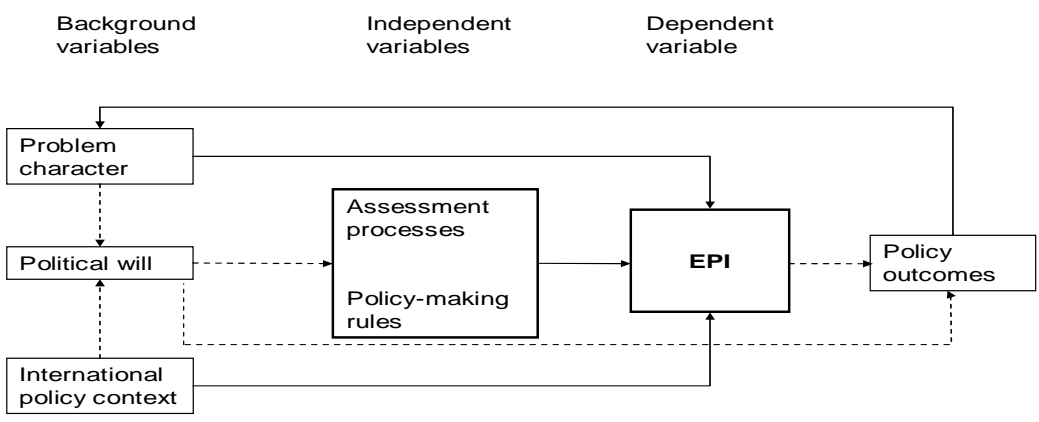

Figure 2.2 An analytic model for explaining EPI outcomes Source: Nilsson and Persson (2003: 353)

The third point of reference we want to highlight is the seminal research of Andrea Lenschow. In our view Lenschow's work represents the strongest single effort towards a clarification of EPI as a specific concept and governing initiative within an EU-context. Given that EPI continues to struggle under quite different interpretations as to what the concept 'really' implies, Lenschow's work offers a possible common reference point for the EPI discourse. Space only allows for the briefest of references, but they contain in our view essential perspectives for the analyses to follow.

First, there is Lenschow's fundamental differentiation between what she sees as three 'dimensions worth investigating in order to explain patterns of EPI in policy sectors and in [EU] Member States': ideas, institutions and actors (Lenschow 2002a: 16-18). As we see it, this differentiation is similar to that outlined by Persson (Table 1.1), with the 'ideational dimension' reflecting Persson's 'normative factors', and the 'institutional dimension' reflecting Persson's 'organisational' and 'procedural

\footnotetext{
${ }^{3}$ Nilsson and Persson designate 'political will' as a 'background variable', but this is open for discussion. The 'will' in question is, in our view, so directly related to both the national context and the EPI process that it just as well can be categorized as an 'independent' variable.
} 
factors'. Lenschow's 'actors dimension' can then be seen as a more contingent aspect of the EPI discourse: that is, which actors, individual and collective, exert what kind of influence on EPI processes - and what does this tell us more inductively about the possibility of trans-contextual generalizations?

The differentiation thus progresses from a relatively abstract discussion of meaning and norms; through a more focused discussion of the possible institutions and procedures deemed necessary/advantageous to pursuing norms; down to a very focused discussion of empirical analyses of actors, influence and outcomes. What we view as crucial in this context is an acceptance of a fundamental meta-feature of social science: that the choice of ideational-normative content structures the perceived purpose of institutions/procedures, as well as the interpretation of empirical analyses. While this observation may for some appear both obvious and trite, we feel that a failure to acknowledge the perspective underlies a great deal of the dissensus within the field. In the analyses below we focus on the ideationalnormative and institutional-procedural dimensions. The goal is to structure both in a manner conducive to a better integration of national assessments and empirical analyses of the role and effects of given actors. If successful the exercises should contribute to a more fruitful research dialogue within the scope of studies conducted (and being conducted) along the lines laid out by Lenschow and her colleagues. ${ }^{4}$

Second, we want to stress two further points - one of agreement, and one of disagreement - with respect to the basic ideational position staked out by Lenschow.

As to the point of agreement, Lenschow cites, in the introduction to her widely cited collection of EPI studies (2002a: 6), the following statement by Angela Liberatore (1997: 107):

The relevance of integration for moving towards sustainable development is straightforward: if environmental factors are not taken into consideration in the formulation and implementation of the policies that regulate economic activities and other forms of social organization, a new model of development that can be environmentally and socially sustainable in the long term cannot be achieved.

This is immediately followed up by Lenschow as follows:

Put differently, EPI represents a first-order operational principle to implement and institutionalize the idea of sustainable development. However, its legitimacy was based

\footnotetext{
${ }^{4}$ In addition to the studies presented in Lenschow (2002a) - several of which reflect crucial controversial issues within the field of EPI research - Lenschow's approach has also influenced at least two major (more general) contributions by her collaborator, Andrew Jordan (Jordan 2002b; Jordan and Schout 2006; Jordan and Liefferink 2004). Jordan and Lenschow (2008) are also currently coordinating a new EPI book project, which should see publication in early 2008. The senior author of the present paper is involved in this project (together with Olav Mosvold Larsen and Audun Ruud at ProSus), and several of the major issues raised here reflect the fruitful discussions within the project team.
} 
not only on this conceptual linkage, but equally on the evolution of the EU treaties. By the early 1980s, the concept of sustainable development had entered the policy programmes of most European governments and the EU; the legal obligation to policy integration was established with the Single European Act in 1987; and a commitment to 'sustainable 'development' was made in the Amsterdam Treaty (1999). (Lenschow 2002b: 6-7)

We are here in complete agreement with both of these statements, and we feel further that the clear gist of the statements is to establish EPI as 'first-order operational principle' - both normatively and 'legally' - for the achievement of sustainable development within the EU. Two problems immediately arise with this interpretation however. First, Lenschow fails to state clearly what the implications of EPI as a 'first-order priciple' are. She does not discuss in detail what the operationalization of EPI should and would mean, if it is indeed an integral first principle of sustainable development. Second, Lenschow offers other perspectives in her introduction which clearly place the 'first-order' nature of EPI-for-SD in doubt. The immediate follow-up discussion of her definitional treatment of EPI gives evidence of a two-pronged ambivalence as to the normative status of the concept. On the one hand she engages in a discussion of why and how the normative-legal intent of EPI has been undermined by conflicting interpretations of how it should be implemented in practice. She here shifts in other words the discourse from a normative-conceptual perspective to a descriptive perspective, without adequately differentiating between the two.

More importantly, however, she also reveals a fundamental ambivalence as to the first-order nature of the concept. At one point - after citing the work of the EEA as a driving force for moving beyond 'end-of-pipe' initiatives towards the decoupling sectoral driving forces - she states that:

In the absence of clearly defined policy goals, indicators and timetables, however, there remains ample room for sectoral policy-makers to evade such substantive environmental responsibilities. The integration process currently faces the challenge of ensuring that substance follows from procedure. (Lenschow 2002b: 7, our emphasis)

This very forceful endorsement of the 'substantive' intent of EPI is, however, immediately succeeded by the following:

The impact of EPI may be reduced not only due to conceptual and hence operational ambiguities, its impact may suffer even more due to conceptual inconsistencies in connection with its 'mother concept'. The compatibility assumptions inherent in sustainable development apply to a highly aggregated (possibly global) level, while EPI applies to sector or even sub-sector policies where there may be real winners and losers as a consequence of policy integration. EPI is likely to encounter conflict which sustainable development causes us to forget. Therefore the legitimating power of sustainable development may collapse on the operational level of EPI. (2002b: 7-8)

In our opinion, nothing is more critical for an understanding of the conceptualnormative nature of EPI than the issues here raised. In the first incidence, Lenschow 
provides a clear and concise endorsement of EPI as a normative and legal 'first principle' vis à vis economic and social dispositions. But in the second incidence, she places this interpretation in serious doubt, laying the blame on a purported conceptual-operational incompatibility between EPI and SD. Her ambivalence on this particular issue is carried through in her concluding chapter to the book, and appears to be shared by a great many other EPI researchers. In the following section, we will argue that it is Lenschow's initial conceptual-normative interpretation that is the correct one; and that her subsequent qualification of the interpretation is related to a common, but nonetheless questionable, understanding of 'sustainable development'. The focus is on the key normative issue of 'trade-offs', and on how the issue can be institutionalized by governments for more effective EPI 'policy outputs, ${ }^{5}$ Reference is made throughout to the concepts and approaches here outlined.

\section{Resolving sectoral policy trade-offs}

\section{EPI as a 'first-order principle'}

Given the uncontestable 'mission' nature of EPI, there is no more crucial question for communicating, implementing or assessing the idea than the issue of normative intent. Whether the EPI 'glass' is happily half full, or sadly half empty; whether a specific instrument for filling the glass is 'really' appropriate to the task; or whether it is indeed EPI that we have in the glass!: all are questions directly related to what we believe EPI should be. The fact that there are very obvious and very pointed differences of opinion on this question, gives testimony to how complex and 'touchy' mission-oriented policy analysis can be. It can be important to recall in this context, therefore, that a 'clear and consistent goal' is the first of the well-known set of 'critical factors' identified by Sabatier and Mazmanian (1979) when judging whether an 'authoritative decision to change an existing state of affairs' is likely to achieve its goal. ${ }^{6}$ As documented in the previous section, there can be no doubt that 'implementing EPI for decoupling for sustainable development' is a strongly sanctioned 'authoritative decision to change an existing state of affairs'. Yet there is considerable doubt as to how the decision should be realized in practice.

As we see it, differences of opinion on this issue can best be focused on the question of assessing the final result - the status of the EPI 'glass'. Allowing for a number of other possible ancillary conflicts, we feel that the conflict of central importance is the question of 'balance' or 'cohesion'. In short, is it the intent of EPI to produce

\footnotetext{
${ }^{5}$ The differentiation between 'policy process' (procedure), 'policy output' (document and/or programme) and 'policy outcome' (the actual results of policies and programmes) is common to policy analysis in political science. Vedung (1997) provides an excellent overview with respect to policy evaluation.

${ }^{6}$ See Lafferty (2004e: 10) for the other factors, and for a broader discussion of the factors in relation to governance for sustainable development.
} 
policies/programmes/initiatives that are somehow 'balanced' with respect to the three dimensions/pillars of sustainable development? Or is it rather the intent to produce decisions/outputs/outcomes that, in one way or another, reflect the semantic essence of the concept: the integration of environmental concerns. Clearly it must be the latter. We are not talking about strategic goals, guidelines or treaty provisions for policy integration per se, but for 'environmental policy integration'. Whatever other disagreements may arise, there can be no doubt that the issue in question is related to a specific normative goal: the integration of environmental concerns into 'the definition and implementation' of other policies and activities (Treaty of the European Uniongoals). This is not disputed by any of the approaches outlined above, and is most clearly stated by Lenschow in her characterization of EPI as a 'first-order operational principle to implement and institutionalize sustainable development'. While some choose to automatically equate the EPI acronym with 'balance' and 'coherence', this seriously begs the question of what EPI implies as a pre-ordained standard for what 'balance' and 'coherence' should look like.

Also here, however, Lenschow provides a clear (initial) signal. Citing Nollkaemper's (2002) excellent analysis of EPI as a 'principle in international law' in her own volume, she endorses EPI as 'a procedural principle' (her emphasis), and goes on to say that: 'It implies that policy-makers in non-environmental sectors recognize the environmental repercussions of their decisions and adjust them when they undermine sustainable development (Lenschow 2002b: 7) It is in this context that she associates EPI with the goal of achieving 'substantive environmental responsibilities', a 'challenge' she identifies as 'ensuring that substance follows from procedure’ (ibid).

It was this same line of reasoning that led the research team at ProSus to define EPI as implying:

... the incorporation of environmental objectives into all stages of policymaking in nonenvironmental policy sectors, with a specific recognition of this goal as a guiding principle for the planning and execution of policy.

Had we stopped here, there would be little to discuss within the EPI research community. This part of the definition is, at any rate, in complete accordance with Lenschow's understanding. In the interest of clarifying what is meant by 'balance' and 'coherence', however, we felt we had to go further. The definition continues, therefore, by stating that the application of the 'guiding principle':

... should be accompanied by: an attempt to aggregate presumed environmental consequences into an overall evaluation of policy, and a commitment to minimize contradictions between environmental and sectoral policies by giving priority to the former over the latter. (Lafferty 2001a: 9; Lafferty and Hovden 2003: 12)

This latter part of the definition can be seen as directly addressing: the 'key challenge' raised by the OECD/EEA (more effective EPI governing mechanisms); the specific nature of both the 'EPI black box' and EPI 'policy outcomes' in the 
Nilsson-Persson analytic model (Figure 2); and, most specifically, the issue of 'procedure vs. substance' raised by Lenschow.

\section{Clarifying the nature of 'principled priority'}

In later work (Lafferty 2004a, 2004d) we have followed up the implications of the definition along three lines. First, we have addressed the question of aggregating 'presumed environmental consequences into an overall evaluation of policy' by further developing a checklist of 'benchmarks' for vertical (sectoral) and horizontal (cross-sectoral) governing mechanisms. Second, we have stressed that by 'environmental objectives' and 'environmental consequences' we mean consequences that undermine the natural life-support capacity of ecosystems. And, third, we have continued to work on the very difficult issue of what we have come to call 'principled priority'; the 'why' and 'how' of resolving contradictions among sectoral and environmental objectives. The first of these issues is taken up in the following section. The second and third warrant further clarification here. They both go to the heart of Lenschow's perceived 'dilemma' in the relationship between EPI and SD.

The question of what is/should be meant by 'environmental objectives' or 'concerns' is, of course, fundamental to the initial 'critical factor' of the Sabatierprospect of a more effective application of EPI is slim indeed. In our view, this issue can be directly resolved within the discourse on the meaning of 'sustainable development' (Lafferty and Langhelle 1999b). The 'mother text' of sustainable development is the Brundtland Report, and the report makes two highly relevant distinctions with respect to 'the environment'. The first distinction is a warning at the very outset of Our Common Future that we must guard against a 'naive' understanding of the environment as something 'separate from human actions, ambitions and needs':

'the 'environment' is where we all live; and 'development' is what we all do in attempting to improve our lot within that abode. The two are inseparable. (WCED 1987:

xi)

This 'warning' is particularly relevant for reserving the normative applicability of EPI for policy trade-offs that involve a reasonable presumption of conflict between sectoral drivers and the natural life-support capacity of ecosystems. The Brundtland Report is, in fact, very specific in its neglect of any concern for ecosystems that are not specifically related to economic drivers.

This sets up a normative 'filter' against trade-offs related to both 'aesthetic environmentalism' (Tidy Town Awards') and 'traditional nature conservation' (the protection of nature for nature's own sake). But the report goes even farther. In a second crucial distinction, the report stresses a need to move away from looking at negative environmental effects in isolation. The environmental aspect of sustainable development is, in other words, to be viewed solely in relation to 'policy sources'. This principle is expressed throughout the report, but is given most explicit 
treatment in the opening section of the concluding chapter on 'The Challenge for Institutional and Legal Change'. The section is entitled 'Shifting the Focus to Policy Sources'. Of the numerous relevant quotes we could use here, we choose only two:

Approaches to environment policy can be broadly characterized in two ways. One, characterized as the 'standard agenda', reflects an approach to environmental policy, laws, and institutions that focuses on environmental effects. The second reflects an approach concentrating on the policies that are the sources of those effects. These two approaches represent distinctively different ways of looking both at the issues and at the institutions to manage them.

Environmental protection and sustainable development must be an integral part of the mandates of all agencies of governments, of international organizations, and of major private-sector institutions. These must be made responsible and accountable for ensuring that their policies, programmes, and budgets encourage and support activities that are economically and ecologically sustainable both in the short and longer terms. They must be given a mandate to pursue their traditional goals in such a way that those goals are reinforced by a steady enhancement of the environmental resource base of their own national community and of the small planet we all share. (WCED 1987: 310, 312, our emphasis)

We cite Our Common Future at length on these issues, because there is a strong tendency - as evident in Lenschow's 'dilemma' - to use sustainable development as an excuse for not applying EPI as a 'first-order principle'. Both practitioners and academics choose to interpret SD to the effect that an abstract 'balance' among the economic, social, and environmental pillars is more important for an assessment of EPI results than a clear judgment as to environmental consequences. Such a perspective is, in our view, simply undefensible. A close reading of Our Common Future is unequivocal in this regard - and Our Common Future is the only extensive textual source for delineating the essential political meaning of 'sustainable development'. Neither the Rio Declaration nor the extensive Rio action plan Agenda 21 - provide further explicit texts on the meaning of the concept.

We would, therefore, summarize our interpretation on this point as follows:

The Brundtland Report is the key text for interpreting the relationship between EPI and sustainable development.

- The SD concept assigns no principled priority to economic activities per se. Economic activities are only treated in the Brundtland Report as a problematic 'pressure' on the sustainability of ecosystems. The 'economic dimension' is explicitly associated with 'traditional' policy goals ('business as usual').

- The 'social dimension' of SD is most specifically and most consistently related to the goal of satisfying the 'essential needs of the world's poor'. The dimension thus clearly indicates an emphasis on 'poverty', and an assumption that 'essential needs' can - and, with respect to consumption, should - be distinguished from needs that are not essential.

- The 'environmental dimension' is clearly profiled as a limiting condition for the pursuit of both economic and social objectives. The 'environment' is viewed as the necessary natural resource base for maintaining life on earth. 
- The need for integrating environmental concerns into all policy areas is the distinct defining 'variable' in the SD equation. It is worth pointing out in this regard that one of the major reasons for establishing the WCED in the first place was to address the man-made degradation of ecosystem capacity as $a$ consequence of extreme poverty.

It is this understanding which, in our opinion, underlies the specific language of Article 6, Part One of the Treaty of the European Union: namely that 'Environmental protection requirements must be integrated into the definition and implementation of Community policies and activities ... in particular with a view to promoting sustainable development'. (EC 2002) Not only is EPI here given a separate article under the introductory section on 'Principles', it is the only article where the term 'must' is used to prescribe a given action. ${ }^{7}$ Note also that the integration of 'protection requirements' is to be manifest in both the 'definition' and 'implementation' of policies. This clearly implies both a stipulated procedure and a specific goal-oriented enactment. Policies that do not include provisions for environmental protection are, in principle, to be avoided by the prescription.

It is primarily as a logical consequence of all of these perspectives that we have formulated EPI as a question of 'principled priority' in favour of the Brundtland understanding of 'environmental objectives'. In addition to this normative position, however, we have also found the notion of 'principled priority' as a necessary pragmatic response to the very obvious and well-documented fact that existing attempts to promote SD through a 'balanced' understanding of EPI clearly are not working. This is particularly obvious with respect to the most outstanding threat to $\mathrm{SD}$, climate-change, but it is also apparent with respect to a much broader range of ecosystem-threatening factors. Most member states of the EU are far off their targets for controlling greenhouse-gas emissions, and the most recent 'Millennium Ecosystem Assessment" finds that nearly 60 per cent of the 'ecosystems that support life on earth are being degraded or used unsustainably' (Wilkins 2006: 296). It was specifically because our running evaluations of SD implementation in Norway demonstrated that environmental concerns were being consistently 'overrun' by other policy objectives, that we initially focused our EPI research on the issue of intra-governmental trade-offs (Lafferty et al. 1997, 2002, 2007). The burden of proof for EPI initiatives that aim only at 'balanced win-win policies objectives' is becoming increasingly precarious.

It is in light of these considerations that we have formulated the EPI problematic as a question of designating environmental concerns as 'trump' in relation to critical trade-offs among competing policy objectives. Having the status of 'trump' in card games implies that certain cards or suits of card have an extraordinary status in relation to the normal rules for resolving the basic competitions of the game. The

\footnotetext{
7 'Must' is also used in Article 15 of the 'Principles', but the usage is prohibitive rather than prescriptive. Given that all other instances of prescription employ 'shall', the usage of 'must' in Article 6 is clearly intentional.
} 
status of trump is determined prior to the dealing of the cards; it is most often applied under special conditions and decision-making rules; and it is game-specific. The relevance of trump in the context of EPI is that implied by Our Common Future. Achieving sustainable development means introducing a new legal and institutional structure for transcending the 'existing', 'traditional' set of value priorities in the trade-off between economic, social and environmental activities. The existing 'trumps' in highly developed societies are invaribly to the advantage of either economic or social-welfare priorities. All such priorities imply burdens on natural resources and life-support systems. The essence of EPI is to 'decouple' this situation by assigning 'principled priority' to ecosystem requirements.

Does this mean that policy concerns other than the environment must invariably give way before environmental concerns? Clearly not. Just as the rules of trump are always stipulated within, and made conditional on, the broader rules of the game, so to with EPI. In our view at least, the resolution of policy trade-offs must be made within a more fundamental set of democratic decision-making rules. The nature of these rules can, however, vary considerably from democratic system to democratic system; and it is a normal feature of democracies to designate certain values as more fundamental than others. Whether determined by constitutions, statutes or administrative rules, all democracies have certain values that are assigned exceptional 'rights' within the fundamental rules of the decision-making 'game'. It is to address this most fundamental aspect of EPI that the EEA identifies both a 'high-level requirement for EPI' as a key aspect of 'political commitment and strategic vision', and a 'mission statement that reflects environmental values' as a basis for 'administrative culture and practices' (Figure 1). It is also to explore the nature of the aspect that Nilsson and Persson designate 'policy making rules' as one of two crucial 'independent variables' in explaining EPI outcomes. Given that the EEA framework is specifically directed towards sectoral (vertical) integration (and does not address cross-sectoral trade-offs); and that the Nilsson-Persson approach focuses mainly on policy learning, with little attention actually devoted to decisionmaking rules - we are confronted by a major task of stipulating just how EPI as 'principled priority' might be applied.

It is towards this end that we have put forth a number of possible governing mechanisms for enhancing the substantive output of EPI by strengthening the procedural 'trump' status of environmental/ecosystem protection. We will here elaborate on only three of these mechanisms: the general form of a 'canon for practical judgment' for EPI; the application of science, assessments and the 'precautionary principle'; and the challenge of finding means to secure the 'political will' that is necessary to support EPI in practice.

Given the prospect of increased consensus as to the normative status of EPI, the implementation discussion can then turn to the question of differentiated assessment. EPI can be analysed and evaluated as procedure, policy and outcome. One can imagine EPI systems that vary on all three dimensions - and not necessarily 
in a cumulative manner. We focus here only on aspects of decision-making to enhance the status of environmental concerns in policy output. How the policy itself is implemented by governments, and what the ultimate outcome of the policy is, are not covered. (See, however, Lafferty 2004a and the empirical studies by ProSus mentioned above for a comprehensive approach to the question of governmental implementation.)

\section{A 'canon for practical judgment'}

The notion of developing a 'canon for practical judgment' as a basic guideline for EPI-related decision-making is inspired by Kant's 'analytic of principles' (see for example Caygill 1994 and Kemp 1968). A 'canon' in this context is 'a general rule, fundamental principle, aphorism, or axiom governing the systematic or scientific treatment of a subject' (OED 1987: 207). The process for applying the 'rule' here is governmental decision-making; and the 'subject' is EPI. In the context of the present discussion, we propose the following as a core statement of the canon for any given political domain:

1. Applying EPI as a first-order principle for decision-making for sustainable development involves the resolution of trade-offs between sectoral policy objectives and environmental objectives.

2. The designated types of policy in question are:

a. economic policies designed to promote sustainable livelihoods for current and future generations

b. social policies designed to satisfy essential needs and eliminate poverty, nationally and globally

c. environmental policies designed to protect and enhance the long-term lifesupport capacity of ecosystems

3. The principles and criteria necessary to achieve (c) constitute a priority 'proviso' for regulating the policy objectives of (a) and (b).

We feel that the logic of this statement roughly corresponds with the normative intent attributed to EPI by the three research approaches outlined above. We feel also that the statement lays an initial foundation for further developing the 'canon' as a practical set of standards and guidelines for making necessary judicious decisions on policy trade-offs under an EPI 'mandate'. We stress the 'judicious' nature of the process to avoid any (further) misunderstanding as to the nature of EPI as 'trump'. To be 'judicious' in this context means to apply an EPI canon in a reflective, prudent and transparent manner. It, again, does not mean that environmental concerns will override economic and social objectives in every incidence of decision-making. The 'balance' among the environmental/ecosystem concerns and other policy objectives will have to be decided on a case-by-case basis. The only requirement of EPI as 'first principle' is to guarantee that every effort is made to assess the impacts of the policies - short, medium and long term on the life-sustaining capacities of the affected ecosystems; and to clearly limit or otherwise qualify in advance those impacts that represent unacceptable risks of degradation. 


\section{Science, assessments and the precautionary principle}

If the general notion of 'principled priority' is attached to a clearly expressed EPI mandate, much would be accomplished. The diffuse notion of EPI as 'balanced policy', and the dominant very limited view of EPI as primarily a search for winwin solutions, would be superceded. We would not expect environmental concerns to trump all trade-offs. But we would expect transparent arguments and politicaladministrative accountability if environmental concerns are judged to be unaffected by sectoral policies.

The very thorny issue of determining risk in the application of the canon would not, however, be resolved. Here the challenge clearly lies with both the posited status of the ecosystem in question; the quality of the assessed 'impacts' from sectoral 'drivers'; and the ability to formulate and communicate risk factors directly into the decision-making process. The first issue is a challenge to the integration of scientific knowledge into the policy-making process; the second is a challenge to the quality, scope and 'weight' of environmental and SD assessments; and the third is a challenge for finding practical mechanisms for applying the 'precautionary principle'.

As for the introduction of scientific knowledge on the 'limits of nature', this is a question of both determining and communicating consensual estimates as to the long-term sustainability of whichever resource or ecosystem 'service' is most affected by the policy initiative in question. While there are several excellent initiatives in place for promoting the 'science of sustainability' on a more general level, there are relatively few examples of scientific advisory councils with a mandate similar to that implied here. There is a relatively high-profile 'Science Advisory Council (SCA)' to the Department for Environment, Food and Agriculture in the United Kingdom, and a similar 'National Council for Science and the Environment (NCSE)' in the United States, but their tasks are very broad and 'informative'. Two more appropriate examples would be the 'Advisory Council for Research on Spatial Planning, Nature and the Environment (RMNO) in the Netherlands, which directly contributes to outlining alternative paths and possible general consequences of policy; and, perhaps most relevant, the 'Scientific Support Plan for a Sustainable Development' in Belgium. The latter is a second-generation plan (SPSD-1 and SPSD 2), which fosters research of high and direct relevance for policy-making. The objectives of the plan are: (1) to clarify the utmost complex problematic of sustainable development; (2) to collect and interpret the scientific basic information, which can give direction to the preparation of a sustainable development policy and its execution; and (3) to formulate proposals and to elaborate instruments in order to set up, evaluate and direct a sustainable development policy. ${ }^{8}$ In our view, a much more concerted effort to institutionalize

\footnotetext{
${ }^{8}$ Typical reports from SPSD-1 and SPSD-2 are: Levers for a Sustainable Development Policy (FSP 2002); The Role of Public Authorities in Integrated Product Policy: Regulators or Coordinators (BSP 2006); and Science and Precaution: An Interactive Risk Assessment -
} 
initiatives like the SPSD, and to assign them a direct function with respect to EPI, would be a significant step in the direction of implementing Article 6 of the EU Treaty.

As for the role of environmental assessments, there is extensive documentation of the usage and consequences of both 'environmental' and 'strategic' impact assessments (EIAs and SEAs), and there are separate EU directives for both. This is clearly a crucial subfield of both the political and academic approaches to EPI. To highlight only three leading contributions in the present context: (1) the work of Sadler and Dalal Clayton (Sadler 2005; Dalal-Clayton and Sadler 2005) on the current status and potential of SEAs in an EPI context; (2) the highly interesting legal debate in Scotland on how SEAs should be interpreted with respect to 'sustainable development' (Jackson and Illsley 2006); and (3) the in-depth analyses carried out by Nilsson et al. on the conceptual nature and practical effects of 'assessments' (broadly conceived and thoroughly documented) within the PINT's learning approach to EPI (Nilsson 2005a; Nilsson and Eckeberg 2007). ${ }^{9}$ All of these approaches provide significant new perspectives and findings for institutionalizing assessments as a crucial mechanism for resolving sectoral SD trade-offs.

Finally, there is the much-discussed role of the 'precautionary principle'. In our view, the principle - added to the normative-conceptual core of SD at the Bergen Conference on Sustainable Development in 1990, and included as Principle 15 of the Rio Declaration - represents a true 'bottom-line' for EPI implementation. Without going into detail here on all of the numerous controversial issues surrounding the principle, we will simply refer to a significant new collection of studies by Fisher et al. (2006). The work brings together both conceptual and empirical analyses of a number of different application areas in Europe, Australia and the United States. Three aspects of the study are particularly relevant for the EPI discourse.

First, there is a proposal for a consensual definition of the concept by René von Schomberg, an expert on science, uncertainty and policy implementation in DG Research of the European Commission. After a thorough analysis of recent legal and conceptual work on the principle, von Schomberg puts for the following definition:

SPIRE (BSP 2005). All reports from the SPSD are available at the website of the Belgian Science Policy (http://www.belspo.be/belspo/fedra/).

${ }^{9}$ The situation in Scotland is particularly interesting. The implementation of the EU SEA Directive has led to an Environmental Assessment (Scotland) Act (EASA) that is to be applied to all public-sector policy strategies, plans and programs; and with the main objective of ensuring that environmental concerns are integrated into non-environmental areas of decision making. This approach is based on EIA-derived methods used in an SEA context so as to constitute a tool for environmental governance. The approach directly incorporates provisions for fostering environmental and social justice, and promotes transparency and accountability by allowing citizens and stakeholders to comment on assessments, and requiring public bodies to explain how they have taken such comments into account (Jackson \& Illsley 2006). 
Where, following an assessment of available scientific information, there are reasonable grounds for concern for the possibility of adverse effects but scientific uncertainty persists, provisional risk management measures based on a broad cost-benefit analysis whereby priority will be given to human health and environment, necessary to ensure the chosen high level of protection in the Community and proportionate to this level of protection, may be adopted, pending further scientific information for a more comprehensive risk assessment, without having to wait until the reality and seriousness of those adverse effects become fully apparent. (Von Schomberg 2006: 37)

Our interpretation of this definition is that it can serve as a normative point of departure for institutionalizing procedures and governing bodies to give 'principled priority' to the advantage of environmental concerns put forth on the basis of 'reasonable' scientific grounds, without a consensus on scientific certainty. Such an interpretation would anchor EPI's 'trump' status within a general principle that is specifically designed to bridge the normative and practical, but that would nonetheless be subject to specific forms of argument and evidence. The major challenge here is to continue working on the specifics of developing legaladministrative institutional procedures.

Second, it is important to stress that such a legal-administrative institutionalization of the precautionary principle would not only allow a more forceful and effective implementation of EPI (the major goal of the OECD/EEA assessments). It would also allow for a much more transparent and accountable 'politics of sustainable development'. If major decisions on policy trade-offs for SD are carried out within structured procedures that reflect the values of joining the 'first-order' EPI principle with the 'bottom-line' precautionary principle, it would be clear for both media and public-stakeholder scrutiny why such decisions have the policy-output profile that they do. It is in this light - the 'spotlight' of trade-off deliberation - that the judicial application of EPI as 'trump' will be decided. If the level of risk to environmental degradation is below a given threshold (and the Fisher et al. volume presents several mechanisms for risk assessment in relation to specific policy issues), then a decision to compromise potential environmental damage will have been made in open forum - and the political-administrative actors will have to stand responsible for the result.

This points towards a third point we would make on the basis of the work by Fisher et al: a crucial distinction by Fisher and Harding (2006) as to two competing frameworks for the 'administrative constitutional' anchoring of the precautionary principle. The authors here differentiate between a 'deliberative-constitutive' framework and a 'rational-instrumental' framework. Whereas the former is primarily an 'academic' normative model, applying the standards of 'deliberative' democratic theory (Deville and Hardin 1997); the latter is a reconstructed model of implementation as derived from a 'communication' on impact assessment from the European Commission (CEC 2002). Space does not allow for further elaboration of the very rich Fisher-Harding analysis here, so we will again simply conclude by stating our belief that the work lays a solid theoretical basis for a more widespread and consequent institutionalization of the precautionary principle as a crucial feature of EPI governance. Their concluding admonition offers a perfect 'bridge' to our 
own conclusion on the principle - a conclusion that poses a direct challenge to their more 'balanced' approach.

... there is a need for scholars and policy makers to take a far more sophisticated approach to thinking about the [precautionary] principle's application because that process of application is not about writing a checklist or carrying out an algorithm but rather about developing the institutional capacity for effective and legitimate decision making in circumstances where there is considerable polarization over what these terms mean. (Fisher and Harding 2006: 132)

\section{EPI and 'political will'}

No 'variable' has received stronger support as a sine qua non for improved SD implementation than 'political will'. It has also been profiled - usually as a predominant factor - in all of the major overviews of EPI problematics, in both the 'political' and 'academic' discourses. As initially stated by the OECD:

A strong political commitment is crucial to achieve the policy integration needed to underpin sustainable development. This must come from the highest levels of government, and be embraced by prime ministers, as well as ministers of economy/finance, social welfare, and the environment. ...

Collective responsibility within government for implementation of decisions which support a sustainable development strategy needs to be clearly established, and include explicit procedures and an assessment of training needs. Coherence across government departments and among different levels of government is vital. (OECD 2001b: 120)

This statement clearly expresses one of the most decisive administrative requirements for improving EPI. Securing 'first-principle' status for environmental policy integration - preferably connected to a judicious application of the precautionary principle - means that the principles in question must be 'blessed' by the political-administrative system in a specific constitutional way. The essence of this process as we see it, is that the principle(s) must be both strongly endorsed by the democratically elected heads of government, and firmly anchored in and through the ongoing political-administrative processes that govern for society. As we have stated earlier (Lafferty 2004e), 'governance is the responsibility of governments'. While it is well and good to accept a need for greater interaction among governments at all levels, citizens and stakeholders, as well as greater 'deliberation' and 'dialogue' among competing 'discourses' as an essential mode of interaction; it is also crucial to acknowledge that both 'sovereignty' and 'subsidiarity' imply political responsibility for public mandates.

In the terms of Fisher and Harding, the 'deliberative-constitutive' and 'rationalinstrumental' models of 'administrative constitutionalism' can be viewed as potentially complementary in achieving substantive EPI-SD results; but they can also be viewed as potentially inimical to such results. Pluralist access to the business of making EPI trade-offs, and the institutionalization of serious deliberativediscursive processes, can increase the total democratic input into the process, increasing thereby transparency. The same process can, however, also increase both 
conflict and disagreement - leading at best to minimalist 'log-rolling', and at worst to 'deadlock' and inaction. Either way, the issue of political accountability for the achievement of long-term, holistic and consequential goals - that is the goals of sustainable development - can be seriously compromised. The issue is a 'dilemma' in the truest sense of the word. We need inclusive decision-making and deliberation to improve both effectiveness in implementation and general norms of democratic legitimacy; but we also need more robust, cumulative and expert administrative steering to achieve the transformative changes necessary for sustainable development. The strong consensus as to a need for increased 'political will' seems to grasp this dilemma by the proverbial 'horns'; though few are the analysts who choose to confront this particular bull head on.

Having let the bull out of its pen, however, we feel a responsibility to propose at least one set of pases de muleta for moving it in a more manageable direction. Here is a list of several of the OECD's key questions on the issue of political leadership and EPI implementation (OECD 2002b: 8 - 9):

- Is there a clear commitment at the highest level to the formulation and implementation of sustainable development objectives and strategies?

- Is this commitment effectively communicated to the various sectors of government machinery and across levels of government?

- When gaps exist between the administrative and political agendas, are specific efforts made to bridge (or fill) them?

- Is leadership expressed through a sequence of priorities over time?

- Is government maintaining a sense of urgency, despite the longer-term nature of the issues related to sustainable development?

- Is there an institutional "catalyst” (ministry, select committee etc.) in charge of enforcing sustainable development strategies?

- Is this "catalyst" located strategically within the government machinery (e.g. at the level of the Prime Minister's office)?

- Are there specific reviews of laws and regulations to check whether they conflict with sustainable development, and are sustainable development objectives embedded in new legislation and regulations?

- Are Organisations moving from narrow sectoral perspectives (e.g. agriculture, industry, transport, etc.) to a more ‘issues-oriented' agenda (e.g. air quality, mobility, poverty reduction, etc.)

- Is sustainable development integrated into regular government exercises (e.g. the budget process)

If the answer to all of these questions is 'yes', we feel that the 'bull' of unsustainable governance would be turned more consequentially in the direction of effective EPI for SD. With such governing benchmarks in place, the cumulative effect of a 'rational-instrumental constitutional administration' would, in principle be biased towards Brundtlandesque outcomes. At that point - but hardly before one could move safely on to the added value of strengthening the deliberative constitutive' mode of governance. 
The major argument of the paper can be summarized in three points: (1) EPI has been identified as a crucial instrument for achieving decoupling; which in turn is a crucial goal of sustainable development; (2) the normative intent of EPI is to function as a 'first-order principle' for resolving trade-offs between sectoral policy goals and environmental/ecological concerns; (3) existing attempts to achieve EPI through governance are widely acknowledged as relatively weak, and relatively non-consequential; (4) the previous three conclusions are in fact common for leading-edge EPI research efforts today; and (5) the major challenge confronted by EU Member States is to develop governing mechanisms that strengthen the 'principled-priority' status of EPI in both vertical (sectoral) and horizontal (governmental) decision making.

Recognizing that these contentions may not be accepted by all students of EPI, we conclude with a final note on the implicit 'opposition' to the argument presented. The 'mainstream' position on EPI is that the principle and its processes are primarily designed to achieve 'balance' or 'cohesion' among competing economic, social and environmental policy objectives. Accepting Lenschow's view of sustainable development as a normatively explicit search for 'win-win' solutions, the proof of successful EPI here is, at a minimum, that given governmental procedures can be shown to have considered the alternative policy objectives; and ideally that the process has resulted in 'balanced' 'win-win' solutions, whereby the objectives of the three pillars are not only not compromised, but in fact enhanced through creative synergy.

Our position on this can be briefly stated as follows. Applying EPI as 'principled priority' in no way compromises a creative and innovative search for 'win-win' solutions, or other 'cohesive' policies for sustainable development. And there can be no doubt that the Brundtland Report views this possibility as an important way to change the quality of economic growth in a more sustainable direction. The problem arises, however, when the very difficult prospect of achieving win-win balance (as massively documented by negative progress on crucial ecological indicators) becomes the dominant approach to EPI. In short, the win-win, balanced approach to EPI is a both subordinate normative possibility within the dominant normative prescription of the WCED/Rio code; and a failed policy empirically. Reversing the 'principled priorities' of both economic liberalism and social democracy is, of course, a major challenge to existing ideologies and decision-making institutions: the challenge of achieving an increasingly elusive and ever more precarious 'balance' of sustainable development. By concentrating solely on 'win-win', we are increasingly risking 'lose-lose'.

Finally - for the sake of a fruitful research dialogue - a concluding caveat. The focus here is solely on the normative premises for institutionalizing EPI as a mechanism for governmental decision making. We are not saying that such an institutionalization will, or even should, guarantee EPI policy 'output' in favor of natural life-support systems in every decision-making instance. Nor are we saying 
that even the strongest pro-environmental 'policy output' will guarantee effective implementation; or that governmental decision-making is enough to achieve change. We are, as indicated, only trying to establish a normative 'bottom line', in principle and procedurally, for a more effective realization of EPI. Without such a mandate at the inception of EPI application; without greater consensus as to the normative intent of EPI within the SD political discourse; and without more effective governing mechanisms for resolving crucial trade-offs in policy formulation - the chances of realizing EPI for sustainable development are slim indeed. Institutionalizing EPI as 'principled priority' clearly does not solve all the challenges hindering more substantive EPI results. But it should, at least, provide clearer signals as to what is expected, and clearer standards for transparency and accountability. Not, in short, a 'silver bullet' for sustainable development; just an open acknowledgement that new and more difficult targets require new modes of gunnery. 
Pursuing sustainable development in Norway: The challenge of living up to Brundtland at home

published before as:

Lafferty, William M., Jørgen Knudsen and Olav Mosvold Larsen (2007): 'Pursuing sustainable development in Norway: The challenge of living up to Brundtland at home', in European Environment, Volume 17, pp. 177-188. 

With the Norwegian Prime Minister, Gro Harlem Brundtland, as Chair of the World Commission on Environment and Development, Norway became an early mover in politics for sustainable development (Langhelle 2000). Political ambitions for SD were manifested in several policy documents and initiatives throughout the 1990s, but a specific "National Strategy for Sustainable Development” was not prepared until 2002 (MoFA 2002), and an "action plan” for implementing the strategy did not appear until late 2003 (MoF 2003). A marked shift in approach can be identified between the launch of the Brundtland Report in 1987 and the adoption of the SD strategy and SD action plan. While the earlier efforts to promote SD were mainly "top-down", with little stakeholder involvement, the later efforts were more inclusive (though not necessarily more consensual). On the other hand, however, the earlier efforts were followed up by formal initiatives to achieve SD policy integration, while the later efforts have yet to be seriously implemented. At the time of writing (December 2006), the current 'red-green' (centre-left) Government has launched a major revision of both the strategy and action plan (along with an external peer review coordinated by the Swedish Ministry of Finance). ${ }^{1}$

In both the Brundtland report (WCED, 1987) and the action plan from Rio (Agenda 21), the goal of adapting economic and social policy to environmental concerns was viewed as the "chief institutional challenge in the 1990s" (WCED, 1987: 313). This challenge was subsequently conceptualized as "Environmental Policy Integration" (EPI), an idea that has been actively profiled by, among others, the UN, EU and OECD as a key feature of "governance for sustainable development" (Lenschow 2002a; Lafferty and Hovden 2003; Lafferty 2004). We have also argued elsewhere, that although SD strategies are an extremely important governing mechanism, they will only function effectively within a supportive context (Lafferty and Meadowcroft 2000a). This interdependency has also been highlighted by the UNCSD in their check-list of "key characteristics" for SD strategies. The strategies should be: based on existing initiatives (such as existing plans); reflect current priorities and take into account emerging issues; be based on the widest possible participation and involvement of all segments of society; involve a system for monitoring and evaluation; and, of most importance in the present context, reflect a country's commitment to put in place the institutional mechanisms necessary to the

\footnotetext{
${ }^{1}$ William M. Lafferty is Professor of Political Science and Director of the Programme for Research and Documentation for a Sustainable Society (ProSus) at the Centre for Development and the Environment (SUM), University of Oslo. Jørgen Knudsen and Olav Mosvold Larsen are both Associate Researchers at SUM/ProSus.
} 
achievement of SD through integrated economic, social and environmental policy planning. ${ }^{2}$

In the following assessment, we have used these perspectives and guidelines to select what we believe to be the most crucial initiatives for promoting strategic SD initiatives in Norway. The initiatives are presented in accordance with the categories suggested for the special issue, and reflect the opinion of the authors that: (1) the documents and routines adopted post-Brundtland can be viewed as an unofficial 'strategy'; (2) the process has been both cyclical and fragmented; and (3) the key factor qualifying the success of the strategic initiatives is an unresolved conflict between the material and welfare opportunities offered by a rapidly expanding petroleum economy, and the "political will" necessary to convert SD norms into SD reality.

\section{Strategic initiatives for sustainable development in Norway}

In order to understand the basis and context for the cyclical and relatively fragmented approach to sustainable development in Norway, we will first briefly outline the major white papers that constitute strategic initiatives. We will then in the following sections present a more detailed account of specific proposals from the documents.

\section{Key SD documents}

The 1989 white paper "Environment and Development: Norway's follow up of the World Commission’s report” (White Paper 46, 1988-89) stands out as the historic point of departure for the Norwegian approach to an SD strategy. The White Paper 46 has been characterized as Norway's first "green plan" (Jänicke and Jörgens 2000), but having been presented by Gro Harlem Brundtland as Prime Minister, and with several specific references to Our Common Future, it is generally acknowledged as the most ambitious and principled SD document produced by a Norwegian government. Mrs. Brundtland described the document as follows:

\footnotetext{
${ }^{2}$ The Norwegian Labour Party is currently sharing Cabinet power with the Centre Party and the Socialist Left Party. The Socialist Left has been a principal proponent of SD, and has been given the crucial portfolios of Minister of the Environment and Minister of Finance. It is the MoF that has responsibility for coordinating the implementation of the SD action plan, and that has also now initiated the review of both the strategy and action plan. The goal of the review is a new strategy which is both more specific with respect to targets and datelines, and more inclusive with respect to involving stakeholders in implementation. The MoF has also commissioned a peer review of the strategy to be coordinated by the Swedish Ministry of Finance. The draft of the new strategy will be presented in the fall of 2007.
} 
The White Paper [46] is the Norwegian Government's major policy document on sustainable development. It presents a plan that involves all ministries, not only that of the environment and implies a change in attitudes and policies, as well as tough challenges for ministries such as energy, industry, transportation, finance, foreign affairs and trade. The Prime Minister's Office has been directly engaged in charting a course for the future that cuts across all these sectors" (Brundtland 1990: 155).

White Paper 46 was thus a "strategy" in practice, if not in name. It specifically transcended a narrow environmental approach; referred explicitly to "sustainable development"; and placed the principle of cross-sectoral policy integration at the centre of the Government's SD programme (Langhelle 2000).

The next major document was White Paper 13 (1992-93), the follow-up report from the Rio Earth Summit in 1992. The principal aim of this document was to give Parliament an overview of the decisions made in Rio, with a detailed assessment of the results. The Government here argued that a precondition for the success of Agenda 21 was that every country should prepare national action plans with the Agenda as a point of departure (White Paper 13 1992-93: 25). As we have seen, however, this goal remained unfulfilled in Norway for another 11 years.

Prior to the "Rio+5" meeting in New York in June 1997 (UNGASS), the Government put forth yet another major policy document entitled "Environmental Policy for Sustainable Development” (White Paper 58 1996-97). While introducing several new mechanisms for the strengthening of environmental policy in all sectors, and making a particularly strong appeal for "Local Agenda 21", the general profile of the White Paper 58 was clearly more narrowly "environmentalist” than either of the two white papers outlined above. Furthermore, it marked a palpable lack of willingness on the part of the MoE to "front" the entire spectrum of SD issues, and no other governmental body at the time filled in the gaps.

The gaps remained open for the next four years. With less than a year left to the WSSD in Johannesburg, the Ministry of Foreign Affairs initiated a process for producing an official "National Strategy for Sustainable Development" (MoFA 2002). Both the process itself and the final (very short) document, were criticized by researchers and NGOs alike (Lafferty et al., 2002). The process was coordinated by an inter-ministerial working group with representatives from several Ministries. The resulting SD strategy is relatively concrete on conventional environmental policies, but is abstract and vague on policies related to socioeconomic issues and the global dimension. In general the strategy reiterated established environmental policy goals, but was very sparse on new objectives and targets.

The turmoil created by the SD-strategy process resulted in a promise by the Government to initiate a more ambitious SD action plan after Johannesburg. This time the responsibility for the process was given to the Ministry of Finance (MoF). The goal was to develop a more consequent platform for the plan by linking it to the annual state budget (making it, in fact, a separate sub-chapter of the budget). As such the procedure is in line with a Norwegian tradition of incorporating major 
policy-integration initiatives into the budgetary process. The consultation procedure for the national SD action plan (also called "National Agenda 21") (MoF 2003) was broader and more interactive than for the SD strategy, and was generally received positively by the environment-and-development community. The resulting plan was clearly more comprehensive and specific than the strategy, with numerous general objectives for a wide range of SD-related issues, but with few targets and timelines. Implementation was entrusted to an inter-ministerial committee of state secretaries (deputy ministers), under the leadership of the Ministry of Finance.

In sum the principal SD-related policy declarations in Norway have been put forth in a relatively haphazard political fashion, with diverse administrative origins and little consistency or cumulative interdependence. In the following sections we look at the process in closer detail, viewing specific strategic aspects of: their "horizontal” and "vertical" dimensions; the instruments used in implementation; the participatory aspect; and the provisions for monitoring and evaluation. ${ }^{3}$

Integrating SD horizontally at the national level

In Norway this dimension is primarily manifest in inter-ministerial coordination and cross-sectoral procedures related to planning and the budget. It is here that the critical SD aspect of cross-sectoral coordination and the prioritisation of alternative interests and goals ("trade-offs") comes in. Although Norway never has had a separate "Green Cabinet" per se, it was made clear in White Paper 46 that the Government itself was to take full responsibility for SD in Norway (Langhelle 2000: 181-183). This was, however, never actively profiled beyond the White Paper, and was certainly not realized in practice. We know of no instance where a Cabinet has been convened with "sustainable development" as a guiding principle for decisionmaking. The most prevalent horizontal governing mechanisms have been ad-hoc, inter-ministerial committees and budgetary and long-term planning procedures.

Most of the earlier ad-hoc committees were designed to report on single issues such as environmental taxes, climate policy, environmental policy instruments, biodiversity and sustainable consumption (Hovden and Torjussen 2002). There have, however, also been instances of inter-ministerial committees of State Secretaries (deputy ministers) with a more explicit responsibility for SD-related issues. A committee of this type was set up by White Paper 46 in 1989, but had little visibility and even less impact on the promotion of SD. More recently similar committees were established to develop the 2002 SD strategy and the 2003 SD action plan. The major accomplishment to date of the committee established to

\footnotetext{
${ }^{3}$ The guidelines are available at the website of the Division for Sustainable Development within the UN Department for Economic and Social Affairs: http://uww.un.org/esa/sustdev/natlinfo/ indicators/isdms2001/isd-ms2001institutional.htm\#strategy.
} 
oversee the action plan within the Ministry of Finance has been to commission a new set of SD indicators (see below). By all indications (statements made in hearings, consultations etc.) this committee does not view its role as an active promoter of the national SD action plan.

A much more ambitious attempt to ensure horizontal integration of SD issues in Norway has been the so-called "National Environmental Monitoring System" (NEMS: resultatoppfølgingsystemet). The NEMS can be characterized as a procedural tool to organize national environmental policies and to integrate environmental concerns into other policy areas. Although horizontal integration is only one of the goals of the system, we will here provide an overview of the main components of this initiative, and make more cursory references to it in the other sections.

Building on and expanding provisions initialized in White Paper 46, the NEMS was formalized in White Paper 58 (1996-97), with the Ministry of the Environment (MoE) given responsibility for operationalization and implementation. As originally designed, the monitoring system was an ambitious effort to develop a monitoring framework for managing, not only sectoral efforts, but also the overall Norwegian national "environmental" effort. Two years after the launch of the system it was further specified in White Paper 8 (1999-2000: 9) that: "Just as the State Budget describes the framework for the Government's economic policy and economic trends, this White Paper is intended to describe the Government's ecological policy and environmental trends." Even more importantly in the present context, the White Paper also declared that: "With this report the Government wishes to emphasize the ecological perspective as the foundation for policy formation in all areas of society" (ibid: 9). An assessment of the provisions of the system thus goes to the core of SD strategy and initiatives in Norway.

The original purpose of the system was to provide continuous reporting and updates on the outcomes and impacts of national environmental policies. The model was specifically outlined as a five-stage "circular" effort, with an interdependent interaction among all five elements (as presented below).

The single most important element of Norway's national environmental policy is the series of bi-annual reports (white papers) on “The Government's Environmental Policy and State of the Environment”. The series constitutes the principal publication and cornerstone of the monitoring system, and is the only element of the system still operational. The reports contain systematic accounts of trends within eight specified priority areas (Box 3.1), and present the main elements and priorities in Norway's “ecological” policy. Four "State of the Environment” (SE) reports have been published thus far, and a fairly strict framework for systematizing the reports has been established. Each priority area is structured in the same way: it contains a presentation of the goals and targets of the specific area, the state of the environment, goals achieved, and the policy instruments and initiatives in use. 


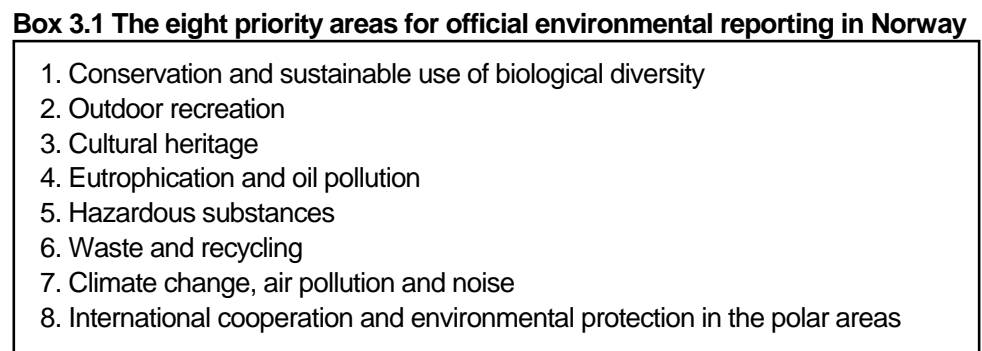

(Source: White Paper 58, 1996-97)

A second component of the NEMS consists of "Sectoral Environmental Action Plans" (SEAPs). These were to be prepared by each ministry, with the ambitious aim of: describing the principal environmental challenges within each sectoral domain; setting objectives and targets; and indicating the policy instruments available to meet the challenges. The plans were to be updated every four years, and were designed to show how each ministry could contribute to fulfilling the Government's overall policy on sustainable development. To date, however, the ministries have prepared only one generation of SEAPs, and, subsequent to an unfavourable evaluation in 2003 (Statskonsult 2003), the plans have now been phased out. According to the MoE further efforts to achieve sectoral integration will be pursued by coupling integration more strongly to the SE reports and/or through the green budgeting provision (EPSB - to be presented below).

A third component of the system - ministerial reporting on the actual implementation of the sectoral action plans - was a crucial element of the original NEMS design. This part of the system (registering progress on the strategic objectives and sectoral targets) was supposed to be executed annually. This was not only to facilitate ministerial follow-up, but also to enable the functioning of the other elements of the system in accordance with the established routines, formats and standards; as well as to facilitate the reporting section in the State of the Environment report. To our knowledge, however, no ministry has ever carried out this task.

The failure of the NEMS to function as designed is of crucial importance with respect to the implementation of the national SD action plan, since the plan specifically builds on this system as a key instrument for achieving cross-sectoral integration. Given that the inter-ministerial committee entrusted with the implementation of the SD action plan has initiated no other steering mechanisms for horizontal integration, the objectives of the action plan remain dormant. 
In the present context the vertical dimension refers to the interaction between the central and local levels of governance. Being a unitary state, with only limited delegation of political and administrative responsibility to the middle (county) level of governance, the principal SD focus in Norway has been on the relationship between national and municipal authorities within the context of "Local Agenda $21 ”$.

A framework for integrating ecological concerns more broadly into Norwegian policy-making was launched in 1997 by a Labour Government under Thorbjørn Jagland (Aall 2001). The framework included approaches to the interaction between relevant ministries and external participants; facilitated both national and regional networks; and provided communication facilities between the MoE and the municipalities (ibid: 85). The MoE had also previously experimented with several SD-related pilot programs, and had financially sponsored the establishment of "environmental officers" in all municipal administrations. These efforts were subsequently channelled into a relatively late, but ultimately very active, initiative on Local Agenda 21 by the MoE. A specific LA21 unit was established in the ministry and special resource units were established within the county administrations to channel information to the municipalities and develop network facilities for joining the central and local levels. (Aall 2001; Bjørnæs and Norland 2002) Other instruments were the dissemination of guidelines and recommendations for LA21, many of which were derived from specific research and evaluation activities (Lafferty 2001b). There were, however, no procedures for coordinating policy priorities between the local and central levels.

The broad-based LA21 initiative thus had no basis in a coherent national SD strategy, and in 2002 the centre-right government phased out most of the resources allocated to the LA21 program. In the SD action plan presented in 2003, Local Agenda 21 was barely mentioned, and no official evaluation of the earlier initiatives has been carried out. Current political signals indicate, however, that centralgovernment support for LA21-like activities will be revived. A comprehensive overview of the LA21 experience in Norway is now available (Lafferty et al. 2006).

The first systematic attempt to promote sectoral integration in Norway was the socalled "Environmental Profile of the State Budget” (EPSB), a relatively modest attempt to "green" the budget. It was introduced as early as 1989, and was presented (until 1992) in the main budget document under the heading "Follow-up on the World Commission for Sustainable Development". The EPSB was the predecessor of the NEMS, and was to achieve three major goals: (1) the ministries were to use the EPSB to highlight the main environmental challenges, targets and initiatives for the sector in the forthcoming fiscal year; (2) the ministries were to provide an overview of budgetary allocations according to their degree of "environmental motivation" (that is, intent - not impact); and, (3) "if possible”, the ministries were 
to assess the environmental effects (actual outcomes) of budgetary allocations for the previous two years (Riksrevisjonen 1999).

This system was the first governing mechanism specifically designed to realize SD policies in Norway, and the task was portrayed in the White Paper 46 (1989) as: "A cross sectoral policy [which] will place new demands on the public administration” (ibid: 71).

Both the scope and the methodology of the EPSB have been developed over time. Since the introduction of the NEMS in 2000, reporting in the EPSB has corresponded to the eight policy priority areas of the NEMS (Box 3.1). The two systems have thus been leading parallel (and somewhat overlapping) lives, despite the fact that the NEMS was originally introduced to replace the EPSB. The problem appears to be a classic case of "unresolved turf" among the ministries. The MoE is responsible for the NEMS, and for the overall coordination and assessment of the environmental reporting from the various ministries, but it is the MoF which has the overall responsibility for coordinating the budget.

Thus in principle all ministries are to specify the environmental impacts of their budgets, and of the main sectoral policy goals in the State Budget. Further, as of 2004, they are to report on the relationship between their budgets and the objectives of the SD action plan. These reports are compiled and presented in the annual National Budget, but thus far the budget overview only refers to sectoral information, with no reference to the implementation of the action plan as a whole.

The budgetary reporting system is still functioning, but the tendency is for the accounts to be less and less detailed for each passing year. With the sectoral action plans phased out and the quality of the budgetary reporting system declining, there is an obvious lack of a coherent framework which connects overall governmental strategy with ongoing sectoral policy implementation. Furthermore, as indicated above, there has been no apparent attempt to integrate the goals and objectives of the SD action plan into sectoral policy, so that the national strategic intent of the plan remains unfulfilled as to both process and results.

In the wake of the first major SD strategy document (White Paper 46), the Government appointed in 1990 a National Council for Sustainable Development (NCSD). The intention was that the Council should play a major role in bringing together strategic stakeholders with key governmental ministries. The Council was chaired by the Prime Minister, with permanent representation for leading ministries, the major umbrella organisations for industry and labour, and Norway's largest environmental NGO. Despite its very ambitious remit, the Council failed to function as a mobilizing and coordinating forum. It held a number of thematic meetings during the first years of its existence, but was quietly phased out in 1994 (Hovden and Torjussen, 2002: 26-27). 
The only other body established of similar nature (in 1993), is the National Committee for International Environmental Questions (NIM). This organ, chaired by the Minister of the Environment, with broad ministerial and NGO representation, functions principally as a forum for contact and communication between the Government and civil society on issues of international environmental importance. Its goal is to guarantee transparency and (relative) consensus on Norway's role in shaping international environmental regimes, and has little to do with promoting sustainable development at home. It still exists, and is a principal manifestation of the type of close state-NGO interaction that typifies Norway's SD performance in international fora.

Both of these bodies were originally presented as important participatory channels for implementing SD policies in Norway. Given, however, that the initial SD white paper was never followed up as a strategy per se, and that it was not until 2003 that the SD action plan was in place, it is clear that the bodies in question have not played a major role in either profiling or implementing domestic SD policy. ${ }^{4}$

With the exception of the MoE initiatives on Local Agenda 21, it thus seems valid to claim that the follow-up of SD-related policies in the first decade after Rio was predominantly top-down and bureaucracy-driven, with at best token stakeholder involvement. This changed somewhat with the brief process for developing the SD strategy in 2002 (though the process itself was judged as seriously flawed); was improved for the preparation of the national action plan in 2003; and was markedly improved for the process leading to Norway's new SD indicator set (see below). Comprehensive stakeholder involvement has also been projected for the revision of the SD strategy to be finalized in 2007.

As described above, reporting on the status of environmental impacts and changes is relatively sophisticated in Norway, and the National Environmental Monitoring System could have been a comprehensive tool for monitoring and evaluating the ecological dimension of SD. But the NEMS model has now been eviscerated, and there are no designated bodies in place to monitor and evaluate SD progress on an ongoing basis. A need for more specific SD indicators was expressed in both the SD strategy and SD action plan, leading to the appointment of an expert commission. The commission conducted several open hearings and appointed a "reference

\footnotetext{
${ }^{4}$ The categories employed reflect the common approach of the special issue (See Steurer and Martinuzzi 2005). They are, however, similar to the approach we have earlier developed for assessing governing mechanisms for sustainable development (with an emphasis on "environmental policy integration" - EPI) (Lafferty, 2001b; Lafferty and Hovden, 2003; Lafferty, 2004c). The analysis here builds on this earlier material.
} 
group" of academics and NGO representatives. The final set of indicators was issued in 2005 (MoF 2005).

The indicators strongly reflect the conceptual logic of Norway's system of "national accounts" and different types of "capital”. The set is designed to cover six issue areas: (1) Climate, ozone and long-range transboundary air pollution; (2) Biodiversity and cultural change; (3) Natural resources; (4) Hazardous substances; (5) Sustainable economic development; and (6) Social issues (MoF 2005). With some minor amendments, the 16 indicators are to be used to evaluate the follow-up of the SD strategic objectives outlined in the SD action plan. The results are to be presented as reports within the framework of the National Budget, and Statistics Norway is assigned responsibility for updating and interpreting changes in the measures. As pointed out by several participants in the reference group, however, the indicators are mainly status-oriented (focussing strongly on the sustainability of national capital stocks), and provide diffuse insights into the relationships between socioeconomic "drivers" and the "responses" necessary to alter negative trends. The role of the indicators in mediating between the SD strategy and the action plan is thus tenuous. The monitoring and evaluation of SD in Norway will thus remain relatively descriptive and static, focused on the presentation of incremental changes in the SD indicators in the annual State Budget, and on the bi-annual reports from the MoE on the "State of the Environment".

\section{Summary of the SD strategy process}

In spite of the variety of strategic provisions and initiatives introduced in Norway, there are currently very few that function as intended. The overall impression is one of cyclical and disjointed political interest - resulting in a fragmented and inconsequent pursuit of the SD strategy. Even in the early Post-Rio 1990s there was a distinct lack of an overarching entity responsible for the horizontal integration of SD. The primary SD-related initiative - the NEMS - was principally designed for monitoring and reporting, not for cross-sectoral coordination or implementation. On the vertical dimension the late-but-effective LA21 process was characterized by openness and cooperation between the MoE, local and regional stakeholders and external experts; but the initiative was both highly cyclical and extremely narrow with respect to the comprehensive Rio Action Plan.

As for those initiatives that in one way or another have been identified with SD goals, it is noteworthy that the "greening of the budget process" has, in differing versions, functioned for almost two decades. The process has, however, been little profiled by the authorities, and never directly coordinated with the reporting and monitoring system. While elements of the NEMS, particularly the sectoral action plans (SEAPs), could have facilitated implementation of SD policies, the plans have never functioned according to design and were discontinued after 2003.

The preparation of both the SD strategy in 2002 and the SD action plan in 2003 marked a "high point" for official emphasis on sustainable development in Norway. In retrospect, however, the emphasis seems to have been largely motivated by the 
national performance requirements for the Johannesburg Summit. With the exception of the much-debated work on SD indicators, follow-up of the strategy and action plan was minimal under the initiating centre-right government, and is now under revision by the existing centre-left government.

\section{Analysing the Norwegian SD profile}

As evident from the above presentation, the process of developing and implementing SD strategy in Norway has neither been consistent, cumulative or consequent. The original white paper - which was primarily a governmental strategy for integrating SD principles in all sectors - was neither explicitly profiled nor followed up as an "SD strategy". SD initiatives between the 1989 White Paper 46 and the 2002 "National Strategy for Sustainable Development" focused principally on the integration of "ecological" concerns in all sectors. The key instruments here were the NEMS and the EPSB. These were designed to be integrative and interactive in the promotion of sustainable development; but have been documented here to be fragmented and relatively ineffective in promoting the SD agenda. The most recent phase, which focuses on the SD strategy and action plan, marks an important shift in responsibility from the MoE to the MoF; but has thus far only resulted in a new set of national SD indicators. The SD action plan has been integrated into the National Budget, but this is only a procedural convention and has not led to new mechanisms for evaluating the objectives of the action plan, or for effectively integrating sectoral initiatives with overall national strategy. The "storyline" for Norway's national strategy for sustainable development is thus one of: "High ambitions - disjointed follow-up - inconsequential results". Why is this so? What are the most plausible explanations for this apparent lack of robust SD processes and significant SD outcomes in the Land of Brundtland?

There are clearly no simple answers to the question, but on the basis of a continuous monitoring of the situation since the Rio Summit, we have identified certain key features of the Norwegian experience which point towards a very "idiographic" explanation. ${ }^{5}$ Norway emerges as a distinct anomaly with respect to sustainable development. It is because the distance between rhetoric and reality is greater for Norway than for most other Western countries, that the case takes on a special significance. In the following, we explore possible reasons for this difference in relatively particular terms. Beginning with the notion of "political will” - as stressed in this context by both academics (Lafferty and Meadowcroft, 2000a; Jordan, 2002a,

\footnotetext{
${ }^{5}$ This assessment contrasts sharply with an earlier assessment made in a report to the UNCSD by Sverdrup (1997). While we agree that the NIM has played an important coordinating role for international environmental policy, it has had virtually no effect on the promotion of SD as a crosssectoral issue in Norway. See the more detailed evaluation in Hovden and Torjussen (2002).
} 
2002b) and international organizations (OECD, 2001, 2002a, 2002b) - we point to the interactive effect between domestic political leadership and international identities and ambitions.

A decisive point of departure for the initial attempts to institutionalize SD principles in Norway is the position of Gro Harlem Brundtland. Through her joint role as Chairperson for the WCED, and Norway's dominant political figure throughout the decade of 1986-96, Brundtland used her WCED role to introduce the principles of Our Common Future directly into Norwegian politics. Under her leadership Norway also played a major role in the international preparations for Rio. These activities led to the highly ambitious White Paper 46 of 1989, and a very high-profile involvement of both Norwegian politicians and NGO leaders in Rio.

But then something happened. Our previous analyses indicate that Gro Harlem Brundtland was (in private) very disappointed with the outcome of Rio (Lafferty et al., 1997 and 2002). Coupled with a conviction that Norway already was launched on a path of SD implementation (a perception that was not unrealistic, given the ambitions of White Paper 46), the attitude of the Government was that Norway was truly a "beacon" on environment and development. This explains why the follow-up document from Rio (White Paper 13) was more a summary overview of what had happened at UNCED than either a strategy or action plan. It also explains why the MoE was exceptionally slow to either react to or endorse the single most successful global initiative from the Rio Action Plan, Local Agenda 21. After initially claiming that Norway already was a "league leader" in promoting SD at the local level, it was not until 1996 that the Government took at closer look at what was going on in the rest of the world - and finally initiated a support programme for LA21. As pointed out above, however, this programme became the only governmental initiative with express reference to Agenda 21 - right up to the adoption of the national SD action plan in 2003.

With White Paper 58 (1996-97) - after Brundtland's withdrawal from the leadership of the Labour Party in 1996 - a second generation of initiatives was grafted on to earlier efforts. These initiatives were, however, neither adequately coordinated with the earlier instruments, or followed up their own right. Throughout the entire decade 1992-2002, Norway increasingly developed an SD profile which was "bifurcated": very active and morally pretentious in international environment-and-development arenas; and increasingly passive and non-consequential in fronting and promoting SD at home. By the year 2000, a comprehensive analysis of SD implementation in high-consumption societies concluded that Norway was "reluctantly carrying the torch” from Rio (Lafferty and Meadowcroft, 2000a).

In our view a major reason for this "reluctance" is the increasingly dominant role of the petroleum sector in the Norwegian economy. The impact of the petroleum economy on the will to pursue sustainable production and consumption in Norway has been massive. The prospect of steadily increasing state revenues from petroleum and gas activities has directly "fuelled" the politics of both "business as usual" and increasing welfare benefits. With the exception of Thorbjørn Berntsen's initial 
period as Minister of the Environment (Labour: 1990-1996), no political leader in power has demonstrated any willingness to either actively promote the Rio Agenda or put significant new SD steering instruments in place. The Government of Kjell Magne Bondevik (a centre-right coalition), finally produced the SD strategy in 2002 and the SD action plan in 2003, and the rhetoric associating these initiatives with the Johannesburg Summit was again very florid and enthusiastic. Also here, however, the follow-up was both limited (SD indicators) and formalistic (a very narrow interpretation of the coordination mandate by the MoF). Given further that the major negative consequences of the petroleum economy are off-shore and global (greenhouse gas emissions), the cumulative result has been an SD political profile which actively embraces a "torch-carrying" role in international development issues, while just as actively pursues a non-sustainable business-and-welfare-as-usual path at home.

\section{Conclusions}

With respect to possible lessons for SD strategies in general, the Norwegian case manifests a relatively unique curve of activity. Beginning with a strong recognition of a need for overarching strategy in the period 1987-1992, the commitment declines progressively in the post-Rio decade, and only re-emerges immediately before and after the WSSD in Johannesburg. One sees throughout the 1990s selective attempts to promote SD through the sectoral integration of "ecological concerns"; but the follow-up of these initiatives fails to correspond with either intentions or possibilities. This trajectory is, for example, in direct contrast to Norway's neighbour Sweden, where political interest in sustainable development per se has resulted in numerous strategic ploys and institutional reforms. As for participation and consultation in Norway, the record is also partial and cyclical. Procedures for consultation with business interests and civil society have been established; but they seldom go beyond consultation, and tend to be largely focused on international negotiations. A late-but-solid effort on Local Agenda 21 (19972001) represents an isolated exception to the general trend, but all-in-all - and allowing for possible new initiatives from the current "red-green" government - the record compares poorly with the participatory goals outlined for "Major Groups" in Agenda 21.

As a final point, however, it must be stressed that these conclusions are specific to the central theme of the current special issue: sustainable development. Nearly all Norwegian ministers of the environment would defend their records as "working for sustainable development" - even if they haven't called it that. And in a certain sense this is of course true. But, as clearly stated in the Brundtland Report, the goal of sustainable development transcends the "standard agenda" of focusing on environmental effects. The SD approach concentrates on "the policies that are the sources of those effects", and the two approaches represent "distinctively different ways of looking both at the issues and at the institutions to manage them" (WCED: 310). In our assessment Norway has perhaps done reasonably well on the "standard" environmental agenda; but has yet to either institutionalize or realize an effective implementation of the SD agenda. Given the 
Pursuing sustainable development in Norway: The challenge of living up to Brundtland at home

peculiarities of the Norwegian situation - the dominating role of Gro Harlem Brundtland at the start of the period, and the dominating effect of the petroleum economy at the end it is difficult to discern relevant lessons for SD strategies in general. 
Norway:

\section{Trying to maintain maximal RES-E in a petroleum driven economy}

published before as:

Knudsen, Jørgen, Olav Mosvold Larsen and Audun Ruud (2008): 'Norway: Trying to maintain maximum RES-E in a petroleum driven economy', in W.M. Lafferty and A. Ruud (eds), Promoting Sustainable Electricity in Europe: Challenging Path

Dependency of Dominant Energy Systems, Cheltenham UK: Edward Elgar, pp. 250278. 

Norway is endowed with abundant energy resources that have been intensively exploited for decades. As one of the world's leading producers of hydro power, Norway normally derives more than 90 per cent of its total national electricity consumption from hydro resources. Norway has, however, also become a major producer of oil and natural gas. In 2006 Norway was the third largest exporter of crude oil in the world, and supplied Europe with about 15 per cent its total natural gas supply. In this regard, Norway has increasingly become a 'petroleum driven economy'. It is at the juncture of these two national energy traits - hydropower and petroleum - that an analysis of governance for renewable electricity (RES-E) must be conducted.

One of the major trends affecting RES-E in Norway is the relationship between hydropower generation and the overall consumption of electricity. By all indications the former has reached a definite limit, while the latter continues to increase. There is, therefore, considerable concern as to the security of national electricity supply in Norway. A phasing in of 'new' RES-E production can in this context be viewed as one of five alternative energy options currently being discussed in the national political discourse (Figure 4.1).

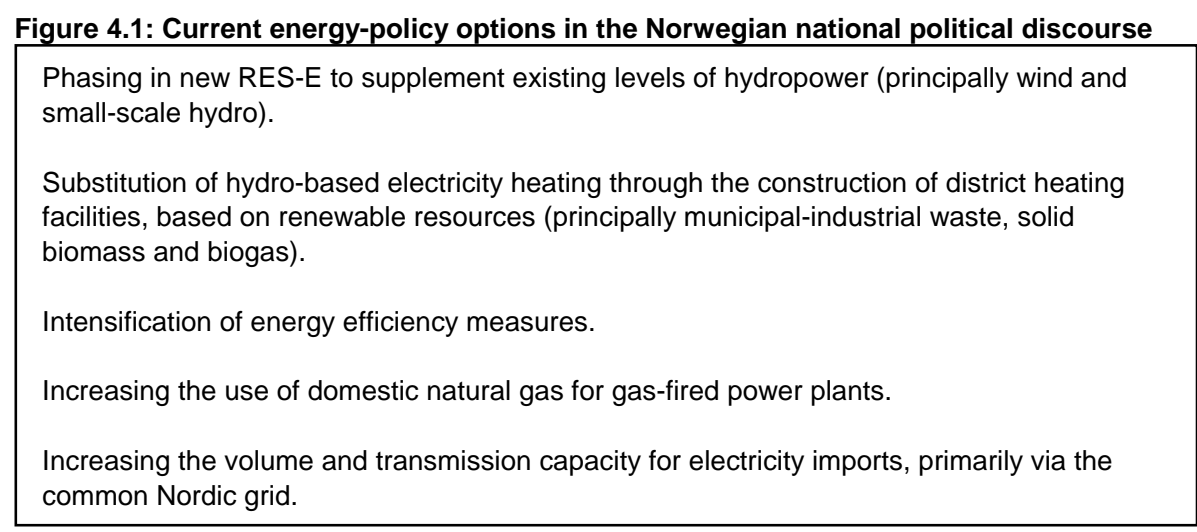

Source: Author's original

Further expansion of large hydropower installations is no longer politically viable. In addition to a promotion of new RES-E as a direct supplement to large-scale hydropower (option 1), an increasingly viable strategy is to substitute hydro-based electricity heating with other renewable (biomass) alternatives (option 2). Since electricity consumption in Norway is among the highest in Europe per capita, increased energy efficiency is also identified as an important component (option 3). The use of Norwegian natural gas resources in gas-fired power plants constitutes yet another possible 'path' for coming to grips with increasing deficits of hydropower (option 4). Lastly, the challenge can be approached by expanding the overall volume and transmission capacity for electricity imports (option 5). 
Perspectives related to these different energy options are woven into the major sections of the chapter, and we return to the options in our summary discussion. As we see it, options 1, 2 and 3 listed in Figure 4.1 are all compatible with the intentions and targets of the EU RES-E Directive - and all three are, in fact, central to the current governmental strategy - though in differing degrees and with differing levels of support.

\section{The EU RES-E Directive and Norway}

The Norwegian participation in the EU internal market, as well as involvement in related EU policy areas, has since 1994 been regulated by the Agreement on the European Economic Area (the EEA Agreement). ${ }^{1}$ Through the EEA Agreement Norway is obligated to follow the regulations related to the internal energy market. An integral part of the process is running consultations and negotiations between the EFTA countries (Norway, Iceland and Liechtenstein) and the EU Commission as to the eventual adoption of EU legal acts within these EFTA countries. The EEA Joint Committee - where the EFTA countries meet with EU Commission representatives - determines whether the legal act in question is to be integrated as part of the EEA Agreement. If accepted by the EEA Joint Committee, the legal act is then transposed to national legislation.

The EU RES-E Directive was finally adopted by the EEA Joint Committee on 8 July 2005, and was subsequently officially endorsed by the Norwegian parliament. ${ }^{2}$ The implementation of the Directive has so far not led to any substantial amendments of the legal framework in Norway since most of the required mechanisms and institutions to promote renewable electricity were already in place. ${ }^{3}$

Despite having a capacity for 100 per cent self-sufficiency in electricity from RES in a year with 'normal precipitation', Norway's indicative target was set at only 90 per cent; a level which is just barely above the lowest level ever recorded for RESbased electricity consumption in Norway (89.5 percent). The target is based on a premise that the annual growth in electricity consumption will not exceeding one

\footnotetext{
${ }^{1}$ Through the EEA Norway, Iceland and Liechtenstein are participating in the Internal Market, while not assuming the full responsibilities of EU membership.

${ }^{2}$ Decision of the EEA Joint Committee No 102/2005 of 8 July 2005, amending Annex IV (Energy) to the EEA Agreement. The formal implementation of the RES-E Directive was then postponed due to delayed adoption by Icelandic authorities; EU legislation must be formally adopted by all EEA countries before entering into force. Thus, the Directive formally entered force in Norway 1 September 2006.

${ }^{3}$ In order to clarify the legal authority related to the issuance of guarantees of origin - as pertaining to the RES-E Directive's Article 5 - the Energy Act was amended by the Parliament in 2006. The Ministry of Petroleum and Energy (MoPE) assesses in its 2007 report to the EFTA Surveillance Authority (ESA) that the existing Norwegian system for licensing for RES-E facilities are based on sound principles, and will be further improved through the ongoing work on that is implementing new guidelines for small hydropower and wind power (MoPE 2007).
} 
per cent during the target period. The Ministry of Petroleum and Energy (MoPE) nonetheless considered the target to be 'ambitious', given projected increases in both consumption and additional production (6-7 TWh for the period 1997-2010). ${ }^{4}$ Not surprisingly, the Directive was considered to be in accordance with Norwegian interests by both the Government and the Parliament, and it was welcomed by Norwegian energy companies. The Directive was also considered to serve 'offensive interests' for Norway, since one of its premises was to promote international physical and financial markets for renewable electricity. ${ }^{5}$ The MoPE has the responsibility for the further follow-up of the Directive in Norway.

\section{General profile of the Dominant Energy System for electricity in Norway}

In 2005 net energy consumption in Norway was 225 TWh, and electricity consumption accounted for 72.6 per cent of total stationary energy use (Table 4.1). The electricity consumption per capita is significantly higher than the OECD average, mainly due to the high amount of electricity used for heating. Traditionally electricity has been relatively cheap in Norway compared to other OECD countries.

Electricity production is dominated by hydropower (more than 90 per cent). The latest comprehensive study of energy use in households (2001) indicates that space heating accounts for 31 per cent of electricity consumed (MoPE 2006a: 36). ${ }^{6}$ The Norwegian energy system cannot be comprehended, therefore, without a thorough understanding of the interaction between hydropower production and electricity consumption.

Table 4.1 Stationary energy consumption in Norway 2005

\begin{tabular}{ll}
\hline Energy source & Per cent of stationary energy consumption \\
\hline Electricity & 72.6 \\
Oil products & 13.0 \\
Various types of gas & 4.3 \\
Bio & 8.0 \\
District heating & 1.5 \\
Other (coke, coal etc) & 0.6 \\
\hline Total (225TWh) & 100 \\
\hline Source: Ministry of Petroleum and Energy (MoPE 2006a: 34)
\end{tabular}

\footnotetext{
${ }^{4}$ Based on the MoPE's preparatory memo on the Directive, dated 26 Aug 2005. ('Rammenotat om dir. 2001/77/EC').

${ }^{5}$ This is based on: 1 ) the assessment of Assistant director general in the MoPE, Mr. Johan Vetlesen [telephone interview conducted by Maria Gjølberg, 7 September 2004]. 2) The national hearing of the Directive where sectoral actors clearly considered the Directive as favourable.

${ }^{6}$ The study was carried out by Statistics Norway in 2001 . There are no regular statistics of electricity consumption for heating available.
} 


\subsubsection{Hydropower}

Today total installed hydroelectric capacity stands at 28000 MW (MoPE 2005: 21). The bulk of this capacity was constructed during the period 1960-90, with the most intense period between 1970 and 1985. Norway is the eighth largest producer of hydro-based electricity in the world (IEA 2006b: 10).

The first hydropower plant to commercially produce electricity for households was constructed in 1885, and hydro-based electricity was a key feature of Norway's late and intense industrialization between 1905 and 1920 (Lafferty 1971, Thue 1994). Hydropower still is a crucial factor for Norwegian energy-intensive industries, and the relatively low costs associated with hydroelectricity are perceived as decisive for the future survival of the traditional Norwegian process industries.

Traditionally the Norwegian State has subsidized the energy-intensive industry with long-term contracts for low-cost supply of electricity. These contracts are now mainly expiring and many companies have concluded new, long-term contracts directly with the energy companies. The public subsidies are no longer viable as it is considered as state aid, and thereby not in accordance with the EEA Agreement. It remains to be seen how possible amendments will affect the overall hydropower balance and eventually the industry's focus on both energy-efficiency and alternative sources such as natural gas.

Historically, most decisions related to energy production in general, and to electricity production in particular, have been related to hydropower. The 1969 discovery of oil and gas at the off-shore Ekofisk field marked the start of the Norwegian petroleum adventure, but petroleum never represented a major challenge to hydropower as the dominant domestic electricity source.

Table 4.2 Electricity production and consumption in Norway 1995-2005 (TWh)

\begin{tabular}{|l|l|l|l|l|l|l|}
\hline Year & Hydropower & Wind & Other & Imports & Exports & Net consumption \\
\hline 1995 & 122.487 & 0.01 & 0.5 & 2.3 & 8.9 & 104.964 \\
\hline 1996 & 104.148 & 0.009 & 0.5 & 13.2 & 4.2 & 104.147 \\
\hline 1997 & 110.938 & 0.01 & 0.47 & 8.7 & 4.8 & 104.893 \\
\hline 1998 & 116.280 & 0.01 & 0.49 & 8 & 4.4 & 110.448 \\
\hline 1999 & 121.882 & 0.02 & 0.54 & 6.8 & 8.7 & 110.520 \\
\hline 2000 & 142.289 & 0.03 & 0.49 & 1.47 & 20.5 & 110.915 \\
\hline 2001 & 121.026 & 0.027 & 0.5 & 10.76 & 7.1 & 113.258 \\
\hline 2002 & 129.837 & 0.075 & 0.56 & 5.3 & 15 & 110.078 \\
\hline 2003 & 106.084 & 0.218 & 0.9 & 13.4 & 5.6 & 104.272 \\
\hline 2004 & 109.291 & 0.252 & 0.9 & 15.3 & 3.8 & 109.623 \\
\hline 2005 & 136.452 & 0.5 & 0.86 & 3.6 & 15.7 & 111.832 \\
\hline
\end{tabular}

Source: www.ssb.no/emner/10/08/10/elektrisitetaar/tab-2007-05-24-12.html (in Norwegian)

The total potential for hydropower production in Norway is estimated at 205 TWh in a year with average precipitation. 118.9 TWh of this capacity is already developed; 44.2 TWh are in regulated watercourses that are (politically) not available for development; leaving a possible 41.9 TWh that can be developed. In 
the current political situation, however, this could only involve small-scale plants. The MoPE considers the 'theoretical potential' for small hydropower to be around 25 TWh (MoPE 2006a: 23). The interest in building small plants is growing and the institutional capacity to handle the increased number of license applications has recently been reinforced.

As indicated in Table 4.2 the actual level of hydropower production varies significantly with changing levels of precipitation and weather-dependent consumption. The hydropower stations are 'supported' by water deposit reservoirs, filled up during spring and summer, and tapped off during winter. The reservoirs are an efficient means of storing energy, and are well suited for co-production with other renewables such as wind power. This, however, is still only on the planning stage.

\section{New renewable energy sources for electricity}

\section{Wind power}

Norway's long coastline offers numerous ideal settings for wind power. In many locations average wind speed is more than 8 meters per second, and on well-suited locations more than 3000 annual work hours are generated (MoPE 2005: 28).

The Norwegian Water Resources and Energy Directorate (NVE) has estimated the physical potential for wind power to be 480 TWh per year, about four times the annual mean electricity production from hydropower (Gan et al. 2005: 38). The downside is that many of the most suited locations are areas with poor electricity transmission capability.

Wind power was introduced in Norway in 1989-93, with the construction of eight turbines (Christiansen 2002: 38). Despite only moderate official support there has, since 1997, been considerable interest in developing wind energy (Gan et al. 2005: 38). As of July 2007, some 31 wind power installations - with a total installed capacity of $1733 \mathrm{MW}$ have been granted with concessions, with $322 \mathrm{MW}$ currently installed (NVE 2007). The installed wind power capacity only provided 0.5 TWh in 2005 (Table 3.2), 0.39 per cent of the electricity consumed that year. When including announced projects, the annual potential amount to more than $3 \mathrm{TWh}$. It is, however, at the time of writing uncertain as to whether the energy companies actually will proceed with the planned projects. This increasing uncertainty is particularly based on the new national feed-in tariff scheme adopted in 2007 (coming into force from 2008), and the energy companies' concern about the stipulated support level for wind power (Econ 2007).

\section{Photovoltaics}

The active use of solar energy through photovoltaic (PV) technology is not very common in Norway, and the contribution to RES-E production is insignificant. Offgrid PV panels are common in summer houses and cottages, but there are currently no grid-connected PV systems in Norway. A passive use of solar energy is more widespread, being closely linked to the construction of houses. Many homes utilize 
passive solar heating, through both insulation standards and the siting of dwellings in the terrain, but there are no reliable estimates available as to the amount of energy saved (Gan et al. 2005: 38).

\section{Biomass}

Despite a significant potential, electricity production from biomass is not very common. There are, however, possibilities for cogeneration in industry, an option that is particularly relevant in the wood-processing industry in conjunction with waste-treatment plants. Biomass can also be used more extensively in districtheating systems, enabling a substitution of hydro-based electricity heating (see below).

\section{Wave and tidal power}

Due once again to Norway's particular coastline, wave and tidal power have been considered to have significant potential. From the late 1970s throughout the 1980s substantial financial support was given to the development of wave energy. Two high-profile wave power projects were publicly funded from about 1976 to 1984 . These were among the very first 'new' RES projects in Norway. Interest in wave power then declined (Christiansen 2002), but in 2003 a prototype tidal energy turbine of $300 \mathrm{KW}$ was installed in the most Northern county of Finnmark and connected to the grid (Kvaløysundet). Still, wave power contributes insignificantly to RES-E production.

\subsubsection{The related challenges of renewable heating and natural gas}

As indicated in the introductory part, the construction of alternative, renewable heating systems, as well as the phasing-in of electricity produced from new gas-fired power plants, also constitutes current political options to amend Norway's increasing deficit of hydropower (see Figure 4.1).

\section{Renewable heating}

Due to Norway's exceptional use of electricity for space and water heating, it has been a principal goal to promote alternative heating sources. Since 1980 the use of petroleum for stationary purposes has been reduced by about 50 per cent, corresponding with an increase of hydroelectricity-based heating (MoPE 2006a: 34). Since petroleum used for heating often is connected to water-based heating systems, this can facilitate a conversion to renewable energy. Bioenergy-based heating is competitive when resources are available at low cost and there is a possibility of connecting to a district heating system. Improving the infrastructure for district heating is thus considered a key measure.

The use of bioenergy as a source of heat is increasing in Norway due to more fluctuating electricity prices (Gan et al. 2005: 38). In 2005, in total 31 district- 
heating facilities supplied approximately $2.4 \mathrm{TWh}^{7}$, mainly in the bigger cities (MoPE 2006a: 40-41). Energy recovery from waste constituted about half of this production of heat, with the rest coming from biofuel, electricity and petroleum. In particular, many new public constructions are now projected with attachment to biomass-based district heating systems, including, in some cases, private dwellings. Such projects of substituting electricity for heating are often financed by the public Energy Fund, and can thus be considered implementing option number 2 identified in the introduction (Figure 4.1).

\section{Natural gas-fired electricity}

Being a leading petroleum producer and exporter, the issue of natural gas-fired power plants has for more than a decade been a recurring theme in the Norwegian public debate. The Norwegian environmental movement has been exceptionally unanimous in its opposition. Proponents claim, however, that global emissions of CO2 will actually decrease, because Norway is increasingly forced to meet its electricity deficit by importing fossil-fuelled electricity (see Table 4.2). Carbon capture and storage (CCS) has been a central issue in this debate.

The issue as a political controversy peaked with the resignation of the centre Government in March 2000, after Parliament had turned down the proposal of committing the gas-fired power plant projects to CCS. The incoming Labour Government then provided licenses for three projects without CCS obligations. For several reasons, however, the concerned companies did not immediately proceed with these projects (Tjernshaugen 2007). Other projects were later proposed, however, and currently two plants are in operation, and a third one is under construction. One of these is located on the south-west coast (Kårstø) and is expected to start its production by the end of 2007. Another project is to be located on the western coast north of Bergen. The major Norwegian oil and gas company, Statoil, has been allowed to build a plant attached to an existing petroleum refinery (Mongstad) which is stipulated to be on line by 2010. Together these two plants will produce close to 6 TWh of electricity annually, about double the wind energy target set for 2010. All current projects are going ahead without CCS, but the Mongstad plant is committed to gradually phasing in CCS technology from 2010 with substantial public financial support. ${ }^{8}$

\footnotetext{
${ }^{7}$ This refers only to heating, but is measured in TWh. Consequently it is not indicated in the overview presented in Table 3.2 .

${ }^{8}$ This builds on an agreement between the Government and the then Statoil, signed in October 2006, where the concession for the gas-fired power plant at Mongstad is conditioned by the installation of CCS facilities. The concession states that a more concrete plan on the phasing-in of full-scale CCS is to be agreed upon by early 2009 (MoPE 2006, Tjernshaugen 2007).
} 


\section{Major actors affecting production and consumption of RES-E}

\subsection{1} Partisan politics and positions towards RES-E ${ }^{9}$

During the last ten years there have been four different governmental constellations in power in Norway: 1997 - 2000 there was a coalition constituted by the Centre Party (SP), the Christian People's Party (KrF) and the Liberal Party (V), based on a parliamentarian minority. 2000 - 2001 there was a minority Labour Party (AP) government, and 2001 - 2005 there was a minority centre-right coalition government (the Conservative Party (H), KrF and V). From 2005 AP, the Socialist Left Party (SV) and SP constitute a 'red-green' cabinet backed by a parliamentarian majority. This is the first time the dominant Labour Party shares cabinet portfolios. Traditionally the Labour Party and the Conservative Party have been leading opponents along the left-right axis. Currently, however, the right wing Progress Party (FrP) is the major opposition party.

Green issues have had various degrees of saliency in the Norwegian partisan politics, often cutting across the dominant cleavage of left-right on welfare-state issues. This cleavage has in particular manifested itself through issues concerning the construction of larger hydropower projects, and later through the debate on natural gas-fired power plants.

To provide a rough picture of political concerns related to RES-E we have analysed: References in the official party programmes from 1997-2005; party positions on recommendations made by the Standing Parliamentary Committee on Energy and Environment (Stortingsinnstillinger); party priorities in national budget recommendations; 'private proposals' by individual Members of Parliament ('Document 8 Proposals ${ }^{10}$ '); Members' 'questions' to the Minister of Petroleum and Energy (over three sessions of Parliament between 2000 and 2005); and in other policy documents (Propositions to the self-constituting 'second chamber', the Odelsting), White Papers and the Government's 'Long term Programme' presented once every four years.

The analysis leads to the following conclusion: Although all parties are more or less positive to RES-E, it is the left wing SV that has the 'most enthusiastic' profile, showing active support through specific proposals in the budget priorities, private proposals, recommendations in the Committee for Energy and Environment and interpellations at question time. SV is also the strongest advocate of an active public role in promoting RES-E.

\footnotetext{
${ }^{9}$ This section is initially based on documentation provided by Maria Gjølberg.

${ }^{10}$ The 'Document 8 ' procedure is a mechanism by which the parliamentarians can raise issues and propose policy measures and/or regulations vis-à-vis the Government. The Government's follow-up depends on the parliamentarian support of the proposal.
} 
Coming from the opposite direction, the populist and right wing $\mathrm{FrP}$ - with a relatively negative profile to the urgency of climate change - has forwarded several private proposals and recommendations. This activity reflects a sceptical approach, in essence an open opposition in principle to promotional subsidies. One explanation for the relatively prominent role of both SV and FrP is that neither of these parties (until recently for SV) has had ministerial and budgetary responsibility as members of the cabinet.

The other political parties all claim varying commitments to RES-E, but in a less active and more general mode. Both the Labour Party and the Conservative Party, who declare their interest in providing Norway with the world's most environmentally friendly energy supply, have been consistently weak in their follow-up on RES-E. One explanation is these parties' wider conception of 'environmentally friendly energy', as they include natural gas with CCS. SV in particular has profiled RES-E as an alternative to natural gas, while FrP, $\mathrm{H}$ and AP the traditional 'growth parties' portray natural gas as environmentally friendly (within a global perspective). A major issue has thus been whether Norway should produce natural gas to replace the import of 'grey' electricity (AP, H and FrP's position), as opposed to both increasing the production of RES-E and reducing the consumption of electricity in general (SV's position) .

The wider political tension related to 'growth vs. conservation' has, however, been gradually attenuated over the last years. Only $\operatorname{FrP}$ appears to maintain an unwavering emphasis on the former over the latter. The other parties seem increasingly comfortable with associating RES-E with both growth and environmental protection.

\section{The role of relevant state entities}

The principal institutional actor in the energy sector is the Ministry of Petroleum and Energy (MoPE). The MoPE is entrusted with coordinating the energy policy of Norway, and thereby also the policies affecting RES-E. In addition, the Ministry of the Environment (MoE) is particularly involved in the cases of land-use and spatial planning. MoE and its subordinate agencies are also responsible for conducting environmental assessments concerning larger RES-E installations such as wind power plants.

\section{Norwegian Water Resources and Energy Directorate - NVE}

As a sub-ordinate agency to the MoPE, the Norwegian Water Resources and Energy Directorate (NVE), has the following responsibilities: Managing Norway's water resources; promoting an efficient energy market and cost-effective energy systems; and promoting efficient energy use. The NVE is by origin anchored within the hydropower segment in Norway. It was established in 1921, and hydrology is still a very prominent interest of this agency. Due to the ambitions of increasing the diversity of energy supply in Norway, NVE has gradually adapted to the role of being an energy directorate. The Directorate is mandated by the Energy Act to issue licenses for new electricity production, including both hydropower and wind power. 
There seems, however, to be a huge capacity challenge related to RES-E. The NVE has repeatedly reported that it is understaffed and not able to handle all the incoming license applications, particularly related to wind power (Montel Power News 2007, NVE 2006).

\section{Enova and the Energy Fund}

Enova SF was established in 2001 as a 'public enterprise' (statsforetak) owned by the MoPE (Ot Prp 35 (2000-2001)). The MoPE manages its ownership through a contractual agreement. While NVE is responsible for issuing licenses for new plants, Enova is responsible for initiating and monitoring support schemes and other promotional activities, related to 'stationary use and production of energy' ${ }^{11}$ Its mandate is to achieve its goal by reducing energy consumption and increasing the supply of wind power and renewable heating systems with 12 TWh in total by 2010 .

This overall objective is composed of the following sub-targets:

- to limit energy use considerably more than if developments were allowed to continue unchecked;

- to increase annual use of water-based central heating based on new renewable energy sources, heat pumps and waste heat of 4 TWh by the year 2010;

- to install wind power capacity of 3 TWh by the year 2010.

In 2006 Enova had a budget of close to EUR 100 million, based on the yield of the Energy Fund. The Energy Fund is mainly financed by an earmarked levy on the electricity distribution tariff. By the adoption of the State Budget for 2007 the above-mentioned objectives have been expanded with an ambition of achieving a joint target of 30 TWh additional RES-E, RES-heating and energy efficiency combined by 2016, compared to the 2001-level. RES-E is stipulated to contribute about one-third of the 2016 objective. The Energy Fund has been supplemented by a new fund, the Basic Fund for Renewable Energy and Energy Efficiency, with approximately EUR 1.25 billion allotted from 2007.

Until 2007 the major RES-E relevant support mechanism has been investment grants for wind power. These were allocated to the most cost-efficient projects that would not have been realized without the investment grant. The Norwegian Parliament has decided that from 2008 this will be replaced with a national feed-in tariff scheme.

As touched upon in other sections in this chapter there is an increasing challenge of realizing the wind power target due to uncertainties of profitability and the difficulties of localization. There is also a huge challenge underlying the promotion of renewable non-electric heating systems in Norway, principally due to the inertia of the dominant hydro-based infrastructure for electricity heating, as well as the

\footnotetext{
${ }^{11}$ Excluding the funding of research and innovation which is the responsibility of the Norwegian Research Council.
} 
relatively low cost of electricity. Compared to the costs of electricity - renewable heating systems are expensive to realize, and in some cases even considered not sufficiently energy-efficient (Rasmussen et al. 2006). In this regard Enova's role can be said to be hampered by its limited mandate. The agency has neither the regulatory authority nor the possibility of altering the market and legal framework affecting the promotion of RES-E production. Continuous market advantages for hydropower-based electricity are probably also reducing the motivation for investing in non-hydro RES-E.

Existing policy measures fail to provide clear and coherent incentives for a more effective implementation of both wind power and renewable heating systems; as well as the coordination of these two main options. In addition to a quite challenging mandate on RES-E and energy efficiency, Enova also has, through other political decisions, an obligation to contribute to increased domestic use of natural gas. Enova's mandate can thus be characterized as both partially contradictory and insufficient.

\section{Branch organizations}

The Norwegian Electricity Industry Association (EBL) is the trade organization for around 260 producers, suppliers, distributors and a few water-regulation associations. The main purpose of EBL is to deal with industry-related economic and political issues on behalf of its members, and to provide as ideal framework conditions for the industry as possible. The EBL is a major supporter of the dominant hydropower regime in Norway by representing the major hydropower producers. EBL has nevertheless supported the criticism of the level of public support for RES, and, in particular, for wind power production.

The Norwegian Wind Energy Association (NORWEA) was established in 2006 and is the industrial body for wind power producers. NORWEA works for the public acceptance of wind power installations, as well as the amendment of the financial framework and, in particular, the promotional support schemes for wind power.

The Federation of Process Industries (PIL) was traditionally perceived as a major defender of the hydroelectric 'faith'. PIL organized companies across a broad spectrum of process industries, most of them highly dependent on electricity. In 2006 PIL merged with the Federation of Norwegian Manufacturing Industries (TBL) to become the Federation of Norwegian Industry (Norsk Industri). There is a close collaboration with EBL in securing support for hydro-powered electricity production. Norsk Industri is, however, mainly concerned with the cost of electricity to its producers, and is also a significant proponent of gas-powered electricity production.

The National Council for Norwegian Municipalities Producing Electricity from Hydropower (LVK) is the interest organization of municipalities having ownership interests in hydropower installations. LVK in general focuses mostly on optimization of revenues for these municipalities. 
A relative newcomer in the RES-E policy field is the National Council for Norwegian Municipalities Producing Wind Power (LNVK) established in 1999, and so far assembling about 30 municipalities. This organization is working for improved framework conditions for wind power construction, improved local influence in planning and licensing processes, as well as providing and developing competence for negotiations with other authorities, landowners and the energy companies.

\subsection{4}

\section{The major RES-E-related companies}

In 1992, as a direct consequence of the Energy Act of 1991, the state-owned enterprise 'National Power Company' (Statkraftverkene) was divided into two separate state-owned units; Statnett SF and Statkraft SF. The first runs the monopoly-based transmission of power and has national system-wide responsibility for the electricity grid, while the second is responsible for the generation of electricity.

Statnett is responsible for the management of the central grid. It is a public enterprise, owned by the State through the MoPE. Electricity from hydropower is not stored and must be used as it is generated. A system operator, in this case Statnett, must, therefore, ensure that supply and demand are in balance at all times. As a transmission-system operator, Statnett owns and operates most of the Norwegian power grid, as well as the Norwegian share of power lines and underwater transmission cables to other countries.

As for Statkraft, its ownership was transferred from the MoPE to the Ministry of Trade and Industry in 2002. In October 2004 Statkraft changed its status from a state-owned enterprise to a limited stock company. With a total power production of 42 TWh, the Statkraft Group is the third largest producer of electricity in the Nordic region, as well as the second largest producer of renewable energy in Europe. Statkraft is the largest hydropower producer in Norway with approximately 30 per cent of total production capacity (MoPE 2005: 22). In Norway it also operates through an increasing number of subsidiaries and attached companies, all of which are regionally important enterprises. Statkraft currently operates wind farms in central and northern Norway.

Norsk Hydro ASA was founded on the exploitation of hydroelectric power for producing fertilizers in the early twentieth century. Norsk Hydro later evolved into a leading off-shore producer of oil and gas, building on its strong semi-state positions in both the process industry and hydroelectricity. The company is the third largest integrated aluminium supplier in the world, relying primarily on hydropower for its Norwegian energy intensive operations. It is generally acknowledged that Norsk Hydro alone accounts for roughly 10 per cent of Norway's total electricity 
consumption. With respect to RES-E, it is important to note that Norsk Hydro was involved in several wind and hydrogen projects, in Norway and abroad and notably off-shore wind power. ${ }^{12}$ However, the petroleum activities were merged with Statoil in October 2007. Included in this merger are also Hydro's wind and hydrogen projects, but energy is still a core business in the new, but smaller Norsk Hydro. ${ }^{13}$

As for Statoil, with its dominant position in the Norwegian economy, it also has a crucial role in the development of $\mathrm{CO} 2$ technology, thus exercising considerable influence on the 'developmental space' for RES-E innovation and path creation in Norway. Until the recent merger, Statoil had no major RES-E activities except some limited bio-energy projects.

Another major actor is the conglomerate Hafslund ASA. Hafslund is both the largest private power-grid owner and the largest power retailer and distributor in Norway. The company also ranks seventh among Norwegian hydropower producers. Hafslund is not directly involved in activities related to RES, but has been a major shareholder in the leading solar-wafer company, Renewable Energy Corporation (REC).

REC is the largest RES-related firm in Norway, and one of the largest solar companies in the world. The company specializes in leading-edge technology related to the manufacture of silica wafers for the PV industry, and has numerous subsidiaries worldwide in different areas of application of PV technology. In addition to REC, new initiatives for solar energy development have recently been taken by other Norwegian companies.

\section{NGOs and growing local resistance to RES-E production}

Climate change and energy issues are major concerns among the key Norwegian environmental NGOs. The NGOs generally stress the need for renewable energy, but also see it as important to come to grips with consumption and to introduce energy efficiency measures. While there are few substantial NGO initiatives aimed at promoting renewable electricity production as such, the Norwegian environmental organizations have been almost unanimously in favour of a green certificate scheme, considered to be more effective than the feed-in tariff scheme agreed upon (further details in subsequent section). During the last $10-15$ years the environmental NGOs have been heavily engaged in the issue of gas-fired power plants and related carbon capture and storage (Tjernshaugen 2007). One could claim

\footnotetext{
${ }^{12}$ The most well profiled pilot project is the experimental plant on the island Utsira, off the southwestern coast of Norway, where Norsk Hydro conducted a demonstration project on hydrogen driven electricity generation based on wind power. Given the merger, this project is currently part of the StatoilHydro portfolio. Further information can be found at: http://www.statoilhydro.com/en/TechnologyInnovation/NewEnergyAndRenewables/Hydrogen/Pa ges/Utsira-prosjektet.aspx

${ }_{13}$ Information on the 'new' and smaller Norsk Hydro: http://www.hydro.com/en/.
} 
that this preoccupation with the gas power issue has over-shadowed engagement related to other aspects of the energy policies, including RES-E. However, there are differences in opinion when it comes to implementation of specific renewable technologies, mainly wind power. Here the environmental NGOs differ in their conservationist orientation, with some being more concerned as to the possible consequences for local landscapes and biodiversity. This scepticism is, however, more outspoken at the regional and local level than in the national debate. Smaller, ad hoc 'resistance groups' have also been established, in order to impede the actual construction of wind power plants, particularly on the western coast. Many of these local groups are gathered in the umbrella organization 'STOP-ravaging-thecoastline' (STOPP rasering av kysten). These groups have also been actively supported by the tourism industry, both locally and nationally.

In parallel to the growing local scepticism towards wind power, the interaction with local stakeholders is increasingly emphasized by the energy companies. The regulatory framework for wind power is quite complex, but it provides various opportunities to inform and involve the local community and stakeholders. Local communities are thus increasingly invited by the energy companies to take an active part in influencing the planning and execution of the projects.

The policy framework for RES-E in Norway

\section{The basic legal-regulatory structure for hydropower}

While the legal procedures affecting non-hydro renewables in certain ways differ from the ones regulating hydropower, the hydropower legal regime constitutes a major historical and institutional basis for the regulation of RES-E in Norway at large.

Management of watercourses has a long tradition in Norway, with the first law on watercourse regulation from 1887. Several acts followed, most of which are still valid. Together these regulations constitute a very hydropower-specific regulatory framework. In 1973 the first Protection Plan for Watercourses (covering 95 watercourses) was adopted. Since then three additional plans (1980, 1986 and 1993), and a supplement to the plans (2004), have been adopted. Together they constitute an extensive body of hydro regulation.

Parallel to this, the Parliament decided in 1981 to establish a Management Plan for Water Resources, encompassing all watercourses not already regulated. The purpose was to rank these watercourses according to the potential rate of return for developing the systems, as well as the degree of expected political controversy in each case. This plan has been the central reference for all subsequent discussions of further development of specific watercourses. The 2004 supplement to the last Protection Plan states that large projects are no longer viable. Additional hydropower development in Norway will in principle have to be in the form of small-scale hydro units. An important additional implication of Parliament's 
decision is that 'micro' and 'mini' hydropower plants (less than $1 \mathrm{MW}$ ) can be given a concession (with some exceptions) even if located in protected water courses. The MoPE adopted in 2007 new guidelines for the licensing of small hydropower plants in order to make the process more coordinated and efficient.

Another important regulation is the Industrial Concession Act of 1917, formulated to ensure a continued national ownership of Norway's important hydropower resources. The Act prescribes to 'whom' and for 'how much' the power plants can sell their resources. According to this Act the Norwegian State takes over any waterfall or hydropower installation managed by private interests, free of charge when a licence expires. This regulation does not, however, restrict the power producers' ability to invest in and improve the plants. The conformity of the Act with the EEA Agreement (as to the principle guaranteeing reversion of ownership to the state) has been heavily questioned by the EFTA Surveillance Authority (ESA). The case was taken to the EFTA Court, and in June 2007 it was decided that Norwegian authorities had to amend the principles in the Act to treat public and private owners equally. At the time of writing the Norwegian government is working on an amended regulation. It is clear from the reactions to the EFTA court judgement that national, and preferably public ownership is considered decisive for politicians at the national and local levels. The main political divergence in the case echoes the general right-left cleavage on the perspective of public vs. private ownership. As to the actual consequences for new RES-E production, it is difficult to see that national public ownership will ensure a higher level of investment than increased private and/or foreign ownership. ${ }^{14}$

The Energy Act of 1990 has been instrumental in changing the overall energy policy orientation in Norway. The Act made Norway the first country in the world to guarantee consumers the right to choose their own suppliers of electricity. The Act is also the basis for the licensing and management of all electric installations and district heating systems; as well as for power trading and the overall coordination of the electricity grid. It also has direct implications for the commercial framework for private sale (contracts, measurement, invoicing) as well as transnational trade in electricity (MoPE 2005). The provisions of the Act pertaining to RES-E installations can be illustrated by a brief reference to the procedures concerning wind power production.

Potential wind power producers must apply for licenses to the Norwegian Water Resources and Energy Directorate (NVE). During its assessment NVE can request

\footnotetext{
${ }^{14}$ In addition to the acts described in this section, hydropower is affected by the following acts: The Watercourse Regulation Act with rules on the regulation of water-storage reservoirs and water levels. The Water Resource Act (2001); constituting the national implementation of the EU Water Framework Directive, it prescribes procedures for a coherent and environmentally benign management of watercourses and groundwater.
} 
specific reports on environmental and other consequences. Facilities having an installed capacity of more than $10 \mathrm{MW}$ are always subject to such reports. The NVE's evaluation of the application is to be coordinated with local authorities' assessment of the localization of the installation. The local authorities' assessment is based on the Planning and Building Act. The NVE - in cooperation with local authorities - is to arrange public hearings with regional and local stakeholders. In addition, other public authorities at the national level are to scope the more specific consequences of the installations in question; inter alia, related to biodiversity and the cultural heritage, in order to identify and rank the level of conflicting interests. As part of the assessment of a license application, the NVE also assesses the necessary grid connection, and the regional and general capacity affected by the new installations. There is, however, no clear, formalized provision as to how to distribute the actual costs of eventual grid amendments

In sum, the framework for planning and assessment prior to the final issuance of a license for wind power production is very complex. The actual time span from an initial announcement of interest to the eventual granting of a license is 3-6 years. The government has in 2007 adopted new guidelines to induce a more coordinated and coherent assessment of wind power and small hydropower plants. The guidelines encourage authorities at the county level to develop regional wind power plans. It remains to be seen whether these voluntary guidelines will lead to a smoother planning process.

The wholesale trade between power producers, suppliers and major consumers of electricity is either taking place bilaterally, or through the Nordic Power Exchange Nord Pool. Nord Pool is a direct consequence of Norway's amended Energy Act of 1990. An increasing number of transactions are being concluded through Nord Pool. Established in 1993, it was the world's first multinational exchange for trading electric power. It was originally a Norwegian-based market, but Sweden joined in 1996, Finland in 1998, and Denmark in 2000. Nord Pool involves the trading and clearance of physical and financial power contracts among the Nordic countries. As of 2006, approximately 350 actors were trading in one or more of Nord Pool's markets.

The common Nordic electricity market has provided increased opportunities for import to Norway in periods of deficit and it has given Norwegian actors access to the wider European market, by trading with both physical and financial contracts. The fluctuations in electricity exports and imports, illustrated by the figures listed in Table 4.2, also indicate the dynamics of these transactions.

\subsubsection{Guarantees of origin and the RECS}

'Guarantees of origin' (GO) constitute an important element of the RES-E Directive. In 2003 the state-owned power-grid company, Statnett, was given temporary responsibility for issuing RES-E certificates of origin in Norway. In order 
to formally codify the RES-E Directive's provisions in Norway, a specific regulation has now been prepared by the Ministry of Petroleum and Energy.

Statnett has also been active in the RECS (Renewable Energy Certificate System), a voluntary certificate system established by European power companies in 2001 as an initiative to create a uniform cross-border certificate trading. Statnett now issues combined GOs and RECS to Norwegian producers. The European trading of such certificates is growing fast, and Norwegian and Swedish electricity producers dominate the European market. It seems uncertain, however, as to whether accumulated profits from this trading will generate more investments in new RES-E production in Norway.

In 1982 the Conservative Government submitted a White Paper on new renewable energy sources in Norway. This was the first, and to date only policy document devoted solely to policies for 'new renewables'. The White Paper presented a relatively optimistic position (White Paper 65 (1981-82): 24). Christiansen (2002) argues, however, that during the 1980s the previous optimism faded. Allocations for research and development remained unchanged.

In a White Paper from 1989 the Labour Government signalled an ambitious climate change policy as a follow-up of the Brundtland Report (White Paper 46 (1988-89)). Reinforced public efforts in support of RES were proposed as a key policy measure to stabilize the CO2 emissions by 2000 (Ibid.: 58). The White Paper further suggested establishing 'goal-oriented' and 'time-limited' R\&D programmes, with specific responsibilities for each RES branch. A subsequent White Paper in 1992 marks a shift towards a more cautious approach (White Paper 41 (1992-93)).

With the adoption of the White Paper on policies for climate change and the emissions of NOx (White Paper 41 (1994-95)), Norway officially abandoned its domestic stabilization target in favour of a cost-effective strategy for the mitigation of greenhouse gas (GHG) emissions. However, at the same time the Labour Government signalled a strengthening of support schemes for the development of new renewable energy technologies. In the White Paper on 'Environmental policy for sustainable development' (White Paper 58 (1996-97)), a new Labour Government proposed that electricity consumption in a so-called 'normal year' should be based entirely on renewable energy sources. Key goals were set to decrease the use of electric heating in cases where new renewable energy sources and technologies could be deployed, and to increase the utilization of bioenergy and water-borne heating by about 5 TWh over a period of 5-10 years.

In 1999 the centre coalition Government proposed alternative approaches for a more environmentally benign energy policy (White Paper 29 (1998-99)). These proposals were partly based on recommendations from an Expert Commission's report on the future prospects for Norway's energy balance (MoPE 1998) triggered by a significantly lower hydropower production in 1996 as shown in Table 3.2. A key 
recommendation from this Commission was increased energy source diversity. Subsequently, as a result of the political process following White Paper 29 in 2001, Enova was established as a public body to promote energy efficiency and the development of RES.

In 2000, with reference to the EU's on-going early preparation of a possible common system for tradable certificates for renewables, the Norwegian Parliament requested the Labour Government to consider a national 'green certificate system'(Budsjettinnst. S.nr. 9 (2000-2001)). On this background the centre-right coalition Government concluded in 2003 that a functional national system would require a wider international market structure (White Paper 9 (2002-2003): 107108). The parliamentary majority nevertheless decided to establish a green certificate scheme, preferably integrated with the Swedish system established in 2003. With more documentation on the possible effects of such a joint market, the MoPE sent to hearing a draft for legislation in early 2005. The intention was to establish a common Swedish-Norwegian certificate system by 1 January 2006.

Disagreements arose, however, between the Swedish and Norwegian negotiators, and in February 2006 the Norwegian centre-left coalition Government decided to abandon the joint green certificate project. This provoked harsh criticism from opposition politicians, energy suppliers, NGOs and the Swedish Government (Dagbladet 2006). The Norwegian Government argued that the scheme would be 'too expensive for Norwegian consumers and industry' and opted instead for a strengthened national promotional scheme through Enova (MoPE 2006b).

As part of the State Budget proposal for 2007, the Government proposed the introduction of a feed-in tariff scheme in support of wind power, small hydropower and bioenergy. The new support scheme will be effective from 1 January 2008. The proposed support level for wind power at approximately 0.01 Euro per KWh has been particularly criticized, as it is far below the average support level for wind power in the EU.

It is difficult to establish a complete picture of the centre-left Government's real motivations for cancelling the joint certificate market with Sweden. The decision to replace it with a national feed-in system is considered as less optimal by the energy companies (Econ 2007). Given the Socialist Left Party's (SV) traditionally favourable position on RES-E, it is likely that the more hydropower- and natural-gas oriented Labour party majority of the Government went against the more RES-E friendly position. ${ }^{15}$ An additional reason could be an ambition to reinforce the

\footnotetext{
${ }^{15} \mathrm{SV}$ has only five of 19 members of the centre-left cabinet. Several centrally positioned SV politicians were reported to be very disappointed by the Government's decision.
} 
replacement of hydroelectricity for heating by renewable alternatives, and thereby de facto (if not as an outspoken strategy) give renewable heating priority. ${ }^{16}$

\section{Efforts for RES-E innovation}

Norwegian innovation policy system suffers in general from "an inherent tendency toward fragmentation"; "poor co-ordination among governmental ministries and autonomous institutions"; and "a general lack of long-term thinking and priorities" (Remøe 2005: 217). This also holds true for 'green innovation' and new renewable energy (Lafferty and Ruud 2006, Larsen 2005). The responsibilities for RES-E innovation are clearly fragmented, and no ministry has a coordinated responsibility for energy and innovation.

As indicated above, the major responsibility for pursuing the promotion of RES was transferred to Enova SF in 2001. Enova has not, however, had a specific mandate for fostering innovation. The agency allocates mainly resources to projects based on well-proven technologies. A basic principle has been Enova's focus on technology use, and not technology development. However, this focus seems to be gradually changing. Enova is now also managing a programme on energy technology development. In cooperation with Innovation Norway, a state-owned company with the responsibility of spearheading the Government's innovation policy, and the Research Council of Norway, Enova also manages a joint programme on innovative energy solutions. Relatively little funding was allocated through these programmes in 2005 and 2006, also due to a low number of applications. Enova points out the general uncertainty about the future public production support as a main reason for this modest interest (Enova 2007).

The Research Council of Norway (RCN) has in particular one programme with direct relevance: RENERGI (Clean Energy for the Future). This programme covers research on both energy production and consumption. In principle, the dimension and funding of the programme does not allow support for major demonstration projects.

In addition to the government-induced programmes, there are several research initiatives at the university level and within larger affiliated research institutions. The Foundation for Scientific and Industrial Research (The SINTEF Group) is of particular importance, with numerous projects related to the development and dissemination of renewable energy. The Centre for Renewable Energy at The Norwegian University of Science and Technology (NTNU) in Trondheim is also an important potential actor, but is still in a relatively early stage of development.

\footnotetext{
${ }^{16}$ This last-mentioned perspective was partly confirmed by the then Minister for Petroleum and Energy, Odd Roger Enoksen in an interview with Montel Power News' Newsletter for Norway (no. 6, week 35 2007).
} 
Nevertheless, it is important to emphasise the substantial R\&D activities conducted by major energy companies. In particular, there is a growing interest in off-shore wind power development in Norway among scientists, technology developers, energy and industrial companies, investors and politicians. These often point to Norway's broad experiences with both off-shore installations and energy technologies in general. ${ }^{17}$ Off-shore wind power is also considered in relation to the power supply to off-shore petroleum installations. These are traditionally operated by gas turbines providing an important share of Norway's CO2 emissions. The alternative could be either supply from on-shore hydropower, or - more in accordance with innovation and the overall security of supply - developing innovative, off-shore wind power generation.

This focus has also been echoed by Norsk Hydro, which has for several years been working on cutting-edge technology for off-shore turbines. The company was granted a license in 2006 from the NVE to set up pilot prototypes of floating offshore wind turbines 11 kilometres off the south-west coast of Norway, and this is followed up by StatoilHydro. ${ }^{18}$ The Government is currently considering more specific efforts for off-shore wind power, but no decision has been made thus far.

Finally, a new development that can lead to major changes in the organization and funding of RES-E-related innovation, is currently taking place. The Norwegian Research Council and stakeholders from research and the energy sector are in 2007/08 involved in a process entitled 'Energy 21'. The aim is to identify the major research and innovation priorities related to domestic energy production and consumption, and thereby contribute to more comprehensive public funding and eventually - induce new policy measures as well.

\section{Phasing in RES-E at the regional level}

Central Norway represents an illustrative region with regard to both the path dependency of the dominant energy system and possible path creation for RES-E. It is also a very succinct illustration of how the five political options listed in Figure 9.1 mobilize different actors and interests in a regional setting.

Central Norway is characterized by a generous abundance of natural resources, including wind, hydro and fossil fuels. Yet, the region nonetheless faces projections predicting a growing deficit of electricity in a year with limited precipitation. This is particularly related to an expansion of energy-intensive industries, in primary

\footnotetext{
${ }^{17}$ For example: 'Vindkraft til evig tid' ('Wind power for ever'); a commentary article in the Norwegian newspaper Dagens Næringsliv, 12 July 2007, written by prominent representatives of research, industry and regional politicians standing out as active proponents for a substantial program for off-shore wind power technology development.

${ }^{18}$ Further details at: http://www.statoilhydro.com/en/Technologylnnovation/ NewEnergyAndRenewables/Pages/default.aspx.
} 
aluminium production (Norsk Hydro), and to the recently established 'Ormen Lange' installation, a gas-processing and production plant related to off-shore gas exploitation. The transmission capacity from the central grid has been considered insufficient given these new major industrial projects. ${ }^{19}$ The deficit is predicted to reach approximately 9 TWh by 2010. ${ }^{20}$ This has resulted in increasing 'regional unrest' from both consumers and industry, and significant political attention nationally - particularly with a current Minister of Petroleum and Energy from the Centre Party, Norway's traditional defender of regional interests.

Two gas-fired power plant projects have been licensed for the region. The first of these (by the company Industrikraft Midt-Norge) has not yet commenced, but is stipulated to deliver 6.4 TWh annually. The project could possibly be realized with a bioenergy component in addition to natural gas. Secondly, Statoil has planned, but not yet finally decided, to construct a plant capable of delivering 7 TWh by 2011 . Both gas-turbine projects have been strongly supported by the actors of the dominant energy system (both hydropower and petroleum), through regional and local politicians and industrial actors. They perceive the gas option as favourable because it strengthens security of supply and stimulates regional economic development. The proponents also perceive it as environmentally benign even without carbon capture and storage (CCS).

Parallel to the gas-turbine option, there has been strong interest in the wind power potential of the region, as the coastline is well suited. Major emphasis has been placed on a relatively spectacular initiative for off-shore wind farms (Havsul). The turbines are to be localized close to the coast of the county of Møre and Romsdal. Altogether these installations were expected to generate about 3 TWh of electricity in a normal year. The Havsul project provides a clear indication of the magnitude of the wind power potential capable of serving this region with energy-intensive industry. Not surprisingly, however, both the size and visibility of the project which is planned to be located relatively close to the coastline, has provoked resistance from local citizens, the tourism industry and conservation-oriented NGOs. The Havsul project was originally divided into four different sub-projects, and one of these was cancelled in 2006 due to strong local resistance. The rest of the project is still under assessment with the NVE.

In addition to possible off-shore wind power, there are several on-shore wind power projects in the region, both installed and projected. Nearly half of the currently installed wind power capacity in Norway is in fact localized in this region (161 MW of $322 \mathrm{MW}$ ), one of them being Norway's largest wind power plant (Smøla). In addition there are several planned projects not yet constructed. The lack of progress

\footnotetext{
${ }^{19}$ It has recently become evident that the consequences of the Ormen Lange project on the regional electricity supply situation were heavily under-documented and under-estimated by the authorities and politicians during the planning period prior to the Parliament's acceptance of the project in 2004 (Teknisk Ukeblad no. 29, 2006).

${ }^{20}$ Statnett Press release 22 February 2006.
} 
is, among other things, due to the low promotional funding schemes - and the challenge of grid access.

The Norwegian geography with long distances between the remote, sparsely populated areas where the wind power potential is localized - and the regional and central grid, represents a specific challenge in this regard. Since the Norwegian electricity supply is organized as one centrally coordinated system, there is little room for regionally differentiated solutions. New wind power projects therefore often imply grid amendments which are at least partly to be financed by the wind power developers. This is the case with several projects localized at the Fosen peninsula within this very region, where one is aiming at a coordinated solution for all planned wind power projects. This issue is not yet finally clarified.

There is also a potential related to new hydropower production, but, as earlier indicated, current political guidelines require that this can only be realized through small-scale plants. The potential contribution is limited, but increasingly controversial with a growing number of projects. With respect to the region's grid capacity, Statnett is projecting an expansion by building a new transmission corridor to the south. ${ }^{21}$ This will improve the flexibility of the regional electricity system, but will also imply environmental and landscape impacts in fragile eco-systems. Besides - contrary to the proposals for wind farms and gas-fired power plants - this will not improve the national energy balance.

In sum, all the more important 'solutions' considered thus far to ameliorate the possible deficit in Central Norway, are intertwined with both national and regionallocal circumstances. The prospect of the most profiled RES-E option - the Havsul off-shore wind power project, is at the time of writing very uncertain. ${ }^{22}$

\section{Summary assessment}

Until very recently Norway has been unique in Europe with an electricity supply totally generated by hydropower. As shown in Table 3.2, however, this has gradually been changing due to increasing levels of overall El consumption. Imports and exports have been growing, and the share of domestic RES as a percentage of total electricity consumption has declined. Norway thus represents a very particular case where the peculiar exigencies of an RES-dominant energy system have reached the political-legal limits of 'old' RES. It is in confrontation with this challenge that we outlined at the start of the chapter five political options that could be pursued (Figure 4.1).

\footnotetext{
${ }^{21}$ Press release from the Ministry of Petroleum and Energy, 14 December 2006.

${ }^{22}$ For further details on Havsul: http://www.havsul.no/Index.asp?lang=Nor\&id=191.
} 
Although there is still approximately 29 TWh of unrealized large-scale hydro generation available, it has clearly been stated by successive political majorities that there will be no more large-scale installations. A potential for small-scale hydro clearly exists as one alternative path, and an interest in this resource is developing. This option fits well with the traditional structure of the Norwegian energy system and can be characterized as a reflection of path-dependencies rather than pathcreation. Nevertheless, as the number of such 'small' plants increases, there is also a growing concern with environmental impacts.

Wind power is the most obvious new renewable energy source in the near future. Wind power is, however, an object of increasing controversy at both national and local levels. In particular, there is increasing uncertainty as to the effect of the new feed-in tariff scheme to be introduced from 2008. It is thus uncertain whether the politically decided target for wind power (3 TWh by 2010) can be realized within the stipulated time frame. However, recent developments hint at an increasing interest both by political, research and industrial actors for a new national innovation programme for off-shore wind power. If this interest eventually leads to actual funding and coordinated implementation, Norway, with its extensive wind power potential and off-shore technology competence, could become an international RES-E technology champion in this area. If such a huge path-creation manoeuvre is to succeed, however, it requires substantial changes towards more integrated perspectives and priorities.

In this context the construction of gas-fired power plants constitutes a critical factor. Gas-fired plants will provide a shift in the dominant hydro-based energy system in Norway. Political differences on the domestic use of natural gas are present within both the current ('red-green') and former (centre-right) governing blocs. The extensive public funding of technologies for carbon capture and storage (CCS) represents a possible solution to this controversy, but it remains to be seen how this option plays itself out, both domestically and with respect to the European Union.

Aside from the crucial effect that a collapse of the CCS option would have on Norway's commitment to the Kyoto protocol, it is also clear that significant increases in gas-fired electricity consumption would undermine Norway's ability to hold the line at a 90 per cent share of RES-E share of total electricity consumption. At present the share of RES-E is in practice reduced by the purchase of fossil-fuel based electricity through Nord Pool (though methods of factoring in import-export effects are not yet in place). One can claim, therefore, that the prevailing technomarket structure of the Norwegian dominant energy system contributes to meet security of supply and industrial development - at the expense of both unrealized potentials for RES-E and increased CO2 emissions.

Given, however, the exceptional Norwegian situation with about 30 per cent of electricity used for space heating (MoPE 2006a: 36), the strategy of substituting electricity for space heating with other renewable energy sources has become a political priority. If this potential is realized successfully, it will clearly lead to an overall reduction in demand for electricity, and thus contribute to improving the 
RES share in the electricity balance. The national energy agency Enova SF gives high priority to this path, but it remains to be seen how successful it can be in actually limiting usage of the 'freed-up' $\mathrm{El}$ - particularly with respect to the price mechanics of the highly 'successful' liberalization of the Nordic electricity market.

The current political and legal framework for the implementation and further development of RES-E policy is also directly affected by traditional approaches to hydropower. Water resource management and the related legal framework represent a specialized and complex regulatory framework. This framework also reflects a long process of political conflict related to the balancing of energy and environmental interests. These regulations thus represent an institutionalization of the traditional political cleavage between those concerned with economic growth and those concerned with environmental protection. This can also explain the challenge of implementing new RES-E projects where the focus in Norway has mainly been on investment subsidies and production support. With the recent increases in the funding scheme managed by Enova, efforts to promote energy efficiency and renewable heating are particularly intensified. The framework thus far, however, does not seem to provide either the stability or regional flexibility for RES-E projects, as experiences from wind power indicate.

The deregulation of the electricity market has contributed to internationalize the market and related market policies in Norway. Issues of new electricity production, grid connection and price dynamics are highly interdependent within the Nord Pool context. Nord Pool transactions are increasingly being influenced by other countries through the ongoing integration of Nord Pool with other regional electricity markets in Europe. The system has also been strongly influenced by the greenhouse gas emission trading schemes, which has further complicated possible predictions of future electricity prices. This integration process is apparently also transforming the interests and perceptions of market actors away from a traditionally national to an internationalized arena. In this light it is also unclear whether the increasing surpluses provided by the Nord Pool transactions will contribute to fulfil the national target of the RES-E Directive.

\section{Conclusion}

The present analysis indicates clear uncertainty as to whether Norway's indicative target of 90 per cent RES-E by 2010 will be reached. With overall consumption of El rising, and the situation for 'normalized' production of RES-E from hydropower approaching a stable level, the probability of missing the target because of growing consumption - and uncertain production from 'new' RES - increases.

Since the 1990s, there has been a shift of influence from governmental regulation to an increasingly complex and less transparent international market arena as a powerful premise for future RES-E production and consumption. Nevertheless, national political decisions still constitute crucial framework conditions, as 
illustrated in Norway by a complex regulatory framework and relatively weak promotional funding schemes.

The newly adopted feed-in tariff scheme (to come on line as of 2008) has led to a growing uncertainty as to the realization of RES-E alternatives to hydropower in Norway. ${ }^{23}$ Simultaneously, the option of increasing El production from natural gas has been actively pursued by both the former and present governments. Norway's huge petroleum industry has through this strategy gained considerable new momentum, and this will hardly be weakened by the highly funded ongoing CCS initiatives.

In this context, it seems most likely that the major corrections for power deficits in Norway will be derived from fossil fuels rather than from new renewable energy sources, at least in the short term. Norway can, therefore, be considered an anomaly within the European context, since its challenge is to maintain existing maximal levels of RES-E in the face of increasing levels of both domestic and imported fossil-fuel electricity.

\footnotetext{
${ }^{23}$ However, policies in this area are constantly changing: In September 2007 the MoPE got a new minister when the leader of the Centre party, Ms. Åslaug Haga, took over this portfolio. She quite swiftly declared that she understood the frustration over the announced support level for RES-E, and signalled a possible revision.
} 
De- and re-coupling energy: Environmental Policy Integration (EPI) and the case of renewable electricity in Scandinavia

published before as:

Knudsen, Jørgen K. (2009): 'De- and re-coupling energy: Environmental Policy Integration (EPI) and the case of renewable electricity in Scandinavia', SINTEF Technical Report TR A6844, Trondheim: SINTEF Energiforskning AS. 

De-coupling economic drivers from ecological degradation is considered to be a crucial dimension of 'sustainable development' (SD), and 'environmental policy integration' (EPI) can be seen as a crucial decision-making principle for achieving de-coupling. EPI also implies institutional mechanisms for the integration of environmental concerns in sectoral policy formulation and implementation (Lenshow 2002a; Lafferty and Hovden 2003; Lafferty and Knudsen 2007; Jordan and Lenschow 2008b). An important sector in this respect is energy, not the least by the potential of renewable electricity (RES-E). In this context, the present article provides a comparative assessment of how initiatives for RES-E in Denmark, Norway and Sweden can be assessed according to recently developed EPI concepts and standards.

A high degree of EPI is often considered to depend on politically determined commitments and objectives of change in the medium to long term (Jordan and Lenschow 2008). At the same time, empirical studies indicate that the phase-in of new RES-E production to a large extent depends on stable, long-term and technology-differentiated incentives which can complement technology development and market mechanisms (Reiche and Bechberger 2004; Mallon 2006; Lafferty and Ruud 2008c). Studying RES-E initiatives within an EPI perspective stands out, therefore, as fruitful and relevant. Focusing on RES-E, the present article also aims to contribute to a more sector-specific understanding of EPI.

In addition the article aims to demonstrate the necessity of understanding the national and regional-local contexts for anchoring more effective RES-E implementation; that is the economic structures and interests, as well as the relevant institutional frameworks and conditions for public steering of energy and electricity policy in specific settings (c.f. Lafferty and Ruud 2008b). The present article will thus assess contextual factors as a background and conditioning agent for the realisation of EPI standards through the promotion of RES-E in Scandinavia. ${ }^{1}$

The three countries in question are usually portrayed as front-runners in pursuing environmentally benign energy policies. They are, however, differently endowed with renewable energy resources and have adopted different RES-E policies. At the same time, the three countries share a wider policy framework and drivers from the international level and have created a common electricity market with Finland (NordPool).

\footnotetext{
${ }^{1}$ The present chapter is substantially building on the author's participation in two recent research projects, as research scientist at the Program for Research and Documentation for a Sustainable Society (ProSus), the University of Oslo: 1) The EU-funded research project Environmental Policy Integration and Multi-Level Governance (EPIGOV). 2) A research project conducted by ProSus providing a comparative assessment of the implementation of the EU RES-E Directive (Dir 2001/77/EC) in eight European countries (Austria, Denmark, Finland, Ireland, Netherlands, Norway, Spain and Sweden) (Lafferty and Ruud 2008).
} 
All three are affected by EU energy and environmental policies; Denmark and Sweden as Member States, and Norway as partner in the European Economic Area (EEA). Furthermore, all countries have commitments under the Kyoto Protocol to greenhouse gas (GHG) reductions and the demands incurred by participation in the EU's emission trading scheme (ETS). Finally - and in the present case most importantly - all countries are committed by the EU Directive on renewable energies (RES), which is replacing the former Directive on RES-E and sets national targets for the total share of RES by $2020 .^{2}$ These directives constitute a particularly interesting case for EPI, since the fulfilment of all three of the related goals (climate change, security of supply and employment/economic development) resonates with EPI standards, and the objective of achieving de- and re-coupling. ${ }^{3}$

The national indicative targets provided for the three countries by the former RES-E directive have not, however, substantially affected national RES-E policies (Chen and Johnson 2008; Karnøe and Buchhhorn 2008; Knudsen et al. 2008). The new RES Directive, on the other hand, is expected to present more demanding requirements. Given the need for a transition period, the potential impact of the new directive will not be assessed in the present context.

The following section presents an outline of the analytical framework employed: This is then followed, in sections 3 and 4, by a comparative assessment of how RES-E initiatives in the three countries reflect the level and type of EPI standards in place. A discussion of contextual factors is then provided in section 5, with a general conclusion in section 6 .

Promoting RES-E in a perspective of sustainable development implies structural changes of traditional energy systems which have negative side-effects, such as resource depletion and ecological degradation (in the form of GHG emissions). A more sustainable energy system should be based on renewable sources, and provide less energy-intensive production and consumption patterns. The issue was given a highly substantial and profiled treatment in the processes following the publication of the Brundtland report in 1987 (WCED 1987, 14-15). The same report also pointed to the need of amending the political-administrative systems within which

${ }^{2}$ C.f. $\operatorname{COM}(2008) 19$ final: Proposal for a Directive of the European Parliament and of the Council on the promotion of the use of energy from renewable sources. Brussels: The European Commission.

${ }^{3}$ In the RES-E Directive's preamble this multiple purpose is phrased in the following manner: "The Community recognizes .... that their exploitation [of renewable energy sources] contributes to environmental protection and sustainable development. In addition this can also create local employment, have a positive impact on social cohesion, contribute to security of supply and make it possible to meet the Kyoto targets more quickly." (CEC 2001). 
sectoral policies - such as energy - are formulated and implemented (WCED 1987: 313). A core assumption is here that the integration of environmental concerns into the decision-making at the outset would provide policy decisions with a higher probability for contributing to such a transition.

This is a particular challenge for public governance, which has constituted the core focus in studies related to environmental policy integration (EPI). In addition to the more academically based research, there have also been a number of EPI-relevant studies from a more practical, political-administrative approach - particularly those conducted by the European Environment Agency (EEA) and the OECD over the last decade, particularly focusing strategies and governance mechanisms in industrialized societies (Lafferty and Meadowcroft 2000a; Lafferty 2004b; Jordan and Lenschow 2008b; EEA 2005a, 2005b; OECD 2001a, 2001b, 2002a). There has yet to emerge, however, a clear consensus as to what EPI implies (or should imply) for governing strategies for SD. This lack of clarity is related to the conceptual basis, the theoretical foundation and the analytical scope, and, most particularly, to the priority that should be accorded environmental concerns. Furthermore, there are few cross-national studies of EPI related to specific policy sectors (Sgobbi 2007). Hence, there is a definite need to clarify EPI further with insights from specific sectors in a comparative perspective. ${ }^{4}$

When applying EPI as a framework for the assessment of a given sector, two major analytical dimensions appear as relevant. The first is related to the strength or authority of EPI as a decision-making principle; and the second is related to the implementation of EPI across levels of governance. In the present study, the first dimension will be addressed within the context of national governance, while the second can be related to the national follow-up of the EU RES-E Directive, as well as to the further implementation of RES-E policies at regional and local levels. The first dimension will here constitute the major analytic focus. ${ }^{5}$

Addressing the issue of EPI as decision-making principle, and given the lack of a clear consensus as to what EPI implies in practice, it is important to refer to the debate on the fundamental criteria involved in an operationalization of 'EPI'. A crucial question here is the priority to be accorded environmental concerns. One position emphasises that the normative intent of EPI is to function as a 'first-orderprinciple' for resolving trade-offs between sectoral policy goals and environmental concerns by which one can achieve an actual de-coupling (Lafferty and Knudsen 2007). According to this approach, a high degree of EPI entails that environmental concerns are considered in an SD perspective, that is integrated as central premises

\footnotetext{
${ }^{4} \mathrm{An}$ important exception to this overall picture is provided by a recent comparative study of EPI in the agricultural and energy sectors in Sweden (Nilsson and Eckerberg 2007).

${ }^{5}$ The EPIGOV project, referred to under endnote 1 above, has addressed both dimensions with a clear emphasis on multi-level governance (MLG). The MLG dimension will not, however, be explicitly treated in the present article, but is substantially analysed in a recent comparative assessment of RES-E policies in the EU and the USA (Knudsen 2009b)
} 
and eventually reflected in the relevant sector's policy decisions (Lafferty and Hovden 2003: 12). This fundamental idea has clear roots in the Brundtland report (WCED 1987: 313).

The notion of EPI as a 'first-order-principle' may seem rigid. The authors purporting this view, however, point out that this does not imply that policy concerns other than the environment must invariably give way. The 'trump' status of the principle in specific cases will depend on the policy process in question (Lafferty and Knudsen 2007). Different categories of environmental concerns can, moreover, often be simultaneously affected by different policy decisions. In relation to RES-E both climate-change and biological diversity can, for example, constitute critical parameters. The outcome of an eventual trade-off between different sets of environmental concerns depends on the overall normative balance of the process applied, most specifically how social and economic concerns are taken into consideration. This will in turn depend on whether the decision-makers employ a medium- or long-term perspective, and, further, whether they perceive relevant changes within a local, national or global context (c.f. Lafferty and Langhelle 1999a: 7).

A major question addressed in the present context is, thus, the status of substantial EPI standards. As indicated above, this is to a large extent a question of de-coupling economic drivers from ecological degradation. Lafferty and Ruud (2006) point to the importance of addressing production and consumption in an integrated manner in order to achieve an actual de-coupling. More limited approaches focusing mainly on optimizing production processes often fail to take into account cumulative effects related to consumption dynamics, leading in the end to overall dysfunctions through, for example, so called “rebound effects” (Grepperud and Rasmussen 2004: 262). RES-E initiatives should, therefore, be considered within a coherent framework addressing parameters of both energy production and consumption.

Building further on the notion of de-coupling, 're-coupling' can be viewed as the process of defining and implementing new, more sustainable means of production and consumption; that is, processes of 'green innovation' (OECD 2001a; Lafferty and Ruud 2006: 455). Re-coupling also resonates with a crucial premise of the Brundtland report which states that continued economic growth is necessary, provided that the quality of growth changes (WCED 1987: 52). In this perspective, RES-E initiatives should be addressed within an overall governmental policy for innovation, with an emphasis on the principled priority for environmental concerns.

Acknowledging the 'first-order' nature of the EPI principle does not resolve, however, how it can best be applied by governments. Should EPI be seen as a mainly political-administrative framework for decision-making with a focus on rules and procedures? Or should one view EPI more in terms of specific policy 'outputs'; or even more substantially, in terms of actual policy 'outcomes' (c.f. Vedung 2004)? Different answers are provided to these questions (c.f. Persson 2007). In the present article, the main empirical references are RES-E relevant policy decisions (policy 
outputs); that is the priorities set and the instruments designed to achieve RES-E policy goals.

In order to assess the extent and degree to which RES-E initiatives in the three countries reflect EPI standards, it is also important to identify more specific steering mechanisms. In this regard, it is analytically fruitful to differentiate between two interactive EPI dimensions: the so-called 'horizontal' and 'vertical' dimensions of EPI (Lafferty 2004a: 204-205). A cross-sectoral, horizontal dimension is here related to a balanced trade-off among sectoral concerns within a specific level of governance (supra-national, national or sub-national); whereas a vertical dimension is related to the implementation of EPI within the different sectors (Lafferty and Hovden 2003: 12; Lafferty 2004a: 205-208).

Building on experiences with various mechanisms in OECD countries, different benchmarks have been developed to indicate operational approaches to EPI along these lines (Lafferty 2004a). Horizontal benchmarks for EPI thus include: a 'constitutional' mandate for endorsing EPI as a principle; an over-arching strategy with clearly enunciated goals and operational principles for pursuing SD. In addition a need to 'anchor' executive responsibilities and 'political will', and to bring into place a specific plan for administrative communication and coordination across sectoral domains (Lafferty 2004a: 206-208).

The vertical benchmarks include sector-specific strategies and action plans for the implementation of the overall strategy with stipulated priorities, targets and designated responsibilities. In addition, budgetary provisions and financial priorities, and a forum for structured dialogue with stakeholders and citizens constitute crucial mechanisms (Lafferty 2004a: 205-206).

It is also important to stress, however, that the coordination and overall integration of horizontal and vertical mechanisms is crucial. The lack of an over-arching SD strategy based on a clear political-institutional mandate often leads to a withering of responsibility (Lafferty and Meadowcroft 2000a; Lafferty 2004b). In this perspective, RES-E initiatives can particularly reflect and support EPI by the existence, for example, of RES-E-relevant programmes and the eventual linkage between such plans and a national strategic framework for SD. An incentive for a stronger promotion of RES-E can also be provided by a more active coordination with other relevant policy sectors, such as environmental, industrial, innovation and regional policies. Such linkages can also represent a potential for re-coupling.

In principle, an effective implementation of EPI standards entails politicaladministrative coordination directly anchored in 'political will' from above. 'Ad hoc' approaches without such anchoring are clearly more fragile in the daily workings and recurring competition among more traditional sectoral interests (Lafferty 2004a: 206). In a more long-term perspective, however, it is also possible that 'policy learning' can lead to some measure of sector-based EPI initiatives (Nilsson and Eckerberg 2007). Furthermore, it is also possible that robust RES-E 
initiatives, as well as related follow-up processes, can in themselves lead to a stronger and more substantial implementation of EPI standards as well.

Political leadership and an enduring, committed mandate to pursue overarching SDrelated goals over time are, therefore, crucial factors for the formulation and management of EPI standards (Lafferty and Meadowcroft 2000a; Lafferty 2004b; Jordan and Lenschow 2008a). To a large extent the same qualities apply to the follow-up of RES-E policy initiatives as well (Mallon 2006; Lafferty and Ruud 2008a). The actual playing out of political leadership and a mandate will, however, also depend on the existing framework and capacity for public steering over the sector, as well as the nature of the economic structures and interests that shape and channel political will.

Applying these perspectives, the following two sections provide an initial comparative assessment of RES-E promotion in Scandinavia, viewed as a specific instance of EPI standards for energy production and usage. Following this, section five addresses contextual factors that can shed light on the different ways in which EPI standards are reflected by the three countries’ promotion of RES-E.

\section{RES-E and EPI standards in Scandinavia}

The present section will outline the main RES-E structures of the three countries, the related policy strategies and tactics, and thereby assess RES-E as a specific instance of EPI standards for energy production and usage.

\subsubsection{Denmark}

Denmark is the Scandinavian country most reliant on fossil sources for electricity production, but also the country with the smallest proportion of electricity consumption. The country is provided with an extensive infrastructure for district heating and a substantially lower proportion of energy-intensive industry compared to the two other countries. Denmark's total energy intensity is actually the lowest of the EU countries (IEA 2006a). Denmark's commitment under the Kyoto Protocol is a 21 percent reduction by 2008-12, which is particularly challenging because of the transport sector. For RES-E, on the other hand, there has been a marked increase from virtually zero in the mid-1970's to 20 percent of total electricity consumption in 2005. Denmark's production of wind power (18 percent of total electricity usage in 2005) is the world's highest per capita.

Having been strongly affected by the oil shocks of the 1970's, Denmark adopted in 1976 a national energy plan aimed at a more diversified and domestically produced energy supply, with RES-E as a high-profile priority. This plan initiated a strategic policy approach which still constitutes the procedural basis for Danish energy policy formulation and implementation. As follow-up mechanisms for the energy plans, Denmark introduced comparatively early a broad range of technology-differentiated 
RES-E incentives - such as guaranteed prices and investment subsidies, including an active promotion of research and innovation (Karnøe and Buchhorn 2008, 86).

In 1990 the Danish parliament adopted, prior to the final outcome of the negotiations on the Kyoto Protocol, an objective of reducing Danish CO2-emissions by 20 percent by 2005. The target determined the major direction of the energy plan adopted the same year (DEA 2000), and from this point onwards Danish energy policies have been intimately connected with the climate-change policy.

As an ongoing premise for the continued existence and strength of the national energy plan, there has been considerable 'push' and support from below. Denmark represents in this regard an interesting case where innovative actors from civil society, science and industry have interacted with national political visions and topdown, regulatory approaches (Garud and Karnøe 2003; Karnøe and Buchhorn 2008). In particular, the combination of local ownership and nationally set incentives has ensured stable popular support for wind power (Hvelpelund 2005: 88).

Furthermore, since 1976 there have been innovative provisions for the siting of RES-E installations, including the allocation of area-specific rights for wind power production. The Danish Planning Act establishes national guidelines designating specific sites for wind-power turbines. At the same time there have been successive reforms of planning and licensing regulations which focus on reducing administrative barriers and delegating decisions towards regional and local levels.

The bottom-up nature of the Danish RES-E initiatives has stimulated processes of dynamic learning-by-doing among multiple actors, as well as interactive conceptions of R\&D. These processes have been systematically funnelled towards scaling-up technologies and thereby created an innovative industrial sector which currently constitutes the backbone of the Danish economy (Garud and Karnøe 2003). These processes also succinctly illustrate the re-coupling potential of the Danish RES-E policies.

In 2007, Denmark's centre-right government adopted a new objective of doubling the renewable share of primary energy use from 15 to 30 percent by 2025, with total energy use to remain at its present level (Ministry of Transport and Energy 2005). Hence, Denmark still operates within a strategic framework coordinating energy and climate-change polices. Furthermore, this framework has been reinforced by a periodically integrated political-administrative mandate - particularly between 1994 and 2001 when there was an integrated Ministry for Environment and Energy. In 2007 a Ministry of Climate and Energy was established.

The Danish profile displays, however, weaker linkages with cross-sectoral strategies for sustainable development. Between 1993 and 2002, however, there was a system of strategic environmental planning with environmental policy status reports, encompassing the energy plans (Dalal-Clayton 1996). Whereas this framework did not entail any further requirements with respect to RES-E, it can be considered as an 
over-arching EPI tool in the Danish context. The current SD action plan is intended to represent an equivalent framework (Danish EPA 2002), but lacks mechanisms for ensuring coherence between overall objectives, sectoral implementation and evaluation.

In sum, therefore, Denmark's integration of RES-E with climate-change mitigation can be seen as a reflection of a vertical, sector-specific approach to EPI. Moreover, the promotion of RES-E is coordinated with measures for a net phase-out of fossil energy production and usage - thereby reflecting a substantial degree of decoupling. In addition Denmark's strong innovative RES-E tradition induces recoupling processes. In particular, the successful implementation of wind power also seems to have stimulated a consolidation and continuous development of this framework and thereby contributed to reinforce EPI standards.

The Norwegian energy profile has traditionally been dominated by hydropower, and more recently by oil and gas. Hydropower provides (in an 'average year') more than 90 percent of the country's total electricity consumption. As of 2008 less than 1 percent was generated by wind power, and an even smaller proportion by biomass. The RES-E profile is further characterized by a high degree of electricity-based heating, and an industrial sector (aluminium and light metals) that uses nearly one third of the country's electricity production. Increasing electricity consumption, power exchanges within the 'Nord Pool' market, and a limited amount of 'new' RES-E production, have all led to increasing shares of imported non-renewable electricity, thereby challenging Norway's advantageous 'green’ position. Moreover, the Parliament has decided that, in principle, construction of new large-scale hydropower is no longer an option (Knudsen et al. 2008).

As for sustainable development, Norway adopted (under Prime Minister Brundtland in 1989) a comprehensive programme, based on the major issues of the Brundtland report, and was in the early 1990's generally considered to be an international frontrunner in trying to implement EPI, principally through linkages with the state budget (Lafferty et al. 2008). Norway's current SD strategy - which is managed by the Ministry of Finance - is only generally indicative for the sectoral ministries (as part of the national budget), with a very low political profile and no significant monitoring procedures (Lafferty et al. 2007).

Whereas Norway is often commended for integrating its SD efforts within the state budget, there is (in contrast to Denmark) no policy-planning framework for the energy sector as a whole. While there is a planning system for the assessment and classification of the country's hydropower resources which includes the designation of protected areas, no such procedures have thus far been developed for other renewables. In particular, wind-power projects suffer in Norway from complex and time-consuming licensing processes (Knudsen et al. 2008: 266). 
On the other hand, however, Norwegian climate policy has, for more than a decade, focused on RES-E as a key contributor to GHG emission reductions. A separate Energy Fund under the auspices of a new public enterprise, Enova, was established in 2001 to provide grants for RES-E projects, and to promote renewable heating and energy efficiency (Knudsen et al. 2008, 259-61). This is the main instrument for reaching Norway's targets of at least 3 TWh per year wind power production by 2010, in addition to 4 TWh from renewable heating. These targets have been extended to 2016, at which time there should have been realised a total energy switch of 30 TWh. The most recent climate-change policy strategy focuses even more strongly on contributions from the different policy sectors than previous strategies. But this has thus far not led to any substantial policy shifts. In 2006, after prolonged negotiations, a proposed common Swedish-Norwegian certificate scheme for RES-E was dropped by the Government. The idea has been revived, however. ${ }^{6}$

An additional important dimension in understanding the position of non-hydro RES$\mathrm{E}$ in Norway is the economic dominance of the petroleum sector. Norway is among the world's largest petroleum exporters, and Europe's (second) largest natural gas supplier. The Norwegian Kyoto commitment to limit GHG emissions to a maximum of one per cent above the 1990 level is challenging to achieve, mainly due to the petroleum and transport sectors.

The petroleum sector ensures generous revenues for the Norwegian welfare-state system. Under the current SD Strategy increased levels of welfare are described as both a major achievement and a continuous objective of future policies, and in the political debate few critical questions have been raised about the dominant position of the sector (Lafferty et al. 2007: 186). The sector's dominance is also reflected in innovation-related policies, where substantially higher amounts of public funding are provided for the development of technologies for carbon capture and storage (CCS) compared to RES-E (Mosvold Larsen 2005; Klitkou et al. 2008).

There are, however, current indications of shifting policy priorities. In 2007, a pilot project for off-shore wind power was granted public financial support, and from 2009 a research and development programme for off-shore wind power is in place. Furthermore, in 2009 several research centres for RES have been established with support from the Norwegian Research Council, including two centres for off-shore wind power. The prospect of using Norwegian RES - principally hydro and offshore wind - as substantial suppliers for the European market, can be considered as a potential for de- and re-coupling in a European perspective. This is, at least implicitly, addressed by the Norwegian energy industry and related research and innovation agents.

\footnotetext{
${ }^{6}$ There are ongoing (as to the spring of 2009) negotiations. The outcome will also depend on the compatibility with the countries' commitments under the EU RES Directive.
} 
Nevertheless, despite recent increases in public financial allocations and industrial interest for RES-E, Norway still lacks a strategic framework and adequate support mechanisms for more effective implementation and phase-in of non-hydro RES-E. Secondly, there is no coherent framework for making trade-off's related to an actual de-coupling of the energy sector. In sum, therefore, Norwegian RES-E initiatives demonstrate, thus far, a very limited reflection of EPI standards.

\subsubsection{Sweden}

Electricity accounts for one-third of Sweden's energy end-use, which is more than Denmark but less than Norway. Hydropower and nuclear power account for roughly equal shares of Sweden's current electricity consumption, together making up some 90 percent. Bioenergy is the most substantial renewable source after hydropower largely through combined heat and power generation (CHP), whereas wind power accounts for about 1 percent (2007), although currently increasing its share (Chen and Johnson 2008: 221-224). Sweden adopted an ambitious GHG objective in 2002, aiming to reduce the country's total emissions by 4 percent in 2008-2012 compared to the 1990 level, thereby over-fulfilling its Kyoto commitment (4 percent increase).

Based on a referendum from 1980, a phase-out of nuclear power by 2010 has been an overall objective for Swedish energy policy. In addition, there has been a policy objective to reduce the oil-dependence of the economy, providing a reduction from approximately 70 percent imports in 1973-4 to just over 30 percent at current levels (Chen and Johnson 2008). The former social-democratic government even proposed a programme for a 100 percent petroleum-free economy by 2020.

Currently, important policy shifts are undertaken by the current centre-right governing coalition. The goal of a petroleum-free economy has thus far not been followed up, and the goal of phasing out nuclear power generation has apparently been abandoned (Regeringskansliet 2009). Nevertheless, in sum, the structural challenges associated with these traditional goals have together substantially influenced Sweden's increasingly progressive RES-E policies over the last decade (Chen and Johnson 2008).

In addition, Sweden is traditionally praised for having one of the world's most ambitious SD polices. An explicit cross-sectoral strategy for SD has only been in place since 2002, but an overall idea of moving Sweden towards a 'green welfare state' was introduced in the 1990's (Lundqvist 2004). As the country was facing a solid economic downturn, a reinforced focus on SD appeared as a political priority with EPI as a key instrument (Lundqvist 2000). The vision of a 'green welfare state' invoked all three dimensions of SD, albeit with a specific priority for the environment (Lundqvist 2001).

Whereas the current SD strategy itself has been viewed as politically insignificant (Nilsson and Persson 2008: 233), the strategic SD framework initiated in the mid1990's can nonetheless be seen as politically strong, actively promoted by the Prime Minister's Office of the previous Labour Government (Lundqvist 2004: 77-78). 
RES-E initiatives were a crucial part, albeit gradually integrated into the more specific climate-change policy framework (Nilsson and Eckerberg 2007: 138). RES$\mathrm{E}$ policies are, moreover, focused by the regular evaluations and revisions of the climate-change mitigation strategies, the last one being undertaken in 2008 (SOU 2008).

It must also be stressed that the system of National Environmental Quality Objectives, NEQO (adopted in 1999), has a specific focus on the de-coupling of sectoral activities, and is considered to be Sweden's most prominent EPI mechanism (Nilsson and Persson 2008: 233). The system includes monitoring and comprehensive evaluation reports on the different sectors, particularly energy (Lundqvist 2004b; Knudsen 2008). The NEQO system and the climate-change policy evaluations thus provide Sweden with an explicit and substantial perspective on de-coupling through RES-E initiatives (Knudsen 2008).

Partly in response to the EU RES-E Directive, a wide variety of support schemes were consolidated into a tradable certificate scheme (TGC) in 2003, with an expanded target of contributing an additional 17 TWh RES-E by 2016 (compared to the 2002 level). The TGC scheme obliges electricity consumers to purchase a stipulated share of RES-E, thereby contributing directly to the funding of RES-E production. The TGC scheme proved to be particularly favourable for biomass, while the picture for wind power was more mixed. Consequently, specific financial measures have been introduced to promote the innovative development of wind power, particularly different off-shore concepts. In addition to various innovative developments in the bioenergy industry, this constitutes an important contribution to re-coupling through RES-E in a Swedish context.

As far as the administrative framework is concerned, adjustments have also been made in the licensing procedures, with increased delegation of authority to the regional and local levels. This also reflects an important dimension in Sweden's overall SD framework, with its emphasis on regional and local projects (Lundqvist 2004b). In particular, since 1998 investment programmes aimed at the local level have contributed to the conversion of petroleum-based district heating to combined heat and power production based on biomass (Aakre and Torvanger 2007: 29).

The regional-local focus has, however, been solidly anchored within a nationally set policy framework, representing a predominantly top-down approach (Lundqvist 2001; Nilsson 2005). So-called 'national interest areas' for wind power have been identified by national authorities (in close cooperation with regional authorities and stakeholders) as a pre-selection process for wind-power sites (Ministry for Sustainable Development 2005). The actual siting and construction of such facilities has, however, still resulted in several central-local conflicts (Söderholm et al. 2007; Ruud et al. 2009).

In sum, Sweden's integration of RES-E within an overall SD strategic orientation reflects a horizontal, sector-encompassing EPI approach. RES-E is increasingly related to climate-change mitigation, but RES-E initiatives are at the same time 
relatively well integrated with other parts of the energy policy. The promotion of RES-E thus involves a potential for an actual de-coupling of the energy sector as a whole.

As indicated by the previous section, RES-E initiatives can reflect EPI standards in different ways, and the three Scandinavian countries demonstrate how their different promotion of RES-E provides different potentials for de- and re-coupling. This is particularly reflected by the level and type of integration with other policy efforts aiming at the change of energy production and usage.

In this regard, Denmark and Sweden have established more coherent, strategic frameworks than Norway, including more clearly enunciated targets and follow-up mechanisms. Danish RES-E initiatives have also been actively linked to policy measures for innovation and industrial development, thereby implying a stronger recoupling potential than the other two countries.

When considering the connection between the strategic level and operational modes, the Danish and Swedish RES-E initiatives have to a larger extent been related to differentiated measures and incentives than the Norwegian ones. Strong policy coherence and robust commitments also represent important signals to investors, producers and consumers of RES-E. The more integrated Danish and Swedish planning frameworks have thus resulted in larger shares of new RES-E production. Norway's lack of a similar framework can be seen as a key reason why the country has encountered stronger operational barriers, resulting in only modest development of new RES-E.

Another important aspect of the more coherent approach to RES-E in Denmark and Sweden is the possibility of identifying dilemmas and trade-offs between different concerns. Sweden disposes of the trade-off mechanism most explicitly linked to SD. Within the Swedish NEQO system, RES-E is assessed in a cross-sectoral perspective, with an emphasis on basic resource use. Moreover, this also includes running evaluations of specific policy instruments and their implementation. Although the learning potential of these mechanisms is substantial, there remain, of course, questions as to the extent to which the NEQO assessments actually contribute to different policy outcomes according to the established goals (Lundqvist 2004b: 142-143; Knudsen 2008).

In sum, the three countries clearly illustrate different ways by which a strategic and promotional framework for RES-E can promote EPI standards. Denmark and Sweden - though differing on their choice of governing mechanisms and policy instruments - are clearly more advanced with respect to RES-E/EPI than Norway. 
Following up such an assessment, the next question we can pose relates to the role of contextual factors. To what degree do such factors shed light on the differing achievements vis-à-vis EPI as illustrated by the three countries' promotion of RESE? As outlined earlier, three main categories of factors are considered to be of importance: Political will in the form of long-term commitments; the operational framework in place for public steering over the sector; and the key economic structures and interests that shape and channel political will.

In Denmark, broad parliamentary agreements have been related to the follow-up of the energy policy plans. Building on an increasingly coherent and environmentally oriented energy-planning process, there occurred a vital shift in 1994 when the political responsibility for energy and environment was merged under the ministerial responsibility of the Social-democratic leader, Svend Auken. Known as a strong exponent of a more sector-encompassing and ambitious environmental policy, Mr. Auken was a key architect of the alliance between the governing Social-Democrats, and the Radical Left Party and Socialist People's Party in Parliament. The three parties together actively opposed the environmental policies of the previous centreright governments, emphasising the need of a stronger RES-E promotion (Andersen et al. 1998).

A substantial policy shift occurred, however, in 2002 when the centre-right government significantly reduced the traditional fixed-price support schemes. The support mechanisms were, however, re-adjusted upwards in 2004, after considerable pressure from, among others, the important national wind power industry (Karnøe and Buchhorn 2008:78).

In Sweden the Social-Democratic Government's programme for ecological modernisation, with a strong focus on RES-E, was supported by the Centre Party and the Green Party in the Parliament (Lundqvist 2004b). A need for 'sustainable livelihoods' and 'alternative economic growth' were important reasons behind the RES-E policy plans from the 1990's onwards, but this rationale has been somewhat modified by the current centre-right governing coalition. In Norway, although there have been broad political coalitions supporting certain crucial overall principles such as the 'moratorium' on further large-scale hydropower development - there have been no substantial agreements with respect to initiatives for 'new' RES-E.

With respect to Denmark and Sweden, though both countries show relatively high levels of political commitment, they also manifest contextual differences as to how these commitments are influencing and being influenced by the existing institutional framework and structure of the energy sector. Although the Danish energy plans have provided important guidelines for the transition towards a more sustainable energy system, the substantive outcome in Denmark is to a large degree a historical product of the interaction with bottom-up processes and NGOs (Hvelpelund 2005). In Sweden, on the other hand, there has been a decidedly stronger top-down approach. 
Nilsson (2006: 226) points here to two core dimensions of the Swedish governing tradition that seem to stimulate EPI in general: a 'seminar culture' under bureaucratic guidance, and a well-established system of corporatist-pluralist representation. This is reflected by the fact that most of the energy policy reforms in Sweden have been preceded by broad commissions and committees scoping different policy options, with active representation from different experts and stakeholders (Nilsson 2006; Nilsson et al. 2007b).

In Denmark we find very different cultural-administrative traditions. Here the historical ownership and management structure of energy production, with local cooperatives as core entities, both induces and facilitates a centrally coordinated policy-planning approach that at the same time achieves high legitimacy through decentralised participation. This has been manifested through the achievement of grid access for smaller RES-E producers, as well as through open dialogue and important 'bottom-up' inputs to the national energy plans. These specific historically anchored structures provide one reason for why Denmark was the last Nordic country to deregulate its electricity sector. The Danish deregulation was, moreover, designed - at least partly - to safeguard the historical structures of the sector (Pedersen \& Rieper 2008: 287).

More generally, deregulation also seems to be contextually dependent in its effects. For Norway it has been maintained that that deregulation has weakened the basis for more coherent and politically defined RES-E strategies (c.f. Thue 1996). In contrast, however, Sweden has established broader promotional programmes for RES-E within a deregulated policy regime. Although market-based thinking is strongly reflected in Sweden's scheme for tradable green certificates, it has also been necessary to introduce a substantial non-market policy framework for the stimulation of off-shore wind power and local siting of on-shore wind turbines.

A general lack of a comparable structural challenge to the supply of energy in Norway (like that experienced by Denmark and Sweden), provides a key reason why Norwegian politicians have been more recalcitrant to prioritise new RES-E production. Norway does have, however, a vital energy-intensive industrial sector on shore which provides vital employment in the less populous regions of Norway. The Norwegian State has historically provided this sector with long-term contracts for low-cost electricity. These contracts are now beginning to expire, and are no longer seen as viable, specifically with reference to the EEA Agreement (Knudsen et al. 2008, 253). In this context, one observes an increasing industrial interest for developing wind power as a supplement to hydropower in the outlying districts.

Energy-intensive industries continue to play an important role in Sweden as well, largely related to wood processing. This industry, however, has had the advantage of contributing to an overall conversion from oil to biomass in connection with the conversion to renewable generation of the extensive infrastructure for district heating (Midttun and Koefoed 2005). 
In Denmark, as indicated above, there is no significant energy-intensive industrial structure. Synergies with traditional industries (mechanical and agricultural industries) were crucial, however, in the establishment of new industrial activities related to wind power and bioenergy (Garud and Karnøe 2003; Buen 2005). The Danish experience demonstrates the importance of the specific nature of the domestic industrial basis and its interaction with a politically formulated, but dynamic and stakeholder-focused framework.

5.6

Danish and Swedish RES-E initiatives reflect EPI standards more substantially than is the case for Norway. This is primarily due to the anchoring of RES-E initiatives within more consistent policy frameworks addressing energy production and usage, with de-coupling as a core perspective. Furthermore, Danish RES-E initiatives also imply a stronger and more innovative re-coupling potential than the other two countries.

As far as more general EPI mechanisms are concerned, Denmark and Sweden also illustrate how EPI can constitute a framework with the potential of facilitating the promotion of RES-E. This is demonstrated by the more consistent procedural and institutional linkages between the strategic level and related follow-up mechanisms in the two countries, however in different ways. The Danish approach is more sector-specific and includes a stronger interaction with stakeholders in bottom-up processes; whereas the Swedish approach is characterised by a more sectorencompassing strategy, within a relatively centralized bureaucratic framework.

A particularly interesting feature to emerge from the present analysis is the manner by which a successful implementation of wind power in Denmark has both stimulated and legitimized further development of a more integrated politicalstrategic framework for energy and climate. Good policy performance 'on the ground' has, in other words, contributed to a general reinforcement of EPI standards throughout the energy system.

In sum, contextual differences among the Scandinavian states have provided different bases for the promotion and integration of RES-E into existing energy systems. The different energy 'paths', and the outcomes they have conditioned, confirm the need to contextualise 'universal models' for reinforcing the de- and recoupling potentials of RES-E initiatives. On a more general level, however, the cases also demonstrate that high levels of EPI achievement depend on solidly anchored and enduring political commitments. 
De- and re-coupling energy: EPI and the case of renewable electricity in Scandinavia 


\section{Integration of environmental concerns} in a trans-Atlantic perspective:

The case of renewable electricity

published before as:

Knudsen, Jørgen K. (2009): 'Integration of environmental concerns in a trans-Atlantic perspective: The case of renewable electricity', SINTEF Technical Report TR A6843, Trondheim: SINTEF Energiforskning AS. 

Nearly a decade after the U.S. rejection of the Kyoto Protocol, there are now expectations of a shift in American policies due to the 2008 presidential election. Several efforts with relevance for climate-change mitigation have been initiated at the state level, including the promotion of renewable electricity (RES-E) through socalled 'Renewable Portfolio Standards' (RPS), and it is expected that these initiatives can form the basis for a new national climate policy under the Obama presidency. In the EU, during the same decade, energy has come to be seen as a key sector for promoting sustainable development (SD), and there is now a common EU policy framework for climate-change and renewable energy, including RES-E (adopted in 2008). In contrast to the USA, climate-change mitigation has thus become a major concern for energy policy in the EU, gradually attaining equal balance with more traditional concerns of security of supply and competitiveness.

The broader challenge of integrating SD concerns into sectoral policies has been particularly treated in relation to the concept of 'Environmental Policy Integration' (EPI). Whereas the SD and EPI discourses have been given substantial treatment by the EU and several of its Member States, the USA has been much more reticent in both areas (Bomberg 2009; Hornbeek 2008).

An emerging tendency to approach energy and climate-change issues in tandem at the U.S. state level raises, however, a question as to what implications can be drawn for further policy integration, as well as to the impacts on future national policies. It is thus fruitful at this stage to assess the status and implications of linking energy and climate policy initiatives in U.S. state governance compared to the EU. The bottom-up character of RES-E promotion and climate-change mitigation in the USA represents an alternative path to the EU where the 'federal' level plays a more active role through strategies and regulations that increasingly bind the national level. ${ }^{1}$ The article thus addresses the fundamental question of the impact of multi-level governance structures on EU and American energy-policy profiles.

Different sub-regions stand out in the U.S. with respect to energy-policy innovation. The North-Eastern states and California are front-runners and role models for other U.S. states. The North-Eastern states, including the six 'New England' states (Connecticut, Maine, Massachusetts, New Hampshire, Rhode Island and Vermont)

\footnotetext{
${ }^{1}$ It should be emphasized, however, that the EU and USA can be considered as different federal systems. The USA has been characterized as a 'federal nation-state', whereas the EU has been labelled a 'multi-dimensional, quasi-federal polity with supranational governance' (Martinelli 2007a: 95). In both cases, however, institutions of self-government and shared government are combined, although in different ways and on the basis of different organizing principles of territorial democracy (Elazar 2001). Given these differences, one could distinguish between 'federated states' in the USA, and 'member-states' in the EU (Fabbrini 2007). In order to simplify, however, I will in the present article employ the common terms of 'state' and 'state level', as well as the 'federal level', for both polities.
} 
Integration of environmental concerns in a trans-Atlantic perspective:

The case of renewable electricity

can be viewed, moreover, as pioneers in terms of inter-state cooperation as manifested by the Regional Greenhouse Gas Initiative (RGGI). And in the EU, the four Nordic countries, Denmark, Finland, Norway and Sweden have been in the forefront in formulating RES-E and climate-change policies. A comparison of RESE policies in the six New England states with similar policies in the four Nordic countries thus presents itself as a fruitful and adequate empirical assessment (c.f. Peterson and Rose 2006: 628).

The chapter opens in section 2 with an outline of the main concepts and the analytical framework employed. Section 3 provides a brief assessment of the EUNordic case, whereas section 4 assesses the six U.S. states. Section 5 provides a comparative analysis of the USA and the EU focusing the importance of different multi-level governance structures, before the concluding remarks in section 6 .

\section{Analytical dimensions: EPI and multi-level governance}

22 years after Our Common Future, the report's emphasis of integrating sustainable development (SD) into mandates of (inter alia) all governmental agencies, thereby making governments responsible and accountable for $\mathrm{SD}$, is still a relevant and recurrent topic within both academic and political discourses (WCED 1987: 312; Lafferty 2004b; Jordan and Lenschow 2008b). The political-institutional challenge pointed out by the WCED has been specifically treated in relation to the concept of 'Environmental Policy Integration' (EPI) (Lafferty and Hovden 2003; Lafferty and Knudsen 2007), with EU countries profiled as the most pertinent empirical cases. When assessing EPI in an EU context, one tends to equate the idea with specific institutional mechanisms or EPI instruments (EEA 2005a; Jordan and Lenschow 2008b). In order to analyze EPI in an American case, however, where fewer such mechanisms are in place, it is important to identify the general principles of the concept.

Despite the many years that have passed since the Brundtland report, there has yet to emerge a clear consensus as to what EPI implies for governing strategies for SD. An important debate relates to the fundamental criteria involved in an operationalization of 'EPI', and whether and how one can empirically identify and measure different levels of EPI. An important contribution in this regard is provided by Lafferty and Hovden (2003). They define 'EPI' as implying:

'... the incorporation of environmental objectives into all stages of policymaking in nongovernmental policy sectors, with a specific recognition of this goal as guiding principle for the planning and execution of policy' (ibid: 9).

The application of this 'guiding principle' should furthermore

'.. be accompanied by: an attempt to aggregate presumed environmental consequences into an overall evaluation of policy, and a commitment to minimize contradictions 
between environmental and sectoral policies by giving priority to the former over the latter.' (ibid: 12).

This definition has been portrayed as 'normative' in comparison to other contributions (Jordan and Lenschow 2008c), which tend to stress 'balance' and 'coherence' without resolving the issue of 'trade-offs'. What is seen as crucial here, however, is the emphasis on EPI as a decisive instrument for SD, and that 'the environmental dimension' is considered as a limiting condition for the pursuit of both economic and social objectives (Lafferty and Knudsen 2007).

In short, a high degree of EPI entails that environmental concerns are directly integrated as central premises and substantially reflected in the relevant sector's policy decisions.

Related to energy production and usage, emissions to the atmosphere in the form of greenhouse gases represent the single most important environmental challenge. An evaluation of the actual sectoral policy performance in terms of reduced levels of emissions would thus imply a thorough analysis of the consequences of different policy decisions and concrete projects. Given the immense scope of this task, the approach chosen here is to assess the relative priority of environmental concerns vis-à-vis alternative energy as expressed through the promotion of RES-E in the form of policy programs and relevant regulations. The assessment of different modes of integrating environmental concerns will be examined in relation to the importance of different multi-level governance (MLG) structures. Here it is important to look at both the processes and institutions for integrating environmental concerns within and across levels, at well as the barriers against such integration.

In general terms, multi-level governance is a relatively extensively employed, but strongly debated concept, with numerous contributions as to different patterns of interaction and causal mechanisms (Pierre and Peters 2005). Furthermore, the recent literature on multi-level governance has been highly focused on the EU and the transition to a less state-centered, more complex polity. Pierre and Peters (2005) criticize this 'EU-centricity' and highlight U.S.-based research on federal-state relations which places greater emphasis on legal and political aspects.

It has been generally recognized that multi-level governance is a major challenge for EPI, but beyond such recognition there are few empirical studies (EEA 2005a: 46; von Homeyer 2006), though some recent studies do attempt to explore EPI within specific federal-state contexts (see Hornbeek 2008; Jordan et al. 2008; Wurzel $2008)^{2}$. Other contributions have emphasized the need for increasing the overall institutional and administrative capacity for coordination, both across levels and

${ }^{2}$ MLG dynamics in relation to EPI are, however, a central problematic within a recently finalized EU-funded research project - Environmental Policy Integration and Multi-Level Governance (EPIGOV). The author of the present article has participated in the project through the ProSus research program at the University of Oslo (regular partner to the project). 
Integration of environmental concerns in a trans-Atlantic perspective:

The case of renewable electricity

within national and EU-level administrations, in order to fully accommodate EU ambitions for different policy areas (Schout and Jordan 2005; 2007).

In this light, a number of background variables related to different structural, political and institutional conditions constitute possible explanations for relevant differences in MLG dynamics and EPI potentials in the EU and the USA.

An important basic distinction in this regard, is the role of the federal level vis-à-vis the state level. Whereas the distribution of powers between these levels is relatively settled by the U.S. Constitution, this is much less so in the EU, where the more open notion of subsidiarity is an important (but still diffuse) governing concept. This notion involves a more functional (less legalistic) principle for determining how goals transcending the nation state in Europe should best be pursued, by whom and at what level of governance (Bomberg 2004: 81). A major aim of the principle is to balance the goals of achieving effectiveness and maintaining closeness to the citizens. The underlying tension of the principle is clearly visible in matters pertaining to EPI, and can be clearly illustrated by the energy-policy sector (Collier 2002). U.S. federalism, on the other hand, implies a firmer horizontal (between the branches of government) and vertical (federal-state) separation of powers. The federal center and its powers are clearly more carefully defined and circumscribed in the U.S. than in the EU (Martinelli 2007a: 96).

Furthermore, the role of the public sector in the economy has been seen as one of the main features that distinguishes 'U.S.-style capitalism' from the European variant, particularly in terms of levels of taxation and public-sector involvement (Chiesi 2007: 44). In addition, there are also important differences as to how economic interests are mediated and represented within the polity, not least with respect to environmental protagonists. The U.S. system is often characterized as more 'pluralistic', while European countries are seen as more 'corporatist'. There are, however, variations in this regard within the EU itself (Martinelli 2007b). Whereas relatively strong ties between labor organizations, industrial federations and political authorities characterize the traditional mode of governance in the Nordic countries (Pallesen 2006), the EU-level and its institutions are more often featured as a pluralistic polity, resembling that of the USA, with a large number of interests competing in order to get access in a complex decision-making system (Martinelli 2007a: 130).

Taken together these background variables imply different potentials for EPIrelevant policy intervention from the federal level. In general, the EU employs a broader portfolio of approaches and instruments - reflecting the European tradition of a more active public steering of the economy, and less settled legalistic principles for top-down governance.

Different perspectives on the distribution of power, as well as the goals and modes for conducting interaction and exchange between levels of governance can, furthermore, be discerned in the MLG literature. In a directly relevant contribution 
Knill and Lenschow (2005b) identify, for example, three ideal-type modes of governance affecting EU-national environmental policies. The prescriptive mode is based on the compliance of national implementers with legally binding EU rules; the communicative mode is associated with information exchange between national and EU-level regulatory agents in a legal or institutional framework; and the competitive mode is understood as competition between national administrative systems to achieve EU requirements (Knill and Lenschow 2005b).

Building on these perspectives, the relative importance of the federal level vis-à-vis the state level will here be analyzed according to three analytical approaches: One emphasizing rule-driven processes (implying a higher degree of top-down steering); a second focusing processes of learning, communication and the transfer of ideas (going both ways); and, lastly, an approach on interest-based processes implying a higher degree of bottom-up initiatives. Somewhat in contrast to the last ideal type ('competitive') mode of governance above, the main focus of the interest-based approach will here be seen as the role of economic interests and the importance of competitiveness.

\section{The EU level}

The EU is considered to be a global front-runner in matters pertaining to SD and EPI. Beginning in the 1990's, it was primarily the EU Commission which made efforts to put the principle into operational practice, mainly aimed at internal procedures (Wilkinson 1997). As these first efforts were considered to provide only mixed results, the 1998 EU Cardiff summit formulated a strategy more explicitly addressing EPI in the decision-making processes, particularly with the aim of increasing the responsibilities of both the Council and the European Parliament (Lenschow 2002a).

Even more significantly, however, EPI was specifically incorporated as EU law by article 6 in the Amsterdam Treaty, reading:

\footnotetext{
'Environmental protection requirements must be integrated into the definition and implementation of Community policies and activities [. . . ] in particular with a view to promoting sustainable development' (EC 2002).
}

The Cardiff process can also be considered as a 'prelude' to the EU Strategy for Sustainable Development, SDS (Pallemaerts 2006: 25). The SDS was adopted at the Göteborg Conference in 2001, and constituted the common EU position at the Johannesburg Summit in 2002 (Tanasescu 2006). The EU SDS is also part of the wider Lisbon strategy for competitiveness. As such, SD is a main concern for the EU's overall policy vision and strategy, and is in principle to be considered when sectoral policies are formulated. 
Integration of environmental concerns in a trans-Atlantic perspective:

The case of renewable electricity

The EU Directive on the promotion of renewable electricity (CEC, 2001) also has strong references to EU's ambitions for SD (Lafferty and Ruud 2008b) ${ }^{3}$. The directive was finally adopted in 2001, after prolonged negotiations (Rowlands, 2005). In January 2008, the EU Commission put forth a number of proposals for more ambitious climate and energy policies including a proposal for a revised Directive on renewable energy, which will replace the current RES-E Directive, and covers both electricity, heating and biofuels. In particular, three overarching objectives have here been formulated for 2020: 20 percent reduction of GHG emissions, 20 percent additional RES, 20 percent more energy efficiency - all with respect to the levels of 2005. The new RES Directive, finally adopted in December 2008, also contains more ambitious and binding national targets (COM(2008) 19 Final). The new directive also, however, omits former ambitions of a common, standardized promotional scheme for the EU as a whole.

Whereas sector-encompassing EPI principles and mechanisms have high priorities on the EU agenda, there remain challenges related to the actual integration of these principles in the various sectoral domains, as well as vis-à-vis the implementation at national and sub-national levels (Lenschow 2005). Nevertheless, the formal basis for formulating common energy-policy measures is the internal market and the environment. The EU can adopt binding environmental legislation by qualified majorities in the Council, in 'co-decision' with the European Parliament. There are important exceptions pertaining to fiscal issues, however, as well as to measures significantly affecting the Member States' energy mix. These matters require unanimity (IEEP/NRDC 2008: 9).

In sum, in addition to the constitutional principle which establishes EPI as an overarching principle (Article 6), the EU's decision-making structure also endorses the goal of a common, standardized top-down approach to EPI with respect to the promotion of RES-E.

The linkage between RES-E promotion and EPI in the Nordic countries

Both EPI mechanisms and RES-E policies have been differentially implemented and connected in the Nordic countries (Knudsen 2009a). All four Nordic countries are committed to combating climate-change by the Kyoto Protocol, and RES-E constitutes an important area for the fulfillment of their obligations to reduce GHG emissions. Moreover, the four largest Nordic countries also share a common, general wholesale electricity market, NordPool. This market structure, which is the

\footnotetext{
${ }^{3}$ In the RES-E Directive's preamble this multiple purpose is phrased in the following manner: "The Community recognizes ... that their exploitation [of renewable energy sources] contributes to environmental protection and sustainable development. In addition this can also create local employment, have a positive impact on social cohesion, contribute to security of supply and make it possible to meet the Kyoto targets more quickly. It is therefore necessary to ensure that this potential is better exploited within the framework of the internal market" (CEC 2001).
} 
world's first cross-national electricity market, clearly influences the economic framework for RES-E promotion in the Nordic region.

In this regard, Denmark and Sweden demonstrate the strongest cases of a linkage between an EPI framework and RES-E promotion (Knudsen 2009a). They are also the most successful in providing new RES-E production capacity. In Sweden a sector-encompassing program for SD, initiated in the mid-1990's, has been connected with a comprehensive energy-policy program that focuses a switch from nuclear and fossil-based generation to a reinforced stimulation of RES-E (Chen and Johnson 2008; Nilsson and Eckerberg 2007).

In Denmark a specific political-institutional dynamic between energy and climatechange has played a vital role, especially during the 1990's. Integrated energy and climate-policy strategies here constitute a framework for an array of differentiated economic and regulatory instruments aimed directly at stimulating the phase-in of RES-E production (Hvelplund 2005; Karnøe and Buchorn 2008). The Danish RESE promotion has also been coordinated with energy efficiency programs, turning Denmark into one of the world's most energy efficient economies (IEA 2006a).

At first glance, however, EU policies have thus far not represented substantial drivers for the relevant national strategies in the Nordic countries. The national indicative targets provided by the EU RES-E Directive are roughly similar to and/or supplemented by national targets set prior to and/or independently of the directive (Chen and Johnson 2008; Karnøe and Buchkhorn 2008; Kivimaa 2008; Knudsen et al. 2008). The EU's reinforced ambitions as expressed by the triple-20 targets for 2020 will, however, imply a more demanding national follow-up in coming years (c.f. $\operatorname{COM(2008)} 19$ final).

\subsection{RES-E promotion and GHG mitigation efforts in the New England States}

\section{RES-E and climate-change in the US context}

As indicated above, there is no political or legal basis for SD or EPI in the USA. Former U.S. President Clinton initiated a follow-up process to the Rio summit in 1992, but the initiatives never led to any substantial, enduring outcomes (Bryner 2000). However, as emphasized by Hornbeek (2008), there has been a practical integration of environmental considerations into other policy sectors in the USA; not least through legislation for pre-scoping and assessing the environmental consequences of various policy plans and projects. In the U.S., therefore, the concept of EPI seems to be primarily grounded in specific practices over time, rather than being viewed as a designated principle to be applied in the pursuit of SD, as has been the case in the EU (Hornbeek 2008). 
Integration of environmental concerns in a trans-Atlantic perspective:

The case of renewable electricity

The question of deeper, structural adjustments of the American economy to accommodate environmental concerns is far off the federal political agenda. Hence, the implications of an international climate-change mitigation regime have been considered to hamper U.S. competitiveness, leading to the Senate's rejection of, and later the Bush administration's complete withdrawal from, the Kyoto Protocol (Schreurs, 2004) ${ }^{4}$.

Given such federal inaction, state-based initiatives have emerged, with 37 states having (by 2008) either adopted or in the process of adopting climate-change policy plans. A handful of states have also passed legislation requiring reductions of GHG emissions (Litz 2008). Parallel to this, regional cooperative initiatives have also emerged over recent years. The New England and Mid-Atlantic states' RGGIcooperation, initiated in 2003, currently covers (2008) the six New England states, as well as New York, New Jersey, Maryland and Delaware. The most prominent feature of the RGGI cooperation is a common cap-and-trade scheme established in 2009, with the ambition of a 10 percent reduction of GHG emissions by 2018. The proceeds of the permit auctions are to be used in support of 'low-carbon-intensity solutions', including RES-E (IEEP/NRDC, 2008).

In addition to the regional cap-and-trade programs, states have also adopted several more specific policy measures in the areas of transportation, land-use and energy (Rabe 2008). Of particular interest in the present context is the promotion of the Renewable Portfolio Standards (RPS). In general terms, an RPS scheme requires that all providers of electricity within a state increase the amount of power they derive from renewable sources over time. Whereas the actual RPS modalities vary widely among states, most of the schemes gradually increase the total volume of RES-E, and define financial penalties in the event of non-compliance (Rabe 2006).

RPS has thus represented a preferred promotional instrument for renewable electricity at the U.S. state level since the 1990's (Rabe 2006). RPS in combination with federal tax rebates constitute the most important drivers for increasing renewable energy capacity in the U.S. (Wiser and Barbose 2008). By 2007, 25 states and the District of Columbia had implemented RPS schemes. Over 50 percent of the non-hydro renewable capacity additions in the USA from 1998 through 2007, mainly wind power, occurred in states with RPS programs (Wiser and Barbose 2008).

As a policy approach RPS is characterized by a considerable degree of political robustness since the schemes are supported by both Democrats and Republicans (Rabe 2006). The most explicit motivations are, however, to strengthen security of

\footnotetext{
${ }^{4}$ This was expected to change somewhat with the majority shift following the Congressional elections in 2006, but no legal act on federal climate-change mitigation has yet (by the fall of 2008) passed either of the chambers. A federal cap-and-trade scheme was a prominent feature of the Lieberman-Warner proposal, which received the strongest support in Senate in 2007/08 but was, however, finally rejected in June 2008.
} 
supply, competitiveness and employment, and are rarely directed mainly at environmental concerns (Rabe 2004, 2006, 2008). Critical voices have, moreover, been raised against RPS as a climate-change related strategy, most particularly because of the difficulty of discerning the actual carbon-reduction impacts (Rabe 2008).

The following section provides an assessment of the six New England states' efforts to promote RES-E, as well as their climate-change policy initiatives. In order to determine whether these policy issues have been linked, eventually integrated, the following assessment criteria have been employed:

- The status of climate-change and/or other environmental concerns in the RPS regulations.

- The extent to which, and how, regulations and/or policy plans addressing climate-change also include RES-E.

- The existence of other relevant measures (regulations, policy programs, institutional mandates) that affect the linkage between climate-change and RESE.

\section{RES-E promotion and climate-change mitigation in the New England States 5}

The states of Connecticut, Maine, Massachusetts, New Hampshire, Rhode Island and Vermont have all enacted legislation establishing RPS schemes. The mixes of specific renewable energy sources and targets differ, but the general promotional aims are the same. As indicated by Table 6.1, the Massachusetts RPS was the first to appear in the region in 1997, whereas New Hampshire's scheme, from 2007, is the most recent one. Further, all these states have adopted climate-change policy plans. New Hampshire and Rhode Island were the first in 2001, while Vermont is the most recent.

\footnotetext{
${ }^{5}$ The empirical data for the present assessment of the New England states are primarily the legislative texts and policy plans, authored by the state authorities. In addition, online oversights provided by the Pew Center for Climate Change and the Union of Concerned Scientists, respectively, on the states' legal acts and other relevant initiatives have been most useful. The author is also most grateful for the background information provided by the Pew Center on Global Climate Change during a meeting in Arlington, VA, on 28 May 2008, with Patrick Hogan, Solutions Fellow, and Heather Holsinger, Senior Fellow for Domestic Policy.
} 
Integration of environmental concerns in a trans-Atlantic perspective:

The case of renewable electricity

Table 6.1 New England states and climate-change policy plans

\begin{tabular}{|c|c|c|c|c|c|c|}
\hline & Connecticut & Maine & Massachusetts & New Hampshire & Rhode Island & Vermont \\
\hline $\begin{array}{l}\text { Climate- } \\
\text { change } \\
\text { policy plan }\end{array}$ & $\begin{array}{l}\text { Climate Change } \\
\text { Action Plan } \\
\text { (2005). }\end{array}$ & $\begin{array}{l}\text { Climate } \\
\text { Action Plan } \\
(2004) .\end{array}$ & $\begin{array}{l}\text { Climate Protection } \\
\text { Plan (2004), but } \\
\text { supplemented by } \\
\text { more ambitious } \\
\text { strategic elements } \\
\text { provided by new } \\
\text { legislation, } 2008 .\end{array}$ & $\begin{array}{l}\text { Report on Climate- } \\
\text { Change policy } \\
\text { challenges (2001). A } \\
\text { revised action plan is } \\
\text { now (end of 2008) } \\
\text { being prepared. }\end{array}$ & $\begin{array}{l}\text { GHG Action } \\
\text { Plan (2002). }\end{array}$ & $\begin{array}{l}\text { Climate } \\
\text { Change } \\
\text { Report } \\
\text { (2007). }\end{array}$ \\
\hline $\begin{array}{l}\text { Climate- } \\
\text { change } \\
\text { legisl. }\end{array}$ & $\begin{array}{l}\text { Global warming } \\
\text { Bill (2008) } \\
\text { (implementing } \\
\text { the RGGI cap- } \\
\text { and-trade } \\
\text { provisions). }\end{array}$ & $\begin{array}{l}\text { Law } \\
\text { implement. } \\
\text { the RGGI } \\
\text { cap-and- } \\
\text { trade } \\
\text { provisions } \\
\text { (2007). } \\
\end{array}$ & $\begin{array}{l}\text { Global Warming } \\
\text { Solutions Act } \\
(2008)\end{array}$ & - & - & - \\
\hline $\begin{array}{l}\text { GHG } \\
\text { emission } \\
\text { reduction } \\
\text { targets } \\
\end{array}$ & $\begin{array}{l}10 \% \text { below } \\
1990 \text { by } 2020, \\
\text { and } 80 \% \text { below } \\
2001 \text { by } 2050 . \\
\end{array}$ & $\begin{array}{l}\text { Pursuant to } \\
\text { the RGGI } \\
\text { and NEG- } \\
\text { ECP. }{ }^{6} \\
\end{array}$ & $\begin{array}{l}10-25 \% \text { below } \\
1990 \text { by } 2020,80 \\
\% \text { below } 2001 \text { by } \\
2050 . \\
\end{array}$ & $\begin{array}{l}\text { Pursuant to the RGGI } \\
\text { and NEG-ECP. }\end{array}$ & $\begin{array}{l}\text { Pursuant to the } \\
\text { RGGI and NEG- } \\
\text { ECP. }\end{array}$ & $\begin{array}{l}\text { Pursuant to } \\
\text { the RGGI } \\
\text { and NEG- } \\
\text { ECP. } \\
\end{array}$ \\
\hline $\begin{array}{l}\text { Inclusion of } \\
\text { RES-E }\end{array}$ & $\begin{array}{l}\text { In the Action } \\
\text { Plan references } \\
\text { to revised RPS } \\
\text { and other } \\
\text { projected RES- } \\
\text { E policy } \\
\text { initiatives. }\end{array}$ & $\begin{array}{l}\text { In the } 2004 \\
\text { Action Plan, } \\
\text { references to } \\
\text { revised RPS } \\
\text { in the action } \\
\text { plan, and on } \\
\text { status in } \\
\text { follow-up } \\
\text { reports. }\end{array}$ & $\begin{array}{l}\text { Explicitly } \\
\text { mentioned as key } \\
\text { sector in the } \\
\text { Global Warming } \\
\text { Solutions Act. }\end{array}$ & $\begin{array}{l}\text { References to RES-E } \\
\text { contributions in the } \\
2001 \text { report, without } \\
\text { explicitly referring to } \\
\text { an RPS. }\end{array}$ & $\begin{array}{l}2002 \text { Action } \\
\text { Plan recomm. } \\
\text { the establishm. } \\
\text { of an RPS } \\
\text { scheme. }\end{array}$ & $\begin{array}{l}2007 \text { Report } \\
\text { provides no } \\
\text { specific } \\
\text { recomm. on } \\
\text { RES-E and } \\
\text { RPS, but } \\
\text { energy is } \\
\text { treated as a } \\
\text { key sector. }\end{array}$ \\
\hline
\end{tabular}

Maine has currently the largest share of RES-E of the present group with about half of its electricity generation being based on renewable sources. At the same time, these states still have a high degree of fossil-fuel energy production which represents an important source of GHG emissions. Electricity production and usage are thus addressed in all the states' climate-change policy plans, with all giving priority to promoting RES-E through some form of RPS scheme.

Looking more closely at the legislative acts establishing the RPS, however, there are only explicit references to climate-change mitigation in the cases of New Hampshire, Rhode Island and Vermont. Furthermore, there is thus far little evidence of amendments to the RES-E promotional schemes that affect the targets set by the climate-change policy plans. Massachusetts has, however, recently adopted new laws strengthening the RES-E ambition in parallel with more ambitious climate targets (see Tables 6.1 and 6.2).

${ }^{6}$ That is, 1990 levels by 2010, 10 percent below 1990 levels by 2020, and 75-85 percent below 2001 levels in the long term. 
Table 6.2 New England states and the status of Renewable portfolio standards (RPS)

\begin{tabular}{|l|l|l|l|l|l|l|}
\hline & Connecticut & Maine & Massachusetts & New Hampshire & Rhode Island & Vermont \\
\hline $\begin{array}{l}\text { RPS } \\
\text { objective }\end{array}$ & $27 \%$ by 2020 & $\begin{array}{l}10 \% \text { additional } \\
\text { by } 2017(30 \% \\
\text { as basic } \\
\text { requirem.) }\end{array}$ & $\begin{array}{l}15 \% \text { by } 2020 \\
\text { (built no earlier } \\
\text { than 1998). }\end{array}$ & $23.8 \%$ by 2025. & $16 \%$ by 2020. & $\begin{array}{l}\text { Utilities } \\
\text { required to } \\
\text { provide RES- } \\
\text { E equal to } \\
\text { general load } \\
\text { growth 2005 } \\
\text { - 2012 }\end{array}$ \\
\hline $\begin{array}{l}\text { RPS legal } \\
\text { status }\end{array}$ & $\begin{array}{l}\text { Current legal } \\
\text { act from 2007, } \\
\text { first regulation } \\
\text { in 1998. }\end{array}$ & $\begin{array}{l}\text { Legal act } \\
\text { (2006), setting } \\
\text { annual cumul. } \\
\text { requirements. }\end{array}$ & $\begin{array}{l}\text { Originally initiated } \\
\text { in 1997, revised } \\
\text { legislation of 2008 } \\
\text { strengthens the } \\
\text { connection with } \\
\text { other energy policy } \\
\text { initiatives, i.e. } \\
\text { energy efficiency. }\end{array}$ & $\begin{array}{l}\text { Legal act from } \\
\text { 2007 setting } \\
\text { annual cumulative } \\
\text { requirements. }\end{array}$ & $\begin{array}{l}\text { Legal act from } \\
\text { 2004 setting } \\
\text { annual cumul- } \\
\text { ative require- } \\
\text { ments. }\end{array}$ & $\begin{array}{l}\text { Legal act of } \\
\text { 2005: If } \\
\text { utilities do } \\
\text { not meet the } \\
\text { requirement } \\
\text { as of 2012, a } \\
\text { formalized } \\
\text { RPS will be } \\
\text { adopted. }\end{array}$ \\
\hline $\begin{array}{l}\text { Inclusion of } \\
\text { climate- } \\
\text { change } \\
\text { concerns }\end{array}$ & $\begin{array}{l}\text { Only reference } \\
\text { to RGG and } \\
\text { related costs. }\end{array}$ & $\begin{array}{l}\text { Not explicitly } \\
\text { referred to in } \\
\text { current RPS } \\
\text { legislation }\end{array}$ & $\begin{array}{l}\text { Not explicitly } \\
\text { referred to in the } \\
\text { RPS-relevant act, } \\
\text { but linkage } \\
\text { apparent in over- } \\
\text { arching climate- } \\
\text { change law (see } \\
\text { table 6.1). }\end{array}$ & $\begin{array}{l}\text { Explicit reference } \\
\text { to RPS as } \\
\text { contributor to GHG } \\
\text { emission } \\
\text { reductions in the } \\
\text { legisl. act. }\end{array}$ & $\begin{array}{l}\text { Explicit } \\
\text { reference to } \\
\text { RPS as } \\
\text { contributor to } \\
\text { GHG emission } \\
\text { reductions the } \\
\text { legisl. act. }\end{array}$ & $\begin{array}{l}\text { adopted } \\
\text { (2008) legal } \\
\text { act on energy } \\
\text { efficiency is } \\
\text { explicitly } \\
\text { grounded in } \\
\text { a climate- } \\
\text { change policy } \\
\text { context, but } \\
\text { does not } \\
\text { provide any } \\
\text { additional } \\
\text { provisions for } \\
\text { RES-E. }\end{array}$ \\
\hline
\end{tabular}

In general the six states include both energy efficiency and RES-E in their climatechange policy plans. Yet Connecticut is the only state to provide an explicit linkage between the state's RPS and energy-efficiency measures. ${ }^{8}$ Whereas there is no such linkage for Massachusetts and Vermont, these states do have more ambitious energy-efficiency programs in addition to the RPS schemes. Moreover,

\footnotetext{
${ }^{7}$ Vermont's RES-E scheme is only considered a de facto RPS because it does not set strict targets, only goals. But according to the Pew Center on Global Climate Change, Vermont's policy counts as an RPS because the state will step in and enforce the targets if they are not met (ClimateWire, 1 May 2008). A new legislative act of 2008 sets a 25 per cent RES objective for the state by 2025, in addition to energy efficiency measures - without, however, presenting any new measures pertaining to RPS.

${ }^{8}$ In addition to RES-E, Connecticut's RPS scheme obliges the state's utilities to procure an increasing amount (from 1 to 4 percent during 2007 - 2010) of electricity sales from energyefficiency projects (State of Connecticut, 2007).
} 
Integration of environmental concerns in a trans-Atlantic perspective:

The case of renewable electricity

Massachusetts has recently reinforced the linkage between RES-E and energy efficiency through its new legislation (see Table 6.2).

Some of the climate-change policy plans are part of ongoing and planned revisions. It is possible that these revisions will lead to a form of policy learning that eventually reinforces integration of RES-E into an overall climate-change policy. Connecticut's climate-change action plan is the most dynamic of those considered here, having an explicit focus on implementation and follow-up mechanisms, thereby implying a potential for policy adjustments (Connecticut Climate Change Action Plan 2005). In addition, both the New Hampshire and Massachusetts plans have been revised following gubernatorial elections and ensuing policy shifts in the state administrations. Yet none of these revisions have thus far led to substantial alterations of the integration of RES-E.

The RGGI cap-and-trade scheme will probably affect the prices and values of RES$\mathrm{E}$ investments, and its impact on GHG reduction targets will thus probably also be evaluated. Whether a reinforced inter-state, regional approach to GHG emissions will induce more standardized, and eventually common approaches to RES-E promotion, remains, however, an open question. Also open is the question as to whether the institutional changes, resulting from mergers of mandates for climatechange and energy/RES-E, will represent a potential for stronger policy integration as well. The most relevant case here is Massachusetts where the Governor in 2007 ordered a merger of the energy and environmental departments in the executive branch.

The possibility of future federal regulations, and the eventual consequences of these, is not addressed in any of the RPS schemes considered here. Eventual federal regulation of this area could modify the potential for states to enact policies with the state's own interests as the main concern, thereby altering some of the initial rationale for the states' formulation of RPS schemes (Rabe 2006: 25 - 26).

\section{Comparative assessment of the EU and U.S. approaches}

As argued above, there are important differences between the EU and U.S. approaches to RES-E and the policy integration of environmental concerns in general. Elaborating on these empirical insights, and building on the perspectives outlined in section 2, the present section provides a comparative assessment of the importance of different multi-level governance structures within the tripartite scheme outlined above: prescriptive or rule-based approaches; communicative approaches; and economic, interests-based approaches.

American policy development is generally considered to be more driven by judicial mechanisms than in Europe, but during the last two decades regulation has been increasingly important as an instrument for fulfilling the EU's reinforced ambitions of common policies (Majone 1993). Drawing on examples from the EU 
environmental policies, Kelemen (2000) contends that there is an increasing volume of common legislation that potentially stimulates a 'U.S.-like litigious approach' to regulation. U.S. governance is, however, still remarkably more characterized by its traditionally stronger emphasis on litigious approaches than the EU (c.f. Lieberman 1983). This can also explain U.S. legislators' recalcitrance to formulate legally binding objectives with economic consequences for commercial interests.

The case to come closest to a prescriptive approach of MLG in the present context is the EU RES-E Directive. On the other side, as observed for the Nordic countries, this directive has thus far had only limited impact on national policies. Having said this, however, the directive is integrated into an increasingly ambitious EU climateand energy policy program that in coming years will lead to stronger national commitments. Compared to the USA, this reflects both a broader political scope for supplementing market-based efforts with wider non-market policy approaches, as well as a stronger top-down approach.

Several researchers have emphasized a need for adding more nuances to the perception of the environmental policy performance of the USA, pointing to ambitious environmental laws, and innovative institutions and mechanisms (Vig and Faure 2004). The introduction of market-based instruments in environmental policies - particularly with respect to air pollution control - originated in the USA and constituted a decisive impetus for the mechanisms of the Kyoto Protocol, and thereby for the very design of the international climate-change regime (Schreurs 2002).

Although such nuances complement the often overly negative portraits of U.S. environmental policies, the EU is nonetheless provided with more comprehensive top-down mechanisms for regulating environmental policies. EPI, for example, is succinctly expressed as a legal obligation, inscribed as a fundamental principle by Article 6 of the EU Treaty (see section 3.1). In contrast, federal competencies for U.S. environmental policy are based largely on the commerce clause of the Constitution, which has represented a barrier for EPI (Hornbeek 2008: 272). Furthermore, by actively hindering states to establish regulations of GHG emissions during the Bush presidency, the U.S. Environmental Protection Agency (EPA) has played a somewhat opposite role when compared to the DG Environment of the EU Commission.

In general, compared to the U.S. federal level 'green issues' are more strongly defended in the EU decision-making system. The voting procedures in the Council

\footnotetext{
${ }^{9}$ This was very clearly illustrated by the legal process whereby the U.S. EPA in February 2008 rejected the state of California's bid for a waiver from U.S. law to set its own tailpipe emissions standards for motor vehicles. 18 other states also wanted to adopt this waiver. Subsequently, these states, supported by a number of environmental groups, sued the EPA for its failure to regulate adequately GHG emissions from motor vehicles (Pew Center on Global Climate Change 2008).
} 
Integration of environmental concerns in a trans-Atlantic perspective:

The case of renewable electricity

of Ministers, with qualified majorities in decisions relevant for the environment, have thus far implied a stronger leverage of green interests as compared to the USA. This tendency is strengthened by a more environmentally benign EU Parliament which has generally contributed to sharpen the edge of the EU environmental ambitions.

Observers have emphasized, however, that the emergence of different climatechange relevant regulations in different U.S. states in recent years have stimulated legal proposals in the U.S. Congress aiming at a national standardization, including measures affecting RES-E (Moslener and Sturm 2008). The Congress has, nevertheless, thus far rejected proposals of a federal RPS three times. It is, however, still possible that a reinforced federal energy and climate-change policy focus can stimulate a federal RES-E policy approach that will eventually restrain the states' current autonomous policy development (Rabe 2006; Litz 2008).

Legal prescriptions are not operated in a void. We now therefore turn to the second analytical approach outlined above; focusing communication and networks. Such factors are often employed to explain the increasingly complex interaction within the EU system between different categories of public and non-public actors and stakeholders at different levels (Knill and Lenschow 2005b). The EU is actually aiming at a reinforcement of both formal and informal networks as an alternative mode of governance, based on the limitations experienced with traditional, hierarchical regulation (Schout and Jordan 2005). In particular, various networks serve to advise the Commission, coordinate national enforcement and promote information exchange among national regulators (Eberlein and Newman, 2008).

In the case of the EU's work on SD there have been features of a 'steering network' involving scientific experts, think tanks, NGOs and industry groups (Bomberg 2009). This network has particularly been activated through the European Consultative Forum on the Environment and Sustainable Development, an independent advisory body (Bosselmann 2007). There is also a European SD Network, composed of public administrators with responsibilities for the national SD strategies (Steurer 2008). Whereas these networks do not have any formal decision-making authority and generally have limited political leverage, they provide the EU institutions with important inputs on both further policy development and implementation. In addition, in the more specific area of RES-E there has also been a strong communication of national experiences 'upwards'. Countries having adopted feed-in tariff schemes to stimulate RES-E production, for example, have promoted these as the best regulatory approach to RES-E in the case of eventual common EU policies (Rowlands 2005).

In contrast, SD initiatives in the USA were largely limited in time (President Clinton's first term of office) and mainly concentrated in the executive branch (Bryner 2000). Partly because of the lack of nation-wide mobilizing forces, policies and initiatives at the state level have demonstrated greater leverage (Bomberg 2009). Activities related to climate-change at the state level have, however, stimulated the 
development of epistemic communities and policy networks (Rabe 2008: 107). In recent years, nation-wide network constellations - encompassing environmental NGOs and industries, have also emerged as arenas for promoting so-called economy-wide GHG mitigation efforts at the federal level, including RES-E. These network constellations have, however, no regular access point to the federal decision-making bodies.

This again emphasizes the historically important role played by the U.S. states as innovative actors contributing to a wider and improved basis for federal environmental policies (Kraemer and Schreurs 2007). The states' regulation of climate-change and RES-E can, therefore, be considered to provide models for other states and future federal regulations. In sum, the transfer of ideas and communication upwards is a more prevalent pattern in the USA, compared to the EU - where such transfers go both ways, albeit with a strong top-down engagement.

Turning to the third and final analytical approach we will focus the role of economic interests. In this regard, there are divergent features both within each of the polities - as well as between them. Whereas the EU's EPI agenda is framed within the SD strategy and anchored at the very top, there are significant conflicts and trade-offs related to the so-called 'Lisbon Agenda' for more competitive economic development. Economic arguments and the potential for innovation and industrial development have, moreover, figured as a key motivation for the RES-E directive itself, and particularly the Danish and German examples of expanding RES-E industries have been prominent in demonstrating such connections. On the other side, the current economic setback substantially impacted on the recent negotiations on the new EU RES Directive. Several Member States then demonstrated considerable recalcitrance vis-à-vis the proposed, demanding national targets fearing that higher energy prices would hamper national industrial competitiveness.

The economic drivers stand out as strong incentives for RES-E at the state level in the USA as well. The economic, interest-driven dimension has been a crucial motivation for the states' promotion of RES-E (as reflected in the RPS regulations), as well as in the overall GHG mitigation policies (Rabe et al. 2005). There is an expanding state government interest in developing RES-E technologies and skills. Indeed, a majority of governors have embraced the notion of developing 'homegrown' energy sources, at least in part, in order to foster long-term economic development (Rabe 2008).

Kraft and Kamieniecki (2007) emphasize that compared to other industrialized countries American business and government has an adversarial rather than a cooperative relationship. This has particularly been the case with respect to environmental issues, although the actual interaction with public actors in policy matters is much more subtle and complex than generally portrayed (Kraft and Kamieniecki 2007: 24). This perspective is further elaborated in an analysis of climate-change mitigation policies at the state level (Rabe and Mundo 2007). 
Integration of environmental concerns in a trans-Atlantic perspective:

The case of renewable electricity

The perspective of interest-driven state policy developments does not, however, preclude the possibility of states engaging in inter-state cooperation on climatechange - like the RGGI - providing there are mutual benefits (Rabe et al. 2005). RGGI-like constellations can, moreover, be seen as an innovative feature of the U.S. polity itself.

\section{Conclusion}

Initiatives for RES-E promotion at the state-level currently represent one of the most forceful expressions of EPI dynamics in the USA. In a situation of federal in-action, all six New England states have undertaken policy efforts representing a reinforced linkage between RES-E and climate-change, although no substantial amendments have been made thus far to reinforce the climate-change concerns vis-à-vis RES-E promotion. Parallel to this, the EU approach to EPI is increasingly manifested through the more issue-specific climate-energy strategy. In the Nordic countries national policy strategies implemented prior to the EU strategies have, however, thus far had a stronger direct effect on RES-E. Nevertheless, the EU provides national RES-E policies with an increasingly demanding policy platform where environmental concerns are crucial. This platform is manifested through patterns of both rule-based and communication-based modes of decision-making and implementation between the levels.

A more specific energy-related EPI-program at the federal level in the USA comparable to that of the EU - is thus not very likely. Concerns for security of supply and competitiveness are likely to retain stronger leverage than environmental concerns, despite the more recent increase in political attention to the challenge of global warming. Compared to the EU, there are few indications of either strengthened rule-based or communication-based modes of interaction between the federal and state levels in relation to RES-E and climate-change. This situation points towards a continued reliance on competition between different interests within and between the states, thereby affecting the formulation of eventual future federal regulations. One can thus assume that the 'first-mover' states will defend existing state-based policy programs formulated according to state-based interests, whereas states with high levels of GHG emissions will probably continue to resist (politically) even modest federal policies.

The New England states' participation in the RGGI cooperation represents, however, a genuine novelty in U.S. policy development. In light of the Nordic cooperation in this area, this indicates the importance of the regional level - and most crucially the interdependence between different federal-regional levels of governance - as an instrument for promoting RES-E in Europe and the United States. 
Monitoring towards more sustainable energy policies?

A comparative assessment of procedures and political impacts in Norway and Sweden

published before as:

Knudsen, Jørgen (2008): 'Monitoring towards more sustainable energy policies? A comparative assessment of procedures and political impacts in Norway and Sweden', Research paper presented at the Easy-Eco Vienna Evaluation of Sustainability Conference, the Research Institute for Managing Sustainability, Vienna University of Economics and Business Administration, 11-14 March 2008. 

In 1987 Our Common Future (1987) addressed the importance of integrating sustainable development (SD) into mandates of - inter alia - all agencies of government, thereby making these agencies responsible and accountable for SD (WCED 1987: 312). Together with Agenda 21 (1992) - this constitute the basis for 'governance for sustainable development' as a topic within both an academic and political discourse. Academically, this issue has been treated in relation to both the analysis of strategies for sustainable development (SDS), and the concept of 'environmental policy integration' (EPI). This paper seeks to relate to both research agendas.

As highlighted by WCED, the Agenda 21 and the ensuing academic literature, a framework relating SD policy objectives to a focused implementation, and regular monitoring and evaluation activities, would facilitate the improvement of policy outcomes and outputs, and thereby the overall consistency of the SD programme. Monitoring is assumed to be a mechanism of specific importance. It provides data on the status for implementing measures for SD, as well as inputs to a process of evaluating and possibly improving policy responses to SD-related challenges.

On this background, this paper aims to highlight the question of monitoring and evaluation, and whether current mechanisms provide a basis for adjusting policies towards SD. The paper will provide a comparative assessment of the characteristics and potentials of such mechanisms in two distinct national contexts. Norway and Sweden are generally viewed as two well-performing states on SD. They differ, however, on policy ambitions and measures; institutional mandates and procedures; and the relative independence of monitoring activities. A main question is whether such differences also imply a differing driving-force for policy adjustment.

The energy sector represents a case in point, characterized by national and even local particularities. Diverging resources, economic and industrial interests, and regulatory and institutional frameworks provide national authorities with very differing points of departure for integrating the energy sectors into strategies for SD. It is also a sector marked by ongoing important changes by the intertwined processes of internationalization, deregulation and climate change.

In both Norway and Sweden stationary energy usage is to a large degree non-fossil based (hydro power in both countries and nuclear power in Sweden). Nevertheless both countries - as a response to international commitments and increasing energy demand - have set targets for promoting 'new-renewables' and improving energy efficiency, however differently.

On this background the present paper aims at discussing the following questions:

What SD-related procedures for monitoring and evaluating energy policy are in place in Norway and Sweden, and what are the main differences? 
Monitoring towards more sustainable energy policies?

A comparative assessment of procedures and political impacts in Norway and Sweden

To what degree and how do the Norwegian and Swedish procedures address and induce policy changes for $S D$ ?

Monitoring of the follow-up of SD can not be assessed in a void, and is therefore considered on the basis of relevant objectives and targets. The paper includes a brief scrutiny of the relevant policy objectives formulated for SD in general and the energy sector in particular, in Norway and Sweden respectively.

Most evaluations of national strategies and initiatives related to governance for SD, point at the importance of political will. In addition, the interaction of political, socio-economic and institutional factors is assumed to be specific to the national context in question, as well as influencing the character and importance of monitoring and evaluation. A final question is therefore:

How can major differences and similarities in organisation, scope and changeorientation be explained?

The paper opens - in section two below - with an outline of the analytical framework employed. Section three provides an assessment of the two countries' monitoring and evaluation procedures. Section four contains an assessment of the major outcomes of these processes related to eventual policy adjustments made by the parliaments. Section five provides a preliminary explanatory analysis.

\section{Analytical framework}

This section first provides a discussion of evaluation as an approach to SD at a national political-administrative level. This discussion is then related to the broader issue of governance for SD and EPI; and thirdly, based on the literature, I will outline some major explanatory factors as a basis for a preliminary analysis of the differences between the two cases.

Up to now the OECD and the European Environment Agency (EEA) have provided most systematic evaluations of national governance mechanisms for SD (including EPI) (EEA 2005a; OECD 2001a, 2001b, 2002a, 2002b). In particular, the OECD has authored a checklist to guide policy-makers on improving policy coherence and integration in which monitoring is ranked as a key mechanism (OECD 2002b). ${ }^{1}$ These evaluations together with recent case studies of national SD strategies

\footnotetext{
${ }^{1}$ The checklist points of specific relevance read: 1) Is there a clear framework for assessing the performance of public organisations with regard to SD?; 2) Are there evaluation and reporting mechanisms to support sustainability appraisal within the public sector; i.e. indicators of progress, cost/benefit analysis, environmental and social impact assessment? 3) Does government make effective use of these evaluation and reporting mechanisms? 4) Have specific external and independent auditing and reporting mechanisms been established? (OECD 2002b: 9 - 10)
} 
indicate a general lack of robust monitoring and evaluation mechanisms (Lafferty et al. 2007; Russels 2007; Tils 2007).

However, monitoring and evaluation mechanisms for SD - in a politicaladministrative context - have so far not been a well-documented area of analysis. One explanation is that evaluation in political science generally has had little prominence (Lafferty 2002c). Lafferty (ibid: 1-2) links this to the apparent feeling of discomfort of mainstream academic political science vis-à-vis issues of values and objectives. Furthermore, as pointed out by O'Toole (2004), the SD programme poses new challenges to implementation and evaluation research since one has to deal with a new form of cross-sectoral, long term and normative policy project (ibid.).

Another fundamental question is how the follow-up of the SD challenge could be harmonised as effectively as possible with the functioning of liberal-pluralistic democracies. Continuously shifting majorities and interest constellations basically weaken the probability of long-term political commitments. The challenge of engaging stakeholders and communities are therefore a key to successful implementation across levels. A politically independent institution with mandate and capacity to monitor and assess SD achievements would also contribute substantially to a continuous and stable administrative and political attention towards SD-related issues. Such features also enable ordinary citizens to examine the SD policy performance of their elected politicians (Lundqvist 2004a: 97-98).

The mandate for monitoring and evaluation should ideally be based on political neutrality to ensure confidence in the outcome of the process. While this would not in itself guarantee reinforced commitment and improved implementation, it would highlight how sectoral institutions and actors actually relate to democratically sanctioned SD objectives.

Canada is an interesting case in this context as it has established several bodies with the mandate of monitoring and assessing the political and administrative performance related to the country's SD commitments (Bouder 2002). In particular, since 1995 there is a Commissioner of the Environment and Sustainable Development (CESD) having a mandate of independent auditing of the federal government's SD performance (ibid: 49). The CESD is appointed by the Auditor General and reports directly to this office which provides the Commissioner with authority and legal stability (ibid.). While the impacts of the CESD reports measures on actual adjustments of policy outputs is mixed, the reports facilitate the parliamentarians' oversight and provide them with regular, independent assessments and recommendations. Since these reports are covering a certain time period there is a possibility of historical learning as well.

'Evaluation' can be defined and understood in different manners. A fruitful point of departure is provided by the methodological approach outlined by Vedung (2004). Firstly, he emphasizes that evaluations could be related to substantive as well as process-oriented purposes. In the present context substantively oriented evaluations 
Monitoring towards more sustainable energy policies?

A comparative assessment of procedures and political impacts in Norway and Sweden

are understood as the energy policy decisions and their effect vis-à-vis SD relevant objectives. Process-oriented evaluations are here viewed as those focusing on steering mechanisms and procedures directed at facilitating the integration of SD objectives into the formulation and implementation of energy policies.

It is also important to emphasise the distinction between policy outputs and policy outcomes. While the first ones generally can be considered results of the decisionmaking process and products of the policy formulation, the last concept can be understood as the effects and impacts of the policy outputs; and the final consequences of the stipulated policy program or project (ibid.).

In addition to assessment of relevant mechanisms and instruments, the OECD has also provided the so-called 'DPSIR model' (Drivers-Pressures-Status-ImpactsResponse), related to 'decoupling'. This concept signifies that necessary environmental protective measures should be pursued regardless of economic growth patterns and business cycles (OECD 2001a). Mechanisms for monitoring and evaluation can clearly be positioned within the cyclical approach represented by the DPSIR model.

The question of decoupling can be related to the change-orientation expressed by SD-relevant objectives, targets and measures. Lafferty and Ruud (2006) emphasise that possible changes can be linked to different stages in a production-consumption chain. A strategy encompassing both production and consumption, aiming at changing both in an integrated manner, is assumed to be more conducive to sustainable development. A more fragmented outlook primarily focused on e.g. optimizing production processes, and not taking into account cumulative effects related to consumption, would thus represent a less change-inducing strategy (ibid.). A decisive question is thus to what extent an SD programme interprets 'SD' as a concept for change.

'SD' as a concept is also widely discussed within the EPI discourse (Lafferty and Knudsen 2007). Premises for clarifying the linkage between the two concepts have therefore been proposed and elaborated in a recent study (ibid.). Here EPI is: 1) identified as a crucial instrument for achieving decoupling, which in turn is a crucial goal of SD; 2) In line with the assessment provided by Our Common Future 'the environmental dimension' should be considered a limiting condition for the pursuit of both economic and social objectives. Thus, the need for integrating environmental concerns into all policy areas is the distinct defining 'variable' in the SD equation; 3) the normative intent of EPI is to function as a 'first-order-principle' for resolving trade-offs between sectoral policy goals and environmental concerns.

The notion of EPI as a 'first-order-principle' may seem rigid. However, the emphasis of this principle does not imply that other policy concerns than the environment must invariably give way. This will depend on the specific policy process in question. The crucial question is whether the decision-makers are provided with sufficient information so as to assess the environmental concerns 
appropriately within an SD context. This can again clearly be related to monitoring and evaluation. A scientifically informed and transparent monitoring should provide decision-makers with a basis for making the necessary trade-offs.

Based on the aspects discussed above - the following key criteria are identified for the assessment of the monitoring and evaluation procedures in Norway and Sweden:

- The mandate for the institution(s) conducting the procedures: Politically independent? How often and with what resources?

- The character of the procedures: Monitoring and/or evaluating policy outputs and/or policy outcomes?

- The purposes of the procedures: 1) Change-orientation; monitoring policy measures' contribution to decoupling? 2) Assessing and providing information for making trade-offs?

Based on the assessment of these criteria, the paper will proceed by examining whether the monitoring data are used as premises for policy adjustments made by the Parliaments.

The third question posed in this paper is related to the explanation of the differences between the two cases. As indicated above, the character and eventual outcome of monitoring and evaluation are assumed to depend particularly on political will. However, political will is not developed or manifested in a vacuum, and is, moreover, not the only relevant variable to consider. The account below will relate relevant background variables to a strategic context of horizontal and vertical dimensions.

Lafferty (2004a) identifies horizontal and vertical dimensions related to a strategic framework for EPI. The extent to which a central authority has developed a comprehensive cross-sectoral strategy for EPI is associated with a horizontal axis (Lafferty 2004a: 206). A vertical dimension is related to the extent to which a particular governmental sector has merged environmental objectives with its characteristic sectoral objectives (ibid: 205). Benchmarks for mechanisms related to both axes are proposed, which - if implemented together - could constitute a basis for a coherent and dynamic strategic framework. According to this framework, horizontal and vertical targets should be anchored in overall strategies, and followed up by concrete action plans and mechanisms to ensure implementation, as well as monitoring (ibid.). This would also imply the possibility of addressing inconsistent policy goals, and identify and eventually clarify goal conflicts. Monitoring activities are thus included as one of the benchmarks, as well as an independent auditor with the mandate of assessing implementation and proposing strategic revisions (ibid: 204 - 208). This approach provides a framework for assessing the context within which monitoring procedures are formulated and operated. 
Monitoring towards more sustainable energy policies?

A comparative assessment of procedures and political impacts in Norway and Sweden

A recently finalized comparative study of EPI in the agriculture and energy sectors in Sweden focuses on learning processes (Nilsson and Eckerberg 2007: Nilsson et al. 2007). The study provides a diachronic analysis of the sectors and their contexts, in terms of actor constellations, the interaction with the relevant institutional framework, and how agendas and perceptions were affected and transformed due to complex and changing patterns of interaction (ibid.). While data of a similar extent are lacking in the Norwegian case, the thorough study provided for Sweden clearly demonstrates the importance of the institutional and socio-economic setting for learning and feed-back processes.

Steurer (2007) emphasises the different roles of politicians and public administrators. He also points to the fact that the general lack of political will within an SD context could actually augment the relevance of the administrative realm (ibid: 202). The emphasis of the different roles and functions of the political level and administrators have also led to the notion of 'cross-horizontal' policy integration; i.e. that inter-ministerial collaboration ought to go hand in hand in both the political and administrative branches of government in order to be effective (Steurer and Martinuzzi 2005: 461). This observation constitutes a forceful reminder of assessing the dynamics at "the inside" of the political-administrative level. It seems to be fruitful to combine such insights with analyses of the interaction with the relevant, eventually sector-specific context - including learning processes - as provided by the Swedish PINTS project. A combined political and institutional analysis conducted within the strategic outlook of horizontal and vertical dimensions of EPI, as referred to above, is here assumed to constitute a fruitful analytical approach.

The various combinations of political, social, economic and institutional factors have also been related to different modes of governance. The ongoing EU-funded project EPIGOV ${ }^{2}$ has thus addressed the importance of modes of governance and multi-level dynamics for EPI at global, EU, national and sub-national-levels. However, a general, initial observation is that most studies of EPI thus far have not framed the discussion in terms of modes of governance.

The governance systems of Norway and Sweden have many common features, not the least a traditionally high degree of corporatist arrangements. However, how equal the governance systems of these two neighbouring countries actually are when examining more particular features as the procedures in question here, is a more open question. A core assumption in the present context is that there are interesting differences even between the two most similar cases of Norway and Sweden. This is also related to the role of parliaments which has not been extensively or consistently analysed so far in EPI-relevant research.

Section 5 provides a preliminary explanatory analysis informed by the contributions briefly discussed above, related to horizontal and vertical axes.

\footnotetext{
${ }^{2}$ See the project's website: http://www.ecologic.de/projekte/epigov/partners.htm
} 


\subsection{Comparing SD-relevant monitoring and evaluation procedures}

\subsubsection{Norway}

\section{SD-related goals and objectives}

The current Norwegian SD strategy was adopted in 2007, replacing the former government's SD action plan from 2004. The most relevant targets for the energy sector - which have been formulated independently of the SD strategy - are related to the increase of renewable electricity and heating, as well as energy efficiency. ${ }^{3}$

Norway's commitment for the reduction of greenhouse gas emissions, based on the Kyoto Protocol, is to limit the emission growth to 1 pct. above the 1990 level. Parliament is currently considering committing the energy sector more specifically, together with other policy sectors, as part of the Government's proposal for a new climate change policy strategy. ${ }^{4}$ This proposal also includes more ambitious national emission reductions; 30 \% by 2020, and $100 \%$ - 'carbon neutrality' - by 2050. The use of the flexible mechanisms under the Kyoto Protocol or similar arrangements is to contribute at least one third of the fulfilment.

\section{SD indicators}

The indicators defined to monitor the SD strategy implementation were originally proposed by an expert commission in 2005, and were criticised for being descriptive and status-oriented with no potential for monitoring decoupling (Lafferty et al. 2007: 184). The indicators were adopted without any changes, and were only marginally revised in 2007. The strategy's only indicator for energy is: Total use of energy pr. unit of the GDP.

Status related to the indicators is assessed by Statistics Norway and presented by the Ministry of Finance in annual status reports on the strategy (as part of the National Budget). In these reports there is, however, no assessment of the impact of policies and the relationship between pressures, impacts and policy responses.

\footnotetext{
${ }^{3}$ The current target is to 1 ) achieve a total change in energy production and use equivalent to 12 TWh by 2010 by the combined effect of increasing the share of wind power (at least 3 TWh by 2010), increasing the share of renewable, non-electric heating (at least 4 TWh by 2010), and more efficient energy use; 2 ) achieve a total change in energy production and use equivalent to 30 TWh by 2016 - compared to the 2001 level - by the combination of the same sub-areas as for 2010. However, no new quantitative sub-targets have so far been formulated, but renewable electricity is assumed to contribute one third.

${ }^{4}$ For the energy sector the government intends to ensure that existing and future measures lead to a reduction of emissions corresponding to $3-5$ mill. tonnes of $\mathrm{CO} 2$ equivalents (White Paper 34, 2006-07: 68).
} 
Monitoring towards more sustainable energy policies?

A comparative assessment of procedures and political impacts in Norway and Sweden

The state Budget and environmental reporting

Procedures related to environmental reporting through the State Budget ("Environmental profile of the state budget”; EPSB) introduced in 1989 - are considered the first systematic attempt to promote sectoral integration in Norway (Lafferty et al. 2007: 182). The requirements stemming from the EPSB have been modified several times. From 2000 the sectoral ministries are to report according to the environmental policy priorities, further elaborated in the next section. Today's reporting in the State Budget is relatively less thorough and specific than by the first version of the EPSB.

The Ministry of Petroleum and Energy (MoPE) thus reports major environmental impacts of energy in the State Budget. However, these reports are very general and not based on sector-specific monitoring. They do not contain any substantial assessment of the policy measures and its relation to neither SD policy goals nor other policy goals. There is neither any discussion of possible goal conflicts.

\section{Environmental monitoring and related energy policy assessments}

The so-called National Environmental Monitoring System (NEMS) can be characterized as a relatively advanced attempt to ensure horizontal integration of the ecological dimension of SD in Norway. The main element of this system is monitoring and reporting to environmental policy priorities. Originally there were 11, but after the latest revision in 2007 there remain only four - with related subpriorities (White Paper 26, 2006-07).

The NEMS system was adopted in 1997 and originally included sectoral environmental action plans (SEAP). However, these plans were only formulated once and were phased out in 2004 as a result of negative evaluations (Statskonsult 2003). The only MoPE SEAP to this date was adopted in 1999. It contains an overview and status of environmental impacts, both relating to national energy production and use and the petroleum sector. The plan did not however include nor entail any substantial evaluation of the sectoral policies vis-à-vis the SD-related objectives (Ministry of Petroleum and Energy 1999).

The general status and major policy responses according to the priority areas are presented and assessed every second year in the Government's report on the State of the Environment. This report is prepared by the MoE building on inputs from among others the MoPE. However, there has not been any systematic assessment of energy in the reports presented thus far.

\section{Other relevant processes and procedures}

The last broad energy policy evaluation was conducted in 1998 by an expert commission (Ministry of Petroleum and Energy 1998). On this basis, the then centre-liberal government proposed targets and policies for alternative, renewable energy production as well as energy efficiency (see above). The implementation of these targets was delegated to the public enterprise Enova. The status vis-à-vis the targets is monitored by Enova itself and presented annually, along with the MoPE's reporting in the State Budget. 


\section{SD-related objectives and targets}

There is no overall SD objective with direct relevance and implications for the energy sector. However, the national SD strategy makes many references to ongoing energy policy processes, and many energy policy initiatives are considered part of the implementation of the strategy.

In 2002 Sweden set itself the target of reducing national emissions of greenhouse gases by at least 4 pct. in 2008 - 12, compared to the 1990 level. This target is far more ambitious than the increase of 4 pct. permitted according to the Kyoto commitment. The energy sector has been considered a key area to fulfil this ambition. Energy-related targets include an ambition of reducing the use of energy: and increase the share of renewables as part of final electricity consumption. This includes achieving at least 17 TWh of additional renewable electricity by 2016. Recently Parliament also decided to set a quantified target for energy efficiency.

In addition, the former Labour government in 2005 expressed its ambition of a petroleum-independent Sweden by 2020. However, the current centre-right government has not yet concluded whether it will pursue this objective.

\section{SD Strategy and indicators}

The Swedish SD strategy was presented the first time in 2002, and was revised in 2004 and 2006. The one energy-relevant indicator monitored is parallel to the Norwegian one; energy use related to the development of the GDP. Status related to the indicator is assessed by Statistics Sweden.

\section{The State Budget and SD-related reporting}

The State Budget contains a chapter on sustainable energy policy with a focus on how decided, implemented and projected policy measures can contribute to the objective of using energy as efficiently as possible (Ministry of Finance 2007: 43). This objective is thus mirroring the SD-strategy indicator on energy efficiency. The state budget also includes a sub-chapter on measures for a "Sustainable energy system in the long run”, i.e. research and technology development.

\section{Environmental monitoring and related energy policy assessments}

In 1999 Sweden established a specific environmental monitoring system with National Environmental Quality Objectives (NEQO). There are 16 such objectives, most of which are supplemented by sub-targets. The system constitutes a comprehensive and flexible framework with regular reports and revisions of the objectives. The NEQO system is to contribute to: 1) Resolving all substantial environmental challenges 'before next generation'; and 2) the implementation of all relevant policy efforts by 2020 (2050 for climate change).

The NEQO system is managed by a council affiliated with the Swedish Environmental Protection Agency (SEPA). The representatives of the NEQO 
Monitoring towards more sustainable energy policies?

A comparative assessment of procedures and political impacts in Norway and Sweden

Council are nominated by the Government. As such, it does not constitute an entirely independent body. One should nonetheless emphasise the Council's role as a critical, scientifically informed agent. In addition, selected sectoral agencies have a specific responsibility to monitor and report on certain objectives.

Based on the reports from the NEQO Council the Minister of the Environment presents an annual progress report on the objectives before Parliament - integrated in the State Budget. The NEQO Council also organises an annual seminar for the Parliamentarians. Every four year the NEQO Council prepares an in-depth study both assessing overall status and evaluating the NEQO structure. The next such study is due in 2008 .

In particular, the NEQO system includes more focused policy strategies, one of which is labelled "More efficient energy use and transports". According to this strategy, and as part of the four-year cycle, relevant sectoral agencies, including the Swedish Energy Agency (SEA) jointly assess energy and transport and relevant policy measures (Swedish Energy Agency et al. 2007). ${ }^{5}$ In addition, as part of the same cycle, the SEA contributes a specific report on essential developments within the energy sector. Hence, the SEA forwarded a report in 2007, including assessments and recommendations for specific policy instruments (Swedish Energy Agency 2007a).

Including several policy recommendations these sector-specific reports in principle contribute to a process of formulating more sustainable energy and transport policies. The reports also include discussions of conflicting goals and what principles should guide the assessment of such conflicts. Thus the reports provide identification of crucial trade-offs and recommendations for the outcome of these.

The cyclical character of this system provides a basis for continual scoping and learning. In particular, the energy-related reports from the SEA and other agencies are addressing how policies can improve to de-couple pressures from impacts. The cooperation between the sectoral agencies provides a multi-disciplinary basis for mutual learning and stronger coordination between particularly energy and transport policies.

\section{Other relevant procedures}

Since 2001 the SEA also monitors the energy sector according to specific energy policy indicators. In addition to status, the annual reports provide an in-depth assessment of specific subjects; the 2007 report focused on secure energy supply (Swedish Energy Agency 2007b). The environmental policy objectives are quite prevalent even in these more sector-specific assessments. The objective of a sustainable energy system is one of the main objectives for the Swedish energy

\footnotetext{
${ }^{5}$ The responsible agencies are: The Swedish Energy Agency, the Swedish Rail Administration, the Swedish Civil Aviation Authority, the Swedish Environmental Protection Agency, the Swedish Maritime Administration and the Swedish Road Administration.
} 
policy and is monitored by several specific indicators related to different resources and categories of energy use (ibid.).

In 2002 the Parliament adopted the current national climate change policy strategy which has been extensively evaluated in 2007 preparing the next strategy expected in 2008 (Swedish Energy Agency and Swedish Environmental Protection Agency 2007). This evaluation is composed of reports and assessment from a number of sectoral agencies, not the least from the SEA.

7.3.3

\section{Comparative summary}

Swedish SD-related monitoring is particularly distinguished by the NEQO system. This system stands out both as more politically independent and more policy focused than the Norwegian NEMS system. The NEQO system focuses on both policy outputs and outcomes and related environmental impacts.

By contrast, in Norway, SD-related monitoring and reporting procedures are provided by the ministerial level, with few or no inputs from a more independent institution. In addition the monitoring is mainly focusing on the general state of the environment, with little or no focus on the impacts of energy policy measures vis-àvis the SD-related objectives.

The cyclical character of Sweden's NEQO system provides a basis for continuous scoping and learning. In particular, the energy-related reports from the SEA and other agencies are addressing how policies can improve to de-couple pressures from impacts. Decoupling is not explicitly treated in the Norwegian reports.

\section{4 \\ Possible political consequences and adjustments}

This section is based on analyses of parliamentarian reports and SD-related energy decisions, as well as of energy policy documents providing SD-related comments and decisions from the last ten years for both parliaments.

7.4.1

Norway

The "political attention" devoted to energy in Norway can be characterized as "specialised" and "fragmented". It is primarily directed towards the more specific issues of petroleum and hydropower, and for the last ten years also non-hydro renewables. Energy use is generally less debated. Political debate on the energy system as a whole is thus lacking. Moreover, even when the government proposed an SD Action Plan in 2003, and never since, Parliament has not debated SD explicitly.

The Government's reporting on SD-related energy matters are treated by the Standing Committee for Energy and Environment. However, for the last ten years there have been no comments or proposals affecting the form or content of this 
Monitoring towards more sustainable energy policies?

A comparative assessment of procedures and political impacts in Norway and Sweden

reporting. In general, most SD-relevant remarks made by the Committee are related to alternative energy, as well as the question of carbon capture and storage.

Although there are no explicit proposals or remarks on energy triggered by the SDrelated monitoring, the Socialist Left Party has occasionally given remarks on the overall arrangements and objectives for SD. In relation to the State Budget proposal for 2005, the party's representatives note the lack of linkages between the horizontal objectives provided by the SD action plan, and specific targets and a follow-up system for the sectoral ministries (Committee Recommendations 9, 2004-05).

The same committee also assesses the Government's bi-annual report on the State of the Environment. As mentioned above, some inputs are provided by the Ministry of Petroleum and Energy in the preparation of the report, but no supplementary assessment is provided for Parliament. One observes once again a general lack of attention towards energy. There has thus far not been any explicit focus on SDrelated measures in relation to energy production and consumption structures.

However, an exception is again provided by the Socialist Left Party, this time together with the three parties associated with the political centre in Norway. ${ }^{6}$ These four parties together are generally acknowledged to be the most consistent supporters of stronger environmental and SD policies. In relation to the 2001 report they provided a common remark on the importance of considering a reduction of the petroleum activities and addressing more robust policy measures for alternative energies and energy efficiency (Committee Recommendations 295, 2000-01: 23). This remark did not, however, lead to any concrete proposals.

The major emitter of greenhouse gas emissions in today's Norway is actually the petroleum sector, providing close to $30 \%$. However, a broader debate on concrete measures substantially limiting the impacts from this sector, has thus far been very little prevalent in the parliamentarian debate.

In total, Parliament's treatments of SD-relevant reports seem to reflect the general lack of substantial inputs and assessments concerning energy that could eventually induce more change-oriented approaches vis-à-vis energy policies. Neither the monitoring of the SD strategy, nor the Government's NEMS-related reporting seem to trigger any parliamentarian interest.

\footnotetext{
${ }^{6}$ These parties are: The Centre Party - traditionally representing the agrarian interests, the Christian People's Party and the Liberal Party.
} 
A national SD strategy for Sweden was adopted the first time in 2002, and revised in 2004 and 2006. All three times Parliament treated the proposals quite thoroughly. However, there were few explicit references to energy.

As elaborated in section 3 the Swedish NEQO system provides a relatively strong basis for possible adjustments of both policy objectives and instruments. Parliament is annually presented with the environmental status based on the NEQO system as part of the State Budget. The Standing Committee on Environmental and Agricultural Affairs usually comments upon this status with some brief references to sectoral policies, but rarely calls for policy amendments.

The Standing Committee for Industrial Affairs handles energy policy issues and the state budget for energy. In general, this committee has not commented upon the SDrelated reports and assessments provided in the State Budget.

The most crucial energy policy issue in Sweden has been the question of phasing out nuclear power production - based on a referendum in 1980. Although there is a parliamentarian decision backing this phase-out, opposition is increasingly voiced, particularly by representatives of the current centre-right governing coalition. In contrast, there have been no important political divergences on the question of introducing more bio-energy and wind power into the energy system. Hence, while there is some latent conflict on nuclear power, there has been a relative political consensus concerning the SD-related objectives for the energy sector in Sweden. This could probably also explain the relative lack of reactions and comments vis-àvis the NEQO reports.

On the other side, the NEQO system seems to be relatively present in the "Parliamentarian consciousness": The NEQO organises each year a session for the parliamentarians with a presentation of its annual report. The complete minutes of these sessions are included in the Environmental Committee's budget report. These minutes reveal an active participation and interest from the MPs.

While the annual reporting does not trigger intense parliamentarian debates, the 4 year in-depth assessment of the NEQO objectives, which also includes energy policy reports, has led to some motions by the Environment and Agriculture Committee. The first, and until now, only such process occurred in 2004. The then minority centre-right opposition particularly proposed to split up the joint energy and transport strategy. This is the only motion concerning the energy-relevant structure and procedures of the NEQO system. Apart this most motions and remarks concern more specific energy policy initiatives which have not reinforced the policy outputs' SD profile.

In fact, the years 2003 - 2005 could be considered a very active period for energy policies in Sweden. The then Labour Government forwarded several energy policy strategies and proposals related to overall SD ambitions for the sector. Given the 
Monitoring towards more sustainable energy policies?

A comparative assessment of procedures and political impacts in Norway and Sweden

parliamentarian majority the proposals included were mostly adopted. The opposition provided motions on modifications, but none of these altered the SDrelated objectives and measures.

In total, the Swedish Parliament is provided with several occasions for an SDrelevant overall treatment of the energy policies. However, few parliamentarians respond to the NEQO-relevant reports on energy policies with respect to the perspectives of more structural changes.

\section{Comparative summary}

The Norwegian Parliament is less engaged in an overall debate of the future structures of the energy policies than its Swedish counterpart. The NEMS system is rarely offered any substantial remark or motion, and the SD action plan and the recently adopted SD strategy was not debated at all. In the Swedish Parliament the NEQO system provides a basis for a more coherent and SD-relevant treatment of the energy policies. However, the substantial and comprehensive NEQO inputs have rarely - at least not directly - led to any substantial amendments. Motions are mostly related to specific energy policy initiatives. However, the NEQO system contributes to safeguard a more continuous and coherent parliamentarian perspective on the SD dimension of energy policies, compared to the Norwegian framework.

\section{Explaining differing procedures and evaluation potentials}

The comparison above demonstrates that the Swedish system is more in accordance with the recommendations forwarded by the OECD and the EEA, and with what one would assume to be effective monitoring and evaluation procedures. Is this more positive performance a reflection of a stronger political commitment by Swedish governments and political majorities, or are key features of the energy sector in Sweden more compatible with overall SD objectives? This section provides a preliminary discussion of possible explanatory variables.

Along the horizontal dimension, related to cross-sectoral SD commitments, Norway's work has been characterized as 'long on promise, but short on delivery' (Lafferty et al. 2007). Relevant governance mechanisms have been developed through four waves - including both up's and down's, but with a gradual downward tendency (Lafferty et al. 2008, forthcoming). In contrast, Sweden's SD work has evolved through more gradual reforms and progressive consolidation of the overarching SD framework. In Sweden as well is it possible to identify several "waves", though generally including more top's compared to Norway (Nilsson \& Persson 2008).

In line with G H Brundtland's position as Norway's Prime Minister, Norway relatively early initiated a programme of introducing SD as an overarching steering principle. However, Norway's SD ambitions from 1989 withered through the 
1990's, accompanied by a period of economic decline. This led to stronger priorities of traditional economic policies for economic growth, and - not the least, a reinforced priority of the Norwegian petroleum sector.

An opposite trend could be observed across the boarder, where Sweden's SD ambitions were given substantial political momentum from 1996 onwards. On the background of an economic recession the social democrats backed by a political majority formulated reform programme giving SD an overall priority (Lundqvist 2000). Green innovation became am important key concept supporting the SD focus (ibid.).

Green issues have had various degrees of saliency in the Norwegian partisan politics, often cutting across the dominant left-right cleavage (Knudsen et al. 2008). An important political divergence is related to the petroleum sector and the issue of further exploitation of the hydropower resources, even within some of the political parties, and criss-crossing all currently alternative governing coalitions. Moreover, this split also seems to prevent more coherent and long-term thinking on the energy policies. A recent "climate policy compromise” between the current government and the opposition concerning the latest climate change policy strategy - could represent a possible shift. The political sensitivity of energy issues also contributes to explain the relatively tight control of the SD-relevant energy monitoring from the ministerial level.

In Sweden political constellations have been more shifting, in particular related to the issues of further exploitation of the water courses (Vedung \& Brandel 2001). However, the issue of nuclear power still is a controversial issue in the Swedish political debate, and has been so since a majority voted for a phase-out in a referendum in 1980. The issue has recently regained salience with the emergence of climate change at the top of the agenda (Chen and Johnson 2008). The positions differ, however, not only pro et con - but also related to eventual preservation of the current reactors vs. further expansion (ibid.). As for hydropower the nuclear issue also has had a tendency to criss-cross alternative governing alternatives, and the current compromise seems to imply a preservation of the remaining reactors.

Hence, it seems that energy policy is subject to political tensions in both countries, although there seems to be more open and stable conflict in the Norwegian case. This "political split" is paralleled by an institutional rivalry in SD-related energy issues, between a weak Ministry of the Environment and a strong Ministry of Petroleum and Energy. Although being responsible for the SD strategy one could claim that the Ministry of Finance so far has not demonstrated any substantial leadership or interest in SD which could have contributed to settle this traditional institutional divergence. The follow-up of the SD strategy is very loosely delegated to the sectoral ministries with few overarching guidelines.

In Sweden such institutional rivalry does not seem be that important, and the energy field has been less institutionally specialised and segmented - currently being a part of the Ministry of Enterprise, Energy and Communication; and, during the period 
Monitoring towards more sustainable energy policies?

A comparative assessment of procedures and political impacts in Norway and Sweden

2004 - 2006, part of the Ministry for Sustainable Development. In addition the Prime Minister's Office has been very actively involved in the SD strategy and its follow-up, thereby providing a stronger political mandate and leverage than is the case in Norway.

In Norway one has observed an increasingly diffuse distinction between the political and administrative levels both within ministries and between ministries and subordinate agencies (Tranøy \& Østerud 2001). The agencies are increasingly integrated into the ministerial level, thereby weakening the possibility of providing more independent and critical assessments and advise. This is clearly the case on the environmental and energy policy fields which are politically sensitive areas, leading to relatively tight political control of the agencies' outputs.

In Sweden the agencies have a much more independent role and the ministers are not constitutionally responsible for the agencies, in contrast to Norway. This traditional distinction between ministries and agencies seems to serve the NEQO system well. The Swedish Environmental Protection Agency's role as lead agency in the NEQO structure, and the sectoral agencies' relatively independent policy assessments on energy and SD, succinctly illustrates the difference with Norway.

Moving more into the energy sector itself there is no tradition of treating energy policies as one coherent field in Norway. The three main sub-sectors constituted by hydropower, petroleum and - from the beginning of the 2000's - alternative renewable energy and energy efficiency, are moreover managed by three separate agencies. The petroleum field probably constitute the sector "most part", but is increasingly integrated towards the other sub-sectors because of the use of gas fired electricity domestically. On this background, as well as the increased importance of the climate change policy issue, there are however tendencies of reinforced interdependencies between these sub-sectors. In Sweden both energy production and use are treated more coherently, being part of more coordinated processes and strategies, and the energy policy field is managed by one agency only.

Both countries have deregulated their electricity production and distribution. However, the deregulation has been following partly different paths (Midttun 2001). Currently, one also observes a stronger market concentration in Sweden than in Norway. It is difficult to assess whether these differences influence the SDdimension substantially. However, Norway's larger number of small electricity companies owned by municipalities and counties depending on the revenues of hydropower production could contribute to a slightly more conservative outlook, in addition to the country's heavier hydropower dominance. 


\subsection{Conclusion}

Monitoring and evaluation of SD-relevant policies are considered key mechanisms by studies of 'governance for SD'. This paper has aimed at providing some insights in a comparative perspective. A major finding is that monitoring activities related to SD strategies tend to be status-oriented and descriptive and that these do not trigger any political debate or political amendments by themselves. The ecological dimension of SD is more explicitly treated by specific procedures in both countries chosen here, and are also more directly related to energy policies.

Sweden's NEQO system stands out as a particularly robust one, based on a relatively strong, independent mandate, and with a dynamic and cyclical character. Norway's NEMS system is much less robust and policy-focused. The NEQO system provides the Swedish Parliament with a solid basis for policy assessments and eventual policy adjustments. Experiences so far indicate, however, that the parliamentarians primarily relate to specific cases and instances more than responding to the overall assessments.

The relatively stronger position of the NEQO system in Sweden compared to Norway could be seen on the background of a generally stronger and more stable political priority of SD. This is reinforced by a structurally and institutionally more “consistent” energy policy field. Sweden's more coherent treatment of energy production and use seems to be a reason for, as well as being reinforced by, the material and institutional structure of the sector. This again seems to contribute to a better basis for SD-relevant policy evaluations. 


\section{References}

Aakre S. \& Torvanger A., 2007, "Case-studies on climate change response policies and strategies of selected Annex I countries: Norway and Sweden", Report 2007: 10, Oslo: CICERO Center for Climate and Environmental Research.

Aall C., 2001, "Norway: LA21 as a means of interpreting and achieving sustainable production and consumption”, in W.M. Lafferty WM (ed), Sustainable Communities in Europe, London: Earthscan Publications Ltd., pp. 83-106.

Aardal B., 1993, "Energi og miljø. Nye stridsspørsmål i møte med gamle strukturer“ (Energy and environment. New issues confronted with old structures - In Norwegian), Rapport 93:15, Oslo: Institutt for samfunnsforskning.

Andersen M. S., Christiansen P.M. \& Winter S.,1998, "Denmark: Consensus seeking and decentralisation", in K. Hanf \& A. Jansen (eds), Governance and Environment in Western Europe - Politics, Policy and Aministration, Harlow: Longman, pp.40-59.

Arentsen M.J., 1998, “The Invisible Problem and How to Deal with It: National Policy Styles in Radiation Protection Policy in The Netherlands, England and Belgium” in M.-L. Bemelmans-Videc, R.C. Rist \& E. Vedung (eds), Carrots, Sticks \& Sermons. Policy Instruments \& Their Evaluation, New Brunswick US \& London UK: Transaction Publishers, pp. 211-230.

Bache I. \& Flinders M., 2004, “Conclusions and Implications”, in I. Bache \& M. Flinders (eds) Multi-level Governance, Oxford: Oxford University Press, pp. 195-206.

Barrett S. \& Fudge C. (eds), 1981, Policy and Action. Essays on the Implementation of Public Policy, London: Methuen.

Bemelmans-Videc M.-L. \& Vedung E, 1998, "Conclusions: Policy Instruments Types, Packages, Choices, and Evaluation”, in M.-L. Bemelmans-Videc, R.C. Rist \& E. Vedung (eds), Carrots, Sticks \& Sermons. Policy Instruments \& Their Evaluation, New Brunswick US \& London UK: Transaction Publishers, pp. 249-273.

Bjørnæs T., Norland I.T., 2002, "Local Agenda 21: Pursuing sustainable development at the local level”, in W.M. Lafferty, M. Nordskag M \& H.A. Aakre HA (eds), Realizing Rio in Norway, ProSus, Oslo, pp. 43-62.

Bomberg E., 2004, "Adapting Form to Function? From Economic to Sustainable Development Governance in the European Union”, in W.M. Lafferty (ed.), Governance for Sustainable Development. The Challenge of Adapting Form to Function, Cheltenham, UK: Edw. Elgar Publ., pp. 61-94.

Bomberg E., 2009, "Governance for Sustainable Development: The United States and the European Union Compared”, in M.A. Schreurs, H. Selin \& S.VanDeever (eds), Transatlantic Environment and Energy Politics: Comparative and International Perspectives, London: Ashgate, pp. 21-40.

Bosselmann K., 2007, "Missing the Point? The EU's Institutional and Procedural Approach to Sustainability", in M. Pallemaerts \& A. Azmanova (eds), The European Union and Sustainable Development, Brussels: VUBPress, pp. 105125. 
Bouder F., 2002, “Canada”, in Governance for Sustainable Development: Five OECD Case Studies, Paris: OECD.

Bressers H.T.A., 2004, "Implementing sustainable development: how to know what works, where, when and how”, in W.M. Lafferty (ed), Governance for Sustainable Development. The Challenge of Adapting Form to Function. Cheltenham: Edw. Elgar Publ., pp. 284-318.

Brundtland G.H., 1990, “Global change and Our Common Future”, in One Earth One Future: Our Changing Global Environment, Silver C.S. \& DeFries R.S. (eds), National Academy Press, Washington D.C.

Bryner G., 2000, “The United States: 'Sorry, Not Our Problem”, in W.M. Lafferty \& J. Meadowcroft (eds), Implementing Sustainable Development: Strategies and Initiatives in High Consumption Societies, Oxford: Oxford University Press, pp. 273-302.

BSP, 2005, Science and Precaution: An Interactive Risk Assessment - SPIRE, D/2005/1191/25, Brussels: Belgium Science Policy.

BSP, 2006, The Role of Public Authorities in Integrated Product Policy: Regulators or Coordinators, D/2006/2201/12, Brussels: Belgium Science Policy.

Budsjettinnst. S. nr. 9 (2000-2001).

Buen J., 2005, "Danish and Norwegian wind industry: The relationship between policy instruments, innovation and diffusion”, in Energy Policy, Volume 34, pp. 3887-3897.

Caygill H., 1994, A Kant Dictionary. Oxford: Blackwell Publishers.

CEC, 2001, "Directive 2001/77/EC of the European Parliament and of the Council of 27 September 2001 on the promotion of electricity produced from renewable energy sources in the internal energy market”, Official Journal of the European Communities, 27 October, L 283/33-40.

CEC, 2002, "Communication from the Commission on Impact Assessment”,

COM(2002) 276 final, Brussels: Commission of the European Communities.

CEC, 2008, “Climate change: Commission welcomes final adoption of Europe's climate and energy package”, Press Release, 17 Dec 2008, Brussels: The European Commission.

CEC, 2009, "Directive 2009/28/EC of the European Parliament and of the Council of 23 April 2009 on the promotion of the use of energy from renewable sources and amending and subsequently repealing Directives 2001/77/EC and 2003/30/EC”, in Official Journal of the European Communities, 5 June 2009, L $140 / 16$.

Chen Y. \& Johnson F.X., 2008, "Sweden: Greening the power market in the context of liberalization and nuclear ambivalence”, in W.M. Lafferty \& A. Ruud (eds), Promoting Sustainable Electricity in Europe: Challenging the Path Dependency of Dominant Energy Systems, Cheltenham UK: Edward Elgar, pp. 219-249.

Chiesi A.M., 2007, "The economic sphere”, in A. Martinelli (ed.), Transatlantic Divide. Comparing American and European Society, Oxford: Oxford University Press, pp. 29-56.

Climate Wire (2008, May 1), "With Ohio added, 64 \% of the U.S. has renewable energy laws", unsigned article in Climate Wire online news service. Retrieved from http://www.eenews.net/climatewire/print/2008/05/01/4 
Collier U., 2002, "European Union Energy Policy in a Changing Climate”, in A. Lenschow (ed.), Environmental Policy Integration. Greening Sectoral Policies in Europe, London: Earthscan, pp. 175-192.

Collier D., 1993, “The Comparative Method”, in A. Finifter (ed.), Political Science: The State of the Discipline, Washington DC: The American Political Science Association, pp. 105-120.

COM(2008) 19 Final: Proposal for a Directive of the European Parliament and of the Council on the promotion of the use of energy from renewable sources (presented by the Commission). Brussels: The European Commission, 23.01.08.

Committee Recommendations 145,2008, Innstilling fra energi- og miljøkomiteen om norsk klimapolitikk, Parliament: Oslo.

Committee Recommendations 9, 2004, Budsjettinnsstilling til Stortinget fra energiog miljøkomiteen, Parliament: Oslo.

Committee Recommendations 295, 2000-01, Innstilling fra enegi- og miljøkomiteen om Regjeringens miljøvernpolitikk og rikets miljøtilstand, Parliament: Oslo.

Connecticut Climate Change Action Plan 2005, Hartford CT.

Christiansen A.C., 2002, "New renewable energy developments and the climate change issue: a case study of Norwegian politics", in Energy Policy, Volume 30, pp 235-243.

Dagbladet (2006), Norge er en energibrems. 08.03.06. (Norway as an energy laggard - in Norwegian).

Dalal-Clayton B., 1996, Getting to Grips With Green Plans, London: Earthscan.

Dalal-Clayton B. \& Sadler B., 2005, Strategic Environmental Assessment: A Sourcebook and Reference Guide to International Experience, London: Earthscan.

Danish EPA, 2002, Dansk strategi for bceredygtig udvikling, Copenhagen: Danish Environmental Protection Agency.

DEA, 1990, Energi 2000 - handlingsplan for en bceredygtig udvikling, Copenhagen: Danish Energy Agency.

Deville A. \& Harding R., 1997, Applying the Precautionary Principle, Sydney: Federation Press.

Driessen P.P.J. \& Glasbergen P. (eds), 2002, Greeening Society. The Paradigm Shift in Dutchh Environmental Politics, Dordrecht: Kluwer Academic Publ.

Durant R.F., Fiorino D.J. \& O’Leary R., 2004a, “Conclusion”, in R.F. Durant, D.J. Fiorino \& R. O’Leary (eds), Envrionmental Governance Reconsidered. Challenges, Choices and Opportunities, Cambridge MA: Massachusetts University Press, pp. 483-525.

Durant R.F., Fiorino D.J. \& O’Leary R. (eds), 2004b, Environmental Governance Reconsidered. Challenges, Choices and Opportunities, Cambridge MA: Massachusetts University Press.

Easton D., 1953, The Political System, New York: Albert Knopf.

Eberlein B. \& Newman A., 2008, "Innovating EU Governance Modes: The rise of incorporated transgovernmental networks", in Governance, Volume 21, Issue 1, pp. 25-52. 
EC, 2002, Consolidated Version of the Treaty Establishing the European Community Official Journal C 325, 24 December 2002. Retrieved from: http://europa.eu.int/eur-lex/en/treaties/dat/C_2002325EN.003301.html.

EC, 2006, "Consolidated Version of the Treaty Establishing the European Community”, in Official Journal of the European Union, C 321 E/46, 29 December 2006.

Econ, 2007, ”Mulig ny norsk energiproduksjon” (Assessment of potential new energy production in Norway - in Norwegian) Rapport 2007-016. Oslo: Econ.

EEA (European Environment Agency), 2005a, "Environmental Policy Integration in Europe: State of Play and an Evaluation Framework”, EEA Technical Report, No. 2/2005, Copenhagen: European Environment Agency.

EEA, 2005b, "Environmental Policy Integration in Europe: Administrative Culture and Practices”, EEA Technical Report, No 5/2005, Copenhagen: European Environment Agency.

EEA, 2005c, The European Environment: State and Outlook 2005. Copenhagen: EEA.

Elazar D.J., 2001, “The United States and the European Union: Models of their Epochs”, in K. Nicolaidis \& R. Howse (eds), The Federal Vision and Levels of Governance in the US and in the EU, Oxford : Oxford University Press, pp. 3153.

Elmore R., 1980, "Backward Mapping: Implementation Research and Policy Decisions”, in Political Science Quarterly, Volume 94, Issue 3, pp. 601-616.

Elzen B., Geels F. \& Green K. (eds), 2003, System Innovation and the Transition to Sustainability: Theory, Evidence and Policy, Aldershot UK: Edw. Elgar.

Enova, 2007, Enovas resultat- og aktivitetsrapport 2006 (Enova's report on activities and outcomes in 2006 - In Norwegian), Trondheim: Enova.

European Research Area, 2009, "Environmental Policy Integration and Multi-Level Governance (EPIGOV). Finalised project”, European Policy Brief, Brussels: European Research Area

Fabbrini S., 2007, Compound Democracies. Why the United States and Europe Are Becoming Similar, Oxford: Oxford University Press.

Fisher E., Jones J. \& von Schomberg R. (eds), 2006, Implementing the Precautionary Principle: Perspectives and Prospects, Cheltenham UK and Northampton MA: Edward Elgar.

Fisher E. \& Harding R., 2006, “The precautionary principle and administrative constitutionalism: The development of frameworks for applying the precautionary principle”, in E. Fisher et al. (eds), Implementing the Precautionary Principle: Perspectives and Prospects, Cheltenham UK and Northampton MA: Edward Elgar, pp. 113-136.

FSP, 2002, Levers for a Sustainable Development Policy, D/2002/1191/41, Brussels: Federal Science Policy.

Gan L., Eskeland G.S., Kolshus H.H., Birkeland H.,van Rooijen S. \&.van Wees M., 2005, "Green Electricity Market Development. Lessons from Europe and the U.S. and Implications for Norway”, Cicero Report 2005:3, Oslo: Cicero, University of Oslo. 
Garud R. \& Karnøe P. (eds), 2001, Path Dependence and Creation, Mahwah, NJ: Lawrence Erlbaum Associates Publ.

Garud R. \& Karnøe P., 2003, "Bricolage versus breakthrough: distributed and embedded agency in technology entrepreneurship”, in Research Policy, Volume 32, Issue 2, pp. 277-300.

Government Communication, 2006, "Strategic Challenges. A Further Elaboration of the Swedish Strategy for Sustainable Development”, Government Communication 2005/06:126, Regeringskansliet: Stockholm.

Grepperud S. \& Rasmussen I., 2004, “A general equilibrium assessment of rebound effects”, in Energy Policy, Volume 26, pp. 261-282.

Hertin J. \& Berkhout F., 2003, “Analysing Institutional Strategies for Environmental Policy Integration: The Case of EU Enterprise Policy”, in Journal of Environmental Policy \& Planning, Volume 5, Issue 1, pp. 39-56.

Homeyer I. von \& Knoblauch D., 2008, "Environmental Policy Integration and Multi-Level Governance - A State-of-the-Art Report”, EPIGOV Paper, Berlin: Ecologic - Institute for International and European Environmental Policy.

Hooghe L. \& Marks G., 2003, "Unraveling the Central State, but How? Types of Multi-level Governance”, in American Political Science Review, Volume 97, Issue 2, pp. 233-243.

Hornbeek J., 2008, “The United States of America”, in A.J. Jordan \& A. Lenschow (eds), Innovation in Environmental Policy? Integrating the Environment for Sustainability, Cheltenham UK: Edward Elgar, pp. 268-288.

Hovden E. \& Torjussen S., 2002, "Environmental policy integration in Norway”, in W.M. Lafferty, M. Nordskag \& A. Aakre (eds), Realizing Rio in Norway: Evaluative Studies of Sustainable Development, Oslo: ProSus, pp. 21-42.

Hvelpelund F., 2005, "Denmark”, in D. Reiche (ed.), Handbook of Renewable Energies in the European Union. Frankfurt am Main: Peter Lang, pp. 83-100.

IEA, 2002, World Energy Outlook 2002, Paris: OECD/EIA.

IEA, 2006a, Energy Policies of IEA Countries. Denmark 2006 Review, Paris: International Energy Agency.

IEA, 2006b, IEA Statistics. Renewables Information, Paris: International Energy Agency.

IEEP/NRDC, 2008, "Climate Change and Sustainable Energy Policies in Europe and the United States". Report from the transatlantic platform for action on the global environment, Brussels/Washington, DC: IEEP/NRDC.

Jackson T. \& Illsley B., 2006, “Strategic Environmental Assessment as a tool of environmental governance: Scotland's extension of the European Union SEA Directive”, in Journal of Environmental Planning and Management, Volume 49, Issue 3, pp. 361-383.

Jacob K. \& Volkery A., 2004, "Institutions and Instruments for Government SelfRegulation: Environmental Policy Integration in a Cross-Country Perspective”, in Journal of Comparative Policy Analysis, Volume 6, Issue 3, pp. 291-309. 
Jänicke M \& Jörgens H., 2000, “Strategic environmental planning and uncertainty: A cross-national comparison of green plans in industrialized countries", in Policy Studies Journal, Volume 28, Issue 3, pp. 612-632.

Jann W. \& Wegrich K., 2006, “Theories of the Policy Cycle”, in F. Fischer, G.J. Miller \& M.S.Sidney (eds), Hanbook of Public Policy Analysis: Theory, Politics and Methods, Boca Raton Fla: CRC Press, pp. 43-62.

Jordan A., 2002a, The Europeanization of British Environmental Policy: A Departmental Perspective, Basingstoke: Palgrave.

Jordan A. (ed.), 2002b, Environmental Policy in the European Union, London: Earthscan Ltd.

Jordan A. 2005. "Introduction: Environmental Actors in the European Union: Actors, Institutions and Policy Processes”, in A. Jordan (ed.), Environmental Policy in the European Union, London: Earthscan Ltd., pp. 1-18.

Jordan A., 2008, “The governance of sustainable development: taking stock and looking forwards", in Environment and Planning C: Government and Policy, Volume 26, pp. 17-33.

Jordan A.J. \& Lenschow A., 2008a, “Environmental policy integration: an innovation in environmental policy?”, in A.J. Jordan \& A. Lenschow (eds), Innovation in Environmental Policy? Integrating the Environment for Sustainability. Cheltenham UK: Edward Elgar, pp. 313-341.

Jordan A.J. \& Lenschow A. (eds), 2008b, Innovation in Environmental Policy? Integrating the Environment for Sustainability, Cheltenham UK: Edward Elgar.

Jordan A.J. \& Lenschow A., 2008c, "Integrating the environment for sustainable development: an introduction”, in A.J. Jordan \& A. Lenschow (eds), Innovation in Environmental Policy? Integrating the Environment for Sustainability, Cheltenham UK: Edward Elgar, pp. 3-23.

Jordan A. \& Liefferink D. (eds), 2004, Environmental Policy in Europe: The Europeanization of National Environmental Policy, London and New York: Routledge.

Jordan A. \& Schout A., 2006, The Coordination of the European Union: Exploring the Capacities of Networked Governance, Oxford: Oxford University Press.

Jordan A.J. \& Schout A., 2008, The Coordination of the European Union. Exploring the Capacities of Networked Governance, Oxford: Oxford University Press.

Jordan A.J., Schout A. \& Unfried M., 2008, “The European Union”, in A.J. Jordan and A. Lenschow (eds), Innovation in Environmental Policy? Integrating the Environment for Sustainability, Cheltenham UK: Edward Elgar, pp. 159-179.

Karnøe P. \& Buchhorn A., 2008, "Denmark: Path creation dynamics and winds of change”, in W.M. Lafferty \& A. Ruud (eds), Promoting Sustainable Electricity in Europe: Challenging the Path Dependency of Dominant Energy Systems, Cheltenham, UK: Edward Elgar, pp. 73-101.

Kelemen R.D., 2000, "Regulatory Federalism: EU Environmental Regulation in Comparative Perspective”, in Journal of Public Policy, Volume 20, Issue 3, pp.133 - 167.

Kemp J., 1968, The Philosophy of Kant, Oxford: Oxford University Press. 
Kemp R., Paro S.\& Gibson R.B., 2005, “Governance for sustainable development: moving from theory to practice”, in International Journal for Sustainable Development, Volume 8, Issue 1/2, pp. 12-30.

Kjellberg F. \& Reitan M., 1995, Studiet av offentlig politikk. En innføring, (The Study of Public Policy. An Introduction - In Norwegian), Oslo: Tano.

Kivimaa P., 2008, "Finland: Big is beautiful - promoting bioenergy in regionalindustrial contexts”, in W.M. Lafferty \& A. Ruud (eds), Promoting Sustainable Electricity in Europe: Challenging the Path Dependency of Dominant Energy Systems. Cheltenham UK: Edward Elgar, pp. 159-188.

Klitkou A., Pedersen T.E., Scordato L. \& Mariussen Å., 2008, "Competitive policies in the Nordic Energy Research and Innovation Area”, eNERGIA, Part 1: Country reports, Oslo: NIFU STEP.

Knill C. \& Lenschow A., 2005a, “Compliance, Communication and Competition: Different Approaches to European Governance and their Impact on National Institutions”, in Journal of Common Market Studies, Volume 43, Issue 3, pp. 583-606.

Knill C. \& Lenschow A., 2005b, “Compliance, Communication and Competition: Patterns of EU Environmental Policy Making and Their Impact on Policy Convergence”, in European Environment, Volume 15, pp. 114 - 128.

Knudsen J.K., 2001, ”Energi og miljø - fra separasjon til sektorintegrasjon? En studie av energipolitisk styring og miljøansvar på departementsnivå i Danmark og Norge2, (Energy and Environment - from separation to sectoral integration? - In Norwegian), FNI Report 2/2001, Lysaker: The Fridtjof Nansen Institute.

Knudsen J., 2008, "Monitoring towards more sustainable energy policies? A comparative assessment of procedures and political impacts in Norway and Sweden”, research paper presented at the Easy-Eco Vienna 2008 Evaluation of Sustainability Conference, the Research Institute for Managing Sustainability, Vienna University of Economics and Business Administration, 11 - 14 March 2008. Submitted to Environmental Policy \& Governance.

Knudsen J.K., 2009a, "De- and re-coupling energy: Environmental Policy Integration (EPI) and the case of renewable electricity in Scandinavia”, SINTEF Technical Report TR A6844, Trondheim: SINTEF Energy Research AS. Submitted to Environment and Planning $C$.

Knudsen J.K., 2009b, "Integration of environmental concerns in a trans-Atlantic perspective: The case of renewable electricity”, SINTEF Technical Report TR A6843, Trondheim: SINTEF Energy Research AS. Revised and re-submitted to the Review of Policy Research.

Knudsen J., Larsen O.M. \& Ruud A., 2008, "Norway: Trying to maintain maximum RES-E in a petroleum driven economy”, in W.M. Lafferty and A. Ruud (eds), Promoting Sustainable Electricity in Europe: Challenging the Path Dependency of Dominant Energy Systems, Cheltenham UK: Edward Elgar, pp. 250-278.

Kooiman J., 2003, Governing as Governance. London: SAGE Publ.

Kraemer R.A. \& Schreurs M.A., 2007, "Federalism and Environmentalism in the United States and Germany”, AICGS Policy Report, No. 31, Washington, D.C: American Institute for Contemporary German Studies, the Johns Hopkins University. 
Kraft M.E. \& Kamieniecki S., 2007, “Analyzing the Role of Business in Environmental Policy”, in M.E. Kraft \& S. Kamieniecki (eds), Business and Environmental Policy. Corporate Interests in the American Political System, Cambridge, MA: MIT Press, pp. 3-31.

Lafferty W.M., 1971, Economic Development and the Labour Movement in Scandinavia, Oslo: University Press.

Lafferty W.M., 2001a, “Adapting government practice to the goals of sustainable development”, Paper prepared for the for the OECD/PUMA Seminar on 'Improving governance for sustainable development', Paris, OECD, 22-23 November 2001.

Lafferty W.M., 2001b, "Local Agenda 21: The pursuit of sustainable development in subnational domains", in D. Devuyst D (ed), How Green is the City: Sustainability Assessment and the Management of Urban Environments, New York: Columbia University Press, pp.63-84.

Lafferty W.M. (ed.), 2001c, Sustainable Communities in Europe, London: Earthscan.

Lafferty W.M., 2002a, “Adapting Government Practice to the Goals of Sustainable Development”, ProSus Working Paper 1/02, Oslo: ProSus.

Lafferty W.M., 2002b, "From environmental protection to sustainable development. Environmental Policy Integration as a Challenge for Applied Science", Inaugural lecture to mark the occasion of the assumption of office as professor of Strategic research for sustainable development in Europe, Enschede: University of Twente, Center for Clean Technology and Environmental Policy (CSTM).

Lafferty W.M., 2002c, “Political Evaluation: Premises, Approaches and Methods”, ProSus Working Paper 2/02, Oslo: ProSus.

Lafferty W.M., 2004a, 'From environmental protection to sustainable development: the challenge of decoupling through sectoral integration', in W. M. Lafferty (ed.), Governance for Sustainable Development. Cheltenham UK: Edward Elgar, pp. 191-220.

Lafferty William M. (ed.), 2004b, Governance for Sustainable Development, Cheltenham UK: Edward Elgar.

Lafferty W.M., 2004c, "Governance for sustainable development: lessons and implications”, in W.M. Lafferty (ed.), Governance for Sustainable Development, Cheltenham UK: Edward Elgar, pp. 319-360.

Lafferty, W.M., 2004d, "Governmental initiatives for environmental policy integration: A further specification of benchmarks and normative standards' Plenary address to the 2004 Berlin Conference on the Human Dimensions of Global Environmental Change, The Free University of Berlin, December 3-4, 2005.

Lafferty W.M., 2004e, "Introduction: form and function in governance for sustainable development”, in W.M. Lafferty (ed.), Governance for Sustainable Development, Cheltenham UK: Edward Elgar, pp. 1-31.

Lafferty W.M, Aall C., Lindseth G. \& Norland I.T. (eds), 2006, Lokal Agenda 21 i Norge: Hvor Mye Hadde Vi? Hvor Mye Ga Vi Bort? Hvor Mye Har Vi Igjen? 
("Local Agenda 21 in Norway: How Much Did We Have? How Much Did We Give Away? How Much is Left?” - In Norwegian), Oslo: Unipub.

Lafferty W.M. \& Eckerberg K. (eds), 1998, From the Earth Summit to Local Agenda 21. Working Towards Sustainable Development, London: Earthscan.

Lafferty W.M. \& Hovden E., 2002, "Environmental Policy Integration: Towards an analytical framework”, ProSus Report, No. 7/02. Oslo: ProSus, University of Oslo.

Lafferty W.M. \& Hovden E., 2003, “Environmental Policy Integration: Towards an Analytical Framework”, in Environmental Politics, Volume 12, Issue 3, pp. 1 22.

Lafferty W.M. \& Knudsen J., 2007, “The issue of 'balance' and trade-offs in environmental policy integration: How will we know EPI when we see it?”, EPIGOV Paper No. 11, Berlin: Ecologic. To be published in von Homeyer et al. (eds) The Promise and Practice of Environmental Policy Integration. A Multi-Level Governance Perspective. Cheltenham UK: Edw. Elgar Publ.

Lafferty W.M., Knudsen J. \& Larsen O.M., 2007, "Pursuing sustainable development in Norway: The challenge of living up to Brundtland at home”, in European Environment, Volume 17, pp.177 - 188.

Lafferty W.M. \& Langhelle O., 1999a, "Sustainable Development as Concept and Norm”, in W.M. Lafferty \& O. Langhelle (eds), Towards Sustainable Development: On the Goals of Development - and the Conditions of Sustainability, London: Macmillan Publishers, pp. 1-29.

Lafferty, W.M. \& Langhelle, O.(eds), 1999b, Towards Sustainable Development: On the Goals of Development - and the Conditions of Sustainability, London: Macmillan Publishers.

Lafferty W.M, Langhelle O.S, Mugaas P., Holmboe Ruge M. (eds), 1997, Rio +5: Norges Oppfølging av FN-konferansen om Miljø og Utvikling, ("Rio +5: Norway's Follow-up of the UN-conference on Envrionment and Development"In Norwegian), Oslo: Tano Aschehoug.

Lafferty W.M., Larsen O.M. \& Ruud A., 2008, “Norway”, in A.J. Jordan \& A. Lenschow, (eds), Innovation in Environmental Policy? Integrating the Environment for Sustainability, Cheltenham UK: Edward Elgar, pp. 202-223.

Lafferty W.M.\& Meadowcroft J. (eds), 1996, Democracy and the Environment. Problems and Prospects, Cheltenham UK: Edw. Elgar.

Lafferty W.M. \& Meadowcroft J. (eds), 2000a, Implementing Sustainable Development: Strategies and Initiatives in High Consumption Societies, Oxford: Oxford University Press.

Lafferty W.M. \& Meadowcroft J., 2000b, “Introduction”, in W.M. Lafferty and J. Meadowcroft (eds), Implementing Sustainable Development: Strategies and Initiatives in High Consumption Societies, Oxford: Oxford University Press, pp. $1-22$.

Lafferty W.M. \& Meadowcroft J., 2000c, "Patterns of Governmental Engagement”, in W.M. Lafferty \& J. Meadowcroft (eds), Implementing Sustainable Development: Strategies and Initiatives in High Consumption Societies, Oxford: Oxford University Press, pp. 337-421.

Lafferty W.M. \& Narodoslawsky M. (eds), 2003, Regional Sustainable Development in Europe, Oslo: ProSus. 
Lafferty W.M, Nordskag M. \& Aakre H.A. (eds), 2002, Realizing Rio in Norway. Evaluative Studies of Sustainable Development,. ProSus, Oslo

Lafferty W.M \& Ruud A., 2004, "Green Innovation Policy in Norway: How can it be evaluated?”, ProSus Working Paper 3/04, ProSus: Oslo.

Lafferty W.M. \& Ruud A., 2006, "Standards for Green Innovation. Applying a Proposed Framework to Governmental Initiatives in Norway”, in Evaluation, Volume 12, Issue 4, pp. $454-473$.

Lafferty W.M. \& Ruud A., 2008a, "Conclusion: Energy path dependency and the promotion of RES-E in Europe”, in W.M. Lafferty \& A. Ruud (eds), Promoting Sustainable Electricity in Europe: Challenging the Path Dependency of Dominant Energy Systems, Cheltenham UK: Edward Elgar, pp. 279-330.

Lafferty W.M. \& Ruud A.., 2008b, "Introduction: Promoting green electricity in Europe: the challenge of integrating contextual factors”, in W.M. Lafferty \& A. Ruud (eds), Promoting Sustainable Electricity in Europe: Challenging the Path Dependency of Dominant Energy Systems, Cheltenham UK: Edward Elgar, pp. 1-44.

Lafferty W.M. \& Ruud A. (eds), 2008c, Promoting Sustainable Electricity in Europe: Challenging the Path Dependency of Dominant Energy Systems, Cheltenham UK: Edward Elgar.

Lafferty W.M., Ruud A. \& Larsen O.M., 2005, "Environmental Policy Integration: How Will We Recognize It When We See It? The Case of Green Innovation Policy in Norway”, in Governance of Innovation Systems: Case Studies in Cross-Sectoral Policy. Paris: OECD, pp. 221-244.

Lægreid P, Roness P.G. \& Rubecksen K., 2006, “Autonomy and Control in the Norwegian Civil Service: Does Agency Form Matter?”, in T. Christensen \& P. Lægreid (eds), Autonomy and Regulation. Coping with Agencies in the Modern State, Edward Elgar: Cheltenham UK, pp. 235-267.

Landman T., 2008, Issues and Methods in Comparative Politics, London and New York: Routledge.

Langhelle O., 2000, "Norway: Reluctantly carrying the torch”, in W.M. Lafferty \& J. Meadowcroft (eds), Implementing Sustainable Development. Strategies and Initiatives in High Consumption Societies, Oxford: Oxford University Press, pp. 174-208.

Larsen O.M., 2005, “Governing Innovation for Sustainable Development: Integration of Environmental and Innovation Policies in Norway”, ProSus Report, No. 4/2005, Oslo: ProSus.

Lenschow A. (ed.), 2002a, Environmental Policy Integration. Greening sectoral policies in Europe, London: Earthscan

Lenschow A., 2002b, "Greening the European Union: An Introduction", in A. Lenschow (ed.), Environmental Policy Integration. Greening Sectoral Policies in Europe London: Earthscan, pp. 3-21.

Lenschow A., 2002c, "New regulatory approaches in "greening” EU policies”, in A. Jordan (ed.), Environmental Policy in the European Union, London: Earthscan Ltd., pp. 295-316.

Lenschow A., 2005, “New Regulatory Approaches in 'Greening' EU Policies”, in A. Jordan (ed.), Environmental Policy in the European Union. Actors, Institutions and Processes, London: Earthscan, pp. 295-316. 
Liberatore A., 1997, “The integration of sustainable development objectives into EU policy-making: Barriers and prospects”, in S. Baker, M. Kousis, D. Richardson \& S. Young (eds), The Politics of Sustainable Development: Theory, Policy and Practice within the European Union, London: Routledge, pp. 108-126.

Lieberman J.K. (1983). The Litigious Society, New York City: Basic Books.

Litz F.T., 2008, "Toward a Constructive Dialogue on Federal and State Roles in U.S. Climate Change Policy”, Report in Solutions White Paper Series, Arlington, VA: Pew Center on Global Climate Change.

Lundqvist L.J., 2000, "Capacity-building or social construction? Explaining Sweden's shift towards ecological modernisation”, in Geoforum, Volume 31, pp. 21-32.

Lundqvist L.J., 2001, "Implementation from Above: The Ecology of Power in Sweden's Environmental Governance”, in Governance: An International Journal of Policy and Administration, Volume 14, pp. 319-337.

Lundqvist L.J., 2004a, "Management by objectives and results: a comparison of Dutch, Swedish and EU strategies for realising sustainable development", in W.M. Lafferty (ed.), Governance for Sustainable Development, Edward Elgar: Cheltenham UK, pp. 95-127.

Lundqvist L.J., 2004b, Sweden and ecological governance. Straddling the fence, Manchester UK: Manchester University Press.

Majone G., 1993, “The European Community Between Social Policy and Social Regulation”, in Journal of Common Market Studies, Volume 31, Issue 2, pp. 153-170.

Mallon K., 2006, Renewable energy policy and politics, London: Earthscan.

Martinelli A., 2007a, "Politics and institutional architectures”, in A. Martinelli (ed.), Transatlantic Divide. Comparing American and European Society, Oxford: Oxford University Press, pp. 95-142.

Martinelli A. (ed.), 2007b, Transatlantic Divide. Comparing American and European Society, Oxford: Oxford University Press.

Martinuzzi A., 2004, "Sustainable development evaluations in Europe - Market analysis, meta evaluation and future challenges”, in Journal of Environmental Assessment Policy and Management, Volume 6, Issue, 4, pp. 411-442.

Martinuzzi A., Schubert U. \&, Störmer E., 2007, “Outlook: future research questions and policy issues”, in U. Schubert \& E. Störmer (eds), Sustainable Development in Europe: Concepts, Evaluation and Applications, Edw. Elgar: Chatham UK, pp. 321-326.

Mazmanian D. \& Sabatier P., 1983, Implementation and Public Policy, Glenview, IL: Scott, Foresman and Co.

Meadowcroft J., 1999, “The Politics of Sustainable Development: Emergent Arenas and Challenges for Political Science”, in International Political Science Review, Volume 20, pp. 219-237.

Meadowcroft J., 2004, "Participation and sustainable development: modes of citizen, community and organisational involvement”, in W.M. Lafferty (ed.), Governance for Sustainable Development,. Edward Elgar: Cheltenham UK, pp. 162-190. 
Meadowcroft J., 2005, “Environmental Political Economy, Technological Transitions and the State”, in New Political Economy, Volume 10, pp. 479-498.

Meadowcroft J., 2007a, "National Sustainable Development Strategies: Features, Challenges and Reflexivity", in European Environment, Volume 17, pp.152163.

Meadowcroft J., 2007b, "Who is in Charge here? Governance for Sustainable Development in a Complex World", in Journal of Environmental Policy \& Planning, Volume 9, pp. 299-314.

Meyer W., 2007, "Evaluation of sustainable development: a social science approach”, in U. Schubert \& E. Störmer (eds), Sustainable Development in Europe: Concepts, Evaluation and Applications, Chatham UK: Edw. Elgar, pp. 33-50.

Midttun A., 2001, "Deregulated Energy Markets and the Environment: The Nordic Experience”, in Environmental Politics, Volume 10, Issue 2, pp. 90 - 114.

Midttun A. \& Koefoed A.L., 2005, "Green Innovation in Nordic Energy Industry: Systemic Contexts and Dynamic Trajectories”, in M. Weber \& J. Hemmelskamp, (eds), Towards Environmental Innovation Systems. Berlin: Springer Verlag, pp. 115-136.

Ministry for Sustainable Development, 2005, Final Report: Analysis of Sweden's success in achieving its national indicative targets for renewable electricity, Stockholm: Ministry for Sustainable Development.

Ministry of Sustainable Development, 2006, “Indikatorer för hållbar utveckling” (Indicators for sustainable development - In Swedish), Ministerial Memo,22 March 2006, Stockholm: Ministry of Sustainable Development

Ministry of Transport and Energy, 2005, Energy Strategy 2025. Perspectives to 2025 and Draft action plan for the future electricity infrastructure, Copenhagen: Ministry of Transport and Energy.

Montel Power News, 2007, "Underbemanning i NVE kan stoppe regjeringens vindkraftmål” (Insufficient capacity in the NVE could hamper the fulfilment of the Government's wind power target - In Norwegian), Newsletter for Norway, no. 14, week 272007.

MoF, Norway, 2003, Norway's Action Plan for Sustainable Development, Oslo: Ministry of Finance, [http://odin.dep.no/filarkiv/206401/nat_action.pdf]

MoF, Norway, 2005 "Enkle signaler i en kompleks verden. Forslag til et nasjonalt indikatorsett for bærekraftig utvikling” (Simple signals in a complex world. Proposal for national indcators for sustainable development - In Norwegian), NOU 5: 2005, Oslo: Ministry of Finance.

MoF, Norway, 2007, Norway's Strategy for Sustainable Development, Oslo: Ministry of Finance:

MoF, Sweden, 2007, Statsbudgetet för 2007, Programområde 21 Energi (State Budget 2007. Programme area 21 Energy - In Swedish), Stockholm: Ministry of Finance.

MoFA, Norway, 2002, National Strategy for Sustainable Development. Ministry of Foreign Affairs, Oslo http://odin.dep.no/filarkiv/158716/SustainableDev_1608.pdf 
MoPE, 1998, “Energi- og Kraftbalansen in Norge mot 2020” (Norway’s Energyand Power Balance towards 2020 - in Norwegian), NOU 11:1998, Oslo: Ministry of Petroleum and Energy.

MoPE, 1999, Miljøhandlingsplan for olje- og energisektoren 1999 (Environmental Action Plan for the petroleum- and energy sector 1999 - In Norwegian), Ministry of Petroleum and Energy: Oslo.

MoPE, 2005, Fakta 2005. Energi- og vassdragsvirksomheten i Norge (Facts 2005: The Energy Sector and Water Resources in Norway - In Norwegian), Oslo: Ministry of Petroleum and Energy.

MoPE, 2006a, Fakta 2006. Energi- og vassdragsvirksomheten i Norge (Facts 2006: The Energy Sector and Water Resources in Norway - In Norwegian), Oslo: Ministry of Petroleum and Energy.

MoPE, 2006b, "Mutual green certificate market will not be established - too expensive for Norwegian consumers", Press release No. 26/06E, Date: February 27, 2006. Oslo: Ministry of Petroleum and Energy.

MoPE, 2007, "Reports in accordance with the Directive 2001/77/EC on the promotion of electricity produced from renewable energy sources in the internal electricity market", Report to the EEA Joint Committee, prepared by the Norwegian Ministry of Petroleum and Energy, available at: http://www.regjeringen.no/Upload/OED/Vedlegg/03-0105241_Reports_in_accordance_with_the_Directive_20-_0717-EC_522610.pdf. NVE (2006), Press Release, dated 19 Oct 2006.

Moslener U. \& Sturm B., 2008, “A European Perspective on Recent Trends in US Climate Policy”, in European Environment, Volume 18, pp. 257 - 275.

Nagel S.S., 2002, Handbook of Public Policy Evaluation, London: Sage Publications.

NEQO Council, 2008, ”Miljömålen - nu är det bråttom!” Miljömålsrådets utvärdering av Sveriges miljömål 2008 (The NEQO Assessment of Sweden's environmental quality objectives 2008 - In Swedish), NEQO Council: Stockholm.

Nilsson M., 2005a, Connecting Reason to Power. Assessments, Learning, and Environmental Policy Integration in Swedish Energy Policy, Stockholm: Stockholm Environment Institute. Doctoral dissertation, Faculty of Technology, Policy and Management, University of Delft, submitted 12.09.05.

Nilsson M., 2005b, "Learning, frames, and environmental policy integration: the case of Swedish energy policy”, in Environment and Planning C: Government and Policy, Volume 23, pp. 207-226.

Nilsson M., 2006, “The role of assessments and institutions for policy learning: A study on Swedish climate and nuclear policy formation”, in Policy Sciences, Volume 38, pp. 225-249.

Nilsson M. \& Eckerberg K. (eds), 2007, Environmental Policy Integration in Practice. Shaping Institutions for Learning, London: Earthscan.

Nilsson M., Eckerberg K. \& Finnveden G., 2007a, “Discussion: What Enabled EPI in Practice?” in M. Nilsson and K. Eckerberg (eds), Environmental Policy Integration in Practice. Shaping Institutions for Learning, London: Earthscan, pp. 137-162. 
Nilsson M., Eckerberg K. \& Persson Å., 2007b, “Environmental Policy Integration and Changes in Governance in Swedish Energy and Agricultural Policy over two Decades”, EPIGOV Paper, Berlin: Ecologic.

Nilsson M. \& Persson Å., 2003, "Framework for Analysing Environmental Policy Integration”, in Journal of Environmental Policy and Planning, Volume 5, Issue 4, pp. 333-359.

Nilsson M. \& Persson Å., 2008, “Sweden”, in A.J. Jordan \& A. Lenschow (eds), Innovation in Environmental Policy? Integrating the Environment for Sustainability, Cheltenham UK: Edward Elgar, pp. 224-246.

Nollkaemper A., 2002, "'Three Conceptions of the Integration Principle in International Environmental Law', in Andrea Lenschow (ed.), Environmental Policy Integration: Greening Sectoral Policies in Europe, London: Earthscan, pp. 22-32.

NVE, 2007, Vindkraft - idriftssatte og planlage anlegg (An oversight over wind power - installed and projected plants - In Norwegian). Oslo: Norwegian Water Resource and Energy Directorate,

http://www.nve.no/modules/module_111/netbasNVE.asp?script=8, 1 July 2007.

OECD, 2001a, Policies to Enhance Sustainable Development, Paris: OECD.

OECD, 2001b, Sustainable Development. Critical Issues, Paris: OECD.

OECD, 2002a, Governance for Sustainable Development: Five OECD Case Studies, Paris: OECD.

OECD, 2002b, "Improving policy coherence and integration for sustainable development: A checklist.” OECD Policy Brief, PUMA, OECD: Paris. [Available as of 01.07.09 at: http://www.oecd.org/dataoecd/60/1/1947305.pdf]

OED, 1987, The Compact Oxford English Dictionary (2 ${ }^{\text {nd }}$ edition), Oxford: Oxford University Press.

O’Toole L.J., 2000, "Research on Policy Implementation: Assessment and Prospects”, in Journal of Public Administration Research and Theory, Volume 10, Issue 2, pp. 263-288.

O'Toole L.J., 2004, “Implementation theory and the challenge of sustainable development: the transformative role of learning”, in W.M. Lafferty (ed.), Governance for Sustainable Development, Edward Elgar: Cheltenham UK, pp. 32-60.

Ot.prp. nr. 35 (2000-2001), Om lov om endringar i lov av 29. juni 1990 nr. 50 om produksjon, omforming, overføring, omsetning og fordeling av energi m.m. (energilova) (Proposition for Amendments of the Energy Act - In Norwegian), Oslo: Ministry of Petroleum and Energy.

Pallemaerts M., 2006, “The EU and Sustainable Development: An Ambiguous Relationship”, in M. Pallemaerts \& A. Azmanova (eds), The European Union and Sustainable Development, Brussels: VUBPress, pp. 19-52.

Pallesen T., 2006, "Scandinavian Corporatism in a Trans-Atlantic Comparative Perspective”, in Scandinavian Political Studies, Volume 29, Issue 2, pp. 131145.

Parsons W., 1995, Public Policy: An Introduction to the theory and Practice of Policy Analysis, Aldershot, UK and Brookfield, US: Edward Elgar. 
Pedersen L.H. \& Rieper O., 2008, “Is Realist Evaluation a Realistic Approach for Complex Reforms?”, in Evaluation, Volume 14, pp. 271-293.

Persson Å., 2004, "Environmental Policy Integration: An Introduction", Background Paper: Project on 'Policy Integration for Sustainability (PINTS), Stockholm: Stockholm Environment Institute (SEI).

Persson Å., 2007, “Different Perspectives on EPI”, in M. Nilsson \& K. Eckerberg (eds), Environmental Policy Integration in Practice. Shaping Institutions for Learning, London: Earthscan, pp. 25-48.

Peterson T.D. \& Rose A.Z., 2006, "Reducing conflicts between climate policy and energy policy in the US: The important role of the states", in Energy Policy, Volume 34, pp. 619 - 631.

Pew Center on Global Climate Change, 2008, "States Sue US EPA over Greenhouse Gas Emissions”, retrieved from http://www.pewclimate.org/node/6152 [accessed on 17 September 2008].

Pierre J., 2000, "Introduction: Understanding Governance”, in J. Pierre (ed.), Debating Governance. Authority, Steering, and Democracy, Oxford: Oxford University Press, pp. 1-9.

Pierre Jon \& Peters B.G., 2005, Governing Complex Societies. Trajectories and Scenarios, Basingstoke: Palgrave Macmillan.

Pressman J.L. \& Wildavsky A., 1984, Implementation, Berkeley: California University Press.

Rabe B.G., 2004, State House and Green House. The Emerging Politics of American Climate Change Policy, Washington DC: Brookings Institution Press.

Rabe B.G., 2006, Race to the Top: The Expanding Role of US State Renewable Portfolio Standards, Arlington, VA: Pew Center on Global Climate Change.

Rabe B.G., 2008, "States on Stereoids: The Intergovernmental Odyssey of American Climate Policy”, in Review of Policy Research, Volume 25, Issue 2, pp. $105-128$.

Rabe B.G., Román M. \& Dobelis A.N., 2005, "State competition as a Source Driving Climate Change Mitigation”, in New York University Environmental Law Journal, Volume 14, Issue 1, pp. 1-53.

Rabe B.G. \& Mundo P.A., 2007, "Business Influence in State-Level Environmental Policy”, in M.E. Kraft \& S.Kamieniecki (eds), Business and Environmental Policy. Corporate Interests in the American Political System, Cambridge, MA: MIT Press, pp. 265-297.

Rasmussen I., Knudsen J. \& Ruud A., 2006, ”Politisk styring og lønnsomhet. En analyse av rammebetingelser for energiomlegging i bygge- og eiendomssektoren i Norge" (Political signals and profitability. Analysis of external conditions affecting energy shifts in the construction and property industry in Norway - In Norwegian), SUM Report No. 12, Oslo: Centre for Development and the Environment (SUM).

Regeringskansliet, 2009, ”En hållbar energi- och klimatpolitik för miljö, konkurrenskraft och trygghet” (A sustainable energy- and climate policy for the environment, competitiveness and safety - In Swedish), Stockholm: Regeringskansliet, 5 Feb. 2009. 
Reiche D. \& Bechberger M., 2004, "Policy differences in the promotion of renewable energies in the EU member states”, in Energy Policy, Volume 32, pp. 843-849.

Remøe S.O., 2005, “Governing Fragmentation: The Case of Norway”, Chapter 8 in S.O. Remøe (ed.), Governance of Innovation systems: Case studies in innovation policy, Paris: OECD Publications.

Rhodes R.A.W., 1997, Understanding Governance. Policy Networks, Governance, Reflexivity and Accountability, Maidenhead and Philadelphia: Open University Press.

Riksrevisjonen, 1999, "Riksrevisjonens undersøkelse vedrørende regjeringens miljørapportering til Stortinget" (Office of the Auditor General's investigations concerning the Government's environmental reports for the Parliament - In Norwegian), Riksrevisjonens Administrative rapporter $\mathrm{nr}$ 1/1999, Oslo: Office of the Auditor General of Norway.

Rist R.C., 1995, "Policy Evaluation”, The International Library of Comparative Public Policy Vol. 3, Cambridge University Press: Cambridge.

Rowlands I.H., 2005, "The European directive on renewable electricity: conflicts and compromises”, in Energy Policy, Volume 33, pp. 965 - 974.

Russel D., 2007, “The United Kingdom's Sustainable Development Strategies: Leading the Way or Flattering to Deceive?”, in European Environment, Volume 17 , pp. 189-200.

Ruud A., Jacobsen G.B. \& Knudsen J.K., 2009, ”Styrket realisering av fornybar energi: Lærdommer fra Sverige og Danmark" (Reinforced realization of renewable energy production: Lessons from Sweden and Denmark - In Norwegian), Teknisk Rapport TR A6807, Trondheim: SINTEF Energiforskning AS.

Sabatier P.A. (ed.), 1999, Theories of the Policy Process, Boulder, CO: Westview Press.

Sabatier P.A. \& Mazmanian D., 1979, “The conditions of effective implementation: A guide to accomplishing policy objectives”, in Policy Analysis, Volume 5, pp. 481-504.

Sadler B. (ed.), 2005, State Environmental Assessment at the Policy Level. Recent Progress, Current Status and Future Prospects, Prague: The Regional Environmental Center for Central and Eastern Europe.

Schout A.\& Jordan A. J., 2005, "Co-ordinating European Governance: SelfOrganising or Centrally Steered?”, in Public Administration, Volume 83, Issue 1, pp. 201-220.

Schout A. \& Jordan A.J., 2007, "EU-EPI, Policy Co-ordination and New Institutionalism”, EPIGOV Paper No. 13, Berlin: Ecologic.

Schreurs M.A., 2002, Environmental Politics in Japan, Germany, and the United States, Cambridge: Cambridge University Press.

Schreurs M.A., 2004, “The Climate Change Divide: The European Union, the United States, and the Future of the Kyoto Protocol”, in N.J. Vig \& M.G. Faure (eds), Green Giants? Environmental Policies of the United States and European Union, Cambridge, MA: MIT Press, pp. 207-230. 
Schreurs M.A., 2007, "Renewable Energy Politics in the United States”, in L. Mez (ed.), Green Power Markets. Support Schemes, Case Studies and Perspectives, Essex: Brentwood, pp. 227-250.

Schubert U. \& Störmer E. (eds), 2007, Sustainable Development in Europe: Concepts, Evaluation and Applications, Chatham UK: Edw. Elgar.

SEA, 2007a, Energiindikatorer 2007. Uppföljning av Sveriges energipolitiska mål (Energy indicators 2007. Follow-up of Sweden's energy policy objectives - In Swedish), Swedish Energy Agency: Eskilstuna.

SEA, 2007b, Energi som miljömål (Energy as environmental quality objective - In Swedish), Swedish Energy Agency: Eskilstuna.

SEPA, 2007, "Miljömål och andra önskemål. En studie av synergier och konflikter" (Environmental objectives and other interests. A study of synergies and conflicts - In Swedish), Rapport 5747, Swedish Environmenal Protection Agency: Stockholm.

Sgobbi A., 2007, "EPI at National Level - A Literature Review”, EPIGOV Paper. Berlin: Ecologic.

Söderholm P., Ek K. \& Pettersson M., 2007, ”Wind power development in Sweden: Global policies and local obstacles”, in Renewable and Sustainable Energy Reviews, Volume 11, pp. 365-400.

SOU, 2008, Svensk klimatpolitik. Betänkande av Klimatberedningen (Swedish climate policy. Assessment from the Climate Committee - In Swedish), Stockholm: Statens Offentliga Utredningar.

State of Connecticut, 2007, House Bill No. 7432: An Act Concerning Electricity and Energy Efficiency, Hartford CT: State House.

Statskonsult, 2003, ”Evaluering av sektorvise miljøhandlingsplaner” (Evaluation of sectoral environmental action plans - In Norwegian), Statskonsult Rapport 2003: 6, Oslo: Statskonsult.

Steurer R., 2007, "From Government Strategies to Strategic Public Management: an Exploratory Outlook on the Pursuit of Cross-Sectoral Policy Integration”, in European Environment, Volume 17, pp. 201-214.

Steurer R., 2008, "Sustainable development strategies”, in A.J. Jordan \& A. Lenschow (eds), Innovation in Environmental Policy? Integrating the Environment for Sustainability, Cheltenham UK: Edward Elgar, pp. 93-113.

Steurer R. \& Martinuzzi A., 2005, “Towards a new pattern of strategy formation in the public sector: first experiences with national strategies for sustainable development in Europe", in Environment and Planning C: Government and Policy, Volume 23, pp. 455-472.

Störmer E. \& Schubert U., 2007, "Evaluation of sustainable development in Europe: context and introduction", in U. Schubert \& E. Störmer (eds), Sustainable Development in Europe: Concepts, Evaluation and Applications, Chatham UK: Edw. Elgar, pp. 1-30.

Sverdrup L.A., 1997, "Norway’s institutional response to sustainable development”, in Environmental Politics, Volume 6, Issue 1, pp. 54-82.

Swedish Rail Administration, Swedish Energy Agency, Swedish Civil Aviation Authority, Swedish Environmental Protection Agency, Swedish Maritime Administration and Swedish Road Administration, 2007, Strategin för effektivare energianvändning och transporter (The Strategy for more effective 
energy usage and transports - In Swedish), Swedish Environmental Protection Agency: Stockholm.

Tanasescu I., 2006, “The Political Process Leading to the Development of the EU Sustainable Development Strategy”, in M. Pallemaerts \& A. Azmanova (eds), The European Union and Sustainable Development, Brussels: VUBPress, pp. 53-77.

Thue L., 1994, Statens kraft: Kraftutbygging og samfunnsutvikling (The Construction of Electricity Production and Societal Development - In Norwegian), Oslo: Cappelen.

Thue L., 1996, Strøm og styring. Norsk kraftliberalisme i historisk perspektiv (Electricity and Governance. Norwegian deregulation of electricity in a historic perspective - In Norwegian), Oslo: AdNotam Gyldendal.

Tils R., 2007, “The German Sustainable Development Strategy: Facing Policy, Management and Political Strategy Assessments”, in European Environment, Volume 17, pp.164-176.

Tjernshaugen A., 2007, Gasskraft. Tjue års klimakamp (Gas-fired Power. 20 Years of Struggle on Climate Change - In Norwegian), Oslo: Pax Forlag.

Tranøy BS \& Østerud Ø., 2001, ”Innledning. En fragmentert stat?” (Introduction. A fragmented state? - In Norwegian), in B.S. Tranøy \& Ø. Østerud (eds), Den fragmenterte staten. Reformer, makt og styring, Oslo: Gyldendal Akademisk, pp. 9-36.

United Nations Commission on Sustainable Development (UNCSD), 2002, Guidance in Preparing a National Sustainable Development Strategy: Managing Sustainable Development in the New Millenium, UNCSD Background Paper 13.

van Kersbergen K. \& van Waarden F., 2004, “'Governance’ as a bridge between disciplines: Cross-disciplinary inspiration regarding shifts in governance and problems of governability, accountability and legitimacy”, in European Journal of Political Research, Volume 43, pp. 143-171.

van Meter, D.S. \& C.E. van Horn, 1975, “The Policy Implementation Process: A Conceptual Framework”, in Administration and Society, Volume 6, Issue 4, pp. 445-488.

Vedung E., 1997, Public Policy and Programme Evaluation, New Brunswick US: Transaction Publications.

Vedung E., 1998, "Policy Instruments: Typologies and Theories", in M.-L. Bemelmans-Videc, R.C. Rist \& E. Vedung (eds), Carrots, Sticks \& Sermons. Policy Instruments \& Their Evaluation, New Brunswick US \& London UK: Transaction Publishers, pp. 21-58.

Vedung E., 2004, Public Policy and Program Evaluation, New Brunswick US: Transaction Publishers.

Vedung E. \& Brandel M., 2001, Vattenkraften, staten och de politiske partierna (Hydroelectricity, the state and the political parties - In Swedish), Uppsala: Bokförlaget Nya Doxa. 
Vig N.J. \& Faure M.G. (eds), 2004, Green Giants? Environmental Policies of the United States and European Union, Cambridge, MA: The MIT Press.

von Homeyer I., 2006, "Environmental Policy Integration and Modes of Governance - State-of-the-Art Report” (Draft), EPIGOV Paper, Berlin: Ecologic - Institute for International and European Environmental Policy.

von Schomber R., 2006, "The precautionary principle and its normative challenges", in Fisher et al. (eds), Implementing the Precautionary Principle: Perspectives and Prospects, Cheltenham UK and Northampton MA: Edward Elgar, pp. 1941.

White Paper 65 (1981-82), Om nye fornybare enerkilder i Norge. (On new, renewable energy sources in Norway - In Norwegian), Oslo: Ministry of Energy and Petroleum.

WCED, 1987, Our Common Future, The World commission on Environment and Development, Oxford: Oxford University Press.

White Paper 46 (1988-89), Miljø og utvikling. Norges oppfølging av Verdenskommisjonens rapport (Environment and development. Norway's follow up of the World Commission's report - In Norwegian), Oslo: Ministry of the Environment.

White Paper 29 (1988-89), Om energipolitikken (On the energy policy - In Norwegian), Oslo: Ministry of Petroleum and Energy.

White Paper 41 (1992-1993), Energiøkonomisering og nye fornybare energikilder (Energy conservation and new, renewable energy sources - In Norwegian), Oslo: Ministry of industry and energy.

White Paper 13 (1992-93), FN konferansen om miljø og utvikling (UNCED) (About the UN Conference on the Environment and Development - In Norwegian), Oslo: Ministry of the Environment.

White Paper 41 (1994-95), Norsk politikk mot klimaendringer og utslipp av nitrogenoksider (NOx) (Norwegian policy directed against climatic changes and emissions of nitro group gases (NOx) - In Norwegian), Oslo: Ministry of Environment.

White Paper 58 (1996-97), Miljøvernpolitikk for en bcerekraftig utvikling. Dugnad for framtida (Environmental Policy for Sustainable Development - In Norwegian), Oslo: Ministry of the Environment.

White Paper 8. 1999-2000, Regjeringens miljøvernpolitikk og rikets miljøtilstand (The environmental policy of the Government and the nation's environmental status - In Norwegian), Ministry of the Environment, Oslo.

White Paper 9 (2002-2003), Om innenlands bruk av naturgass mv. (On domestic use of natural gas etc. - In Norwegian), Oslo: Ministry of Petroleum and Energy.

White Paper 26 (2006-07), Regjeringens miljøpolitikk og rikets miljøtilstand (The environmental policy of the Government and the nation's environmental status - In Norwegian), Oslo: Ministry of the Environment.

Wilkins H., 2006, “United Nations Secretary-Generals High Level Panel on System Wide Coherence and the environment: incremental change or UN reform?”, in International Journal of Global Environmental Issues, Volume 6, Issue 4, pp. 285-300. 
Wilkinson D., 1997, “Towards Sustainability in the European Union? Steps Within the European Commission to Integrate Environment into Other European Union Policy Sectors”, in Environmental Politics,Volume 6, Issue 1, pp. 153 - 173.

Williams R., 2007, "The integration of environmental protection requirements into EC development cooperation policy” (Draft), EPIGOV Research Papers, Berlin: Ecologic - Institute for International and European Environmental Policy.

Wiser R. \& Barbose G., 2008, Renewables Portfolio Standards in the United States. A Status Report with Data Through 2008, Berkeley, CA: Lawrence Berkeley National Laboratory.

Wurzel R.K., 2008, “Germany”, in A.J. Jordan \& A. Lenschow (eds), Innovation in Environmental Policy? Integrating the Environment for Sustainability, Cheltenham UK: Edward Elgar, pp. 180-201.

Yin R.K., 1994, Case Study Research - Design and Methods, $2^{\text {nd }}$ Ed., Thousadn Oaks CA: Sage Publ. Inc. 


\section{Summary}

The principal theme of the present doctoral dissertation is to provide new insights into 'environmental policy integration' as a normative and practical steering instrument in the promotion of sustainable development. The empirical focus of the dissertation research is on energy policy as a means for affecting climate-change.

22 years after publication of the report Our Common Future, the report's emphasis of integrating sustainable development (SD) into mandates of (inter alia) all governmental agencies is still a relevant and recurrent topic, both academically and politically. The challenge of making governments responsible and accountable for SD has been specifically treated in relation to the concept of 'Environmental Policy Integration' (EPI). EPI is also a central issue within the broader academic discourse of governance for sustainable development.

Various EPI processes and more-or-less formalised governance mechanisms have been introduced at international (not least by the EU), national and sub-national levels during the last two decades. Simultaneous with these developments, there has also been an accelerated focus on climate-change mitigation and adaptation on the global policy agenda, and this in turn has led to an increased interest in the development of 'alternative' ('sustainable') energy solutions. A more sustainable energy system should be based on renewable sources, and provide less energyintensive production and consumption patterns.

Few academic contributions have, however, treated EPI in relation to specific policy sectors (such as energy), and there are nearly no cross-national comparisons of how EPI is being pursued at the sectoral level of governance. It is important, therefore, to identify and assess sectoral governing mechanisms; what works where, when and how? What are the crucial normative criteria for realising EPI in practice, and how are such criteria manifested (or not) in different sectoral contexts?

On this background, the main research question of the present dissertation is:

How can we clarify the conceptual nature of EPI so as to strengthen its analytic potential as a framework for comparative evaluation of sectoral policy implementation?

In an attempt to answer these questions more specifically, the dissertation research focuses on the energy policy sector, through the six research papers composing the dissertation. In this regard, the research papers draw on empirical data from the Nordic countries, the EU and USA.

The dissertation identifies three prevalent analytical dimensions in the current EPI research: (1) analyses of the normative-pragmatic importance of EPI as an instrument for implementing sustainable development; (2) studies of how EPI can be implemented and followed up within a multi-level governance framework - in 
the present context by comparing the EU with the USA; and (3) studies of the nature and specific consequences of EPI mechanisms. As a fourth, supplemental dimension, several of the studies also provide analyses of the importance of contextual factors as to the status and implementation of EPI standards and mechanisms.

Regarding the first analytical dimension, there has yet to emerge a clear conceptual consensus as to what EPI implies (or should imply). The first research paper thus focuses on the concept of EPI, based on an analysis of the current research. The paper develops a normative baseline for the concept, closely related to sustainable development. A crucial question here is the priority to be accorded environmental concerns. Paper 1 emphasises that the normative intent of EPI is to function as a 'first-order-principle' for resolving trade-offs between sectoral policy goals and environmental concerns by which one can achieve an actual de-coupling between economic development and environmental damage. According to this approach, a high degree of EPI entails that environmental concerns are considered in an SD perspective, and further integrated as central premises, and eventually reflected in the relevant sector's policy decisions. This conceptual understanding of EPI constitutes the platform for the remaining five research papers of the dissertation which address the nature of evaluative standards inherent in the EPI concept by comparative case studies. This involves basic values as well as benchmarks for actual procedures and institutional mechanisms.

Building on insights reflected in Paper 1, the second paper provides a case study of Norway's Strategy for sustainable development, including initiatives for EPI. Such a strategy is considered to depend on an interaction between the intra-governmental (horizontal) and sector-specific (vertical) dimensions of EPI. The article employs these dimensions in a systematic evaluation of relevant Norwegian governmental initiatives. The main conclusion is that the Norwegian SD profile is 'long on promise' but 'short on delivery'; and that a prevalent reason for this profile is the influence of a booming petroleum economy on distributional politics.

As a basis for an empirical understanding of EPI within the energy sector, paper 3 provides an analysis of the conditions for a transition of the energy system towards sustainable development. The background is the promotion of renewable electricity (RES-E) through the EU RES-E Directive from 2001. The paper assesses Norway's follow-up and the contextual factors that condition the promotion of RES-E in the country. The paper documents that the attempts to promote new RES-E in Norway have been only moderately successful thus far, not least due to the lack of a coherent, strategic framework and adequate mechanisms for more effective implementation and phase-in of non-hydro RES-E.

Paper 4 raises the more specific issue as to the connection between EPI and the promotion of RES-E, focusing how RES-E initiatives can reflect the level and type of EPI standards at the national level in the three Scandinavian countries (Denmark, Norway and Sweden). In addition, paper 4 provides an analysis of contextual factors conditioning such a connection. In sum, contextual differences among the 
Scandinavian states have provided different bases for the promotion and integration of RES-E into existing energy systems. The different energy 'paths', and the outcomes they have conditioned, confirm the need to contextualise relevant efforts for EPI.

The fifth research paper focuses on the second analytical dimension referred to above; the multi-level governance challenge of EPI, by providing a comparative assessment of the EU and the USA. The paper discusses the importance of different structures and processes between the supranational/federal level and the national/state level, with an empirical focus on RES-E. The paper documents that the six 'New England states' of the USA promote RES-E without any substantial integration with climate-change concerns, whereas the EU has employed a more top-down approach where climate-change is more prevalent. Policies stemming from the EU level represent an increasingly important driver for the Nordic countries, whereas in the USA similar impulses have been clearly lacking from the federal government.

Paper 6 focuses the third analytical dimension of EPI referred to above by assessing the monitoring mechanisms for SD-relevant policy evaluation of stationary energy in Norway and Sweden, and to what extent these mechanisms provide feed-back to decision-makers that can induce policy changes in a more sustainable direction. The paper documents that Sweden is characterised by more effective arrangements than Norway, based on a more independent mandate and explicit focus on policy change. A major finding is, however, that this structure has not triggered any substantial political interest and engagement, nor given rise to political amendments by themselves. The Swedish system, nevertheless, appears to constitute a more robust platform for policy-learning and actual policy changes.

In conclusion, the dissertation documents how EPI can be employed as both a substantive, normative standard in the study of the energy sector, as well as being reflected by institutional and procedural mechanisms. It further demonstrates the importance of combining a perspective on the overall, SD-related anchoring of EPI - conceived as a horizontal, sector-encompassing dimension - with a more sectorspecific- and differentiated approach. In conclusion, it has been found both analytically and empirically fruitful to consider EPI in a sectoral context within such an interactive, two-dimensional framework.

Finally, the dissertation emphasises that a crucial dimension for the research on EPI is the linkage between a normative-empirical understanding - firmly rooted in the concept of 'sustainable development' - and the strategic challenge of implementing the related, democratically set objectives for SD and EPI. 


\begin{abstract}
About the author
Jørgen Kjetil Knudsen (1971) is a Research Scientist at SINTEF Energy Research AS in Norway. Between 2005 and 2008 he worked as a researcher at the Program for Research and Documentation for a Sustainable Society (ProSus), the University of Oslo. Before this period he was employed in the Norwegian civil service, among other positions as senior executive officer in the Ministry of the Environment, Department for climate-change policies.
\end{abstract}

His current research focus is related to governance for sustainable development, with a particular focus on the EU, including Environmental policy integration (EPI). More particularly, he is currently involved in projects analysing policies for renewable energy production and usage; in the EU, the Nordic countries and the USA. 
